\title{
Deteç̧ão de estruturas finas e ramificadas em imagens usando campos aleatórios de Markov e informação perceptual
}

\author{
Talita Perciano Costa Leite
}

\author{
TESE APRESENTADA \\ $\mathrm{AO}$ \\ Instituto de MATEMÁticA E EstatísticA \\ DA \\ Universidade DE SÃo PAUlo \\ PARA \\ OBTENÇÃO DO TÍTULO \\ $\mathrm{DE}$ \\ DOUTOR EM CIÊNCIAS
}

\author{
Programa: Ciências da Computação \\ Orientador: Prof. Dr. Roberto Hirata Jr. \\ Coorientador: Prof. Dr. Roberto Marcondes Cesar Junior
}

Durante o desenvolvimento deste trabalho o autor recebeu auxílio financeiro da CAPES (processos 870666/98-3 e 0310-10-7) e da FAPESP (processo 2008/06081-4)

São Paulo, agosto de 2012 


\section{Detecção de estruturas finas e ramificadas em imagens usando campos aleatórios de Markov e informação perceptual}

Esta versão definitiva da tese/dissertação contém as correções e alterações sugeridas pela Comissão Julgadora durante a defesa realizada por Talita Perciano Costa Leite em 28/08/2012.

Comissão Julgadora:

- Prof. Dr. Roberto Hirata Junior (orientador) - IME-USP

- Prof. Dr. Nelson Delfino D'Ávila Mascarenhas - UFSCar

- Prof. Dr. Alejandro César Frery Orgambinde - UFAL

- Profa. Dra. Florence Tupin - ENST/Paris-FR

- Prof. Dr. João Eduardo Kogler Junior - EP-USP 


\section{Agradecimentos}

Dedico meus sinceros e especiais agradecimentos:

- Aos meus pais pelo exemplo de luta e superação, por todos os ensinamentos e por toda a confiança em mim depositada. Obrigada por sempre estarem ao meu lado nesta longa e difícil caminhada da vida;

- À Jihan Zoghbi, que me deu o enorme prazer de ter essa grande amizade e parceria durante todos os momentos desta etapa da minha vida. Agradeço por todo o apoio, compreensão e ricos ensinamentos;

- Ao Prof. Dr. Roberto Hirata pela orientação e dedicação a este trabalho, pelo aprendizado técnico, pela amizade e parceria, pelas ricas discussões que pudemos realizar durante o desenvolvimento deste trabalho;

- Ao Prof. Dr. Roberto C. Marcondes pela co-orientação deste trabalho. Agradeço por toda ajuda, apoio, discussões e orientações;

- À Profa. Florence Tupin pela grande colaboração neste trabalho, por me dar a oportunidade de trabalhar em parceria durante o doutorado sanduíche realizado na Télécom ParisTech, Paris-FR. Agradeço pela rica orientação e dedicação a este trabalho;

- À Télécom ParisTech pela oportunidade de me receber como aluna de doutorado em estágio. Agradeço por toda a estrutura que me foi disponibilizada, que foi de extrema importância para o desenvolvimento da minha pesquisa;

- Ao Prof. Lúcio de Castro Jorge pela colaboração e oportunidade de trabalho em conjunto com a EMBRAPA;

- A todos os queridos membros do grupo de processamento de imagens e sinais da Télécom ParisTech, especialmente Benoit Petitpas, Charles Deledalle, Aymen Shabou, Guillaume Larracoexea e Flora Dellinger, que me acolheram de braços abertos e que foram de grande ajuda na pesquisa do doutorado sanduíche; 
- A meus queridos amigos e companheiros Ana Beatriz, Alexandre Freire, David Pires, Jorge Guevara, Leissi Castañeda, Silvia Cristina, Fabricio Martins Lopes, David Martins, André Yoshiaki e Fernando Kulaif, pela rica amizade, apoio e conhecimento transmitidos e pela ótima companhia que tornou esta difícil caminhada bastante prazerosa;

- A todos os ex-integrantes e integrantes do grupo Vision do Instituto de Matemática e Estatística da Universidade de São Paulo;

- À Universidade de São Paulo e, especificamente, ao Instituto de Matemática e Estatística pela formação, apoio e toda infraestrutura que me foi fornecida durante o curso de doutorado em Ciência da Computação;

- À CAPES pela bolsa de doutorado durante os primeiros meses de doutorado (processo número 870666/98-3);

- À CAPES pela bolsa de doutorado sanduíche de um ano fornecida para realizar parte da minha pesquisa na Télécom ParisTech (processo número 0310/10-7);

- À FAPESP pela bolsa de doutorado (processo número 2008/06081-4);

- À todos os que colaboraram direta e indiretamente no desenvolvimento deste trabalho. 
A meus queridos pais e a minha grande amiga Jihan Zoghbi.

"Você não pode ensinar a criança a cuidar de si mesma, a não ser que a deixe tentar por si. Ela cometerá erros e a partir desses erros brotará sua sabedoria." (Henry Ward Beecher) "É na educação dos filhos que se revelam as virtudes dos pais." (Coelho Neto)

"E o que importa não é o que você tem na vida, mas quem você tem na vida..." (William Shakespeare) 
PERCIANO, T. Deteç̧ão de estruturas finas e ramificadas em imagens usando campos aleatórios de Markov e informação perceptual. 2012. 194 f. Tese (Doutorado) - Instituto de Matemática e Estatística, Universidade de São Paulo, São Paulo, 2012.

Estruturas do tipo linha/curva (line-like, curve-like), alongadas e ramificadas são comumente encontradas nos ecossistemas que conhecemos. Na biomedicina e na biociências, por exemplo, diversas aplicações podem ser observadas. Justamente por este motivo, extrair este tipo de estrutura em imagens é um constante desafio em problemas de análise de imagens. Porém, diversas dificuldades estão envolvidas neste processo. Normalmente as características espectrais e espaciais destas estruturas podem ser muito complexas e variáveis. Especificamente as mais "finas" são muito frágeis a qualquer tipo de processamento realizado na imagem e torna-se muito fácil a perda de informações importantes. Outro problema bastante comum é a ausência de parte das estruturas, seja por motivo de pouca resolução, ou por problemas de aquisição, ou por casos de oclusão.

Este trabalho tem por objetivo explorar, descrever e desenvolver técnicas de detecção/segmentação de estruturas finas e ramificadas. Diferentes métodos são utilizados de forma combinada, buscando uma melhor representação topológica e perceptual das estruturas e, assim, melhores resultados. Grafos são usados para a representação das estruturas. Esta estrutura de dados vem sendo utilizada com sucesso na literatura na resolução de diversos problemas em processamento e análise de imagens. Devido à fragilidade do tipo de estrutura explorado, além das técnicas de processamento de imagens, princípios de visão computacional são usados. Busca-se, desta forma, obter um melhor "entendimento perceptual" destas estruturas na imagem. Esta informação perceptual e informações contextuais das estruturas são utilizadas em um modelo de campos aleatórios de Markov, buscando o resultado final da detecção através de um processo de otimização. Finalmente, também propomos o uso combinado de diferentes modalidades de imagens simultaneamente.

Um software é resultado da implementação do arcabouço desenvolvido e o mesmo é utilizado em duas aplicações para avaliar a abordagem proposta: extração de estradas em 
imagens de satélite e extração de raízes em imagens de perfis de solo. Resultados do uso da abordagem proposta na extração de estradas em imagens de satélite mostram um melhor desempenho em comparação com método existente na literatura. Além disso, a técnica de fusão proposta apresenta melhora significativa de acordo com os resultados apresentados. Resultados inéditos e promissores são apresentados na extração de raízes de plantas.

Palavras-chave: Segmentação de imagens, visão computacional, estruturas finas, campos aleatórios de Markov, fusão de imagens. 
PERCIANO, T. Detection of thin and ramified structures in images using Markov random fields and perceptual information. 2012. $194 \mathrm{f}$. PhD thesis - Institute of Mathematics and Statistics, University of São Paulo, São Paulo, 2012.

Line- curve-like, elongated and ramified structures are commonly found inside many known ecosystems. In biomedicine and biosciences, for instance, different applications can be observed. Therefore, the process to extract this kind of structure is a constant challenge in image analysus problems. However, various difficulties are involved in this process. Their spectral and spatial characteristics are usually very complex and variable. Considering specifically the thinner ones, they are very "fragile" to any kind of process applied to the image, and then, it becomes easy the loss of crucial data. Another very common problem is the absence of part of the structures, either because of low image resolution and image acquisition problems or because of occlusion problems.

This work aims to explore, describe and develop techniques for detection/segmentation of thin and ramified structures. Different methods are used in a combined way, aiming to reach a better topological and perceptual representation of the structures and, therefore, better results. Graphs are used to represent the structures. This data structure has been successfully used in the literature for the development of solutions for many image processing and analysis problems. Because of the fragility of the kind of structures we are dealing with, some computer vision principles are used besides usual image processing techniques. In doing so, we search for a better "perceptual understanding" of these structures in the image. This perceptual information along with contextual information about the structures are used in a Markov random field, searching for a final detection through an optimization process. Lastly, we propose the combined use of different image modalities simultaneously.

A software is produced from the implementation of the developed framework and it is used in two application in order to evaluate the proposed approach: extraction of road networks from satellite images and extraction of plant roots from soil profile images. Results using the proposed approach for the extraction of road networks show a better performance 
if compared with an existent method from the literature. Besides that, the proposed fusion technique presents a meaningful improvement according to the presented results. Original and promissing results are presented for the extraction of plant roots from soil profile images.

Keywords: Image segmentation, computer vision, thin structures, Markov random fields, image fusion. 
PERCIANO, T. Détection de structures fines et ramifiées dans des images digitales en utilisant des champs de Markov et des informations perceptuelles. 2012. 194 f. Thèse de Doctorat - Institut de mathématiques et de statistiques, Université de São Paulo, São Paulo, 2012.

Des structures linéaires/courbées, allongées et ramifiées sont souvent trouvés à l'intérieur de nombreux écosystèmes connus. Dans la biomédecine et des biosciences, par exemple, des différentes applications peuvent être observées. Par conséquent, le processus d'extraire ce type de structure est un défi constant dans les problèmes d'analyse d'images. Cependant, des difficultés diverses sont impliqués dans ce processus. Les caractéristiques spectrales et spatiales de ce type de structures sont généralement très complexes et variables. Considérant en particulier les plus minces, ils sont très fragiles à tout type de processus appliqué à l'image, puis, il devient facile la perte de données cruciales. Un autre problème très commun est l'absence d'une partie des structures, soit en raison de la résolution d'image faible et des problèmes d'acquisition de l'image ou en raison de problèmes d'occlusion.

Ce travail vise à explorer, décrire et développer des techniques pour la détection/segmentation des structures fines et ramifiées. Différentes méthodes sont utilisées de manière combinée, dans le but de parvenir à une meilleure représentation topologique et perceptuel des structures et, par conséquence, des résultats meilleurs. Les graphes sont utilisés pour représenter les structures. Cette structure de données a été utilisée avec succès dans la littérature pour le développement de solutions pour nombreux problèmes de traitement et d'analyse d'images. En raison de la fragilité des structures que nous traitons, certains principes de vision par ordinateur sont utilisés en plus des techniques habituelles de traitement d'images. Ce faisant, nous cherchons pour une meilleure compréhension de la perception de ces structures dans l'image. Cette information perceptive ainsi que des informations contextuelles sur les structures sont utilisées dans un modèle de champ de Markov. Un processus d'optimisation est utilisé pour la recherche de la détection finale. Enfin, nous proposons l'utilisation combinée des différentes modalités d'imagerie simultanément. 
Un logiciel est résulté de la implémentation du framework et il est utilisé dans deux applications afin d'évaluer l'approche proposée: l'extraction des réseaux routiers à partir d'images satellitaires et de l'extraction des racines des plantes à partir d'images de profil du sol. Les résultats obtenus avec l'approche proposée pour l'extraction des réseaux routiers montrent une meilleure performance si on la compare avec une méthode existante de la littérature. En plus de cela, la technique de fusion proposée présente une amélioration significative en fonction des résultats présentés. Des résultats originaux et prometteur sont présentés pour l'extraction des racines des plantes à partir d'images de profil du sol.

Keywords: Segmentation d'image, vision pour ordinateur, structures fines, champs aléatoires de Markov, fusion d'image. 
Lista de Abreviaturas $\quad \mathrm{xv}$

Lista de Símbolos xvii

Figuras $\quad$ xxiii

Tabelas $\quad \mathrm{xxv}$

Algoritmos xxvii

1 Introdução $\quad 1$

1.1 Comentários preliminares 1

1.2 Aplicações 3

1.3 Filosofia e motivações 4

1.4 Contribuições 5

1.5 Organização da tese 6

\section{$\begin{array}{lll}\text { PARTE I } & \text { Revisão da Literatura } & 7\end{array}$}

2 Filtragem e segmentação de estruturas finas e ramificadas $\quad 9$

2.1 Filtragem de estruturas finas 10

2.2 Detecção e segmentação de estruturas finas 12

2.3 Ligação de bordas/cristas 14

3 Modelagem utilizando grafos $\quad 17$

3.1 Segmentação e classificação de imagens

3.2 Registro de imagens 18

3.3 Detecção de cristas 19

3.4 Problemas adicionais 20 
4 Aplicações de campos aleatórios de Markov

4.1 Segmentação e classificação 24

4.2 Registro 24

4.3 Restauração e remoção de ruído 25

4.4 Detecção de mudanças e fusão de imagens $\quad 26$

5 Limitações e problemas em aberto $\quad 27$

\section{PARTE II Metodologia 29}

\section{Introdução 31}

7 Definições 35

7.1 Imagens

35

7.1.1 Vizinhanças

7.1.2 Contradomínios

7.2 Grafos 37

7.2.1 Grafo de pixels

7.2.2 Grafo de primitivas

7.3 Noções de probabilidade e estatística

39

7.4 Problema de rotulação

41

7.5 Campos aleatórios de Markov

7.5.1 Campo de Markov

7.5.2 Campo de Gibbs

45

7.5.3 Equivalência entre campo de Gibbs e o campo de Markov

7.5.4 Amostragem de um campo aleatório de Markov

7.5.5 Máxima Probabilidade a Posteriori (MAP) e campos aleatórios de Markov 49

7.5.6 Algoritmo de Recozimento Simulado 50

7.5.7 Algoritmo ICM (Iterated Conditional Mode) 51

7.5.8 Passos gerais da abordagem MAP/campos markovianos

7.6 Princípios da Teoria de Gestalt 53

\section{Etapa de baixo nível 57}

8.1 Detector de bordas Canny 57

8.2 Deteçã̃o usando morfologia matemática $\quad 60$

8.3 Filtro de Frangi 62

8.4 Filtro steerable 63

8.5 Detecção por razão (ratio-based detector) e correlação cruzada (cross-correlation-based detector) 
8.6 Análise de precisão

64

8.7 Problema de ligação de cristas

74

8.7.1 Máscara direcional adaptativa 74

8.7.2 Direção da crista e distância geodésica $\quad 75$

8.7.3 Experimentos $\quad 76$

8.8 Introduzindo fusão de diferentes tipos de dados em baixo nível

$9 \quad$ Etapa de alto nível 83

9.1 Modelagem com grafos - Introduzindo o uso de componentes conexas

9.2 Processamento em alto nível - campos aleatórios de Markov

87

9.2.1 Abordagem multiescala 91

9.2.2 Introduzindo uma segunda etapa de processamento em alto nível

10 Visão global do método proposto

95

10.1 Arcabouço para detecção de estruturas finas e ramificadas

10.2 Software para detecção de estruturas finas

96

\section{PARTE III Aplicações 103}

11 Redes de estradas em imagens de satélite 105

11.1 Sensoriamento remoto

105

11.1.1 Espectro eletromagnético

105

11.1.2 Sensores $\quad 106$

11.2 Resultados 108

11.2.1 Imagens provenientes de um mesmo sensor

108

11.2.2 Imagens provenientes de sensores diferentes

116

12 Raízes de plantas 123

12.1 Introdução 123

12.1.1 Imagens simuladas $\quad 125$

12.2 Experimentos preliminares $\quad 129$

12.2.1 Imagens simuladas 129

12.2.2 Imagens reais 131

\section{PARTE IV Considerações finais 137}

\section{Conclusões e comentários adicionais $\quad 139$}

13.1 Contribuições 139 
13.2 Perspectivas $\quad 140$

13.2.1 Uma aplicação em desenvolvimento 141

Apêndice I: Artigos em conferências $\quad 160$

Apêndice II: Artigos em periódicos 161 


\section{Lista de Abreviaturas}

Pixel

$2 \mathrm{D}$

$3 \mathrm{D}$

SAR

COSMO-SkyMed/CSK

EMBRAPA

SEL

SIARCS

DAG

MRF

EM

SA

OpenCV

ICM

$\mathrm{MCC}$
Elemento de imagem (Picture Element).

Duas dimensões.

Três dimensões.

Radar de Abertura Sintética (Synthetic Aperture Radar).

COnstellation of small Satellites for the Mediterranean basin

Observation.

Empresa Brasileira de Pesquisa Agropecuária.

Ligação de bordas sequencial (Sequential Edge Linking).

Sistema Integrado para Análise de Raízes e Cobertura do Solo.

Gráfico acíclico dirigido.

Campo aleatório de Markov (Markov Random Field).

Maximização da esperança (Expectation Maximization).

Recozimento simulado (Simulated Annealing).

Open Source Computer Vision.

Modos condicionais iterativos (Iterated Conditional Modes).

Coeficiente de correlação de Matthews (Matthews Correlation) Coefficient. 
$\mathbb{R} \quad$ Conjunto dos números reais.

$\mathbb{Z} \quad$ Conjunto dos números inteiros.

$\mathbb{N} \quad$ Conjunto dos números naturais.

$S \quad$ Suporte de uma imagem/conjunto de sítios.

$s \quad$ Sítio em $S$.

$\partial_{s} \quad$ Sistema de vizinhança de $S$.

$\emptyset \quad$ Conjunto vazio.

$d(s, t) \quad$ Distância entre os sítios $s$ e $t$.

$\mathcal{C} \quad$ Conjunto de cliques.

$\mathcal{C}_{k} \quad$ Conjunto de cliques de cardinalidade $k$.

$c \quad$ Clique em $\mathcal{C}$.

$G(V, \mathcal{E}) \quad$ Grafo definido pelo conjunto de vértices $V$ e pelo conjunto de $\operatorname{arestas} \mathcal{E}$.

$\Omega \quad$ Espaço de amostras.

$P(A) \quad$ Probabilidade da ocorrência do evento $A$.

$P(A \mid B) \quad$ Probabilidade da ocorrência do evento $A$ dada a ocorrência do evento $B$.

$F_{X}(t) \quad$ Função de distribuição cumulativa.

$\mathbb{L} \quad$ Conjunto de rótulos, estados, descritores.

U Energia global.

$U_{c} \quad$ Energia do clique $c$.

$V_{c} \quad$ Potencial do clique $c$.

$X_{s} \quad$ Variável aleatória associada ao sítio $s$.

$X=\left(X_{s} ; X_{t} ; \ldots\right) \quad$ Campo aleatório.

$x=\left(x_{s} ; x_{t} ; \ldots\right) \quad$ Realização do campo aleatório $X$.

$Z$ Função de partição de Gibbs / constante de normalização.

$x_{s} \quad$ Rótulo do sítio $s$ na configuração $x$.

$x_{\partial s} \quad$ Rótulos dos sítios vizinhos de $s$ na configuração $x$. 


\section{Figuras}

\section{Capítulo 1}

1.1 Exemplos de imagens com estruturas finas

1.2 Partes aumentadas da imagem de raiz.

\section{Capítulo 6}

6.1 Exemplo simples do processo geral da abordagem em dois níveis.

6.2 Exemplo do processo geral da abordagem em dois níveis na presença de ruído e, consequentemente, de falsas detecções.

\section{Capítulo 7}

7.1 Ilustração de grafos de pixels com vizinhanças 4-conexa e 8-conexa gerados a partir de uma imagem.

7.2 Ilustração de grafo de primitivas onde a vizinhança é definida pela relação entre os segmentos (neste caso relação através das extremidades).

7.3 Ilustração de grafo de adjacência de regiões onde a vizinhança é definida pela fronteira entre as regiões.

7.4 Ilustração dos cliques pela vizinhança 8-conexa em uma grade, onde $\mathcal{C}_{k}$ indica o conjunto de cliques de cardinalidade $k$.

7.5 Exemplos de ilusões de óptica e imagens com figuras geométricas.

7.6 Exemplos de cada um dos princípios de Gestalt.

\section{Capítulo 8}

8.1 Máscara para detecção de linhas usada considerando um pixel específico $p(x, y)$ dada uma direção, comprimento e largura. 
8.2 Curvas ROC para cada conjunto de imagens: (a) Curva ROC para o conjunto de imagens simuladas de raízes (b) Curva ROC para o conjunto de imagens reais de raízes (c) Curva ROC para o conjunto de imagens de retina.

8.3 Resultados das detecções para uma imagem simulada de raiz usando os melhores parâmetros.

8.4 Resultados das detecções para uma imagem real de raiz usando os melhores parâmetros.

8.5 Resultados das detecções(Canny e Frangi) para uma imagem de retina usando os melhores parâmetros.

8.6 Resultados das detecções (Morfologia matemática, steerable e Tupin) para uma imagem de retina usando os melhores parâmetros.

8.7 Exemplo da rotação da máscara dependendo do histograma direcional local.

8.8 Cálculo da direção de borda por Wang \& Zhang.

8.9 Termo $\Theta\left(P_{e}, P_{c}\right)$ da Equação 8.21.

8.10 (a) Imagem original de raiz de planta. (b) Mapa de cristas final após ligação, sobreposto à imagem original. (c) e (f) Áreas selecionadas a partir do mapa de cristas. (d) e (g) Resultados da ligação por [Wang \& Zhang, 2008]. (e) e (h) Resultados pelo método de ligação proposto.

8.11 (a) Imagem original de raiz de planta. (b) Mapa de cristas final após ligação, sobreposto à imagem original. (c) e (f) Áreas selecionadas a partir do mapa de cristas. (d) e (g) Resultados da ligação por [Wang \& Zhang, 2008]. (e) e (h) Resultados pelo método de ligação proposto.

8.12 (a) Imagem original de raiz de planta. (b) Mapa de cristas final após ligação, sobreposto à imagem original. (c) Mapa de cristas sem ligação. (d) Mapa de cristas final após ligação pelo método proposto.

8.13 Duas imagens de satélite obtidas de uma mesma região sendo a da esquerda a imagem de radar (a) e a da direita a imagem óptica (b).

8.14 Exemplo de detecção de linhas usando o detector por razão/correlação cruzada e o método de fusão de baixo nível proposto. (a) Resultado da detecção de linhas para a imagem radar. (b) Resultado da detecção de linhas para a imagem óptica. (c) Resultado da detecção de linhas através da fusão de baixo nível proposta.

\section{Capítulo 9}

9.1 Modelagem do grafo proposto por Tupin et al.. (a) Exemplo de detecção de linhas. (b) Aproximação poligonal das estruturas. (c) Adição das conexões possíveis entre os segmentos de reta. (d) Grafo gerado a partir dos segmentos. 84 
9.2 Modelagem de grafo proposta em que são usadas componentes conexas ao invés de segmentos de reta. (a) Exemplo de detecção de cristas. (b) Detecção das componentes conexas e dos cruzamentos. (c) Adição das possíveis conexões entre componentes conexas. (d) Grafo gerado a partir das componentes.

9.3 Exemplo do método de melhor caminho para obter as conexões possíveis entre primitivas. (a) Região de interesse de uma imagem radar. (b) Resultado da detecção de cristas da região escolhida. (c) Conexões obtidas por Tupin et al.. (d) Conexões obtidas usando o método proposto.

9.4 Cálculo do ângulo entre duas componentes conexas considerando o vetor direção nas extremidades de cada componente.

9.5 Comparação do cálculo da medida para o termo de verossimilhança usando segmentos de reta (a) e componentes conexas (b).

9.6 (a) Imagem de teste original (b) Imagem de magnitude resultante da detector de cristas por razão e correlação cruzada (c) Imagem binária da detecção de cristas (d) Imagem resultante do afinamento aplicado à imagem binária da detecção de cristas (e) Grafo de componentes conexas.

9.7 Alguns resultados de extração variando os parâmetros do campo Markoviano: (a) $K_{e}=0,3, K_{\mathcal{L}}=-0,12, K_{c}=0,3, K_{i}=0,3$ (b) $K_{e}=0,3, K_{\mathcal{L}}=-0,12$, $K_{c}=0,3, K_{i}=0,1$ (c) $K_{e}=0,3, K_{\mathcal{L}}=-0,12, K_{c}=0,1, K_{i}=0,1$ (a) $K_{e}=-0,05, K_{\mathcal{L}}=-0,12, K_{c}=0,1, K_{i}=0,1$

9.8 Modelagem do grafo para o passo adicional de alto nível. (a) Exemplo de saída da primeira etapa de alto nível. (b) Extensão das componentes conexas. (c) Grafo final obtido após extensão.

\section{Capítulo 10}

10.1 Diagrama de blocos representando todos os passos do arcabouço proposto.

10.2 Tela principal do programa implementado - leitura de imagens.

10.3 Tela principal do programa implementado - detecção de cristas.

10.4 Tela principal do programa implementado - construção do grafo.

10.5 Tela principal do programa implementado - busca pela rotulação ótima do grafo por otimização.

\section{Capítulo 11}

11.1 Resultados para imagens ópticas: (a) Imagem original (b) Ground-truth (c) Resultado da detecção onde as estradas detectadas corretamente estão marcadas em verde, as detectadas incorretamente estão marcadas em vermelho e as estradas ausentes estão marcadas em preto. As setas em azul destacam uma estrada importante que não foi detectada. 
11.2 Resultados para imagens ópticas: (a) Imagem original (b) Ground-truth (c) Resultado da detecção onde as estradas detectadas corretamente estão marcadas em verde, as detectadas incorretamente estão marcadas em vermelho e as estradas ausentes estão marcadas em preto.

11.3 Resultados para imagens de radar: (a) Imagem original (b) Ground-truth (c) Verde: detecção correta. Vermelho: detecção incorreta. Preto: estradas não detectadas. Observe que a estrada que não foi detectada usando a imagem óptica (Figura 11.1(c)), foi detectada neste caso.

11.4 Resultados para imagens de radar: (a) Imagem original (b) Ground-truth (c) Verde: detecção correta. Vermelho: detecção incorreta. Preto: estradas não detectadas. A seta em azul destaca uma estrada que não foi detectada usando a imagem de radar, mas que foi detectada usando a imagem óptica (Figura 11.2(c))

11.5 Resultados para a fusão das imagens de radar e ópticas: (a) (d) Resultados usando apenas as imagens ópticas (b) (e) Resultados usando apenas as imagens de radar (c) (f) Resultados usando a abordagem de fusão proposta. Verde: detecção correta. Vermelho: detecção incorreta. Preto: estradas ausentes.

11.6 Imagens multitemporais originais. Primeira linha: (a) Uma das imagens da pilha de imagens TerraSAR-X (b) Média quadrática das 13 imagens da pilha TerraSAR-X (c) Ground-truth correspondente à região. Segunda linha: (d) Uma das imagens da pilha COSMO-SkyMed (e) Média quadrática das 4 imagens da pilha (f) Ground-truth correspondente à região. Terceira linha: (g) Uma das imagens da pilha TerraSAR-X, região de Chamonix (h) Média quadrática das 13 imagens da pilha (i) Ground-truth correspondente à região. 119

11.7 Resultados para as imagens multitemporais. Primeira linha: (a) Resultado obtido usando apenas a imagem da média quadrática da pilha de imagens TerraSAR-X (b) Resultado obtido usando a abordagem de fusão proposta nas 13 imagens TerraSAR-X (c) Resultado obtido fundindo os últimos dois resultados apresentados anteriormente. Segunda linha: (d) Resultado obtido usando apenas a imagem da média quadrática das imagens da pilha COSMOSkyMed (e) Resultado obtido aplicando a fusão de baixo nível proposta nas 4 imagens da pilha COSMO-SkyMed (f) Resultado obtido fundindo os últimos dois resultados apresentados anteriormente. Terceira linha: (g) Resultado obtido usando apenas a imagem da média quadrática das imagens da pilha TerraSAR-X (região de Chamonix) (h) Resultado obtido aplicando a fusão de baixo nível proposta nas 13 imagens da pilha TerraSAR-X (região de Chamonix) (i) Resultado obtido fundindo os últimos dois resultados apresentados anteriormente. Verde: detecção correta. Vermelho: detecção incorreta. Preto: estradas ausentes. 
11.8 Análise da influência do número de imagens usadas para a fusão das imagens da pilha TerraSAR-X. Pode-se observar que realizando a fusão das primeiras 6 imagens da pilha, obtém-se uma medida próxima da melhor.

\section{Capítulo 12}

12.1 Perfil da placa com pregos depois de lavada.

12.2 Imagem típica de um perfil de solo com raízes.

12.3 Telas do simulador de raízes implementado.

12.4 Imagens simuladas e suas respectivas imagens de referência.

12.5 Experimento para extração de raízes realizado com imagem simulada.

12.6 Experimento para extração de raízes realizado com imagem simulada.

12.7 Experimento para extração de raízes realizado com imagem simulada.

12.8 Experimento para extração de raízes realizado com imagem real de perfil de solo.

12.9 Experimento para extração de raízes realizado com imagem real de perfil de solo.

12.10Experimento para extração de raízes realizado com imagem real de perfil de solo.

\section{Capítulo 13}

13.1 Exemplo de aplicação do arcabouço proposto a uma imagem de membranas corioalantóicas: (a) Imagem original (b) Resultado da detecção. 


\section{Capítulo 8}

8.1 Valores mínimos e máximos para cada detector de linhas.

8.2 Número de refinamentos para os parâmetros de cada detector utilizado.

\section{Capítulo 11}

11.1 Parâmetros utilizados para as imagens ópticas.

11.2 Comparação de resultados entre o método proposto e o método de Tupin et al..112

11.3 Parâmetros utilizados para as imagens de radar.

11.4 Avaliação quantitativa dos resultados comparando o uso de um único sensor e a abordagem de fusão.

11.5 Parâmetros utilizados para fusão de imagens ópticas e de radar.

11.6 Parâmetros utilizados para fusão de imagens multitemporais.

11.7 Avaliação quantitativa dos resultados.

\section{Capítulo 12}

12.1 Parâmetros utilizados para as imagens simuladas/reais de perfil de solo. 


\section{Capítulo 7}

7.1 Algoritmo de recozimento simulado.

\section{Capítulo 8}

8.1 Algoritmo de detecção de linhas através de operadores morfológicos.

8.2 Algoritmo de detecção de estruturas lineares usando razão e correlação cruzada. 65

8.3 Algoritmo de ligação de cristas proposto. 
Observações preliminares

\section{Introdução}

"Uma caminhada de mil léguas começa sempre com o primeiro passo."

Provérbio chinês

Neste capítulo apresentamos o problema de segmentação de imagens que contêm estruturas finas e ramificadas. A seção está dividida em cinco partes: em Comentários Preliminares, apresentamos o problema principal a ser explorado; em Aplicações apresentamos algumas aplicações reais onde as técnicas podem ser aplicadas; em Filosofia e Motivações, apresentamos as motivações e a ideia principal do projeto de doutorado; em Contribuições, citamos as principais contribuições deste trabalho e na última seção, apresentamos a organização da tese.

\subsection{Comentários preliminares}

A segmentação de imagens [Davies, 2005; Gonzalez \& Woods, 2008; Shapiro \& Stockman, 2001; Umbaugh, 2005] é uma etapa importante em vários métodos de análise e processamento de imagens que tomam como entrada imagens e fornecem como saída atributos extraídos a partir destas imagens. O objetivo da segmentação é subdividir o domínio da imagem em regiões ou objetos constituintes. Os pixels de uma região segmentada são similares com respeito a alguma característica ou propriedade, como cor, intensidade ou textura. Regiões adjacentes são significativamente diferentes com respeito às mesmas características. O nível de detalhe ao qual é realizada a subdivisão depende do problema que está sendo tratado e da resolução da imagem. Isto significa que a segmentação deve parar quando os objetos ou regiões de interesse em uma aplicação são detectados, ou quando a resolução da imagem não nos permite subdividir elementos menores que um pixel.

A segmentação de imagens complexas é uma das tarefas mais difíceis em processamento de imagens. A precisão da segmentação determina o eventual sucesso ou falha de procedimentos de análise computadorizados. Por esta razão, considerável cuidado deve ser tomado 
para melhorar as técnicas e métodos e conseguir uma segmentação precisa.

Normalmente, o processo de segmentação depende bastante do tipo de imagem que está sendo usada. Desta forma, é difícil encontrar um algoritmo que possa ser aplicado a uma variedade grande de imagens. Por este motivo, os esforços para desenvolver um novo algoritmo de segmentação são geralmente voltados para uma determinada classe de imagens, ou seja, imagens que compartilham propriedades em comum.

Este projeto tem por objetivo estudar e desenvolver técnicas de segmentação aplicadas a imagens com estruturas finas e ramificadas. Alguns exemplos de imagens são apresentadas na Figura 1.1.

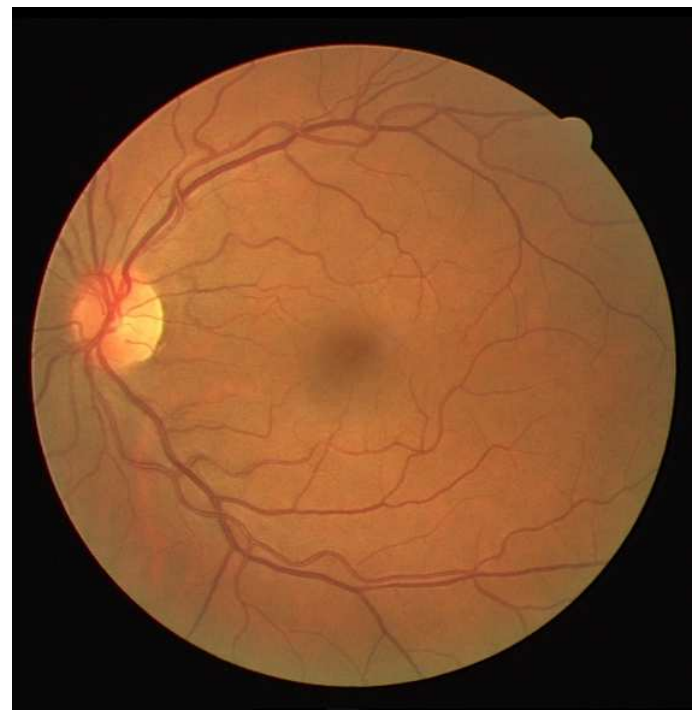

(a) Imagem de retina

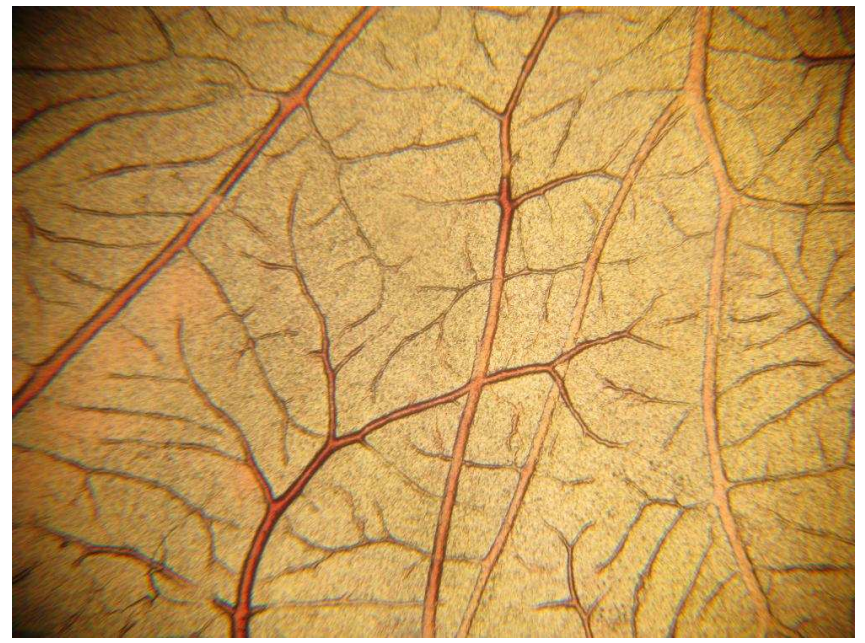

(b) Imagem de membranas corioalantóicas (CAM) de embrião de galinha

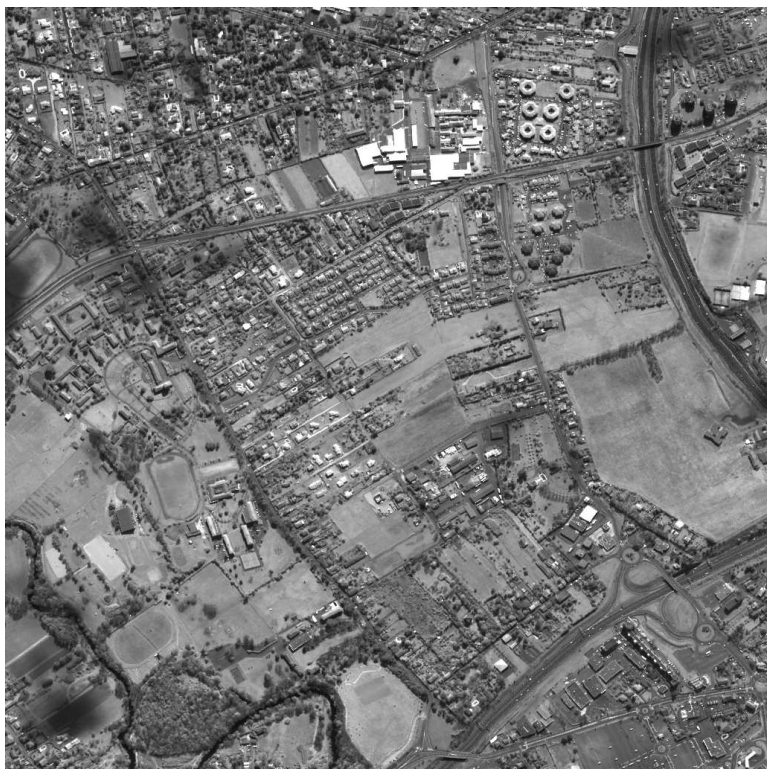

(d) Imagem de satélite óptico

(c) Imagem de raiz

Figura 1.1: Exemplos de imagens com estruturas finas

Por estruturas finas entende-se qualquer estrutura com dimensões bastante alongadas 
(em relação às dimensões da imagem) e eventualmente com corpo ramificado, por exemplo, neurônios, vasos sanguíneos, raízes, estradas e rios. A grande maioria das técnicas de segmentação contém algum pré-processamento para facilitar os passos seguintes. Isto é, o pré-processamento visa eliminar problemas como presença de ruído e níveis indesejáveis de luminosidade e contraste. Nesta etapa de pré-processamento são usados, na grande maioria dos casos, filtros que objetivam melhorar a qualidade das imagens. O grande problema com relação a aplicar estes filtros em imagens com estruturas finas é que, devido às características dos mesmos, parte das estruturas finas são normalmente perdidas, pois podem ser confundidas com estruturas indesejáveis da imagem, como ruídos por exemplo. Surge então a principal motivação deste trabalho: desenvolver algoritmos de segmentação que sejam sensíveis a estruturas finas e ramificadas.

\subsection{Aplicações}

A parte teórica deste projeto busca soluções eficientes e resultados satisfatórios que possam atender a diversas aplicações práticas como:

- Segmentação de estruturas como rios e estradas em imagens de satélites [Negri et al., 2006; Smits et al., 1996; Tupin et al., 2002, 1998];

- Segmentação de raízes de plantas com o objetivo de estudar suas características e desenvolvimento [Chen \& Zhou, 2010; Huang et al., 1992; Jing et al., 2011; Song et al., 2011a];

- Segmentação de árvores e plantas com o intuito de obter informações sobre medidas, padrões de desenvolvimento e investigar a quantidade de biomassa [Chen \& Li, 2007; Golzarian, 2011; Paproki et al., 2011; Quan, 2009];

- Segmentação de vasos sanguíneos em imagens de retina para auxiliar no estudo de doenças [Cornforth et al., 2005; Cree et al., 2005; Soares et al., 2006; Walter et al., 2007];

- Segmentação de imagens de neurônios para estudos em neurociência [Dima et al., 2002; Peng et al., 2003];

- Desenvolvimento de software de reconstrução 3D para visualização de estruturas vasculares ou com características semelhantes.

Uma demonstração da abrangência em aplicações que este projeto deve atingir pode ser vista em [Sánchez et al., 2003]. Este artigo apresenta alguns tipos de redes ramificadas que podem ser encontradas na natureza: folhas, rios, padrões ramificados geológicos e geofísicos e faz um estudo específico sobre a estrutura ramificada de um tipo de coral chamado gorgoniano. Todas as aplicações envolvendo essas imagens podem se beneficiar dos bons algoritmos de segmentação e análise de imagens com estruturas finas. 


\subsection{Filosofia e motivações}

As estruturas contidas nas imagens que são usadas neste trabalho são finas e "frágeis" ao ponto de que nem todas as informações das mesmas podem ser obtidas diretamente a partir da informação local dos pixels da imagem. Observe por exemplo a Figura 1.2, que mostra duas partes aumentadas da imagem de raiz apresentada na Figura 1.1. Nestas imagens fica clara a existência de estruturas subpixel na imagem, além da ocorrência do problema de oclusão de parte das estruturas.
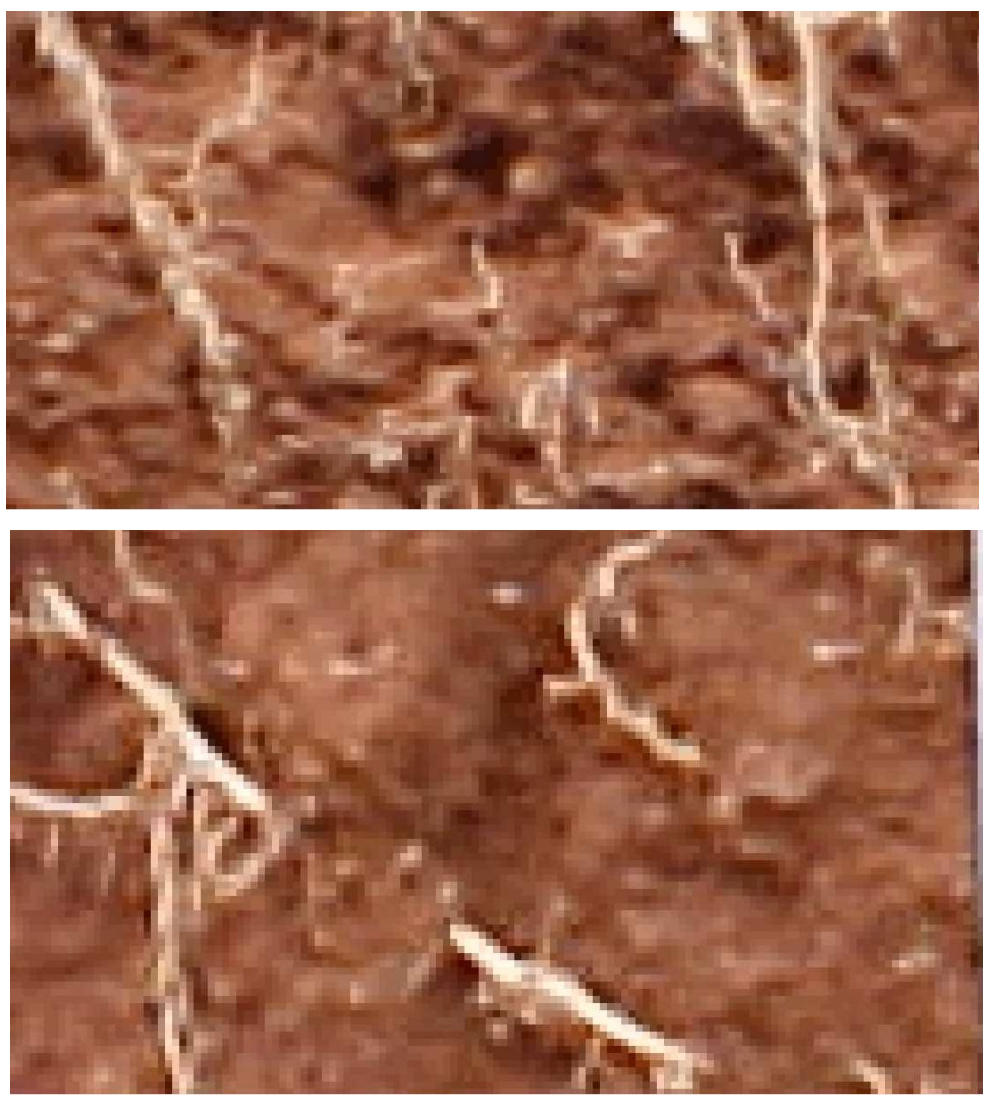

Figura 1.2: Partes aumentadas da imagem de raiz.

Em outras palavras, apenas técnicas usuais de processamento de imagens não são suficientes para que haja a detecção correta e completa destas estruturas. Por este motivo, princípios de mais alto nível precisam ser empregados para tratar tais estruturas como, por exemplo, os princípios de Gestalt em visão como: proximidade, semelhança, fechamento e continuidade [Palmer, 1999]. Estes princípios estão diretamente relacionados ao conceito de agrupamento perceptual, o qual refere-se a habilidade do sistema visual humano de extrair relações de percepção a partir de características primitivas locais, e globais, sem o conhecimento do conteúdo da imagem, e agrupá-las para obter estruturas de alto nível.

Vale ressaltar que os algoritmos desenvolvidos por este trabalho ajudarão no processamento de imagens médicas, como no caso dos exemplos de aplicações citados anteriormente: imagens de retina e neurônios. A etapa de segmentação de imagens é muito importante no processamento de imagens médicas, influenciando bastante na interpretação final das 
imagens e no diagnóstico de doenças.

A filosofia do projeto proposto é utilizar técnicas de processamento de imagens aliadas a princípios de mais alto nível, buscando informações que estão além dos pixels da imagem (informações adicionais àquelas já presentes localmente nos pixels), de forma que as estruturas finas possam ser segmentadas. A comunidade de visão computacional tem estudado problemas análogos como ligações de bordas quebradas, modelagem de ilusões (como o triângulo de Kaniza [Kanizsa, 1979]) e agrupamento perceptual [Lowe, 1985]. O objetivo deste projeto é aproximar o processamento que o sistema visual humano realiza para perceber estas estruturas. Não temos conhecimento de trabalhos que aliem os conceitos e princípios citados anteriormente para resolver o problema de segmentação de imagens, e mais especificamente, de imagens com estruturas finas.

\subsection{Contribuições}

As principais contribuições deste trabalho são as seguintes:

- Desenvolvimento de um arcabouço unificado que é fácil de usar, estender e acrescentar dados de diferentes modalidades.

- Introdução do uso de componentes conexas para representar estruturas detectadas em baixo nível

- Uso de dois campos markovianos de forma hierárquica, incluindo processamento multi-escala, uso de informação contextual e de conceitos de visão computacional

- Fusão de dados de diferentes modalidades

- Desenvolvimento de um software para geração de imagens simuladas de perfil de solo (raízes)

- Proposta de um novo método de ligação de cristas/bordas

- Análise da detecção de cristas em imagens de retina e raízes usando cinco métodos de detecção

- Desenvolvimento do software resultante da implementação do arcabouço proposto

- Extração de redes de estradas em imagens de satélite:

- Resultados para imagens de uma única modalidade (imagens ópticas e SAR separadamente)

- Resultados usando o método de fusão proposto (imagens ópticas e SAR combinadas)

- Resultados usando o método de fusão proposto para combinação de imagens multitemporais

- Aplicação original em extração de raízes em imagens de perfil de solo 


\subsection{Organização da tese}

A tese está divida em quatro partes:

1. A Parte I é dedicada à revisão da literatura sobre trabalhos relacionados a este projeto. No Capítulo 2 são revisados trabalhos sobre filtragem, detecção e segmentação de estruturas finas. No Capítulo 3, são apresentados trabalhos do estado da arte envolvendo modelagem com grafos e no Capítulo 4 campos aleatórios de Markov. Por fim, as limitações encontradas em métodos existentes são apontadas e as nossas sugestões para superar as mesmas são apresentadas no Capítulo 5.

2. Na Parte II a metodologia desenvolvida, juntamente com as técnicas envolvidas, são descritas em detalhes. No Capítulo 6 é feita uma breve introdução de forma a contextualizar a proposta. Em seguida, no Capítulo 7, as definições necessárias e que são utilizadas na metodologia são apresentadas. Nos capítulos 8 e 9, as duas principais fases do método proposto são descritas detalhadamente, seguidas de um resumo geral do arcabouço proposto. Finalmente, a apresentação do software resultante da implementação do arcabouço conclui esta parte.

3. A Parte III refere-se à apresentação dos resultados obtidos com a aplicação do método desenvolvido em aplicações específicas. No Capítulo 11, os resultados obtidos na extração de estradas em imagens de satélite são apresentados. No Capítulo 12, os resultados obtidos na extração de raízes em imagens de perfis de solo são apresentados.

4. A Parte IV conclui esta tese com os comentários finais e a descrição de alguns trabalhos futuros.

Ademais, estão relacionados ao final do texto todos os trabalhos publicados em congressos e periódicos resultantes deste projeto. 


\section{Parte I}

\section{Revisão Bibliográfica}

Nesta parte fazemos um apanhado da literatura sobre métodos relacionados a este trabalho. Primeiramente são revisados trabalhos sobre filtragem, detecção e segmentação de estruturas finas. Em seguida, são apresentados trabalhos do estado da arte envolvendo modelagem com grafos e campos aleatórios de Markov. Por fim, as limitações encontradas em métodos existentes são apontadas e as nossas sugestões para superar as mesmas são apresentadas. 

Revisão bibliográfica

\section{Filtragem e segmentação de estruturas finas e ramificadas}

"Aprender é a única coisa de que a mente nunca se cansa, nunca tem medo e nunca se arrepende."

Leonardo Da Vinci

A literatura é rica em trabalhos que abordam o estudo de estruturas finas e ramificadas. A detecção e análise de estruturas do tipo linha/curva (line-like, curve-like) são um desafio constante em problemas de processamento e análise de imagens. Em imagens biomédicas encontramos vasos sanguíneos, neurônios, fibras de pele, estruturas de células, músculos e ossos. Várias outras aplicações podem ser citadas como detecção de estradas e rios em imagens de satélite, rachaduras em estradas ou materiais e linhas de impressão. Existem estudos sobre tais estruturas encontradas na natureza e também sobre a modelagem matemática e caracterização das mesmas. Em um dos trabalhos na área, proposto por Waite, foi criado um programa de computador capaz de modelar árvores enraizadas e particularmente as estruturas ramificadas encontradas na botânica e em brônquios. Outro trabalho proposto em 1996 apresenta a caracterização da estrutura de redes de rios usando dimensões fractais relacionadas às leis de Horton [Tarboton, 1996]. Zhi et al. comparam alguns modelos que descrevem estruturas ramificadas de plantas, buscando o que melhor se encaixa neste caso. Estruturas ramificadas de pulmões também foram exploradas em [Horsfield \& Cumming, 1967; Horsfield et al., 1971; Majumdar et al., 2001; Weibel, 1987] assim como de retina em [Masters, 2004]. Material adicional sobre o assunto pode ser encontrado em [Dodds \& Rothman, 1999; Sánchez et al., 2003; Turcottea et al., 1998].

O interesse em estruturas finas e ramificadas envolve geralmente sua representação geral para reconstrução, por exemplo, ou a busca de determinadas características como tamanho, largura, curvatura e topologia (padrões de ramificação para análise da arquitetura geral). 
Além disso, a extração destas estruturas é um passo essencial para a segmentação de redes completas ou parciais e objetos maiores. A tarefa de detectar estruturas finas em imagens é considerada bastante difícil. Alguns motivos contribuem para este fato como a resolução, precisão e qualidade geral das imagens. Observe que as propriedades intrínsecas destas estruturas (finas, alongadas, ramificadas e curvadas) tornam-as propensas a ruídos. Isto faz com que processamentos realizados em imagens contendo estas estruturas, como detecção, reconstrução ou segmentação, resultem em descontinuidades ao longo da estrutura. Questões chave estão envolvidas no processamento de estruturas deste tipo, devido às suas características específicas: (i) como melhorar a qualidade visual das imagens com estruturas finas e (ii) como remover o ruído sem perder informações importantes da estrutura.

Neste capítulo realizamos uma breve revisão de métodos que envolvem a detecção e segmentação de estruturas finas.

\subsection{Filtragem de estruturas finas}

Técnicas de filtragem de estruturas lineares/curvadas são baseadas normalmente na eliminação de ruído mantendo o máximo possível das informações das estruturas ou no realce das estruturas evitando o aumento de ruído. Usualmente, aplica-se algum pré-processamento para detectar as estruturas em ambos os casos. Métodos locais de detecção envolvem préprocessamento e segmentação para extrair bordas [Canny, 1986] e cristas (linhas centrais, ridges) [Haralick, 1983]. Já os métodos globais podem ser divididos em duas categorias: os que usam filtros para extrair bordas ou cristas das estruturas, juntamente com algum processo de refinamento [Frangi et al., 1998; Sato et al., 1997], e os que aplicam alguma estratégia de rastreamento a partir de sementes localizadas dentro da estrutura.

Diversos métodos bem conhecidos na literatura consideram apenas a intensidade dos pixels para realizar a extração de linhas: watershed, esqueletização, filtros direcionais (filtros Steerable [Jacob \& Unser, 2004; Perona, 1991], operadores de linha [Dixon \& Taylor, 1979], filtros de quadratura [Andersson \& Knutsson, 1991; Granlund \& Knutsson, 1995], filtros de Gabor [Bigün \& Hans du Buf, 1994; Chen et al., 2000]), detecção de bordas [Canny, 1986], detecção de cristas [Lindeberg, 1996] e ondaletas [Unser \& Van De Ville, 2009]. Estes métodos são baseados em bancos de filtro de orientação e buscam a orientação que corresponde à resposta máxima de um banco de filtro.

Por outro lado, outros métodos existentes na literatura consideram a imagem como sendo uma função e as linhas são detectadas como cristas: métodos baseados em derivadas (gradiente, tensores [Bigun et al., 2004; Bigun \& Granlund, 1987; Knutsson, 1989], derivadas de segunda ordem), métodos baseados em momentos, morfologia matemática, caminhos mínimos, curvelets.

Filtros clássicos como o da mediana, média, convoluções lineares e filtros morfológicos assumem que as estruturas são localmente isotrópicas, ou seja, uma janela grande o suficiente estará no interior da estrutura [Gonzalez \& Woods, 2008]. Filtros que não assumem estruturas isotrópicas filtram apenas áreas de baixo gradiente em uma determinada região. 
Observe que estruturas alongadas podem não apresentar partes com gradiente suficientemente baixo por causa de ruído ou por causa das bordas da estrutura. Para este tipo de estrutura, normalmente assume-se que uma das dimensões é significativamente maior (mais alongada). Assim, a filtragem é aplicada ao longo desta direção sem necessariamente perder todas as informações sobre a estrutura. Filtros direcionais como as transformadas de Hough e Radon podem ser usados para detectar segmentos de retas ou outras estruturas com formas conhecidas, mas, para o caso de estruturas curvadas, a detecção torna-se bem mais desafiadora.

Alguns métodos da morfologia matemática usam conjuntos de elementos estruturantes direcionais para realizar a detecção [Czerwinski et al., 1999; Kutka \& Stier, 1996; Orkisz et al., 1997]. Porém, estes métodos dificilmente conseguem detectar estruturas em escalas variadas, pois são projetados para análise em escalas fixas. Extensões destes métodos para várias escalas podem ser desenvolvidos, mas o custo computacional pode aumentar consideravelmente.

Uma abordagem proposta por Truc et al. utiliza características direcionais (do tipo linha) extraídas da imagem, através de um banco de filtros direcionais, para obter uma análise hessiana mais precisa na presença de ruído. Assim, este método é capaz de detectar estruturas menores e finas.

Outro tipo de filtragem conhecido na literatura é o de difusão isotrópica. Esta abordagem, apesar de remover ruído, destrói estruturas finas, o que não é desejável. Para superar este problema, vários autores propuseram abordagens anisotrópicas, onde a orientação local das estruturas é estimada e a filtragem é realizada localmente ao longo desta orientação. Isto preserva estruturas pequenas e evita o borramento das bordas de estruturas maiores. Também existe a filtragem anisotrópica não-linear, que foi aplicada na literatura principalmente para a filtragem de vasos sanguíneos [Krissian, 2002; Krissian et al., 1997; Orkisz et al., 1997].

Um outro tipo de abordagem interessante para estruturas finas é chamada de arcabouço de espaço de escala linear. Podemos citar métodos de detecção de bordas e cristas [Bigun \& Granlund, 1987; Danielsson \& Lin, 2001; Lindeberg, 1998] que usam a matriz hessiana ou a tensor de estrutura [Deguchi et al., 2001]. Para isso, a difusão anisotrópica geralmente é usada [Perona, 1998], onde informação tensorial é usada para difusão somente dentro da estrutura, enquanto que fora dela a difusão torna-se isotrópica.

Especificamente para imagens de redes vasculares, existem diversos trabalhos que buscaram caracterizar as propriedades anisotrópicas destas estruturas. Um conjunto de filtros da média direcionais foi usado em [Chen \& Hale, 1995]. A diferença entre as respostas mais forte e mais fraca foi usada como um medida anisotrópica. De fato, a intensidade média ao longo de um vaso deve ser maior que nas direções perpendiculares. Um algoritmo que funciona em tempo real, baseado em um conjunto de filtros lineares obtido através de combinações de kernels Gaussianos sensíveis a vasos de diferentes orientações e raios foi proposto em [Poli \& Valli, 1997]. 


\subsection{Detecção e segmentação de estruturas finas}

Existem diversos trabalhos na literatura relacionados a este projeto que foram desenvolvidos abordando problemas como segmentação de neurônios, detecção de estruturas finas em imagens SAR (Synthetic Aperture Radar), segmentação de veias e vasos sanguíneos, entre outros.

Na área de sensoriamento remoto, trabalhos como os de Lacoste et al., Segl \& Kaufmann e de Smits et al. abordam a detecção e segmentação de estruturas lineares em imagens de satélite. Vale citar alguns trabalhos clássicos importantes nesta área como [Berthod \& Serendero, 1988; Merlet \& Zerubia, 1996; Shneier, 1982; Tupin et al., 1999; van der Brug, 1976]. No trabalho descrito em [van der Brug, 1976], três algoritmos para detecção de linhas (linear, não-linear e semi-linear) são propostos. Shneier foi um dos primeiros a utilizar uma pirâmide de imagens em diferentes resoluções para extrair estruturas lineares. O uso da extração de cristas e da ligação de cristas quebradas através de informações de intensidades e orientações foi introduzido em Berthod \& Serendero.

Nos últimos anos, novos sensores de satélites ópticos (Quickbird, Pleiades) e de radar (TerraSAR-X, COSMO-SkyMed) que fornecem imagens de alta resolução têm sido lançados. Estes novos sensores abrem novas perspectivas para problemas de reconhecimento de padrões e, especificamente, para extração de redes de estradas. De fato, novas abordagens explorando as características destes sensores de alta resolução tem sido propostas na literatura [Hedman et al., 2010; Negri et al., 2006; Poulain et al., 2008; Tison et al., 2004]. O problema de extração de redes de estradas em sensoriamento remoto tem sido estudado por um longo período devido a sua importância em muitas aplicações como planejamento urbano, desenvolvimento e atualização de mapas, gestão de tráfego, desenvolvimento industrial, cartografia e assim por diante. Além disso, o volume imagens coletadas vem crescendo rapidamente nos últimos anos e, consequentemente, processos manuais passam a consumir muito tempo. Este problema em particular é considerado uma tarefa bastante difícil, principalmente porque as características espectrais e espaciais das estradas podem ser muito complexas e variáveis. Apesar do que se pode imaginar, usar imagens com melhor resolução não torna o problema mais fácil. De fato, as estradas, ou parte delas, podem ser mascaradas devido à presença de objetos como veículos, sinais de trânsito e prédios.

Existem muitos trabalhos na literatura que propõem diferentes abordagens, sejam elas automáticas ou semi-automáticas. Uma abordagem bastante utilizada em geral é a análise em duas etapas. A primeira etapa é dedicada à extração de primitivas de baixo nível e a segunda etapa consiste em um passo de alto nível que busca extrair a rede final usando informação estrutural/contextual. Considerando a primeira etapa, diferentes métodos propostos na literatura usam técnicas como deteç̧ão de bordas [Canny, 1986; Steger, 1998; Zhou et al., 1989], filtros de máscara de estradas [Gamba et al., 2006], filtragem direcional adaptativa [Dell'Acqua et al., 2005], análise estatística [Skriver et al., 2005] e operadores morfológicos [Chanussot et al., 1999; Katartzis et al., 2001]. Considerando a segunda etapa, existem 
trabalhos na literatura que usam minimização de uma função de custo global aplicando campos aleatórios de Markov [Katartzis et al., 2001; Negri et al., 2006; Smits et al., 1996; Tupin et al., 2002, 1998], métodos de rastreamento [Vosselman \& Knecht, 1995; Zhou et al., 2005] e programação dinâmica [Barzohar \& Cooper, 1996]. Outros trabalhos também usam algoritmos genéticos para esta fase [Jeon et al., 2002].

Existe um grupo de métodos de segmentação de estruturas finas que não depende da detecção de bordas, cristas ou outras estruturas primitivas. Fazem parte deste grupo os métodos baseados em crescimento de regiões como os encontrados em [Adams \& Bischof, 1994; Hanson \& Riseman, 1978; Haralick \& Shapiro, 1985; Horowitz \& Pavlidis, 1974] e em [Clemens, 1991; Hahn et al., 2001]. Estes métodos baseiam-se na definição de "sementes" que caracterizam diferente classes ou objetos nas imagens, e no "crescimento" destas sementes até que regiões inteiras sejam encontradas. Para o processo de crescimento, as decisões são baseadas em valores de intensidades vizinhos. No caso destes métodos é importante observar que eles são locais e dificilmente é possível incorporar informações de forma no processamento. As sementes utilizadas podem ser detectadas automaticamente, principalmente no caso em que elas constituem a raiz de uma árvore vascular [Naegell et al., 2005]. Algumas propriedades mais sofisticadas foram também utilizadas nestas abordagens como em [Naegel et al., 2007], onde foram consideradas informações a priori relacionadas à forma e tamanho dos vasos a serem segmentados, ou como em [Passat et al., 2005], onde foram usadas informações sobre a topologia dos vasos.

A segmentação de estruturas vasculares é uma tarefa particularmente desafiadora. Os principais motivos desta dificuldade são as modalidades específicas de aquisição de imagens, a natureza tridimensional, a presença de outros tecidos e a quantidade de ruído e artefatos. Além disso, propriedade físicas e anatômicas do tecido variam bastante em termos de tamanho, aparência, topologia e geometria. Esta variação é ainda maior quando trata-se de casos patológicos. Algumas referências importantes nesta área são [Dehkordi et al., 2011; Kirbas \& Quek, 2004; Lesage et al., 2009; Qian et al., 2009; Suri et al., 2002a,b].

Métodos baseados em derivadas também são bastante populares na literatura. Observe que vasos, estradas, neurônios e rios consistem em estruturas brilhantes em fundo escuro ou o inverso. Considerando uma imagem como uma função, as estruturas aparecem como o máximo ou o mínimo desta função. A imagem é convoluída com uma série de derivadas gaussianas com diferentes valores de desvio padrão e diferentes direções. As respostas obtidas são combinadas em uma matriz. No caso da análise de primeiras derivadas esta matriz é chamada de tensor de estrutura. Os métodos mais recentes na literatura que usam esta análise para a segmentação das estruturas são [Bauer \& Bischof, 2008; Deguchi et al., 2002; Fridman et al., 2003; Verdú-Monedero \& Angulo, 2008].

Da mesma forma que a primeira derivada, a segunda derivada também pode ser usada. Esta também é uma abordagem popular, a qual usa informação da segunda derivada para caracterizar a geometria local da imagem [Canny, 1986]. A matriz hessiana é a ferramenta mais comum para capturar este tipo de informação. Uma imagem pode ser convoluída com 
as segundas derivadas da gaussiana, e suas respostas formam a matriz hessiana. A ideia geral por trás da análise de autovalores da matriz hessiana é extrair uma ou mais direções principais da estrutura local da imagem. Assim, são obtidas a direção de curvatura mínima, a direção principal na estrutura tubular e uma alta curvatura no plano transversal da estrutura. Isto faz com que o filtro seja mais eficiente se comparado com os filtros de linha de múltiplas orientações. A matriz hessiana pode capturar características de forma dos objetos como tubos, planos e ruído. Algumas referências dentro deste contexto podem ser encontradas em [Agam et al., 2005; Hladůvka \& Gröller, 2002; Manniesing et al., 2006; Nemitz et al., 2007; Orlowski \& Orkisz, 2009; Schmitt et al., 2004; Wyatt et al., 2006].

Um método de segmentação automática de neurônios em imagens de microscopia confocal foi proposto em [Dima et al., 2002]. O processo realiza uma detecção de bordas usando a transformada ondaleta 3D, faz uma validação das bordas encontradas e, assim, realiza a segmentação dos neurônios. A técnica de segmentação paralela de Potts para realizar o reconhecimento de neurônios foi usada em [Peng et al., 2003]. Podem ser encontrados diversos trabalhos abordando a segmentação de vasos sanguíneos em retina. Algumas referências sobre o assunto são [Cornforth et al., 2005; Cree et al., 2005; Soares et al., 2006; Walter et al., 2007]. Outras técnicas que vêm sendo utilizadas no problema de segmentação de vasos sanguíneos da retina são os modelos de contorno deformáveis ou modelos Snake e a análise subpixel. Aplicações destas técnica podem ser vistas em [Espona et al., 2008a,b; Li et al., 2006].

Com relação à segmentação de raízes em imagens de perfis de solo, um sistema chamado SIARCS (Sistema Integrado para Análise de Raízes e Cobertura do Solo) foi lançado em 1996 pela EMBRAPA (Empresa Brasileira de Pesquisa Agropecuária) para análise de raízes e cobertura do solo [CNPDIA, 1996]. Neste sistema está incluída a segmentação de imagens de raízes, porém a segmentação é feita de forma bastante simples e parte dela é manual. Além disso, as imagens precisam estar em condições adequadas com relação a aquisição e contraste, por exemplo. Na literatura podem ser encontrados trabalhos que objetivam a análise da estrutura de raízes de plantas, para obtenção de informações sobre crescimento através de medidas, para reconstrução em três dimensões e para análise de propriedades morfológica [Blanchfield \& Chen, 2010; Chen \& Zhou, 2010; Huang et al., 1992; Jenneson et al., 1999; Jing et al., 2011; Song et al., 2011a; Tian et al., 2006; Zheng et al., 2011]. Porém nenhum deles lida com imagens de perfis de solo iguais ou similares às utilizadas neste trabalho.

\subsection{Ligação de bordas/cristas}

A detecção de cristas ( ridges), bem como a detecção de bordas, é um problema fundamental em processamento de imagens e visão computacional. A partir da detecção, informações importantes são geralmente extraídas de uma imagem. Este tipo de característica pode ser usado, por exemplo, para identificar, segmentar ou registrar objetos em uma cena. Porém, a detecção deve ter uma boa qualidade de forma que informações úteis possam ser extraídas. É muito comum que detectores de bordas/cristas forneçam bordas/cristas não contínuas, isto é, mapas com muitas descontinuidades e, assim, sem os contornos totalmente conectados 
como desejado. Para lidar com esse problema e para formar bordas/cristas conectados, um passo de ligação deve ser realizado.

O problema de ligação de bordas vem sendo estudado por muitos anos sendo bastante relacionado com ligação de cristas. Um algoritmo consideravelmente conhecido é o SEL (Sequential Edge Linking), proposto em 1985 por Eichel \& Delp. Ele consiste em um algoritmo de busca para detecção e ligação de bordas que usa um campo e uma cadeia aleatórios de Markov para modelar o problema. Pelo modelo usado, muitos parâmetros devem ser fornecidos para obter resultados aceitáveis [Eichel et al., 1988].

Em [Miller et al., 1993], um algoritmo em dois passos foi proposto. Neste algoritmo são usadas informações de distância, direção e magnitude dos segmentos de borda para construir um sistema de pesos para ligar as bordas. Existem outros algoritmos na literatura baseados em direção, informação local ao redor de pontos finais e minimização de função de custo [Hajjar \& Chen, 1999; Li et al., 2003; Wang \& Zhang, 2008]. O algoritmo proposto por Wang \& Zhang realiza alguns melhoramentos a estes métodos relacionados a medida da direção da borda e a distância usada na função de custo para a ligação das bordas. A medida da direção da borda é mais precisa, incorporando todas as possíveis direções entre $0^{\circ}$ e $360^{\circ}$ graus. A distância geodésica é usada para medir a proximidade entre dois pontos finais, de forma que informação de intensidade da imagem seja usada.

Na literatura, podem ser encontrados outros métodos de ligação de bordas que usam conceitos de morfologia matemática e modelos conexionistas [Basak et al., 1994; Shih \& Cheng, 2004] ou que combinam medidas locais e globais para ligação de pontos de borda como os descritos em [Sappa \& Vintimilla, 2006, 2007]. Finalmente, associado ao problema de ligação de bordas, métodos de agrupamento de bordas também podem ser encontrados [Stahl \& Wang, 2007]. Porém, agrupamento de bordas visa detectar estruturas e bordas salientes, ao invés de melhorar a detecção de bordas conectando pequenas bordas. 
Revisão bibliográfica

\section{Modelagem utilizando grafos}

“As coisas, por si sós, não são interessantes, mas tornam-se interessantes apenas se nos interessamos por elas."

S. Ceccato

Nos últimos anos, o uso de grafos surgiu como uma representação unificada para análise e processamento de imagens. Muitos métodos poderosos de processamento de imagens tem sido formulados em grafos de adjacência de pixels, grafos de regiões e grafos de primitivas. Devido a sua natureza discreta e simplicidade matemática, estas representações tornam-se bastante interessantes no desenvolvimento de métodos de processamento de imagens eficientes e comprovadamente corretos. Neste capítulo fazemos uma breve revisão dos principais métodos encontrados na literatura que fazem uso destas representação para o tratamento de problemas bem conhecidos de processamento e análise de imagens.

\subsection{Segmentação e classificação de imagens}

A teoria de grafos tem sido bastante utilizada no problema de segmentação de imagens. Uma abordagem comum de segmentação usando grafos é composta pelos seguintes passos principais:

1. Suavização da imagem de entrada

2. Criação de um grafo onde:

- cada pixel da imagem suavizada é um vértice do grafo e o peso do vértice corresponde ao valor de intensidade do pixel, e

- cada vértice está conectado por arestas a seus vértices vizinhos (dependendo da vizinhança, 4- ou 8-conexa) e o peso de cada aresta corresponde a diferença absoluta de intensidade entre os pixels ou qualquer outro valor proveniente de uma função de comparação entre dois pixels. 
3. A partir daqui o processamento é feito sobre o grafo:

- Para realizar a segmentação, um processo de "fusão" de vértices é executado, onde dois vértices são fusionados (a aresta entre os dois vértices correspondentes é removida) se o peso é menor do que um limiar definido previamente;

- O peso do vértice fusionado geralmente é atualizado com a média dos pesos dos vértices fusionados;

4. Ao final deste processo, as bordas das regiões presentes na imagem são criadas a partir do grafo obtido no item anterior.

Na literatura são encontrados trabalhos em diferentes áreas de aplicação que utilizam a teoria de grafos para segmentação. Em [Falcao et al., 2000], um método rápido da família dos algoritmos conhecidos como live wire [Falcão et al., 1998; Mortensen \& Barrett, 1995] e live lane [Falcão \& Udupa, 2000; Kang \& Shin, 2002] é proposto para a segmentação de imagens médicas em duas e três dimensões. A segmentação do córtex cerebral é explorada em [Han et al., 2002], para a representação topológica da superfície do córtex, onde o autor propõe uma abordagem multi-escala baseada em morfologia matemática. Ainda na área médica encontramos trabalhos para segmentação de volumes utilizando a transformada imagem-floresta [Falcão \& Bergo, 2004] e para a segmentação e vasos sanguíneos em imagens de retina [Xu et al., 2011b]. A técnica de casamento de grafos também vem sendo utilizada para este tipo de problema como em [Consularo \& Cesar, 2005; Consularo et al., 2007; Noma et al., 2012].

Em [Shi \& Malik, 2000], o problema de segmentação é tratado de forma global (agrupamento perceptual) através do particionamento de um grafo de pixels da imagem.

Grafos de adjacência de regiões também são usados em segmentação de imagens como em [Tsaig \& Averbuch, 2002], onde é proposto um método para a segmentação automática de objetos em movimento em vídeo. O problema é tratado como uma rotulação do grafo de regiões baseada em informações de movimento.

Abordagens para classificação de imagens que utilizam grafos são encontrados na literatura: classificação de imagens de satélite [Camps-Valls et al., 2007; Chen et al., 2011], classificação de imagens usando hipergrafos [Yu et al., 2012], uso de regularização funcional discreta em grafos com pesos para a segmentação e classificação de imagens de microscopia contendo elementos biológicos como células, citoplasma e núcleo [Ta et al., 2007].

\subsection{Registro de imagens}

A teoria de grafos pode ser usada também para o problema de registro de imagens. $\mathrm{O}$ uso do algoritmo de árvore geradora mínima é amplamente usado na literatura. Considere duas imagens a serem registradas, uma chamada de referência $\left(I_{0}\right)$ e a outra secundária $\left(I_{1}\right)$, com suporte de tamanho $M \times N$. Seja $\left(y_{0 k}, y_{1 k}\right)$ um par de valores de intensidade extraído do pixel da posição $k$ de cada uma das imagens. Assume-se que $\left\{\left(y_{0 k}, y_{1 k}\right)\right\}_{k=1}^{M \times N}$ 
são realizações independentes e identicamente distribuidas de um par de variáveis aleatórias $\left(Y_{0}, Y_{1}\right)$ com densidade conjunta $f_{01}\left(y_{0}, y_{1}\right)$. Quando duas imagens estão bem registradas, regiões de interesse correspondentes devem sobrepor-se e a distribuição de probabilidade conjunta possui valores altos para as combinações dos valores de intensidade, minimizando o valor da entropia das imagens sobrepostas; de forma similar, se há um mal registro entre duas imagens, ocorre uma dispersão da distribuição de probabilidade conjuta, aumentando a entropia [Ma et al., 2000]. Consequentemente, o registro ótimo pode ser encontrado pelo algoritmo que busca a transformação que minimiza a entropia entre duas imagens. Esta entropia pode ser estimada pelo tamanho de uma árvore geradora mínima. Em [Ma et al., 2000] é proposto um método para registro de imagens usando representação em grafos e a entropia de Rényi, que é usada como a métrica de dissimilaridade entre as imagens. O registro é realizado minimizando o tamanho da árvore geradora mínima que gera o grafo obtido da sobreposição das imagens.

O trabalho encontrado em [Sabuncu \& Ramadge, 2008] faz uma análise detalhada do uso de grafos geradores mínimos como método de registro de imagens de diferentes modalidades. Em [Neemuchwala et al., 2002] é analisada uma técnica eficiente e de baixo custo computacional para a construção de árvores geradores mínimas. Entropic spanning graphs são usados para estimar entropia e divergência no problema de registro de imagens. Recentemente, o registro de imagens usando uma função objetivo baseada em campos aleatórios de Markov foi abordado em [Mahapatra \& Sun, 2012]. Neste caso, uma abordagem de graphcut multi-escala é usada para realizar o registro com precisão de subpixels. Um algoritmo de casamento de pontos característicos, processo essencial para o registro de imagens, foi recentemente proposto em [Liu et al., 2012]. Finalmente, um outro trabalho recente aborda o problema de registro entre imagens tridimensionais de tomografia computadorizada usando casamento de grafos e a teoria de campo médio (mean field theory) [Wang et al., 2012].

\subsection{Detecção de cristas}

Outra aplicação de teoria de grafos é a extração de linhas centrais de estruturas e de esqueletização. O conceito de linhas centrais, também chamadas de eixo medial ou simétrico (apesar de que existem autores que consideram estas estruturas diferentes), foi introduzido em [Blum, 1967]. Em um objeto tubular uma única linha central geralmente ocupa todo o comprimento do objeto. Caso a estrutura possua uma forma mais complexa, é provável que existam várias linhas centrais conectadas umas as outras através da estrutura. A topologia de um grupo de linhas centrais como esta forma algo que se parece com o esqueleto do objeto, por isso o processo de extração destas linhas chama-se esqueletização.

Existem diversas abordagens na literatura que utilizam grafos para a detecção de linhas centrais de estruturas. Alguns métodos para extração das linhas centrais em imagens tridimensionais de ressonância magnética e tomografia podem ser encontrados na literatura. O método proposto em [Bitter et al., 2001] utiliza um grafo construído a partir de uma aproximação de um esqueleto tridimensional. Cada aresta do grafo possui um peso calcu- 
lado através da distância Euclideana da borda do objeto. A linha central é obtida através do algoritmo de Dijkstra neste grafo. Já em [Ge et al., 1999], o processo consiste em obter um esqueleto tridimensional do volume binarizado através de afinamento topológico, depois circuitos e ramificações indesejáveis são podados do esqueleto usando técnicas de busca em grafos. O resultado é modificado para gerar um caminho centralizado entre dois pontos finais definidos pelo usuário. Uma técnica similar é proposta em [Bouix et al., 2005]. Em [Wan et al., 2002], Wang et al propõem um método para extração das linhas centrais e ramificações em imagens de coloscopia. Durante o processo, o algoritmo faz uso de um grafo direcionado com pesos construído a partir do volume da imagem de tomografia de onde é calculada a árvore geradora mínima.

Um trabalho proposto recentemente [Hassouna \& Farag, 2009] apresenta um framework automático para computar esqueletos contínuos com precisão subvoxel a partir de objetos volumétricos. O método usa um ponto de referência dentro do objeto para propagar duas frentes de onda com energias diferentes. Uma dessas frentes converte o objeto em um grafo (grafo de level set), a partir do qual os nós topológicos proeminentes do objeto são determinados. Esqueletos são rastreados a partir destes nós ao longo de um campo de custo construído a partir da outra frente de onda até que o ponto de origem seja alcançado. Outras referências importantes que usam grafos e árvores para extração do esqueleto de estruturas são [Asian \& Tari, 2005; liu et al., 1998; Ruberto, 2004; Sebastian et al., 2004; Siddiqi et al., 1998; Torsello \& Hancock, 2001; Zhu \& Yuille, 1995].

\subsection{Problemas adicionais}

A teoria de grafos vem sendo utilizada em outros problemas além dos explorados anteriormente. Por exemplo, alguns trabalhos propõem o uso de grafos para organização perceptual. Em Murino [1994], utiliza-se uma representação de primitivas descritivas de diferentes tipos em termos de conjuntos de variáveis aleatórias associadas aos nós de um grafo relacional para realizar agrupamento perceptual. O problema de agrupamento é tratado como um processo de rotulação desse grafo. Sarkar propõe uma nova estratégia para organização perceptual em Sarkar \& Soundararajan [2000]. O framework consiste em uma fase de treinamento usando autômatos estocásticos e a fase de agrupamento é baseada em partição em grafo. A técnica de partição em grafo também é explorada em Soundararajan \& Sarkar [2001]. Diferentes medidas de partição são analisadas como corte mínimo, corte médio e corte normalizado de Shi-Malik para buscar os melhores agrupamentos.

Os chamados shock graphs (grafos de singularidades) são usados para o reconhecimento e casamento de formas em Sebastian et al. [2004]; Siddiqi et al. [1998]; Zaboli \& Rahmati [2007]. Estas singularidades são estruturas como cantos, pontes, linhas ou pontos do esqueleto de um objeto. Um shock graph é a descrição de um esqueleto como um grafo acíclico dirigido (DAG) construído a partir das singularidades do esqueleto. Desta forma, um processo de casamento do grafo ou de subgrafos pode ser realizado para o reconhecimento de formas. Especificamente para reconhecimento de faces podem ser encontrados na literatura 
trabalhos que usam casamento de grafos Cesar et al. [2002]; Liu \& Lee [2001]; Park et al. [2005]; Revaud et al. [2010]; Tefas et al. [2001]; Wiskott et al. [1997]; Xu \& Luo [2006]. 
Revisão bibliográfica

\section{Aplicações de campos aleatórios de Markov}

"Deve-se aprender lendo mais em profundidade do que em largura."

Quintiliano

Para o problema de interpretação de informação visual, restrições contextuais tornam-se bastante necessárias. Os contextos espacial e visual são essenciais para que uma cena seja entendida/percebida. Visualizando o processo de reconhecimento de objetos e percepção de uma cena em diferentes níveis de abstração, podemos observar o seguinte: os objetos presentes na cena são reconhecidos de acordo com as suas características em uma representação em baixo nível. As características dos objetos são identificadas através do contexto de primitivas em um nível ainda mais baixo. Por fim, as primitivas são extraídas no contexto dos pixels da imagem no nível mais baixo possível de abstração. Assim, o uso de restrições contextuais é indispensável para qualquer sistema de visão.

A teoria de campos aleatórios de Markov (MRF) fornece uma maneira conveniente e consistente para modelar entidades dependentes de contexto como pixels de imagens ou outras primitivas. Isto torna-se possível através da caracterização das influências mútuas entre essas entidades usando distribuições condicionais de campos aleatórios de Markov.

Pelos motivos citados anteriormente, campos aleatórios de Markov têm sido amplamente aplicados para resolver problemas de visão como restauração e segmentação de imagens, reconstrução de superfícies, detecção de bordas, análise de textura, fusão de dados, organização perceptual, casamento e reconhecimento de objetos, remoção de ruído, dentre outros. Faremos a seguir uma breve revisão da bibliografia relacionada a alguns destes problemas. Um arcabouço geral para a resolução de problemas de análise de imagens usando a teoria de Markov é proposto em [Li, 1994, 1995]. 


\subsection{Segmentação e classificação}

Na literatura são encontrados diversos métodos de classificação não-supervisionada usando campos aleatórios de Markov. Alguns trabalhos clássicos nessa área podem ser encontrados na literatura [Andrey \& Tarroux, 1998; Kervrann \& Heitz, 1995; Manjunath \& Chellappa, 1991; Panjwani \& Healey, 1995]. Manjunath \& Chellappa abordam o problema de segmentação de textura, onde considera-se um modelo Markov-Gauss de segunda ordem para a densidade de probabilidade condicional da intensidade dado um rótulo de textura. Outro trabalho relacionado com segmentação de textura pode ser encontrado em [Panjwani \& Healey, 1995] para o caso de imagens coloridas. Os modelos de campos aleatórios de Markov são usados para modelar texturas em termos de interação espacial dentro de cada plano de cor e também a interação entre diferentes planos de cor. Estes modelos são então usados por um algoritmo de segmentação baseado em agrupamento hierárquico aglomerativo. O método proposto por Kervrann \& Heitz possui o diferencial de não necessitar de conhecimento sobre as diferentes regiões de textura, seus parâmetros ou o número de classes de textura. O processo é baseado na análise nas estatísticas locais e globais de segunda ordem e de mais alta ordem das imagens originais. O mapa de segmentação é modelado usando um campo aleatório de Markov que inclui uma classe outlier que permite a criação dinâmica de novas regiões durante o processo de otimização. Trabalhos mais recentes sobre o assunto são reportados em [Deng \& Clausi, 2005; Fjortoft et al., 2003; Frery et al., 2007; Picco \& Palacio, 2011], sendo todos voltados para o problema de classificação de imagens de satélite.

$\mathrm{Na}$ área de imagens médicas, a segmentação de imagens de cérebro usando campos markovianos é abordada em [Held et al., 1997; Huang et al., 2010; Mabrouk et al., 2012; Scherrer et al., 2009; Zhang et al., 2001]. Mais especificamente, Huang et al. e Mabrouk et al. usam campos aleatórios ocultos de Markov.

Dois trabalhos recentes também na área de classificação de imagens de satélite são reportados em [Zhang et al., 2011; Zheng et al., 2012]. Zheng et al. propõem o uso de um campo aleatório de Markov multirresolução juntamente com um campo difuso (fuzzy), que é usado para estimar os parâmetros envolvidos através dos quais as restrições espaciais são definidas.

\subsection{Registro}

Em [El-Baz et al., 2006], um campo aleatório de Markov-Gibbs é usado para modelar a aparência visual da imagem de um objeto. A similaridade com um protótipo é medida por uma energia de Gibbs. O alinhamento é realizado por uma transformação que maximiza a similaridade.

Em [Glocker et al., 2009], o registro linear de imagens médicas é realizado através de uma formulação com campo aleatório de Markov. A estimação dos parâmetros de transformação é tratado através da rotulação e otimização discreta sobre um grafo. Neste grafo, os vértices representam os parâmetros e as arestas modelam as dependências entre pares de vértices. $\mathrm{O}$ método é aplicado no registro de imagens de modalidades diferentes (ressonância magnética 
e tomografia computadorizada).

Mahapatra \& Sun propõem o uso de um campo aleatório de Markov para o registro de imagens de ressonância magnética do coração. O campo usa informação de gradiente e saliências da imagem [Mahapatra \& Sun, 2011].

O trabalho reportado em [Cordero-Grande et al., 2012] propõe uma abordagem para o registro de imagens (ressonância magnética e tomografia computadorizada) baseada em um campo aleatório de Markov discreto de deformações e em um processo de casamento de blocos. Características de intensidade e gradiente são usadas no casamento de blocos, que garante a fidelidade de uma deformação aos dados. Informações a priori inseridas no campo mantém a suavidade da transformação.

Recentemente, o trabalho reportado em [Mahapatra \& Sun, 2012] introduz o uso de informação de segmentação para o registro de imagens. O campo aleatório de Markov utilizado para o problema de rotulação envolvido, onde os rótulos são definidos como a ocorrência conjunta de campos de deslocamento, para o caso de registro, e a probabilidade da classe de segmentação. A função objetivo captura a dependência mútua entre os rótulos de registro e segmentação. A técnica de cortes em grafo (graph-cut) é usada para obter o resultado final do registro com precisão subpixel.

\subsection{Restauração e remoção de ruído}

Os métodos de restauração de imagens que usam campos markovianos normalmente envolvem dois campos: um que garante a continuidade (valores de intensidade a serem recuperados) e outro que garante a descontinuidade (preservação das bordas).

Em [Zhang, 1993], a estimação do modelo de degradação e a restauração propriamente dita são realizadas simultaneamente usando um campo markoviano e o algoritmo EM (Expectation-Maximization). A teoria de campo médio é usada para diminuir o custo computacional do algoritmo EM.

O diferencial no trabalho reportado em [Figueiredo \& Leitao, 1997] é a não utilização de informação a priori de bordas. As localizações das descontinuidades são interpretadas como parâmetros determinísticos desconhecidos de um campo aleatório de Markov Gauss, que modela as intensidades. Assim, as descontinuidades são obtidas diretamente da imagem. O mesmo tipo de campo é usado em [Molina et al., 2003] para a restauração de imagens multicanal.

Em [Soccorsi et al., 2010], os autores propõem um método para remoção de ruído speckle de imagens de radar de abertura sintética (SAR) usando regularização não-quadrática. A função objetivo é definida usando um modelo da imagem, um gradiente e um modelo a priori. Para modelar a informação a priori, um campo aleatório de Markov-Huber é utilizado. Outro trabalho que aborda o problema de redução de ruído speckle é reportado em [Xie et al., 2002]. Os autores propõem o uso combinado de uma técnica de redução de ruído usando uma ondaleta (wavelet) bayesiana e regularização de imagem usando um campo de markoviano.

Um trabalho proposto recentemente em [Xingshi et al., 2011] introduz o uso de classifi- 
cação fuzzy na remoção de ruído baseada em campos aleatórios de Markov.

\subsection{Detecção de mudanças e fusão de imagens}

Outros problemas abordados na literatura através do uso de campos markovianos, principalmente na área de sensoriamento remoto, são a detecção de mudanças em imagens de satélite e a fusão de imagens. Em [Carincotte et al., 2006], um método não-supervisionado de detecção de mudanças em imagens SAR multitemporais é proposto. O detector log-ratio é usado para lidar com mudanças juntamente com uma versão fuzzy de campos aleatórios ocultos de Markov, caracterizando o método como uma técnica fuzzy de detecção de mudanças com uma abordagem estatística. Uma técnica também não-supervisionada é proposta em [Moser et al., 2011], para a detecção de mudanças em imagens ópticas. O diferencial deste trabalho é o uso de uma abordagem multiescala para aumentar a precisão dos resultados de detecção através do uso de ondaletas. O campo markoviano é usado para combinar as características multiescala e as informações contextuais.

No caso de fusão de imagens, são encontrados na literatura trabalhos como os propostos em [Tupin \& Roux, 2005; Xu et al., 2011a]. Tupin \& Roux fazem uso de um campo markoviano definido sobre um grafo de adjacência de regiões para realizar a fusão de duas imagens SAR e uma imagem óptica. Da imagem óptica é usado o resultado de uma supersegmentação e as características de elevação são obtidas por um casamento estrutural de características extraídas das duas imagens SAR. Dessa forma, a estimação de um modelo de elevação é obtido. Xu et al. exploram o problema de fusão de imagens multiespectrais. Modelos baseados em campos markovianos são usados para incorporar restrições contextuais no modelo de fusão. 
Revisão bibliográfica

\section{Limitações e problemas em aberto}

"A mente humana, uma vez ampliada por uma ideia nova, jamais volta a suas dimensões originais."

Oliver Wendell Holmes

Os métodos apresentados no Capítulo 2 apresentam uma ampla variedade de escolha para a resolução de um determinado problema. A escolha depende da aplicação e das restrições envolvidas. Algumas escolhas principais que devem ser feitas são: se o método deve ser automático ou não; se a eficiência é uma prioridade alta; o quão os resultados devem ser precisos. Uma fragilidade da grande maioria dos métodos existentes na literatura é a incapacidade de detectar automaticamente bifurcações/cruzamentos das estruturas. Outra fragilidade é a incapacidade de tratar dados incompletos quando parte da estrutura não é vista.

É interessante observar que, de maneira geral, faltam ferramentas para a análise específica de estruturas muito finas, apesar de serem muito importantes em várias áreas. Por exemplo, a detecção de capilares em imagens de redes de vasos sanguíneos em vários casos são mais importantes para detectar determinadas doenças do que a detecção de vasos maiores.

Uma forma de superar algumas das limitações dos métodos existentes é através da combinação de diferentes métodos complementares. Abordagens deste tipo têm se apresentado como uma maneira de alcançar melhores resultados. A escolha de cada passo depende de restrições computacionais e dos requisitos para o passo subsequente.

Especificamente para a limitação relativa ao tratamento de dados incompletos, o uso de técnicas de visão computacional, como conceitos de mais alto nível perceptual, mostram-se bastante viáveis, no intuito de tentar "restaurar" os dados faltantes. Não são encontrados na literatura trabalhos que aliam processamento de imagens e visão computacional para resolver este tipo de problema. Proposta esta que parece ser bastante promissora para obter resultados significativos de segmentação das estruturas finas. Uma outra maneira que vem 
se tornando cada vez mais comum na literatura é o uso de fusão de imagens de diferentes modalidades de uma mesma estrutura/região para a complementação de dados. Levando em consideração especificamente o problema de extração de redes de estradas (uma das aplicações tratadas neste trabalho), a fusão de imagens foi utilizada por poucos trabalhos até os dias atuais. Hedman et al. (2010) e Lisini et al. (2006) usam fusão em nível de característica/propriedade (feature) para melhorar os resultados da extração de estradas em imagens de alta resolução. Um trabalho recente propõe uma abordagem usando dados de imagens ópticas e de imagens SAR para extrair estradas com diferentes características e fornece a possibilidade de realizar a fusão de resultados provenientes de diferentes modalidades [Lisini et al., 2011]. Além disso, a necessidade de métodos de processamento de imagens multisensor para resolver problemas relacionados à interpretação de cenas vem aumentando consideravelmente [Brunner et al., 2008; Poulain et al., 2009; Sportouche et al., 2009; Tupin \& Roux, 2003].

Observa-se (Capítulo 3) que o uso de modelagem com grafos é uma escolha interessante, flexível, para a representação de estruturas finas e ramificadas, tanto para a obtenção de informações das estruturas (forma, tamanho, área, volume, etc), como também para o uso de técnicas de alto nível para uso de informação contextual. Neste caso surge a possibilidade do uso de campos aleatórios de Markov, como visto no Capítulo 4.

Neste trabalho estamos interessados em combinar as técnicas citadas anteriormente para tratar o problema de detecção de estruturas finas e ramificadas. Alguns pontos importantes estão envolvidos na técnica proposta:

- Modelagem com grafos

- Uso de informação contextual

- Uso de conceitos de visão computacional

- Técnica multiescala

- Fusão de dados

A abordagem proposta é descrita no que segue. 


\section{Parte II}

\section{Metodologia}

Esta parte é dedicada à descrição detalhada da abordagem proposta. Primeiramente é feita uma breve introdução de forma a contextualizar a proposta. Em seguida, as definições necessárias e que são utilizadas na metodologia são apresentadas. Logo após, as duas principais fases do método proposto são descritas detalhadamente, seguidas de um resumo geral do arcabouço proposto. Finalmente, a apresentação do software resultante da implementação do arcabouço conclui esta parte. 



\section{Introdução}

"É fazendo que se aprende a fazer aquilo que se deve aprender a fazer."

Aristóteles

Dentre os métodos de segmentação discutidos na Parte I, o grupo de técnicas baseadas na análise em dois níveis foi escolhido como base para este trabalho. Dois trabalhos relacionados diretamente a esta pesquisa servem como referência para a metodologia proposta. Em [Tupin et al., 1998] é proposto um método de detecção não supervisionada de redes de estradas em imagens de satélite. O método, quase totalmente automático, é composto por dois passos principais:

1. Detecção de linhas na imagem original:

- Visa extrair estruturas lineares através de detecção local (candidatos a segmentos de estradas);

- São usados dois detectores de linha, os quais levam em consideração as propriedades estatísticas do ruído speckle (ruído característico de imagens SAR).

2. Esquema de conexão de segmentos:

- Visa identificar as estradas reais dentre as candidatas utilizando um modelo markoviano sobre o conjunto de segmentos detectados no primeiro passo;

- Inclui um critério global para lidar com os resultados de deteç̧ões pobres do primeiro passo (poucos segmentos com grandes descontinuidades nas estruturas reais e muitas detecções falsas);

- Novo modelo baseado em campos aleatórios de Markov para estradas. Este modelo é definido em um conjunto de segmentos. Conhecimento a priori sobre a forma da estradas é introduzido pela associação de certos potenciais a subconjuntos de segmentos; 
- Um algoritmo de Simulated Annealing é usado para minimizar a energia associada do campo Markoviano.

No segundo passo, um grafo é construído a partir dos segmentos detectados no primeiro passo. O campo Markoviano é definido a partir deste grafo e o processo de identificação da estrada é modelado como a extração da melhor rotulação do mesmo. Em Tupin et al. [2002] a ideia é aprimorada para imagens de satélite de áreas urbanas, as quais tornam o problema mais difícil. Este arcabouço ajuda no desenvolvimento do método proposto pelo projeto aqui descrito.

Observe que estas técnicas em dois níveis partem do princípio de que as estruturas procuradas na imagem podem ser "construídas" a partir de fragmentos detectados em uma etapa de baixo nível. Utilizando uma representação formal destes fragmentos e mapeando as relações entre eles em mais alto nível, ou seja, usando informações contextuais, é possível reconstruir as estruturas na imagem. Esta ideia pode ser ilustrada como no exemplo simples apresentado na Figura 6.1. Dada uma imagem com uma determinada estrutura como na Figura 6.1(a),

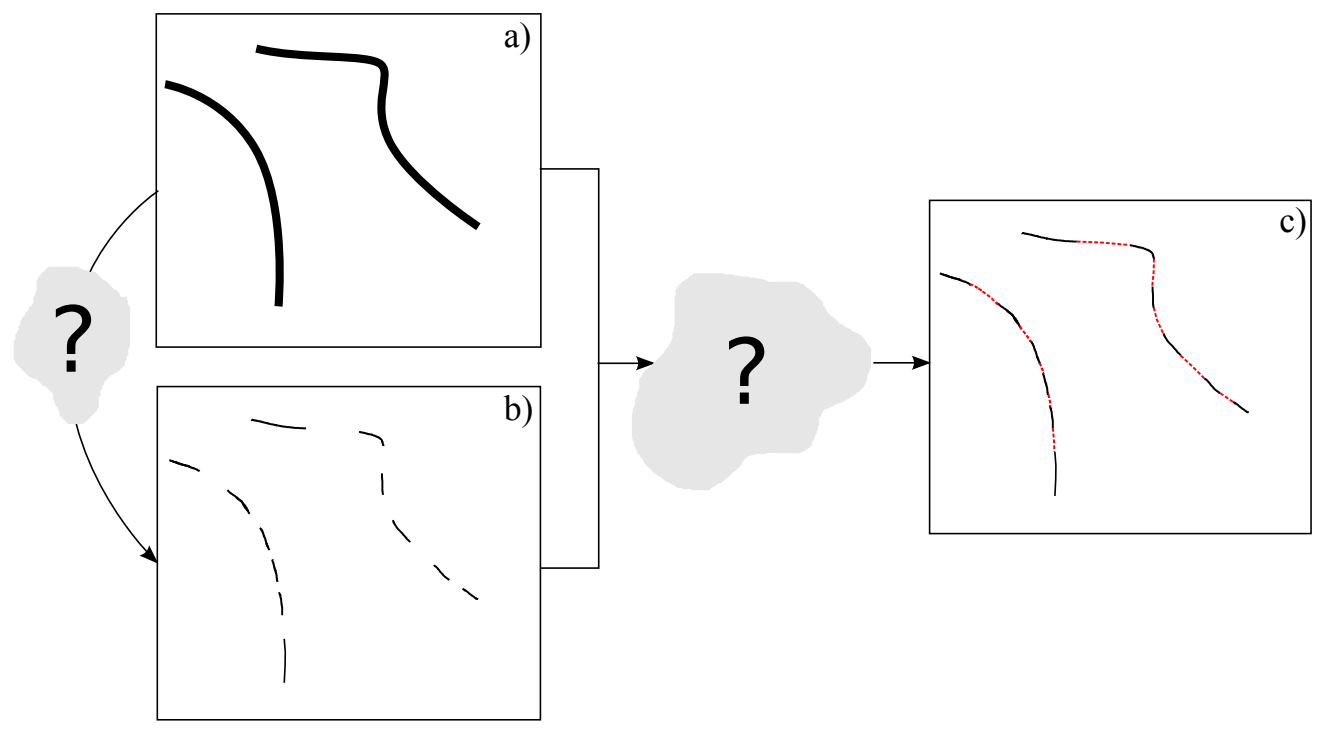

Figura 6.1: Exemplo simples do processo geral da abordagem em dois níveis.

suponha que através de um processo de detecção de baixo nível, os fragmentos apresentados na Figura 6.1(b) foram obtidos. Estruturando estes fragmentos e usando informações provenientes das estruturas na imagem original é possível reconectá-los e obter as estruturas procuradas, como ilustrado na Figura 6.1(c).

Considere agora um exemplo mais elaborado, onde o problema é tratado na presença de algum tipo de ruído, como apresentado na Figura 6.2. Neste caso, além de detectar as estruturas procuradas, o processo de baixo nível também detectou estruturas indesejadas. Observa-se, desta forma, que o processamento de mais alto nível deve ser capaz não só de reconstruir as estruturas buscadas, como também descartar outras que são apenas ruídos proveniente da imagem original. A partir destes dois exemplos iniciais, surgem as seguintes questões: 


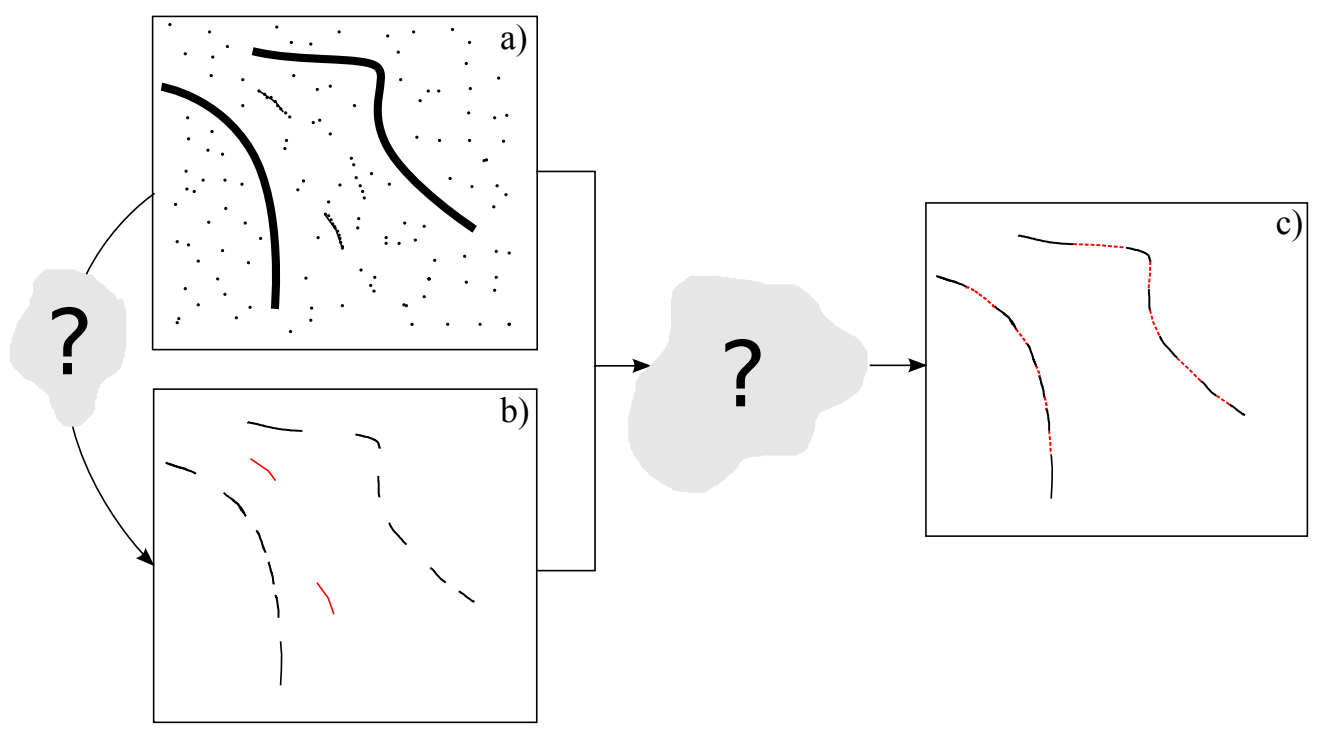

Figura 6.2: Exemplo do processo geral da abordagem em dois níveis na presença de ruído e, consequentemente, de falsas detecções.

\section{Como realizar a detecção de baixo nível?}

Como representar/estruturar os fragmentos detectados?

Como utilizar as informações contextuais e de mais alto nível para reconstruir as estruturas?

Estas questões correspondem aos dois níveis que constituem este tipo de abordagem: um de baixo nível e outro de alto nível. Sendo que este último pode ser dividido em duas partes: modelagem estrutural e processamento em alto nível propriamente dito. O ponto chave que deve ser compreendido é que para obter sucesso usando este tipo de arcabouço é preciso garantir a detecção de grande parte das estruturas buscadas em baixo nível, mesmo que isto resulte em uma alta taxa de detecção de ruídos. Isto se deve ao fato de que o objetivo do processamento de alto nível é o de filtrar as falsas detecções usando informações contextuais sobre as estruturas buscadas.

As questões levantadas anteriormente são o alvo desta parte do texto. Nos capítulos que seguem, cada uma destas etapas é apresentada em detalhes juntamente com as principais técnicas estudadas relacionadas a cada uma delas. Naturalmente, as contribuições deste trabalho serão apresentadas e destacadas em cada uma das etapas. 


\section{Metodologia}

\section{Definições}

"O conhecimento é a vida da mente."

Abu Bakr

Neste capítulo são apresentadas as definições e formalismos matemáticos necessários para o completo entendimento deste trabalho e que são utilizados nos próximos capítulos do texto. Primeiro apresentamos a notação usada neste texto para imagens digitais. Em seguida, são abordadas definições relacionadas a grafos, campos aleatórios de Markov, otimização e visão computacional.

\subsection{Imagens}

O conjunto dos números reais será denotado $\mathbb{R}$, o dos números inteiros $\mathbb{Z}$ e o dos números naturais (incluindo o zero) $\mathbb{N}$.

Neste texto uma imagem é uma função definida sobre uma grade finita euclidiana regular bidimensional sobre um subconjunto dos vetores reais $p$-dimensionais, isto é, o conjunto $S=[0, m-1] \times[0, n-1] \subset \mathbb{Z}^{2}$ denotará o suporte das imagens. Os elementos de $S$, que chamaremos de coordenadas, podem ser expressos por $(i, j) \in S$, onde $0 \leq i \leq m-1$ é a linha, e $0 \leq j \leq n-1$ é a coluna.

Uma imagem é um objeto da forma $f: S \rightarrow K$, onde $K \subset \mathbb{R}^{p}$ é o conjunto dos possíveis valores para cada coordenada e $p$ é o "número de bandas" da imagem (mais detalhes a seguir). Um pixel é um par $(s, f(s))$.

No que segue descreveremos dois elementos importantes ao se tratar de imagens: a estrutura espacial, caracterizada pelo conceito de "vizinhança", e o conjunto dos valores possíveis em cada posição da imagem, isto é, o seu contradomínio. 


\subsubsection{Vizinhanças}

Algumas das mais importantes operações com imagens dependem não apenas do valor observado na coordenada $s \in S$, mas também dos valores observados em uma região próxima dessa coordenada. Torna-se, portanto, importante definir com precisão o conceito de "proximidade".

Dada a natureza discreta do suporte $S$, há várias maneiras de definir a vizinhança da posição $s \in S$, que será denotada $\partial_{s}$ e que, por definição, não inclui a própria coordenada $s$. Um caso extremo é o da vizinhança vazia, isto é, $\partial_{s}=\emptyset$; no outro extremo, cada coordenada pode ter como vizinhos todos os outros pontos, ou seja, $\partial_{s}=S \backslash\{s\}$.

É comum ouvir dizer "usaremos os quatro vizinhos mais próximos"; isso é intuitivo mas, não resolve corretamente a definição de vizinhança em bordas e esquinas da imagem. Para tomar conta de todas as situações possíveis podemos usar o conceito de distância [Deza \& Deza, 2006], por exemplo

$$
\partial_{s}=\{t \in S \backslash\{s\}: d(s, t) \leq k\}
$$

onde $d(s, t)$ é alguma distância entre as coordenadas $s, t \in S$. As distâncias mais frequentes são a de Manhattan (ou $L_{1}$ ), a euclidiana (ou $L_{2}$ ) e a de Kolmogorov (ou $L_{\infty}$ ) dadas, respectivamente, por

$$
\begin{aligned}
d_{1}(s, t) & =\left|s_{1}-t_{1}\right|+\left|s_{2}-t_{2}\right|, \\
d_{2}(s, t) & =\sqrt{\left(s_{1}-t_{1}\right)^{2}+\left(s_{2}-t_{2}\right)^{2}}, \quad \mathrm{e} \\
d_{\infty}(s, t) & =\max \left\{\left|s_{1}-t_{1}\right|,\left|s_{2}-t_{2}\right|\right\} .
\end{aligned}
$$

Na relações acima temos $s=\left(s_{1}, s_{2}\right)$ e $t=\left(t_{1}, t_{2}\right)$, com $s_{1}, t_{1} \in[0, m-1]$ e $s_{2}, t_{2} \in[0, n-1]$.

Assim, relacionando as bem conhecidas vizinhanças 4-conexa e 8-conexa com as distâncias, temos:

- Vizinhança 4-conexa de uma posição $s \in S$ : conjunto de pontos a uma distância Manhattan igual a 1.

- Vizinhança 8-conexa de uma posição $s \in S$ : conjunto de pontos a uma distância de Kolmogorov igual a 1.

\subsubsection{Contradomínios}

Tal como comentado anteriormente, uma imagem é uma função que a cada coordenada do suporte $s \in S$ atribui um valor em $\mathbb{R}^{p}$, com $p \geq 1$ inteiro. Denotamos por $K$ o contradomínio da imagem $f$. A forma em que os valores do contradomínio são efetivamente armazenados em um computador digital é denominada "quantização".

O contradomínio mais simples é o binário, onde temos $K=\{0,1\}$. A visualização de uma imagem binária pode ser feita de diversas maneiras, por exemplo atribuindo a cada valor 0 a 
cor preta e a cada valor 1 a cor branca. Fica assim claro que a visualização de uma imagem está apenas associada ao seu contradomínio, mas não está necessariamente determinada por ele.

Um outro contradomínio frequentemente encontrado nas aplicações é o formado pelos primeiros 256 inteiros, começando no 0 , isto é, $K=\{0,1, \ldots, 255\}$. Outros conjuntos possíveis são os inteiros, valores em ponto flutuante e os números complexos.

Quando se trata de contradomínios multidimensionais, é comum que sejam usadas $p$ cópias do mesmo contradomínio unidimensional para definir o espaço de valores da imagem, isto é, teremos imagens binárias $p$-dimensionais, imagens byte $p$-dimensionais e assim por diante. Cada uma das dimensões irá medir, tipicamente, diferentes propriedades da cena, isto é, do mundo real. Exemplos deste tipo de imagens são as chamadas imagens multiespectrais e hiperespectrais.

\subsection{Grafos}

Um grafo [Bondy \& Murty, 2008] é um par ordenado $G=(V, \mathcal{E})$, onde $V$ é um conjunto de vértices ou nós, e $\mathcal{E}$ é um conjunto de arestas, as quais são elementos de $V \times V$. Em outras palavras, uma aresta liga dois vértices e é representada por um par não ordenado de vértices. A ordem de um grafo é dada por $|V|$, que corresponde a seu número de vértices.

Os grafos usados neste trabalho são simples e não direcionados, ou seja, não possuem loops (não existe aresta de um vértice para ele mesmo) e uma aresta ( $a, b)$ é igual a aresta $(b, a)$.

Como visto na Parte I, grafos vem sendo cada vez mais utilizados em problemas de visão computacional e reconhecimento de padrões. Definimos a seguir os dois tipos de grafos mais usados na literatura.

\subsubsection{Grafo de pixels}

Um dos tipos de grafos usados mais comumente é o grafo de pixels, ou seja, cada pixel é representado por um vértice do grafo e as arestas são definidas pelas vizinhanças 4 ou 8-conexas. A Figura 7.1 ilustra um exemplo de mapeamento de uma imagem para um grafo de pixels.

Esses grafos são bastante utilizados em segmentação e restauração de imagens. Os dois tipos de vizinhanças usados facilita a implementação computacional dos métodos e faz com que possuam tempo de cálculo baixo. Isto se dá ao fato de que o número de vizinhos é fixo e pequeno. Apesar das vantagens citadas, este tipo de grafo e vizinhanças podem não ser apropriados para certos tipos de problemas como, por exemplo, casos em que é interessante usar informação estrutural de objetos em uma imagem.

\subsubsection{Grafo de primitivas}

O grafo de primitivas é definido através de estruturas "pré-detectadas" da imagem, como cristas e bordas, por exemplo. Neste caso, cada vértice do grafo representa uma estrutura (que também chamaremos de sítio) e a vizinhança passa a depender das relações entre 


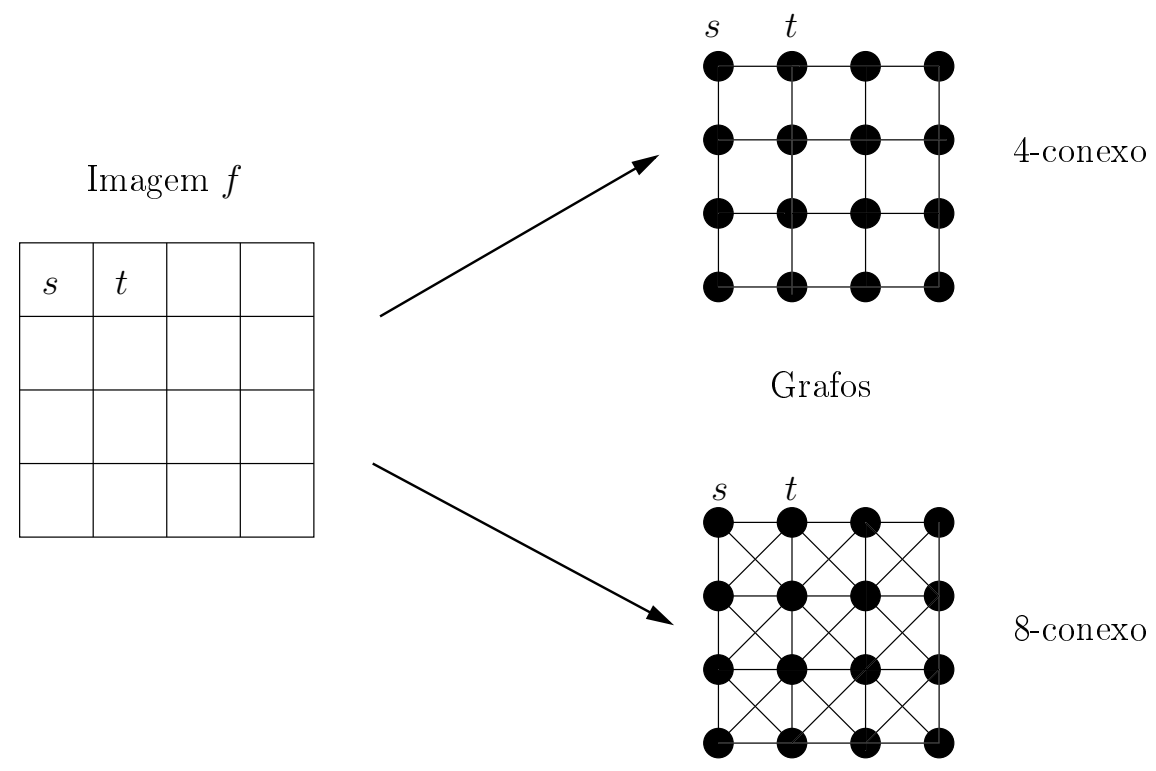

Figura 7.1: Ilustração de grafos de pixels com vizinhanças 4-conexa e 8-conexa gerados a partir de uma imagem.

as estruturas, como ilustrado na Figura 7.2. Nesta figura as primitivas são os segmentos de

Cristas detectadas a partir de uma Imagem $f$

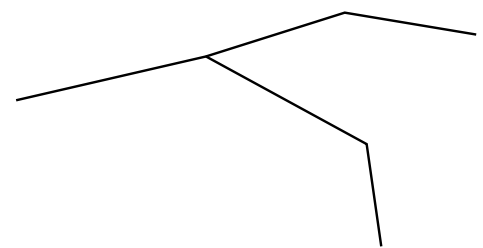

Grafo

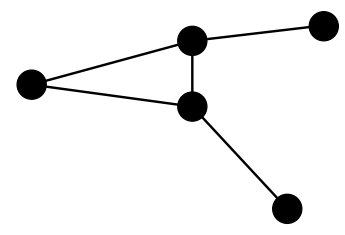

Figura 7.2: Ilustração de grafo de primitivas onde a vizinhança é definida pela relaçấo entre os segmentos (neste caso relação através das extremidades).

reta, os quais são mapeados para os vértices do grafo. Este tipo de representação leva grande vantagem sobre o grafo de pixels em certos tipos de problemas, como em reconhecimento de objetos, onde a escala a nível de pixels pode não ser necessariamente a melhor. Nestes casos, o uso de primitivas torna-se suficiente e mais adequada pois representa melhor a noção de continuidade de um objeto. Além disso, o grafo de primitivas carrega a noção de vizinhança inerente aos modelos Markovianos (apresentados a seguir neste capítulo), facilitando o uso de ferramentas eficazes para problemas de interpretação de dados. Um outro interesse na utilização de grafos de primitivas é a redução considerável do tamanho do grafo e, consequentemente, a diminuição do tempo de execução de algoritmos nestes grafos. Assim, o uso de algoritmos de otimização torna-se mais viável e o tempo necessário de execução é menor.

Outro exemplo de grafo de primitivas bastante usado na literatura para interpretação de imagens é o grafo de adjacência de regiões (Region Adjacency Graph). As primitivas neste caso são regiões normalmente provenientes de uma super-segmentação da imagem, mas 
podem ser definidas a partir de qualquer partição da imagem, $\mathcal{R}=\left\{\mathcal{R}_{i}: 1 \leq i \leq n\right\}$ com $n \in \mathbb{N}$. Uma partição, neste caso do suporte $S$ da imagem, é uma coleção de subconjuntos não-vazios e disjuntos de $S$ cuja união é o próprio $S$. Cada região $\mathcal{R}_{i}$ de $\mathcal{R}$ define um vértice do grafo, e dois vértices são adjacentes se as regiões que os representam também são adjacentes, como ilustrado na Figura 7.3. Este grafo possui normalmente os atributos de
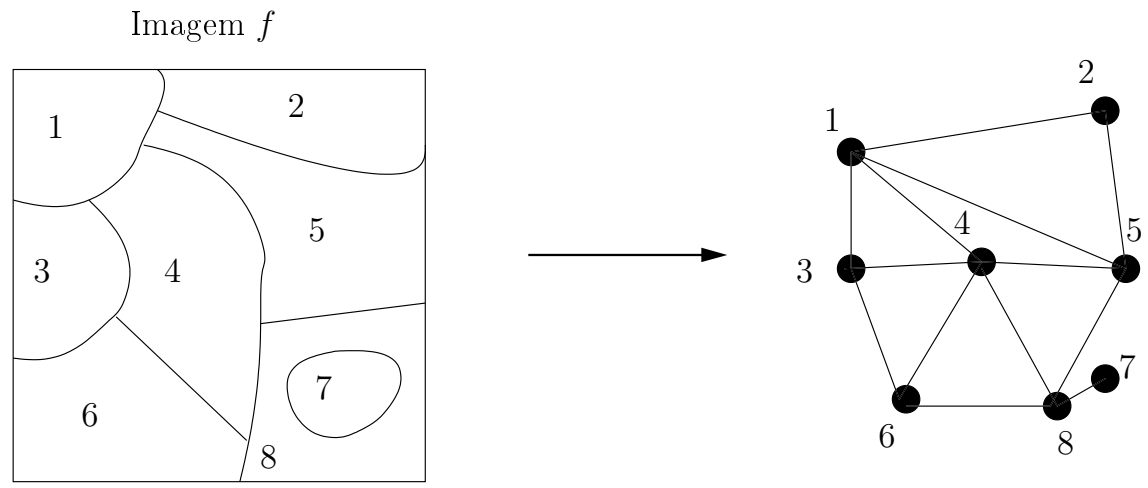

Figura 7.3: Ilustraçẫo de grafo de adjacência de regiões onde a vizinhança é definida pela fronteira entre as regióes.

tamanho das regiões nos vértices e da largura das fronteiras das regiões nas arestas.

Algumas aplicações bem conhecidas que usam grafos de adjacência de regiões são a segmentação de vídeo e a segmentação por agrupamento de regiões.

\subsection{Noções de probabilidade e estatística}

Introduziremos brevemente nesta seção algumas definições básicas de probabilidade e estatística que são usadas nas próximas seções deste capítulo. Não é objetivo deste trabalho apresentar profundamente esta abrangente área e todos os conceitos envolvidos. O livro de Dekking et al. [2005] pode ser consultado para maiores detalhes.

Probabilidade é uma área da matemática que trata fenômenos aleatórios, ou seja, experimentos que não podem ser controlados completamente, mas o conjunto de possíveis resultados (eventos) são conhecidos. Esses experimentos podem ser repetidos por um número arbitrário de vezes, sob as mesmas circunstâncias, e podem ser observados. O chamado espaço de amostragem, denotado por $\Omega$, é o conjunto de todos os possíveis eventos de um experimento aleatório. Denotaremos por $A, B$ dois eventos contidos em $\Omega: A, B \subset \Omega$. Os principais objetos envolvidos na teoria da probabilidade são as variáveis aleatórias, os processos estocásticos e eventos.

Uma probabilidade é qualquer especificação de valores para resultados $P: \Omega \rightarrow \mathbb{R}$ que possui as seguintes propriedades:

1. Não-negatividade: $P(A) \geq 0$ para todo $A \subset \Omega$.

2. Qualquer resultado é um elemento do espaço de amostras $P(\Omega)=1$.

3. Aditividade: $P(A \cup B)=P(A)+P(B)$ sempre que $A$ e $B$ são disjuntos, i.e., $A \cap B=\emptyset$. 
A probabilidade condicional refere-se à probabilidade de ocorrer um evento $A$ sabendo que ocorreu um outro evento $B$. A probabilidade de $A$ dado $B$ é denotada por $P(A \mid B)$ e é definida como:

$$
P(A \mid B)=\frac{P(A \cap B)}{P(B)}
$$

dado $P(B)>0$. Se os eventos $A$ e $B$ são independentes, então $P(A \cap B)=P(A) P(B)$, ou seja:

$$
P(A \mid B)=\frac{P(A) P(B)}{P(B)} .
$$

O teorema de Bayes permite relacionar as probabilidades de $A$ e $B$ com as respectivas probabilidades condicionadas mútuas:

$$
P(A \mid B)=P(B \mid A) \frac{P(B)}{P(A)}
$$

Ao invés de trabalhar com conjuntos arbitrários, todo resultado será transformado em um conjunto da reta real, $X: \Omega \rightarrow \mathbb{R}$. Essa transformação, se bem definida, é conhecida como variável aleatória. Sobre uma variável aleatória é possível saber apenas a probabilidade se qualquer evento possível. Este conhecimento leva a afirmação de que a distribuição da variável aleatória é conhecida. Uma das maneiras mais convenientes de saber a distribuição de uma variável aleatória $X$ é através da função de distribuição cumulativa, que é definida como:

$$
F_{X}(t)=P(X \leq t)
$$

Exitem três tipos básicos de variáveis aleatórias: discreta, contínua e singular. Nos interessa nesta tese apenas as duas primeiras as quais definiremos a seguir:

Definição 1 (Variável aleatória discreta). É qualquer variável aleatória que mapeia um espaço de amostras finito ou contável.

Assumimos, sem perda de generalidade, que $X: \Omega \rightarrow \mathbb{Z}$. A distribuição de tais variáveis aleatórias também é caracterizada por um vetor de probabilidades, denotado e dado por:

$$
p_{X}=(\ldots,(-1, P(X=-1)),(0, P(X=0)),(1, P(X=1)), \ldots)=(i, P(X=i))_{i \in \mathbb{Z}} .
$$

Pela propriedade 2 acima, tem-se $\sum_{i \in \mathbb{Z}} P(X=i)=1$.

Definição 2 (Variável aleatória contínua). A variável aleatória $X$ é contínua se existe uma função $h: \mathbb{R} \rightarrow \mathbb{R}_{+}$tal que $F_{X}(t)=\int_{-\infty}^{t} h(x) d x$ para todo $t \in \mathbb{R}$.

A função $h$, caso exista, é chamada de densidade, que caracteriza a distribuição de $X$, ou apenas a densidade de $X$.

Definição 3 (Modelo discreto uniforme). Uma variável aleatória segue um modelo discreto 
uniforme com $k \geq 1$ se sua distribuição é caracterizada pelo vetor de probabilidades

$$
\left(\left(1, \frac{1}{k}\right), \ldots,\left(k, \frac{1}{k}\right)\right)
$$

Definição 4 (Modelo uniforme contínuo). Uma variável aleatória $X: \Omega \rightarrow[a, b]$, com $a<b$, segue a lei uniforme no intervalo $[a, b]$ se a densidade que caracteriza sua distribuição é

$$
h(x ; a, b)=\frac{1}{b-a} \mathbb{1}_{[a, b]}(x),
$$

onde $\mathbb{1}_{A}$ é a função indicador do conjunto $A$.

A distribuição uniforme é muito importante em probabilidade e estatística computacional. Ela é a base dos algoritmos para gerar ocorrências de variáveis aleatórias de qualquer tipo de distribuição (ver [Bustos \& Frery, 1992] e as referências inclusas).

\subsection{Problema de rotulação}

Muitos problemas de análise e interpretação de imagens podem ser tratados como problemas de rotulação, nos quais a solução do problema é um conjunto de rótulos associados aos pixels ou primitivas da imagem. A rotulação também é uma representação natural para o estudo de campos aleatórios de Markov, usados neste trabalho.

Um problema de rotulação é especificado em termos do conjunto de sítios $S$, que pode representar um pixel ou uma primitiva, e um conjunto de rótulos. Um conjunto de sítios pode ser caracterizado em termos de sua regularidade. Sítios em uma grade são considerados espacialmente regulares, como para uma imagem $2 \mathrm{D}$ de tamanho $m \times n$. Sítios que não apresentam regularidade espacial são considerados irregulares, como no caso das primitivas (cristas, segmentos, bordas, regiões, etc), que são estruturas extraídas da imagem em um nível de abstração mais alto. Neste texto tratamos os sítios de forma não ordenada, ou seja, uma ordem lexicográfica é usada para referenciar um sítio arbitrário de $S$ por $i \in\{1, \ldots, N\}$, onde $N=m n$.

A cada sítio está associado um descritor, que representa o estado do sítio. Um descritor pode ser um nível de cinza, um rótulo ou qualquer outra informação que caracterize seu estado, e pode possuir valores em $\mathbb{L}$, o conjunto de rótulos. Este conjunto pode ser contínuo ou discreto. Consideramos neste texto apenas os conjuntos de rótulos discretos, onde um rótulo pode assumir um valor discreto em um conjunto de $M+1$ rótulos:

$$
\mathbb{L}=\{0,1, \ldots, M\}
$$

O problema de rotulação refere-se a associação de um rótulo de $\mathbb{L}$ para cada um dos sítios em $S$. Para uma imagem $f$, por exemplo, podemos definir uma rotulação $L=\left\{L_{1}, \ldots, L_{N}\right\}$ de sítios em $S$ em termos dos rótulos em $\mathbb{L}$. No caso da associação de cada sítio a um único rótulo, $L_{i}=L(i)$ pode ser considerada uma função com domínio $S$ e imagem $\mathbb{L}$. Como o 
suporte da função é todo o domínio $S, L$ é um mapeamento de $S$ para $\mathbb{L}$, ou seja,

$$
L: S \rightarrow \mathbb{L}
$$

Na teoria dos grafos o problema de rotulação é mais conhecido como problema de coloração [Bondy \& Murty, 2008]. No uso em campos Markovianos uma rotulação é chamada de configuração. Em visão computacional uma configuração pode corresponder a uma imagem, a um mapa de primitivas, à interpretação de objetos em uma imagem, entre outros.

Para o problema de rotulação discreta de $N$ sítios e $M+1$ rótulos, existe um número total de $(M+1)^{N}$ rotulações possíveis. Dentre todas estas possíveis rotulações, existem apenas algumas que consistem em boas soluções ou que são ótimas considerando algum critério. Neste ponto, existem dois passos importantes ao lidar com métodos de otimização para o problema de rotulação:

\section{Como definir um critério ótimo}

\section{Como encontrar sua solução ótima}

Ao tratar um problema de rotulação em imagens, torna-se indispensável o uso de informação contextual, visto que cada primitiva da imagem possui, além de suas características individuais, relações com suas primitivas vizinhas. Essas relações, por sua vez, podem caracterizar informações estruturais de mais alto nível. Por exemplo, considerando os sítios de uma imagem como pixels, cada pixel possui um valor de intensidade relacionado a ele. Considere uma vizinhança 4-conexa, uma informação contextual simples seria considerar a diferença de intensidades entre os pixels dentro desta vizinhança e definir que uma diferença "pequena" significaria que estes pixels pertencem a uma mesma região homogênea da imagem.

Formalmente, restrições contextuais podem ser expressas localmente através de probabilidades condicionais $P\left(L_{i} \mid L_{i^{\prime}}\right)$, onde $L_{i^{\prime}}$ corresponde ao conjunto de rótulos dos outros sítios diferentes de $s_{i}\left(s_{i} \neq s_{i^{\prime}}\right)$, ou de forma global como a probabilidade conjunta $P(L)$. Como as informações locais podem ser observadas diretamente, normalmente uma inferência global é realizada baseando-se nas propriedade locais. Observe que no caso de problemas onde os rótulos são mutuamente independentes, ou seja, sem considerar informação contextual, teríamos uma situação simples onde:

$$
P(L)=\prod_{s_{i} \in S} P\left(L_{i}\right)
$$

$\mathrm{e}$

$$
P\left(L_{i} \mid L_{i^{\prime}}\right)=P\left(L_{i}\right), s_{i^{\prime}} \neq s_{i}
$$

Assim, a rotulação $L$ pode ser encontrada considerando apenas os rótulos locais de forma individual. Já no caso do uso de informação contextual, os rótulos são mutuamente dependentes. Neste ponto, a teoria de campos aleatórios de Markov ajuda a solucionar o problema. 


\subsection{Campos aleatórios de Markov}

A teoria dos campos aleatórios de Markov [Kindermann, 1980; Li, 2009] baseia-se na relação local entre os sítios $s \in S$ de uma imagem $f$. Esta relação é definida por um sistema de vizinhança $\partial_{s}$. A partir deste sistema de vizinhança, pode-se definir um sistema de cliques. Um clique pode ser um único sítio de $S$ ou um conjunto de sítios onde todos são vizinhos de todos. Desta forma, o sistema de cliques e o número de posições afetadas por ele depende diretamente do sistema de vizinhança usado. Definimos por $\mathcal{C}$ o conjunto de cliques relativos à vizinhança $\partial$ e por $\mathcal{C}_{k}$ o conjunto de cliques de cardinalidade $k$. Tomando-se como exemplo o grafo com vizinhança 8-conexa da Figura 7.1, podem ser definidos cliques de cardinalidade 1,2,3 e 4, como apresentado na Figura 7.4.

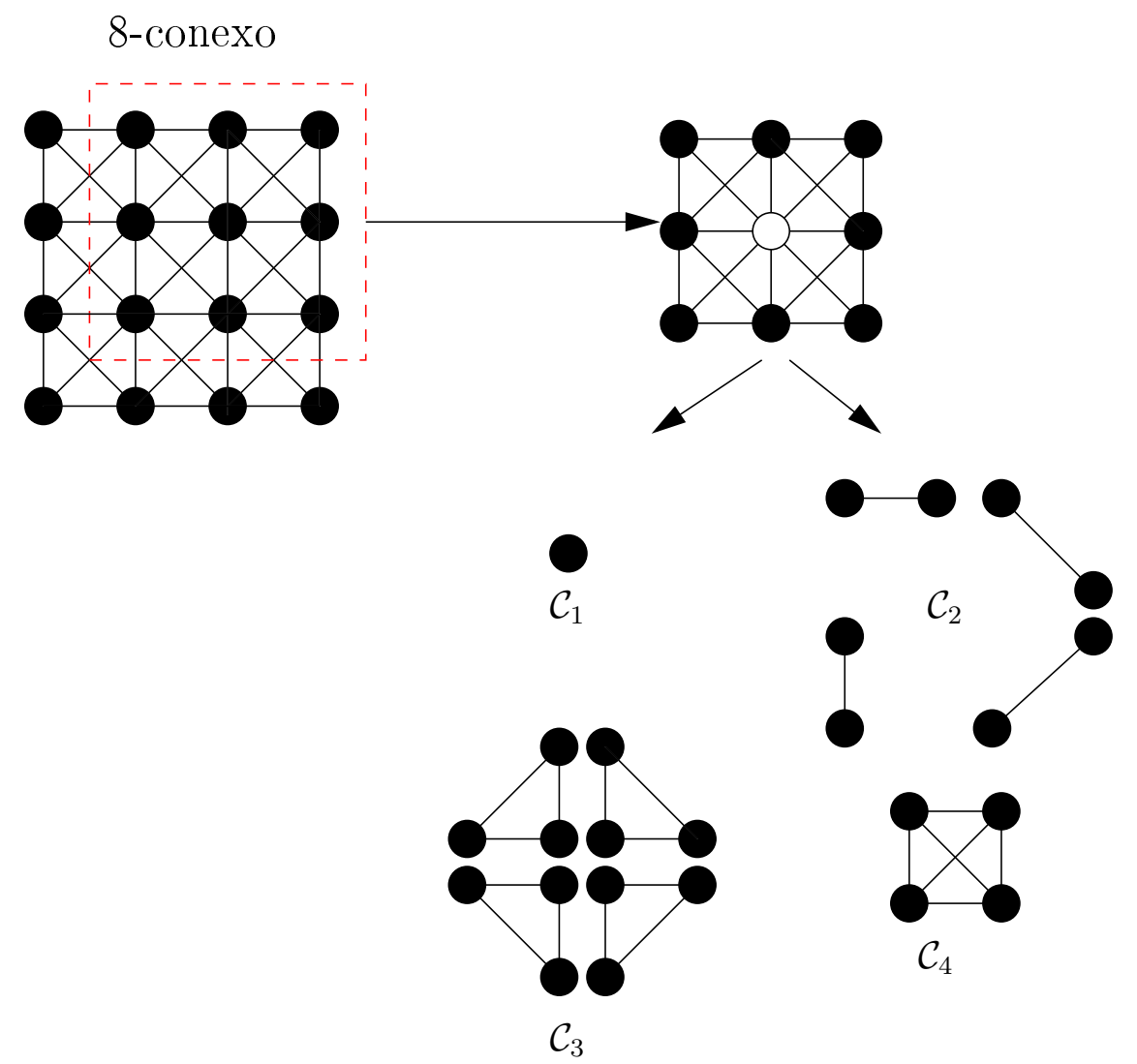

Figura 7.4: Ilustração dos cliques pela vizinhança 8-conexa em uma grade, onde $\mathcal{C}_{k}$ indica o conjunto de cliques de cardinalidade $k$.

Como dito anteriormente, a cada sítio de $S$ está associado um descritor. As relações locais entre os descritores de sítios vizinhos podem ser expressas como um potencial de clique. A um clique $c \in \mathcal{C}$ associa-se um potencial que depende dos descritores dos sítios que constituem este clique como veremos nas próximas seções.

Lembramos que, as definições dadas anteriormente valem para qualquer tipo de sítio (e grafo), apesar dos exemplos terem sido ilustrados para o caso de uma grade regular onde os sítios são os próprios pixels da imagem. Desta forma, dado um conjunto de sítios $S$ enumerável (nós do grafo), e uma relação de vizinhança $\partial_{s}$, os cliques são definidos como os 
subgrafos completos do grafo. Grafos definidos sobre regiões ou outras estruturas como segmentos, bordas, cristas, ou seja, grafos mais gerais, permitem o tratamento de um problema em mais alto nível.

Para definir um campo markoviano é necessário considerarmos uma modelagem probabilística da imagem, ou seja, a imagem é considerada uma realização de um campo aleatório. Seja um sítio $s \in S$ e uma variável aleatória (v.a.) $X_{s}$ associada a este sítio, a qual pode ter valores pertencentes a $\mathbb{L}$. Usamos a notação $X_{s}=x_{s}$ para denotar o evento em que $X_{s}$ possui o valor $x_{s}$ e a notação $\left(X_{s}=x_{s} ; X_{t}=x_{t} ; \ldots\right)$ para denotar um evento conjunto. Para simplificar a notação, abreviamos esse evento conjunto como $X=x$. Desta forma, podemos definir um campo aleatório $X=\left(X_{s} ; X_{t} ; \ldots\right)$ tendo seus valores em $\Omega=\mathbb{L}^{|S|}$. Finalmente, de acordo com esta modelagem probabilística, uma imagem é uma realização $x=\left(x_{s} ; x_{t} ; \ldots\right)$ do campo. Para um conjunto de rótulos discreto $\mathbb{L}$, a probabilidade de que a variável aleatória $X_{s}$ possua o valor $x_{s}$ é denotada por $P\left(X_{s}=x_{s}\right)$, a qual abreviamos para $P\left(x_{s}\right)$. A probabilidade conjunta é denotada por $P(X=x)=P\left(X_{s}=x_{s} ; X_{t}=x_{t} ; \ldots\right)$, a qual abreviamos para $P(x)$. Esta probabilidade conjunta permite calcular de alguma forma a verossimilhança da imagem. As probabilidades condicionais locais de um valor em um sítio permitem medir a ligação estatística entre um descritor e os valores observados nos sítios dos quais depende a distribuição condicional. A hipótese markoviana permite o cálculo destas quantidades. Lembramos que tratamos o problema considerando que $\mathbb{L}$, o espaço de descritores, não é contínuo, e assim, todas as probabilidades com que trabalhamos podem ser manipuladas e os teoremas apresentados em seguida são válidos. Fazendo um paralelo com o problema de rotulação apresentado na seção anterior, o espaço de descritores neste caso é o conjunto de rótulos.

\subsubsection{Campo de Markov}

Definição 5 (Campo de Markov). X é um campo aleatório de Markov (Markovian Random Field - MRF) em $S$, dado um sistema de vizinhança $\partial_{s}$, se e somente se as condiçôes abaixo são satisfeitas:

1. (Positividade) $P(x)>0, \forall x \in \Omega$

2. (Propriedade markoviana) $P\left(x_{s} \mid x_{\bar{s}}\right)=P\left(x_{s} \mid x_{\partial_{s}}\right)$,

onde $x_{\bar{s}}=\left(x_{t}\right)_{t \neq s}$ e $x_{\partial_{s}}=\left\{x_{t} \mid t \in \partial_{s}\right\}$. Em outras palavras, $X$ é um campo de Markov se e somente se a probabilidade condicional local em um sítio depende apenas da configuração da vizinhança deste sítio. A positividade é assumida por razões técnicas e normalmente é satisfeita na prática. Por exemplo, quando a condição de positividade é satisfeita, a probabilidade conjunta $P(x)$ de qualquer campo aleatório é determinada unicamente por suas probabilidades condicionais locais [Besag, 1974; Li, 1995]. A propriedade markoviana representa as características locais de $X$. Geralmente, no caso de uma imagem, o conhecimento local é suficiente para obter uma interpretação parcial da mesma, ou seja, a hipótese markoviana se justificará tanto para grafos de pixels como para grafos mais globais, de primitivas. 
Para especificar um campo markoviano pode-se utilizar as probabilidade condicionais locais $P\left(x_{s} \mid x_{\partial_{s}}\right)$ através da probabilidade conjunta $P(x)$. Existem alguns problemas envolvidos no uso das probabilidades condicionais [Besag, 1974], porém existe uma maneira de especificar a probabilidade conjunta graças a um resultado teórico [Hammersley \& Clifford, 1971] sobre a equivalência entre campos aleatórios de markov e distribuições de Gibbs que veremos em seguida.

\subsubsection{Campo de Gibbs}

Definição 6 (Campo de Gibbs). X é um campo aleatório de Gibbs (Gibbs Random Field GRF) em $S$, dado um sistema de vizinhança $\partial_{s}$, se e somente se suas configurações seguem uma distribuição de Gibbs, a qual é definida por:

$$
P(x)=\frac{1}{Z} \exp (-U(x))
$$

onde $U(x)$ é definida como na Equação $\% .10$ e

$$
Z=\sum_{x \in \Omega} \exp (-U(x))
$$

$Z$ é uma constante de normalização chamada de função de partição de Gibbs.

$U(x)$ é a função de energia, que é definida como a soma dos potenciais de todos os cliques possíveis de $\mathcal{C}$ :

$$
U(x)=\sum_{c \in \mathcal{C}} V_{c}(x)
$$

De maneira similar, a energia local de um sítio é definida como a soma dos potenciais de todos os cliques a que este sítio pertence:

$$
U_{s}(x)=\sum_{c \in \mathcal{C} / s \in S} V_{c}(x)
$$

Observe que diferentemente do campo aleatório de Markov, o campo de Gibbs é caracterizado por sua propriedade global (distribuição de Gibbs). Para calcular uma distribuição de Gibbs é necessário calcular a constante $Z$, que é a soma de todas as configurações possíveis em $\Omega$. Sabemos que existe um número combinatorial de elementos em $\Omega$ para um conjunto discreto $\mathbb{L}$. Assim, conclui-se que seu cálculo torna-se completamente inviável, até mesmo para um problema de tamanho razoável. Porém, veremos a seguir que é possível decompor a energia global de um campo de Gibbs em uma soma de energias locais.

Definição 7 (Campo de Gibbs com potencial associado a vizinhança $\partial$ ). X é um campo aleatório de Gibbs com potencial associado a um sistema de vizinhança $\partial$ se sua probabilidade 
é uma medida de Gibbs associada ao sistema de vizinhança $\partial$ :

$$
P(x)=\frac{1}{Z} \exp (-U(x))=\frac{1}{Z} \exp \left(-\sum_{c \in \mathcal{C}} V_{c}(x)\right)
$$

Com $P(x)$ escrita desta forma, é possível utilizar as probabilidades condicionais locais. É importante notar que quanto menor for a energia de uma de uma configuração de um campo de Gibbs, maior será sua probabilidade de ocorrência.

Muitas vezes pode ser conveniente escrever a energia de uma distribuição de Gibbs como a soma de mais de um termo, onde cada um refere-se a cliques de determinada cardinalidade. Por exemplo, considerando o caso de um campo com cliques de cardinalidade máxima 2, ou seja, considerando uma vizinhança 4-conexa, a energia pode ser escrita como:

$$
U(x)=\sum_{s \in S} V_{1}\left(x_{s}\right)+\sum_{s \in S} \sum_{t \in \partial_{s}} V_{2}\left(x_{s}, x_{t}\right)
$$

Queremos escrever a probabilidade condicional $P\left(x_{s} \mid x_{\partial_{x}}\right)$, assim usamos a equação 7.13 apenas para o sítio $s$ e sua vizinhança, ou seja, a somatória externa nos dois termos são eliminadas. Assim, pela equação 7.8, a probabilidade condicional pode ser escrita como:

$$
P\left(x_{s} \mid x_{\partial_{x}}\right)=\frac{\exp \left(-\left(V_{1}\left(x_{s}\right)+\sum_{t \in \partial_{s}} V_{2}\left(x_{s}, s_{t}\right)\right)\right)}{\sum_{x_{s} \in \mathbb{L}} \exp \left(-\left(V_{1}\left(x_{s}\right)+\sum_{t \in \partial_{s}} V_{2}\left(x_{s}, s_{t}\right)\right)\right)} .
$$

\subsubsection{Equivalência entre campo de Gibbs e o campo de Markov}

Apresentamos nesta seção um teorema fundamental na teoria de probabilidade, o qual estabelece uma equivalência entre a propriedade local de um campo aleatório de Markov e a propriedade global de um campo aleatório de Gibbs [Hammersley \& Clifford, 1971].

Teorema 1 (Teorema de Hammersley-Clifford). X é um campo aleatório de Markov em $S$, positivo $(P(X=x)>0, \forall x \in \Omega)$, dado um sistema de vizinhança $\partial_{s}$ se e somente se $X$ é um campo aleatório de Gibbs em $S$, dado $\partial_{s}$. Hipóteses: $S$ finito ou enumerável; $\partial_{s}$ limitado; espaço de estados $\mathbb{L}$ discreto.

Existem algumas provas deste teorema na literatura como em [Besag, 1974; Moussouris, 1974]. A prova apresentada por [Li, 2009] é a seguinte. Considere a probabilidade condicional

$$
P\left(x_{s} \mid x_{\bar{s}}\right)=\frac{P\left(x_{s}, x_{\bar{s}}\right)}{P\left(x_{\bar{s}}\right)}=\frac{P(x)}{\sum_{x_{s}^{\prime} \in \mathbb{L}} P\left(x^{\prime}\right)}
$$

onde $x^{\prime}=\left\{x_{1}, \ldots, x_{s-1}, x_{s}^{\prime}, \ldots, x_{n}\right)$ é qualquer configuração que coincide com $x$ em todos os sítios exceto possivelmente $i$. Escrevendo $P(x)=\frac{1}{Z} \exp \left(-\sum_{c \in \mathcal{C}} V_{c}(x)\right)$, temos

$$
P\left(x_{s} \mid x_{\bar{s}}\right)=\frac{\exp \left(-\sum_{c \in \mathcal{C}} V_{c}(x)\right)}{\sum_{x_{s}^{\prime}} \exp \left(-\sum_{c \in \mathcal{C}} V_{c}\left(x^{\prime}\right)\right)} .
$$


Divide-se $\mathcal{C}$ em dois conjuntos $\mathcal{A}$ e $\mathcal{B}$, sendo que $\mathcal{A}$ é o conjunto de cliques contendo $s$ e $\mathcal{B}$ é o conjunto de cliques que não contêm $s$. Então podemos escrever a equação 7.16 como

$$
P\left(x_{s} \mid x_{\bar{s}}\right)=\frac{\exp \left(-\sum_{c \in \mathcal{A}} V_{c}(x)\right) \exp \left(-\sum_{c \in \mathcal{B}} V_{c}(x)\right)}{\sum_{x_{s}^{\prime}} \exp \left(-\sum_{c \in \mathcal{A}} V_{c}\left(x^{\prime}\right)\right) \exp \left(-\sum_{c \in \mathcal{B}} V_{c}\left(x^{\prime}\right)\right)}
$$

Como $V_{c}(x)=V_{c}\left(x^{\prime}\right)$ para todo clique $c$ que não contem $s, \operatorname{logo} \exp \left(-\sum_{c \in \mathcal{B}} V_{c}\left(x^{\prime}\right)\right)=$ $\exp \left(-\sum_{c \in \mathcal{B}} V_{c}\left(x^{\prime}\right)\right)$. Assim, a probabilidade condicional depende somente dos potenciais dos cliques contendo $s$,

$$
P\left(x_{s} \mid x_{\bar{s}}\right)=\frac{\exp \left(-\sum_{c \in \mathcal{A}} V_{c}(x)\right)}{\sum_{x_{s}^{\prime}} \exp \left(-\sum_{c \in \mathcal{A}} V_{c}\left(x^{\prime}\right)\right)}
$$

isto é, depende dos rótulos dos vizinhos de $s$. Isto prova que um campo aleatório de Gibbs é um campo aleatório de Markov. A prova de que um campo aleatório de Markov é um campo aleatório de Gibbs pode ser consultada em [Griffeath, 1976].

O teorema fornece uma maneira simples de calcular a probabilidade conjunta $P(X=x)$ especificando as funções para os potenciais dos cliques $V_{c}(s)$ e escolhendo as funções potenciais apropriadas para o comportamento desejado do sistema. Desta forma é possível incorporar informação a priori nas interações entre os estados. Veja que não temos o problema com o cálculo da constante de normalização $Z$ para encontrar a probabilidade de uma configuração $x$, visto que é possível calcular em cada sítio a probabilidade condicional local. Os algoritmos de amostragem de campos markovianos utilizam esta expressão como base.

\subsubsection{Amostragem de um campo aleatório de Markov}

Existem diversos amostradores de campos markovianos na literatura. Nesta seção apresentamos os amostradores utilizados neste trabalho.

\section{Amostrador de Gibbs}

O amostrador de Gibbs, proposto por Geman \& Geman em 1984, propõe criar iterativamente um conjunto de configurações. Esse amostrador consiste em uma forma geral realizar uma amostragem a partir de um grande número de variáveis fazendo a amostragem de cada variável por vez. O amostrador é aplicável para casos em que a distribuição conjunta não é conhecida explicitamente (ou é difícil fazer uma amostragem de forma direta), mas a distribuição condicional de cada variável é conhecida. A ideia é que, partindo de uma configuração, a próxima será dada baseando-se em uma probabilidade condicional. Após a convergência do algoritmo, que ocorre após um número de iterações suficiente, as configurações geradas são realizações que seguem a lei global de Gibbs. Para gerar a configuração $n$, partindo de uma configuração na iteração $n-1$, os sítios da configuração são atualizados sucessivamente. Na iteração $n$, o processo é realizado através das seguintes etapas:

1. Escolhe-se um sítio $s$;

2. Considerando o sítio $s$, de acordo com os vizinhos $x_{\partial_{s}}$ para a configuração da iteração 
anterior $x^{(n-1)}$, calcula-se a probabilidade condicional local:

$$
P\left(x_{s} \mid x_{\partial_{s}}\right)=\frac{\exp \left(-\sum_{c \in \mathcal{A}} V_{c}(x)\right)}{\sum_{x_{s}^{\prime}} \exp \left(-\sum_{c \in \mathcal{A}} V_{c}\left(x^{\prime}\right)\right)}
$$

3. Atualiza-se o sítio $s$ aleatoriamente segundo a lei $P\left(x_{s} \mid x_{\partial_{s}}\right)$.

A convergência [Roberts \& Smith, 1994] ocorre quando o número de iterações é suficientemente grande ou quando o número de mudanças é muito pequeno. A escolha do sítio $s$ na primeira etapa pode ser feita de qualquer maneira, contanto que todos os sítios sejam cobertos um grande número de vezes (teoricamente infinitas vezes). Normalmente escolhe-se aleatoriamente um sítio seguindo a lei uniforme ou, de forma mais simples e clássica, varrendo o conjunto de sítios linearmente. Este algoritmo gera um conjunto de configurações $x^{(n)}$ que são observações de um conjunto $X^{(n)}$ de campos aleatórios constituindo uma cadeia de Markov. Após a convergência, as configurações $x^{(n)}$ geradas são realizações da lei global $P(x)$, independentemente da configuração inicial $x^{(0)}$. Esse amostrador é utilizado no algoritmo de recozimento simulado que será apresentado no decorrer desta seção.

\section{Amostrador de Metrópolis}

O algoritmo de Metrópolis proposto em [Metropolis et al., 1953] é baseado em um princípio similar ao amostrador de Gibbs e consiste também em um algoritmo de relaxação probabilística. O princípio é o de construir um conjunto de imagens que são amostras que seguem a lei do campo de Markov após um número suficientemente grande de iterações. Porém, a atualização em um sítio é realizada de forma diferente. Na iteração $n$, o processo é realizado através das seguintes etapas:

1. Escolha de um sítio $s$;

2. Escolha aleatória de um descritor $\lambda$ em $\mathbb{L}$ segundo uma lei uniforme;

3. Cálculo da variação de energia por $x_{s}^{(n-1)} \rightarrow \lambda$ :

$$
\left.\Delta U=U_{s}\left(\lambda \mid \partial_{s}^{(n-1)}\right)\right)-U_{s}\left(x_{s}^{(n-1)} \mid \partial_{s}^{(n-1)}\right)
$$

4. Então, dois casos são possíveis:

(a) $\Delta U<0$, a mudança é aceita: $x_{s}^{(n)}=\lambda$;

(b) $\Delta U \geq 0$, a mudança é aceita ou rejeitada com probabilidade $p=\exp (-\Delta U)$ e $1-p$.

O sistema de varredura dos sítios e o critério de parada são similares àqueles do amostrados de Gibbs. A diferença está na escolha aleatória do novo descritor ao invés de considerar a lei definida por todos os descritores. No caso em que é considerada apenas a variação de 
energia entre duas configurações, o algoritmo de Metrópolis é mais rápido a cada etapa se comparado com o amostrador de Gibbs, que precisa do cálculo da função de partição local. Por outro lado, a convergência pode ser mais lenta pois as transições nem sempre são aceitas, diferentemente do amostrador de Gibbs.

\subsubsection{Máxima Probabilidade a Posteriori (MAP) e campos aleatórios de Markov}

Para o problema de rotulação abordado neste trabalho utilizamos a chamada Teoria Bayesiana de Decisão [Berger, 1985], teoria fundamental em estimação e tomada de decisão. De forma geral, esta teoria sustenta que quando a distribuição a priori e a função de verossimilhança de um determinado padrão são conhecidos, o melhor que se pode estimar a partir deste conhecimento é uma rotulação Bayesiana. Neste contexto, a solução de Máxima Probabilidade a Posteriori (MAP) é amplamente utilizada.

Considere um conjunto de dados $y$, uma imagem por exemplo, como sendo uma realização de um campo aleatório $Y$. Seja $x$ uma realização deste conjunto de dados rotulado modelada por um campo aleatório $X$, que é o campo de rótulos no nosso caso. Veja que existe uma ligação entre estes dois campos: o processo de aquisição da imagem leva o campo "ideal" $X$, que é a solução buscada, no campo ruidoso $Y$, que é observado. É importante notar que o espaço de configurações de $X$ e $Y$ não são necessariamente os mesmos e que o nosso objetivo é fazer o caminho inverso: encontrar uma realização de $X$ a partir dos dados ruidosos $y$. Uma solução seria encontrar uma realização que maximize a probabilidade condicional $P(x \mid y)$. De acordo com a teoria Bayesiana:

$$
P(x \mid y)=\frac{P(y \mid x) P(x)}{P(y)}
$$

em que

- $P(y \mid x)$ : é a distribuição de probabilidade condicional do campo de observação, ou função de verossimilhança de $y$ para $x$ fixo;

- $P(x)$ : modelo Markoviano para o problema, onde a informação a priori é inserida (informação contextual);

- $P(y)$ : é uma constante quando $y$ é dado, ou seja, independe de $x$.

A estimação MAP é dada por

$$
\hat{x}=\underset{x \in \Omega}{\arg \max } P(x \mid y) .
$$

Como $X$ é um campo markoviano temos

$$
P(x)=\frac{\exp (-U(x))}{Z},
$$


e desta forma, podemos escrever

$$
P(x \mid y) \propto \exp (-U(x \mid y))
$$

onde $U(x \mid y)=U(y \mid x)+U(x)$. Ou seja, a estimação MAP é equivalente a encontrar a energia a posteriori mínima:

$$
\hat{x}=\underset{x \in \Omega}{\arg \min } U(x \mid y) .
$$

Um algoritmo capaz de encontrar o(s) estado(s) de energia minimal é o Recozimento Simulado ou, de forma mais conhecida, Simulated Annealing - $S A$, que veremos a seguir.

\subsubsection{Algoritmo de Recozimento Simulado}

Existem diferentes algoritmos para a busca de uma solução minimal, que pode ser única (mínimo global) ou um dentre múltiplos mínimos globais. O problema da busca de um mínimo global torna-se bastante difícil se a função de energia contem muitos mínimos locais. Existem algoritmos de minimização local e de minimização global, sendo que para estes últimos ainda não existem métodos eficientes que garantem alcançar soluções minimais globais. O Recozimento Simulado [Kirkpatrick et al., 1983; Černý, 1985] é um algoritmo estocástico para otimização combinatória que permite encontrar as configurações que correspondem ao máximo da probabilidade de um campo Markoviano. Afim de utilizar este algoritmo, devemos escrever as probabilidades envolvidas nas distribuições de Gibbs com um parâmetro de temperatura. Isto porque o algoritmo simula o processo térmico de recozimento físico onde uma substância física é derretida a alta temperatura e depois é resfriada lentamente na busca de estados e energia baixa. Trabalharemos então com uma distribuição de Gibbs dada pela seguinte probabilidade:

$$
P_{T}(x)=(P(x))^{1 / T}=\frac{1}{Z(T)} \exp \left(-\frac{U(x)}{T}\right),
$$

onde $Z(T)=\sum_{x} \exp \left(-\frac{U(x)}{T}\right)$ e $T>0$. Podemos analisar esta probabilidade em termos do parâmetro de temperatura $T$. Os casos limites são apontados abaixo:

1. $T \rightarrow 0: P_{T}(x)$ concentra-se em $\Omega^{*}=\left\{x_{1}, \ldots, x_{k}\right\}$, conjunto de configurações que atingem a energia minimal de $U(x)$.

2. $T=1: P_{T}(x)=P(x)$.

3. $T \rightarrow \infty: P_{T}(x)$ é uma distribuição uniforme em $\Omega$, visto que

$$
\exp \left(-\frac{U(x)}{T}\right) \rightarrow 1 \text { e } \sum_{x} P_{T}(x)=1 \Rightarrow P_{T}(x) \rightarrow \frac{1}{|\Omega|}
$$

A forma geral do SA é apresentado no Algoritmo 7.1. Aplica-se um algoritmo de amostragem, como o amostrador de Gibbs apresentado anteriormente, sucessivamente a medida que o valor 


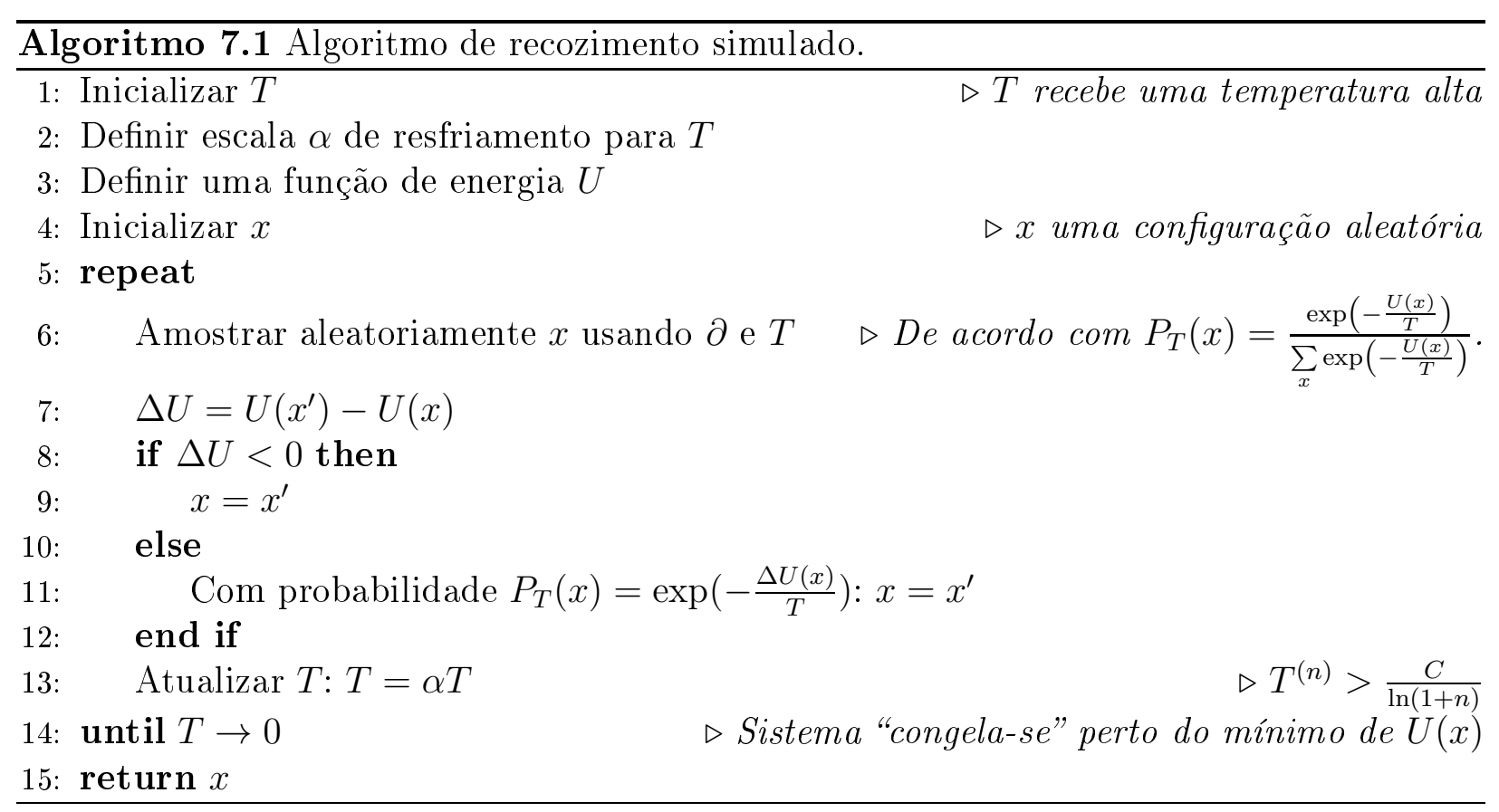

de $T$ diminui. Inicialmente, atribui-se um valor suficientemente alto para $T$ e a $x$ atribui-se uma configuração aleatória. Para um valor fixo de temperatura, a amostragem é realizada de acordo com a distribuição de Gibbs $P_{T}(x)=\frac{\exp \left(-\frac{U(x)}{T}\right)}{\sum_{x} \exp \left(-\frac{U(x)}{T}\right)}$. Então, a amostragem converge para o equilíbrio na temperatura atual $T$. O decaimento de $T$ é realizado de acordo com uma taxa previamente escolhida. Este processo continua até que $T$ se aproxime de 0 , ponto em que o sistema "congela-se" perto do mínimo de $U(x)$.

De acordo com o teorema de convergência desenvolvido por Geman \& Geman, se a sequência de decaimento das temperaturas satisfaz $\lim _{t \rightarrow \infty} T^{(n)}=0$ e $T^{(n)}>\frac{C}{\ln (1+n)}$, então o sistema converge para o mínimo global independentemente da configuração inicial $x^{(0)}$. A constante $C$ envolvida no decaimento depende da variação da energia global maximal sobre $\Omega$.

\subsubsection{Algoritmo ICM (Iterated Conditional Mode)}

O algoritmo de recozimento simulado apresentado anteriormente é bastante lento em termos de tempo de execução pois ele necessita da geração de um grande número de configurações de forma gradual à medida que a temperatura diminui. Por este motivo, os algoritmos chamados subótimos são muitas vezes usados na prática. Um destes algoritmos bastante conhecido é o ICM, proposto em [Besag, 1986]. Apesar do ICM ser muito mais rápido, não existe uma prova de convergência para um mínimo global.

Este algoritmo é iterativo de maneira que, a cada etapa, os valores $x_{s}$ do conjunto de sítios são modificados. A grande diferença deste algoritmo é que a modificação de um valor é feita de forma determinística, ou seja, o ICM não é um algoritmo estocástico.

Partindo de uma configuração inicial $x^{(0)}$, um conjunto de imagens é construido convergindo para uma aproximação MAP $\hat{x}$ buscada. A cada etapa $n$, o processo funciona da seguinte maneira: todos os sítios são percorridos e, em cada sítio, as duas operações seguintes 
são efetuadas:

1. Cálculo das probabilidades condicionais locais, para todos os valores possíveis de $\lambda$ em $\mathbb{L}$ do sítio:

$$
P\left(\lambda / y, \hat{x}_{r}(k), r \in \partial_{s}\right)
$$

2. Atualização do valor pelo $\lambda$ que maximiza a probabilidade condicional local:

$$
\hat{x}_{r}(k+1)=\underset{\lambda}{\arg \max } P\left(\lambda / y, \hat{x}_{r}(k), r \in \partial_{s}\right)
$$

O processo termina quando o número de mudanças de uma etapa para outra torna-se suficientemente pequeno.

Este algoritmo, ao contrário do recozimento simulado, é muito rápido (geralmente uma dezena de varreduras é suficiente para atingir a convergência) e de baixo custo computacional pois necessita apenas do cálculo das energias condicionais locais. Porém, os resultados dependem fortemente da inicialização. O ICM assemelha-se a um gradiente descendente ou a um recozimento simulado "congelado" à temperatura nula, e pode, desta forma, ficar "bloqueado" em um mínimo local mais próximo da inicialização.

\subsubsection{Passos gerais da abordagem MAP/campos markovianos}

De forma geral, para utilizar a abordagem MAP/campos markovianos na resolução de problemas de visão computacional, deve-se seguir os seguintes passos abaixo:

1. Definir o problema de visão como um problema de rotulação levando em consideração as naturezas de regularidade dos sítios e de continuidade dos rótulos, e escolher uma representação Markoviana apropriada $x$.

2. Derivar a energia a posteriori para definir uma solução MAP para o problema.

3. Encontrar a solução MAP.

Para derivar a energia a posteriori, os seguintes passos são necessários:

1. Definir um sistema de vizinhança $\partial$ em $S$ e o conjunto de cliques $\mathcal{C}$ para $\partial$.

2. Definir os potenciais a priori dos cliques $V_{c}(x)$ para obter $U(x)$.

3. Derivar a energia de verossimilhança $U(y \mid x)$.

4. Fazer a adição das energias $U(x)$ e $U(y \mid x)$ para obter a energia a posteriori $U(x \mid y)$.

Finalmente, busca-se pela configuração Markoviana que maximiza a distribuição a posteriori, utilizando um algoritmo de otimização como o Simulated Annealing.

O modelo a priori depende do tipo de cena (do tipo de estrutura) esperado. Em análise de imagens, normalmente utiliza-se os modelos de Gibbs. O modelo de verossimilhança depende 
de considerações físicas envolvidas do processo de aquisição (transformações, ruído, etc.). Geralmente assume-se um modelo gaussiano (mas nem sempre é o caso, como por exemplo em imagens com ruído multiplicativo). Os parâmetros em ambos os modelos precisam ser especificados de forma que as definições dos modelos fiquem completas. A especificação pode ser feita de maneira manual, mas espera-se (e é desejável) que seja feita de forma automática.

\subsection{Princípios da Teoria de Gestalt}

Gestalt é um termo alemão, da psicologia, que significaria em português "forma", "conjunto unificado" ou "configuração". Normalmente utiliza-se o termo original pois não há uma tradução direta em português que corresponda ao significado real do termo. Este termo refere-se a teorias da percepção visual desenvolvidas por psicólogos alemães nos anos 1920 [Kanizsa, 1996; Wertheimer, 1923]. Estas teorias tentam descrever como o sistema visual humano tende a organizar elementos visuais em grupos unificados quando certos princípios são aplicados.

De acordo com esta teoria, o que leva à percepção visual não é apenas a soma de pequenas partes dos objetos em questão, mas sim a totalidade. A organização perceptual dos objetos leva a um estrutura global, através da qual pode-se determinar características como forma e dimensão. Este fato faz com que alteremos a percepção do que observamos. Os fenômenos de ilusão de óptica ou imagens com figuras geométricas são exemplos de tais alterações. Observe a Figura 7.5

O que ocorre de forma geral é que, a primeira vista a percepção é global e unificada, desconsiderando partes isoladas e considerando suas relações. Depois de um certo tempo, passamos a ver os detalhes/partes que compõem o todo. A partir de uma série de experimentos, os gestaltianos definiram leis de percepção, chamadas de gestalts parciais [Desolneux et al., 2007]. Algumas destas propriedades geométricas simples são apresentadas a seguir.

Fechamento A organização visual da forma tende naturalmente para uma ordem espacial, resultando em uma sensação de fechamento visual pela continuidade de elementos em uma ordem estrutural definida. Um exemplo deste princípio é o Triângulo de Kanizsa apresentado na Figura 7.5(f).

Figura/fundo Figura 7.6(a) Existe uma tendência perceptual de separar figuras do seu fundo baseando-se em uma ou mais variáveis, como contraste, cor, tamanho, etc. Este princípio refere-se à relação entre um objeto e o que o rodeia. As vezes esta relação é estável, ou seja, é fácil separar o objeto do fundo, mas muitas vezes essa relação é variável, onde o fundo e o objeto variam, dependendo da atenção que damos a determinados pontos da figura.

Similaridade Figura 7.6(b) Objetos que compartilham características como forma, tamanho, cor, textura ou valor, são vistos perceptualmente como um todo.

Proximidade Figura 7.6(c) Esta lei afirma que objetos ou formas que estão próximas 


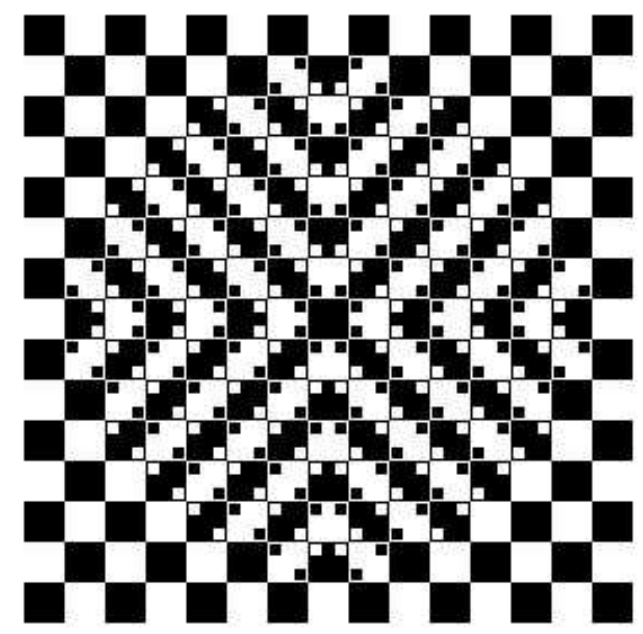

(a) Efeito de lente pelos elementos retos e inclinados. As linhas horizontais são absolutamente paralelas.

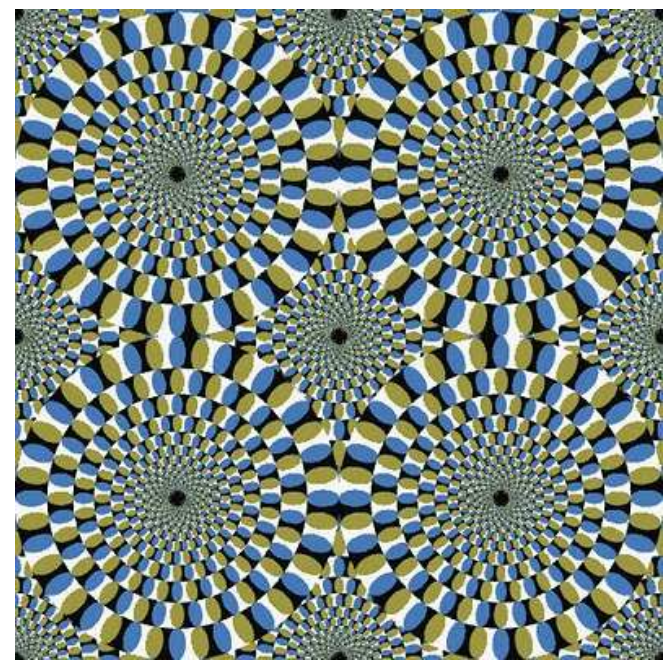

(c) Sensação de movimento.

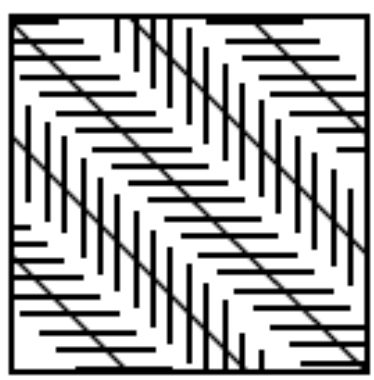

(e) Ilusão de Zoellner: as diagonais internas são paralelas mas parecem convergir e divergir de forma alternada.

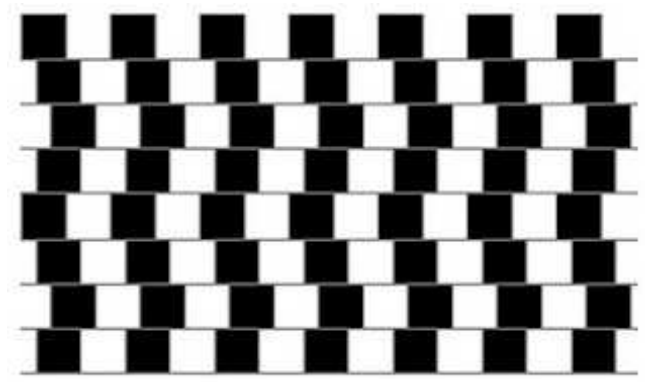

(b) Apesar de parecer diferente, as linhas horizontais são absolutamente paralelas.

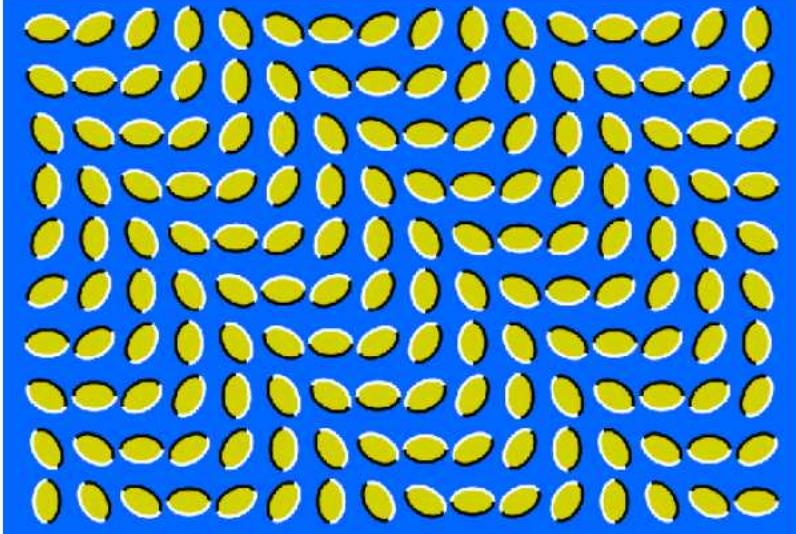

(d) Sensação de movimento.

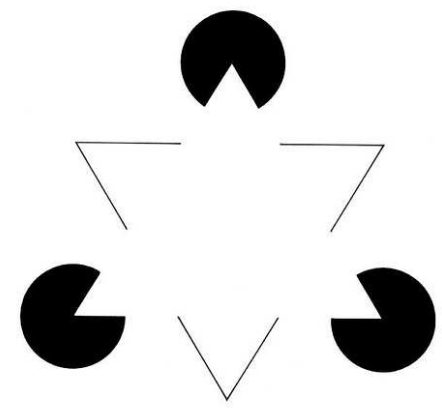

(f) Triângulo de Kanizsa: é possível enxergar o triângulo branco nitidamente.

Figura 7.5: Exemplos de ilusões de óptica e imagens com figuras geométricas.

entre si parecem formar grupos. Mesmo que formas, tamanhos e objetos sejam radicalmente diferentes, eles aparecem como um grupo se estiverem próximos o suficiente. 
Boa Continuidade Figura 7.6(d) Esta lei afirma que existe uma tendência do sistema visual humano de dar continuidade a formas além dos seus limites finais. Ou seja, elementos acompanham outros elementos para permitir a continuidade do "movimento" em uma determinada direção, de forma que a melhor forma possível (a mais estável estruturalmente) seja alcançada.

Simetria Figura 7.6(e) A figura é percebida como um todo, e não como partes individuais de compõem a figura. Exclui-se a impressão de que algo está fora de equilíbrio, faltando ou errado.

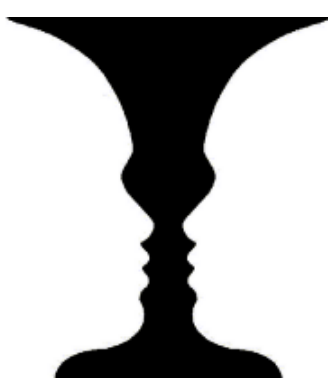

(a) Vaso de Rubin: o vaso e as faces alternam entre objeto e fundo.

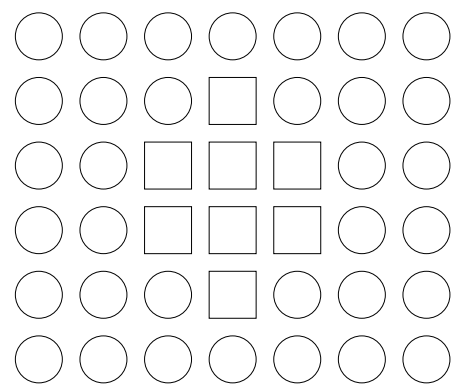

(b) Similaridade: visão de dois grupos de acordo com a forma.

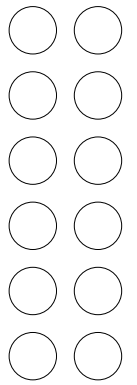

(c) Proximidade: objetos separados em dois grupos pela proximidade, mesmo possuindo formas idênticas.

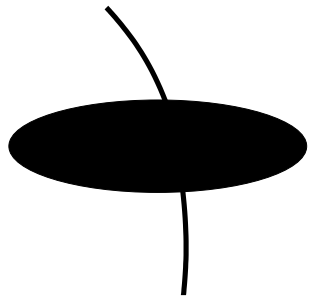

(d) Continuidade: objetos agrupados por boa continuidade.

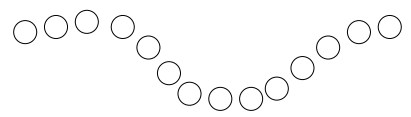

(e) Simetria: se existe simetria, a tendência é perceber o conjunto simétrico como um todo, e não suas partes separadamente. Nesta figura observa-se dois quadrados sobrepostos e não duas figuras simétricas que se tocam nas pontas.

Figura 7.6: Exemplos de cada um dos princípios de Gestalt.

Neste trabalho nos interessa particularmente a boa continuidade e, por isso, discutiremos esta propriedade com mais detalhes no que segue. A base para o entendimento desta lei é o Princípio de Helmholtz introduzido em [Desolneux et al., 2000a, 2001]. De forma geral, este princípio pode ser interpretado da seguinte forma: conseguimos detectar uma determinada configuração que não é genérica, isto é, que possui uma probabilidade muito pequena de ocorrer por acaso. Consequentemente, este princípio perceptual afirma que qualquer con- 
figuração detectada possui uma baixa probabilidade, mas toda configuração improvável é perceptualmente relevante.

Considere $n$ objetos locais observados, $O_{1}, O_{2}, \ldots, O_{n}$, os quais possuem uma característica $\mathcal{Q}$ em comum (cor, orientação, textura, etc). Como saber se esses objetos devem ser considerados de um mesmo grupo? Para tomar esta decisão, calcula-se o número esperado de grupos de $n$ objetos quando assume-se "mentalmente" que a característica $\mathcal{Q}$ é uniformemente e independentemente distribuída sobre os $n$ objetos. Essa suposição de independência não é realista, mas é uma suposição a-contrario. Se este número esperado (também chamado de número de alarmes falsos ou taxa de alarmes falsos) é muito baixo, então o grupo deve ser considerado como significativo, visto que o mesmo não poderia ocorrer por acaso.

Definição 8 (Evento $\epsilon$-significativo [Desolneux et al., 2000b]). Um evento é $\epsilon$-significativo se o número esperado de ocorrências deste evento é menor que $\epsilon$ sob a hipótese aleatória uniforme a-contrario. Quando $\epsilon \leq 1$, diz-se simplesmente que o evento é significativo.

Esta definição é bastante genérica e precisa ser complementada com modelos a-contrario apropriados. Se o princípio de Helmholtz é verdadeiro, eventos são percebidos se e somente se eles forem significativos de acordo com a definição anterior.

Não é objetivo deste trabalho desenvolver um novo modelo a-contrario. A breve discussão feita anteriormente é suficiente para o entendimento do princípio de boa continuidade utilizado no arcabouço desenvolvido. 


\section{Etapa de baixo nível}

"Uma vida sem desafios não vale a pena ser vivida."

Theodore Roosevelt

Uma fase inicial e importante do processo de segmentação de imagens com estruturas finas é a detecção de informações básicas a partir da imagem que serão usadas em fases posteriores do processo. O principal objetivo nesta fase é obter a localização das estruturas na imagem a partir da detecção de linhas. Duas considerações devem ser feitas com relação a esta operação:

- Os detectores usados devem ser aplicados diretamente à imagem evitando, assim, a perda de informações delicadas das estruturas mais finas. Isto significa que nenhum tipo de filtro deve ser aplicado à imagem antes da operação de detecção de cristas.

- A principal meta é detectar a maior quantidade de cristas que correspondam a raízes (ou veias e artérias, no caso de imagens de retina). O problema de falsas detecções não é atacado neste estágio.

Tendo em mente as considerações anteriores foi realizado um estudo e busca na literatura de detectores de linhas mais apropriados para o problema, ou seja, detectores mais sensíveis a estruturas finas. A partir destes estudos foram escolhidos o detector de bordas Canny, operadores morfológicos, o filtro de Frangi, o filtro steerable e a detecção por razão e correlação cruzada, os quais são apresentados nas próximas seções. O objetivo do estudo e análise detalhados desses detectores é avaliar e encontrar os melhores detectores para os conjuntos de imagens usados no trabalho, já que esta etapa é muito importante, e influencia diretamente, no processamento das etapas posteriores.

\subsection{Detector de bordas Canny}

Existem diversos detectores de bordas na literatura, dentre eles o detector de Canny [Canny, 1986], estando entre os mais conhecidos e utilizados na área. A performance do detector de 
bordas Canny é superior a outros detectores de bordas existentes, apesar da sua complexidade ser mais elevada. O algoritmo foi desenvolvido de forma a alcançar três objetivos básicos:

1. Baixa taxa de erro. Todas as bordas da imagem devem ser encontradas ou o mais próximo disso;

2. Pontos de borda devem ser bem localizados. A localização das bordas fornecida pelo detector deve ser a mais real possível. Assim, a distância entre o ponto detectado e o centro da borda verdadeira deve ser mínima;

3. Detectar um único ponto de borda. A correspondência entre o ponto de borda detectado e o ponto de borda verdadeira deve ser de um para um, ou seja, não pode haver múltiplos pixels de borda detectados para um único ponto de borda existente.

Este detector de bordas consiste na realização de quatro passos principais:

1. Suavizar a imagem de entrada para remover ruído;

2. Computar as imagens de magnitude do gradiente, $M(x, y)$, e o ângulo do gradiente, $\alpha(x, y)$. As bordas devem ser marcadas onde os gradientes da imagem possuem grandes magnitudes;

3. Aplicar supressão não-máxima na imagem da magnitude do gradiente. Apenas máximos locais devem ser marcados como borda;

4. Usar limiarização dupla e análise de conectividade para detectar e ligar bordas.

A seguir, estes passos são descritos de forma sucinta. Para maiores detalhes sugere-se consultar as referências [Canny, 1986; Gonzalez \& Woods, 2008].

A suavização da imagem é realizada aplicando um filtro gaussiano. Esta etapa é necessária para reduzir o ruído evitando que o mesmo seja confundido como borda. O algoritmo de Canny encontra as bordas onde ocorre uma mudança maior na intensidade de níveis de cinza da imagem. Estas áreas são encontradas calculando-se os gradientes da imagem. Os gradientes em cada pixel da imagem suavizada podem ser determinados usando as máscaras Sobel, Prewitt e Roberts.

Os três critérios acima podem ser formulados matematicamente e, desta forma, soluções ótimas para as formulações podem ser buscadas. De fato, foi o que Canny fez para tentar resolver o problema de deteç̧ão de bordas. Como é difícil encontrar uma solução fechada que satisfaça todos as formulações anteriores, foi usada otimização numérica com bordas de profundidade 1-D acrescidas de ruído Gaussiano. Uma boa aproximação para o detector ótimo de bordas de profundidade é a primeira derivada da Gaussiana:

$$
\frac{d}{d x} e^{-\frac{x^{2}}{2 \sigma^{2}}}=\frac{-x}{\sigma^{2}} e^{-\frac{x^{2}}{2 \sigma^{2}}}
$$


A abordagem em uma dimensão aplica-se na direção da normal da borda. Como a direção da normal é, a princípio, desconhecida, seria necessário aplicar o detector de bordas 1-D em todas as direções possíveis. Pode-se aproximar este processo suavizando primeiro a imagem com uma função Gaussiana 2-D circular, computando o gradiente do resultado e, por fim, usando a magnitude do gradiente e a direção para estimar a "força" da borda e a direção em cada ponto. Desta forma chega-se a uma generalização do resultado em 1-D para duas dimensões.

Seja $f(x, y)$ a imagem de entrada e $G(x, y)$ a função gaussiana:

$$
G(x, y)=e^{-\frac{x^{2}+y^{2}}{2 \sigma^{2}}}
$$

Obtém-se uma imagem suavizada, $f_{s}(x, y)$, convoluindo $G$ e $f$ :

$$
f_{s}(x, y)=G(x, y) \star f(x, y)
$$

Depois é obtida a magnitude e direção do gradiente:

$$
M(x, y)=\sqrt{g_{x}^{2}+g_{y}^{2}}
$$

$\mathrm{e}$

$$
\alpha(x, y)=\tan ^{-1}\left[\frac{g_{y}}{g_{x}}\right]
$$

com $g_{x}=\partial f_{s} / \partial x$ e $g_{y}=\partial f_{s} / \partial y$. As máscaras Sobel, Prewitt e Roberts podem ser usadas como aproximações de $g_{x}$ e $g_{y}$. A Equação (8.3) é implementada usando uma máscara Gaussiana $n \times n$. As matrizes $M(x, y)$ e $\alpha(x, y)$ possuem o mesmo tamanho da imagem a partir da qual foram computadas.

A imagem da magnitude do gradiente encontrada no passo anterior contém "cristas" (ridges) largas ao redor de máximos locais. O próximo passo é "afinar" estas cristas. Uma abordagem é usar supressão não-máxima (non-maximum suppression [Nixon \& Aguado, 2008]). Existem várias formas de realizar este processo, mas geralmente é especificado um número de orientações da normal da borda (vetor gradiente). Por exemplo, em uma região $3 \times 3$, pode-se definir quatro orientações para uma borda passando pelo ponto central da região: $90^{\circ}, 0^{\circ},+45^{\circ} \mathrm{e}-45^{\circ}$.

Sejam $d_{1}, d_{2}, d_{3}$ e $d_{4}$ as quatro direções básicas citadas anteriormente, na mesma ordem. Para uma região $3 \times 3$ centrada em todo ponto $(x, y)$ em $\alpha(x, y)$, é possível formular o seguinte algoritmo de supressão:

1. Encontra-se a direção $d_{k}$ que é a mais próxima a $\alpha(x, y)$.

2. Se $M(x, y)$ é menor do que ao menos um de seus vizinhos ao longo de $d_{k}$, então define-se $g_{N}(x, y)=0$ (supressão); caso contrário, define-se $g_{N}(x, y)=M(x, y)$ 
onde $g_{N}(x, y)$ é a imagem obtida após a supressão não-máxima. A imagem $g_{N}(x, y)$ contém apenas as bordas afinadas; é igual $M(x, y)$ com os pontos de borda não-máximos suprimidos.

Finalmente é necessário limiarizar $g_{N}(x, y)$ para diminuir pontos falsos de borda. O algoritmo proposto por Canny utiliza uma limiarização adaptativa com dois limiares: um limiar baixo, $T_{L}$, e um limiar alto, $T_{H}$. Os pixels de borda mais "fortes" do que $T_{H}$ são marcados como "fortes"; os pixels mais "fracos" do que $T_{L}$ são suprimidos e os pixels com valor entre os dois limiares são marcados como "fracos".

Após o processo de limiarização, dependendo do valor de $T_{H}$, as bordas tipicamente possuem descontinuidades (gaps). Desta forma, o último passo do algoritmo é realizar um procedimento para rastrear as bordas e formar bordas mais longas, gerando um mapa mais "limpo".

Pela definição vista anteriormente, é claro que, na verdade, Canny definiu um detector de bordas e não um detector de cristas. Para seguir as duas consideração feitas no início desta seção, foi necessário realizar pequenas mudanças no algoritmo de Canny. A primeira delas é retirar o primeiro passo do algoritmo, ou seja, não suavizar a imagem de entrada. Desta forma, as informações delicadas das estruturas mais finas serão mantidas. Outra mudança é usar como imagem de magnitude a própria imagem de entrada. Vendo a imagem como uma superfície, os pontos de mudança brusca de níveis de cinza estarão localizados no centro das estruturas buscadas (como sendo um esqueleto), ao contrário da imagem de magnitude, que destaca as mudanças nas bordas da imagem. Realizando estas duas mudanças e aplicando o novo algoritmo, obtém-se, ao invés de bordas, cristas, e evita-se a perda de informações (detalhes) da imagem excluindo o passo de suavização.

\subsection{Deteç̧ão usando morfologia matemática}

Outra forma usada para detectar segmentos a partir da imagem original foi a utilização de operadores morfológicos. A linguagem da morfologia matemática é a teoria de conjuntos. Sendo assim, diversos problemas de processamento de imagens podem fazer uso de um ferramental unificado e poderoso oferecido pela morfologia matemática. Em morfologia matemática, conjuntos representam objetos em uma imagem. Por exemplo, o conjunto de todos os pixels brancos em uma imagem binária é uma descrição morfológica completa da imagem. No que segue, são usadas funções digitais da forma $f(x, y)$ e $b(x, y)$, onde $f(x, y)$ é uma imagem em níveis de cinza e $b(x, y)$ é um elemento estruturante. Elementos estruturantes são pequenos conjuntos ou sub-imagens usados para explorar propriedades da imagem de interesse. Elementos estruturantes em morfologia em níveis de cinza podem ser de duas categorias: plano e não-plano. Os elementos estruturantes planos possuem apenas duas dimensões e são usados para imagens também com duas dimensões. De forma similar, os não-planos são os elementos estruturantes que possuem mais de duas dimensões e são usados para imagens também com mais de duas dimensões. Assume-se que estas funções são discretas, ou seja, se $\mathbb{Z}$ denota o conjunto dos inteiros reais, então as coordenadas $(x, y)$ são inteiros do produto cartesiano $\mathbb{Z}^{2}$ e $f$ e $b$ são funções que atribuem um valor de intensidade 
(um número real do conjunto dos números reais, $\mathbb{R}$ ) para cada par distinto de coordenadas $(x, y)$. Se os níveis de intensidade são também inteiros, então $\mathbb{Z}$ substitui $\mathbb{R}$. Definimos a seguir os operadores morfológicos utilizados [Gonzalez \& Woods, 2008].

A erosão de $f$ por um elemento estruturante plano $b$ em qualquer posição $(x, y)$ é definida como o valor mínimo da imagem na região coincidente com $b$ quando a origem de $b$ está em $(x, y)$. Formalmente, a erosão em $(x, y)$ de uma imagem $f$ por um elemento estruturante $b$ é dada por

$$
[f \ominus b](x, y)=\min _{(s, t) \in b} f(x+s, y+t)
$$

onde $x$ e $y$ são incrementados através de todos os valores requeridos de forma que a origem de $b$ visite todo pixel em $f$.

De forma similar, a dilatação de $f$ por um elemento estruturante plano $b$ na posição $(x, y)$ é definida como o valor máximo da imagem na janela delineada por $\breve{b}$ quando a origem de $\breve{b}$ está em $(x, y)$. Isto é,

$$
[f \oplus b](x, y)=\max _{(s, t) \in b} f(x+s, y+t)
$$

onde $\check{b}=b(-x,-y)$.

A dilatação condicional de $f$, i.e., a dilatação de $f$ condicionada a $g$, a qual envolve a dilatação de uma imagem seguida de uma interseção com alguma condição, é definida por

$$
[f \oplus b]_{g}(x, y)=[f \oplus b](x, y) \wedge g(x, y)
$$

A abertura é um operador que, de forma genérica, é usado para suavizar contornos de uma imagem e para remover ruídos. A abertura de $f$ por um elemento estruturante plano $b$ é dada por:

$$
[f \circ b](x, y)=[f \oplus[f \ominus b]](x, y)
$$

O fechamento é um operador que tende a recuperar a forma inicial das estruturas de uma imagem que foram dilatadas. Para isso, a imagem dilatada é erodida:

$$
[f \bullet b](x, y)=[f \ominus[f \oplus b]](x, y)
$$

Seja o operador morfológico de abertura por reconstrução [Dougherty \& Lotufo, 2003] aplicado a uma imagem $f$. Tal operador é composto por:

- erosão de $f$, resultando em uma imagem $g$

- inf-reconstrução da imagem $f$ a partir de $g$, isto é, a dilatação infinita de $g$ condicionada à imagem $f$ (a cada iteração, faz-se uma dilatação na imagem seguida de uma interseção com $f$, até que a dilatação não modifique mais a imagem).

O operador top-hat da abertura por reconstrução aplicado a uma imagem $f$ é definido como sendo a subtração $f-\gamma_{r e c}(f)$, onde $\gamma_{r e c}(f)$ denota a abertura por reconstrução de $f$. 
Dada as definições anteriores, os três passos seguintes são usados para detectar segmentos na imagem de entrada:

1. Aplicação do operador top-hat da abertura por reconstrução

2. Limiarização da imagem resultante do passo anterior

3. Afinamento da imagem limiarizada para obter o resultado final

A aplicação do top-hat da abertura por reconstrução à imagem em níveis de cinza tem um efeito que pode ser explicado pela seguinte analogia: suponha que a imagem em níveis de cinza seja equivalente a uma superfície onde, quanto maior for o nível de cinza, maior é a altitude. A aplicação do operador sobre tal superfície resulta numa superfície rebaixada, onde todas as altitudes ficam próximas de zero mas os pontos de maior altitude continuam mais altos que os demais.

Assim, a subsequente aplicação de um operador de limiarização de parâmetro baixo (1, por exemplo) resulta numa imagem binária que representa os segmentos detectados.

Usando os conceitos apresentados anteriormente, o Algoritmo 8.1 em Python (usando Pymorph [Lotufo \& Machado, 2003]) realiza a detecção de linhas na imagem original.

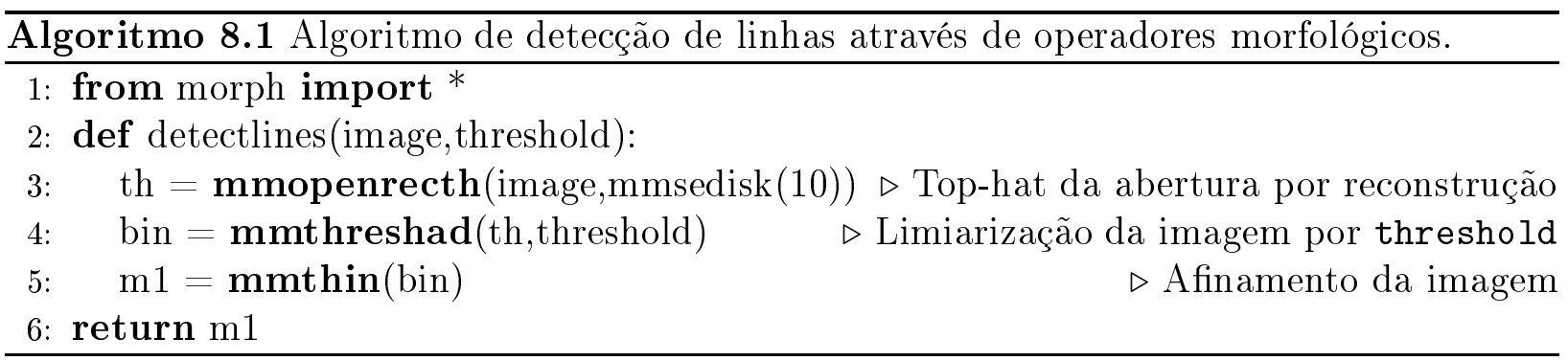

\subsection{Filtro de Frangi}

O filtro de Frangi [Frangi et al., 1998] foi proposto para a detecção de vasos sanguíneos. Na literatura assume-se que o perfil de intensidade de um vaso na seção transversal pode ser modelada por uma função gaussiana e que a intensidade não muda muito ao longo dos vasos. Características de derivadas de segunda ordem, como curvaturas em filtros de melhoria baseados em matriz hessiana, são usadas para diferenciar vasos de outras estruturas. O uso da informação de segunda ordem (matriz hessiana) justifica-se da seguinte forma. Através da derivada segunda de uma gaussiana na escala e é possível medir o contraste entre as regiões que estão dentro e fora do intervalo $(-e, e)$ na direção da derivada. Vasos possuem baixa curvatura ao longo das suas linhas centrais e alta curvatura na direção transversal. A análise dos autovalores da matriz hessiana permite a aquisição das duas direções principais nas quais a estrutura de segunda ordem local da imagem pode ser decomposta. Desta forma é possível saber diretamente a direção da menor curvatura.

Considere os três autovalores da matriz hessiana $\lambda_{1}, \lambda_{2}$ e $\lambda_{3}$ em ordem crescente de magnitude, ou seja, $\left|\lambda_{1}\right| \leq\left|\lambda_{2}\right| \leq \lambda_{3}$. Frangi propõe a seguinte medida vesselness para o 
caso 2D para uma escala $e$ :

$$
\mathcal{V}_{o}(e)= \begin{cases}0 & \text { se } \lambda_{2}>0 \\ \exp \left(-\frac{\mathcal{R}_{\mathcal{B}}^{2}}{2 \beta^{2}}\right)\left(1-\exp \left(-\frac{\mathcal{S}^{2}}{2 c^{2}}\right)\right) & , \text { caso contrário }\end{cases}
$$

$\mathcal{R}_{\mathcal{B}}=\left|\lambda_{1}\right| /\left|\lambda_{2}\right|$ é uma medida de blobness em 2D que representa a excentricidade da elipse de segunda ordem. $\mathcal{S}=\sqrt{\lambda_{1}^{2}+\lambda_{2}^{2}}$ é uma medida de estruturação de segunda ordem (second order structureness). Os parâmetros $\beta$ e $c$ são constantes, limiares que controlam a sensibilidade do filtro tipo linha line-like às medidas $\mathcal{R}_{\mathcal{B}}$ e $\mathcal{S}$. A matriz hessiana é calculada diretamente da imagem através da filtragem da mesma usando as segundas derivadas de uma gaussiana.

A medida vesselness é calculada para diferentes escalas e a resposta máxima para cada pixel da imagem é considerada. O resultado do filtro é um mapa de probabilidades dos pixels serem vasos ou não. Para encontrar o eixo central dos vasos, aplicamos uma limiarização, seguida de um operador de afinamento, a este mapa de probabilidades.

\subsection{Filtro steerable}

Os filtros steerable [Jacob \& Unser, 2004] são detectores de características 2D, ou ainda, uma classe de funções steerable baseadas na otimização de um modelo tipo Canny. Estes filtros possuem expressões fechadas e fornecem operadores que possuem uma seletividade de orientação melhor do que os detectores clássicos baseados na matriz Heissiana. Para obter um detector de cristas, derivadas de alta ordem da Gaussiana são usadas. Um limiar deve ser aplicado ao resultado final para a obtenção de uma imagem binária com o mapa de cristas. Este limiar, assim como nos outros detectores, também controla a precisão da deteç̧ão. Uma implementação destes filtros está disponível como plugin para o programa ImageJ [Abramoff et al., 2004].

\subsection{Detecção por razão (ratio-based detector) e correlação cruzada (cross-correlation-based detector)}

Um outro detector existente na literatura, proposto em [Tupin et al., 1998], faz a junção de dois detectores: o de razão, que será referenciado neste texto por D1, e o de correlação cruzada, referenciado por D2. Tupin et al. estudam estes detectores estatisticamente através de probabilidades de detecção e falsos alarmes considerando as propriedades do ruído speckle totalmente desenvolvido. Os dois detectores são calculados considerando que um dado pixel, $p$, pertence a uma região de linha, $r_{1}$, e as respostas dos detectores são calculadas usando a razão e a correlação cruzada entre $r_{1}$ e cada região ao seu redor, $r_{2}$ a $r_{3}$, como apresentado na Figura 8.1. A região $r_{1}$ é obtida através da definição de um valor de comprimento $w$ e de um valor de largura $h$ ao redor de $p$, e as regiões $r_{2}$ e $r_{3}$ possuem o mesmo tamanho que $r_{1}$. A razão e a correlação cruzada entre duas regiões $i$ e $j$ são definidas como 


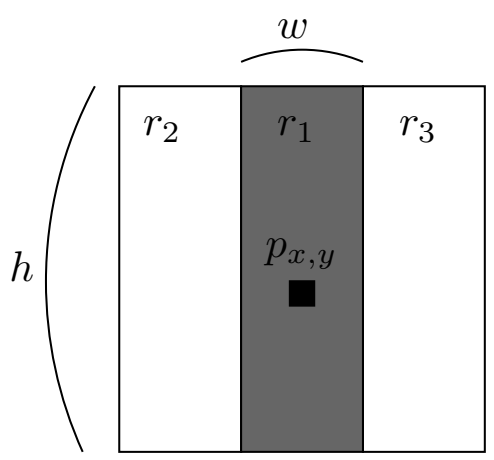

Figura 8.1: Máscara para detecção de linhas usada considerando um pixel específico $p(x, y)$ dada uma direção, comprimento e largura.

$$
r_{i, j}=\min \left(\frac{\mu_{i}}{\mu_{j}}, \frac{\mu_{j}}{\mu_{i}}\right)
$$

$\mathrm{e}$

$$
\rho_{i j}^{2}=\frac{1}{1+\left(n_{i}+n_{j}\right) \beta}
$$

respectivamente, onde

$$
\beta=\frac{n_{i} \gamma_{i}^{2} c_{i j}^{2}+n_{j} \gamma_{j}^{2}}{n_{i} n_{j}\left(c_{i j}-1\right)^{2}}
$$

$n_{i}$ indica o número de pixels da região $i, \mu_{i}$ é a média empírica da região $i, c_{i j}=\mu_{i} / \mu_{j}$ é o contraste empírico entre as regiões $i$ e $j$, e $\gamma_{i}$ é o coeficiente de variação (razão entre o desvio padrão e a média). Para cada pixel da imagem, as respostas dos detectores D1 e D2, $d_{1}$ e $d_{2}$, são calculadas para diferentes direções e comprimentos, e uma soma simétrica é usada para combinar as duas medidas [Bloch, 1996]:

$$
\sigma\left(d_{1}, d_{2}\right)=\frac{d_{1} \cdot d_{2}}{1-d_{1}-d_{2}+2 \cdot d_{1} \cdot d_{2}}
$$

Uma soma simétrica representa um operador de agregação "híbrido" no sentido de que o mesmo pode possuir os comportamentos severo (conjuntivo), indulgente (disjuntivo) ou cauteloso (compromissado) dependendo valores de $d_{1}$ e $d_{2}$. Desta forma, um comportamento variável é alcançado quando ocorre a combinação das respostas dos detectores. Finalmente, apenas o valor máximo de fusão dentre todas as combinações possíveis de direção e comprimento é utilizado. A resposta final da detecção é uma imagem de magnitude que, posteriormente, passa por um processo de limpeza (cleaning) e afinamento (thinning) resultando em uma saída binária. O Algoritmo 8.2 resume brevemente o processo de detecção descrito acima.

\subsection{Análise de precisão (Publicado em [Perciano et al., 2010a])}

Como estão sendo usadas algumas formas de detecção de segmentos/estruturas lineares, foi realizada uma análise da precisão destes métodos. Esta análise permite ajustar os parâmetros envolvidos nos métodos, escolhendo valores ótimos para os mesmos. Para 


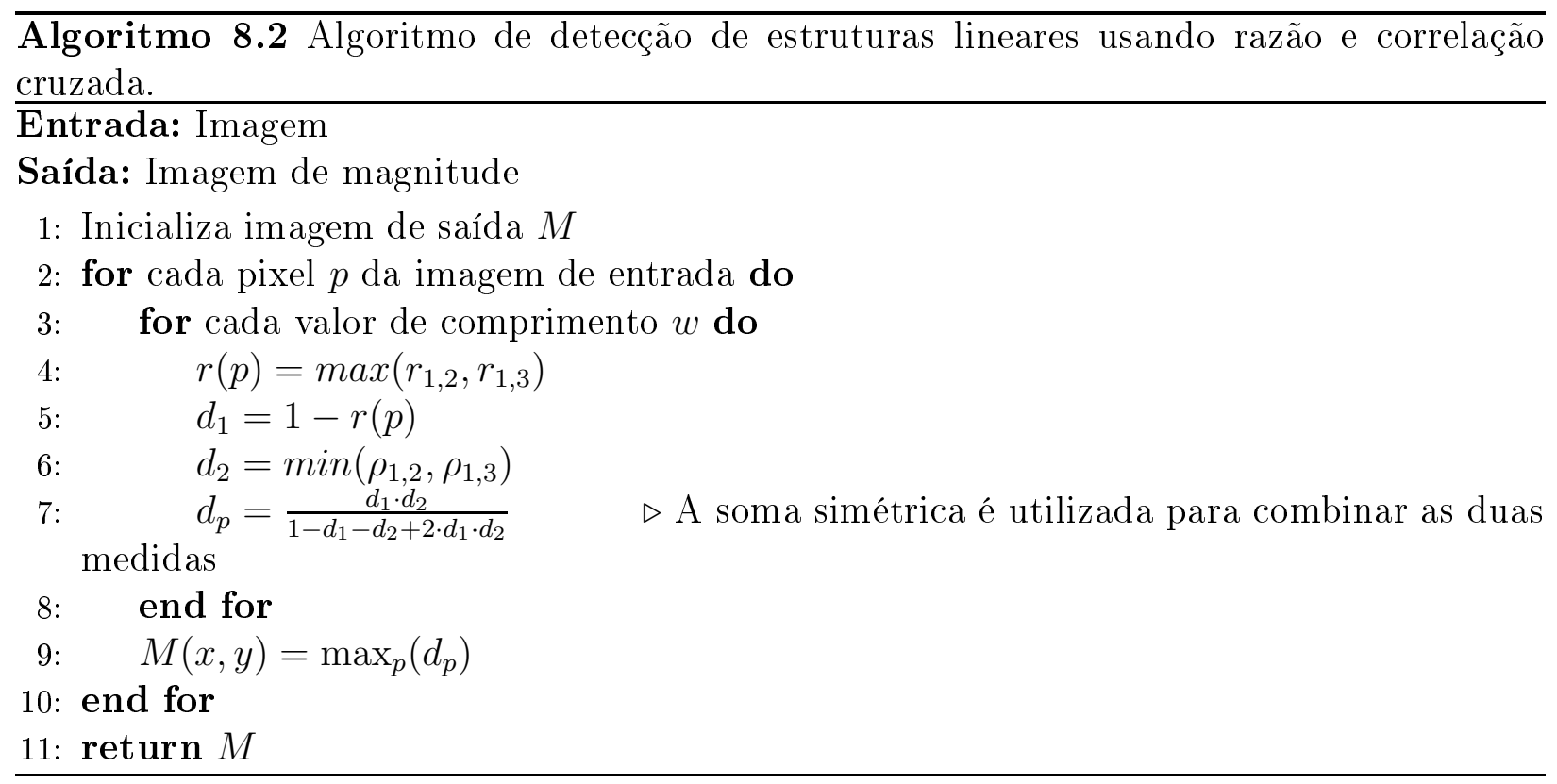

fazer a análise necessita-se das segmentações manuais ground-truths das imagens nas quais foram detectados os segmentos. Por isso, para esta análise, foram usados bancos de imagens de retina, as imagens simuladas e algumas das imagens reais de raízes das quais foram obtidos os ground-truths.

A análise foi realizada utilizando conceitos envolvidos na avaliação de classificadores. Para o processo de avaliação é preciso ter em mãos três imagens:

1. O ground-truth para a detecção de segmentos

2. Resultados das detecções de segmentos da imagem original usando

- o detector Canny

- morfologia matemática

- o filtro Frangi

- o filtro Steerable

- o detector de razão de correlação cruzada.

Colocando em termos comuns da área de classificação, estas imagens (binárias) são formadas por pixels classificados em duas classes: estrutura (1) e não-estrutura (0). Para facilitar, pixels pertencentes a classe estrutura serão ditos como classificados positivamente. De forma similar, pixels pertencentes a classe não-estrutura serão ditos como classificados negativamente. A primeira imagem dos três itens acima é a que contém os rótulos verdadeiros para cada classe. As avaliações das outras duas imagens (classificações obtidas pelos dois métodos de detecção) são feitas com base nestes rótulos. A seguir definimos os conceitos envolvidos para a análise de precisão. Mais informações sobre esses conceitos podem ser encontradas em [Baeza-Yates \& Ribeiro-Neto, 1999; Olson \& Delen, 2008]. 
Verdadeiro positivo - Pixel que pertence a classe estrutura e que foi classificado positivamente.

Falso negativo - Pixel que pertence a classe estrutura e que foi classificado negativamente.

Verdadeiro negativo - Pixel que pertence a classe não-estrutura e que foi classificado negativamente.

Falso positivo - Pixel que pertence a classe não-estrutura e que foi classificado positivamente.

Precisão (precision) - Medida que está relacionada com exatidão/fidelidade. É o número de verdadeiros positivos dividido pelo total de pixels rotulados como sendo positivos. Formalmente:

$$
P=\frac{v p}{v p+f p}
$$

Sensibilidade ou revocação ( recall) - Medida que está relacionada com completude/perfeição. É o número de verdadeiros positivos dividido pelo total de verdadeiros positivos e falsos negativos. Formalmente:

$$
S=\frac{v p}{v p+f n}
$$

Especificidade (specificity) - Probabilidade que um pixel seja classificado como negativo dado que o mesmo seja negativo. Formalmente:

$$
E=\frac{v n}{v n+f p}
$$

Medida $F$ - Média harmônica ponderada de precisão e sensibilidade ou coeficiente de correlação de Matthews. Formalmente:

$$
F=2 \frac{P \cdot S}{P+S}
$$

A partir das medidas de revocação e especificidade é possível desenhar uma curva ROC, que é o gráfico da revocação vs. (1 - especificidade) variando o parâmetro do classificador (detector de segmentos). Com o objetivo de buscar os melhores parâmetros para cada método de detecção de segmentos, para cada conjunto de imagens foi realizado o processo descrito em [Bowyer et al., 2001], porém mais simplificado, que consiste basicamente nos seguintes passos:

1. Primeiro deve-se escolher os valores mínimo e máximo para cada parâmetro dos de- 
Tabela 8.1: Valores mínimos e máximos para cada detector de linhas.

\begin{tabular}{l|c|c}
\hline Detectores & Parâmetros & Valores (min - max) \\
\hline \multirow{2}{*}{ Canny } & $T_{L}$ & $0-1$ \\
& $T_{H}$ & $0-1$ \\
\hline \multirow{2}{*}{ Morfologia Matemática } & $T$ & $0-100$ \\
& $D$ & $0-15$ \\
\hline \multirow{2}{*}{ Frangi } & $T$ & $0-1$ \\
& $\beta$ & $1-20$ \\
\hline \multirow{2}{*}{ Steerable } & $T$ & $0-1$ \\
\hline \multirow{2}{*}{ Tupin } & $r$ & $0-1$ \\
& $\rho$ & $0-1$ \\
\hline
\end{tabular}

tectores. A Tabela 8.1 apresenta os valores utilizados para cada detector .

2. Inicialmente os intervalos de cada parâmetro são subdivididos uniformemente para gerar quatro valores para cada parâmetro.

3. A partir dos intervalos com quatro valores podem ser feitos refinamentos da seguinte maneira:

- Para cada dois valores sucessivos do intervalo, cria-se um novo valor que é a metade do subintervalo compreendido entre estes dois valores. Desta forma, suponha que tem-se para um determinado detector inicialmente $4 \times 4 \times 4$, ou seja, quatro valores para cada parâmetro. Após o refinamento realizado no primeiro parâmetro, por exemplo, passaríamos a ter $7 \times 4 \times 4$.

A Tabela 8.2 apresenta o número de refinamentos realizados para os parâmetros de cada detector.

4. Para obter a curva ROC de uma imagem, são aplicados os detectores para cada conjunto possível de parâmetros obtidos a partir dos refinamentos feitos no passo anterior.

5. Por fim, é calculada a mediana das curvas ROC de todas as imagens. Foram usadas 10 imagens reais de raízes, 20 imagens de retina e 20 imagens simuladas de raízes.

No final do processo descrito anteriormente, é obtida uma curva ROC para cada detector. A partir destas curvas é possível encontrar os parâmetros ótimos para cada um deles. Como explicado anteriormente, o objetivo desta etapa é tentar detectar o maior número de pixels possível que constituem raízes (ou vasos sanguíneos) na imagem, obtendo um número aceitável de pixels que não constituem raízes e foram detectados como tal. Assim, os parâmetros escolhidos são aqueles pontos das curvas ROC que se aproximam mais da coordenada $(1,1)$. 
Tabela 8.2: Número de refinamentos para os parâmetros de cada detector utilizado.

\begin{tabular}{l|c|c}
\hline Detectores & Parâmetros & Número de refinamentos \\
\hline \multirow{2}{*}{ Canny } & $T_{L}$ & 2 \\
& $T_{H}$ & 2 \\
\hline \multirow{2}{*}{ Morfologia Matemática } & $T$ & 4 \\
& $D$ & 2 \\
\hline \multirow{2}{*}{ Frangi } & $T$ & 3 \\
& $\beta$ & 1 \\
\hline \multirow{2}{*}{ Steerable } & $T$ & 6 \\
\hline \multirow{2}{*}{ Tupin } & $r$ & 2 \\
& $\rho$ & 2 \\
\hline
\end{tabular}

As curvas ROC obtidas referentes a cada detector, para cada conjunto de imagens, são apresentadas na Figura 8.2.

Pode-se observar na Figura 8.2(a) que para as imagens simuladas de raízes obtem-se resultados bons para todos os detectores. Já no caso das imagens reais de raízes e de retina, os detectores Frangi e Tupin são os que obtêm os melhores resultados. Pode ser observado nos gráficos que algumas curvas não alcançam o ponto extremo $(1,1)$. Isto ocorre pelo fato de que nenhum valor para os parâmetros dos detectores referentes a esses casos resultam em uma imagem em que todos os pixels foram classificados positivamente.

Os melhores parâmetros obtidos através na análise realizada foram aplicados a uma imagem de exemplo de cada um dos conjuntos de imagens e os resultados são apresentados nas figuras seguintes:

- A Figura 8.3 apresenta os resultados para cada detector para uma imagem simulada de raiz;

- A Figura 8.4 apresenta os resultados para cada detector para uma imagem real de raiz;

- As Figuras 8.6 e 8.6 apresentam os resultados para cada detector para uma imagem de retina. 


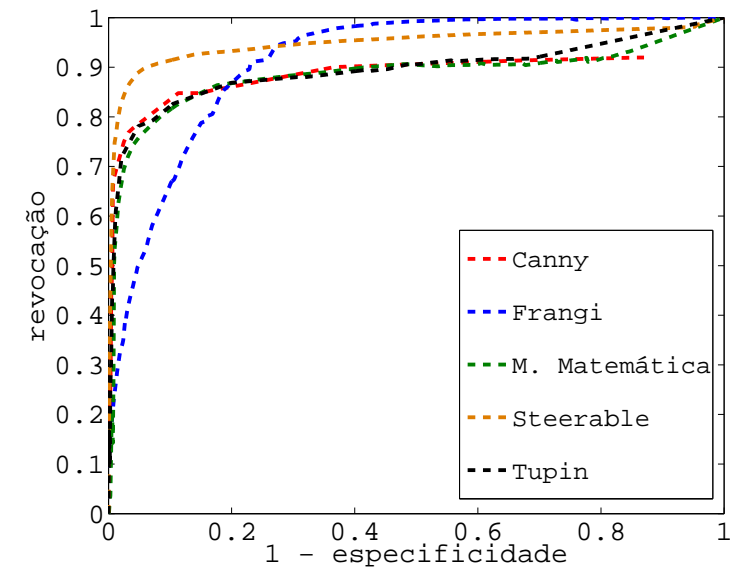

(a) Imagens simuladas de raízes.

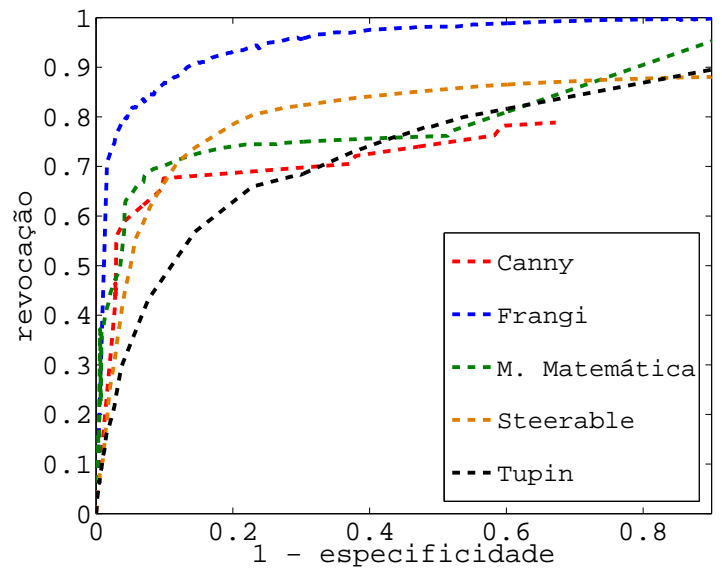

(b) Imagens reais de raízes.

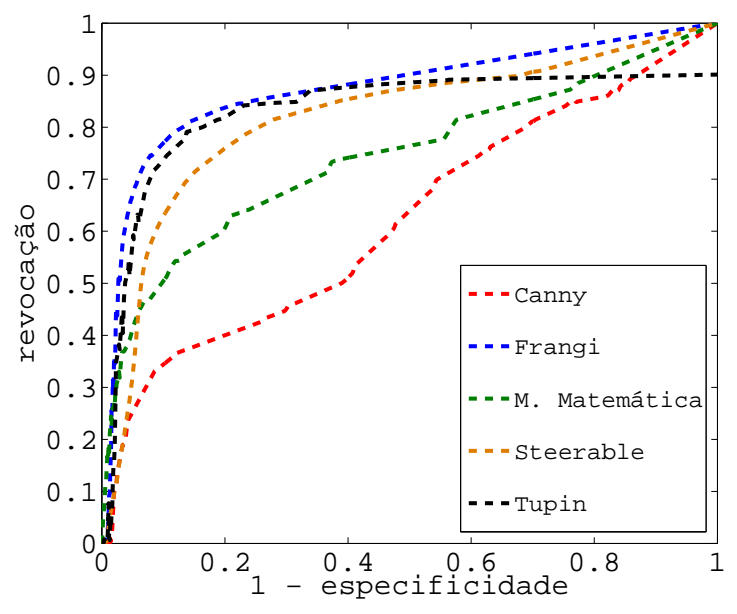

(c) Imagens de retina.

Figura 8.2: Curvas ROC para cada conjunto de imagens: (a) Curva ROC para o conjunto de imagens simuladas de raizes (b) Curva ROC para o conjunto de imagens reais de raizes (c) Curva $R O C$ para o conjunto de imagens de retina. 


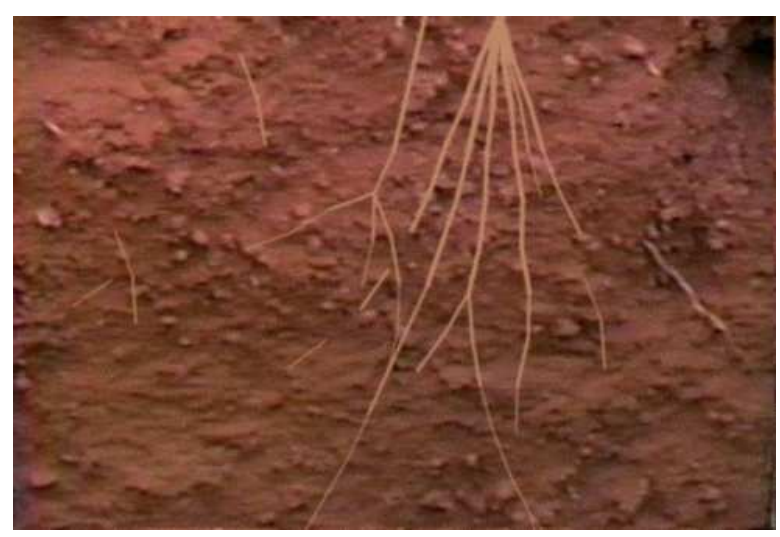

(a) Imagem original

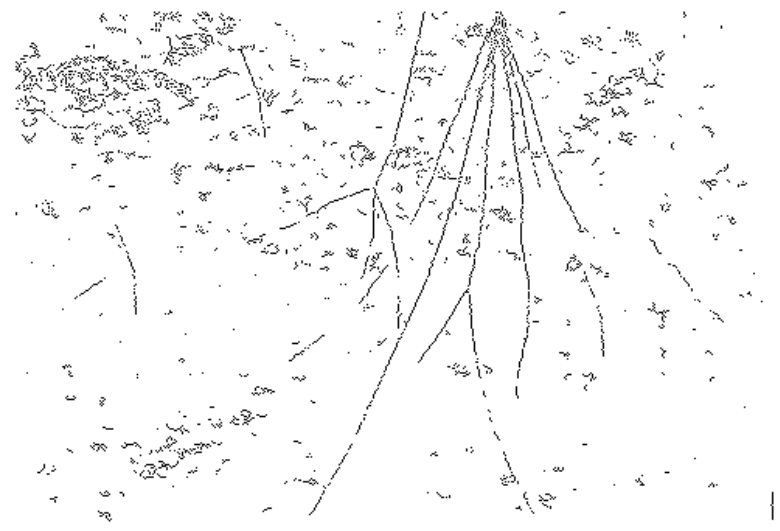

(c) Canny

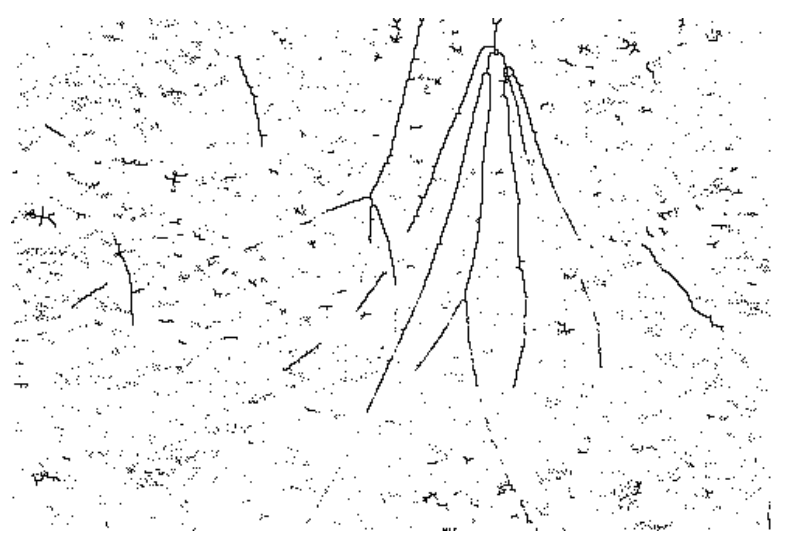

(e) Morfologia matemática
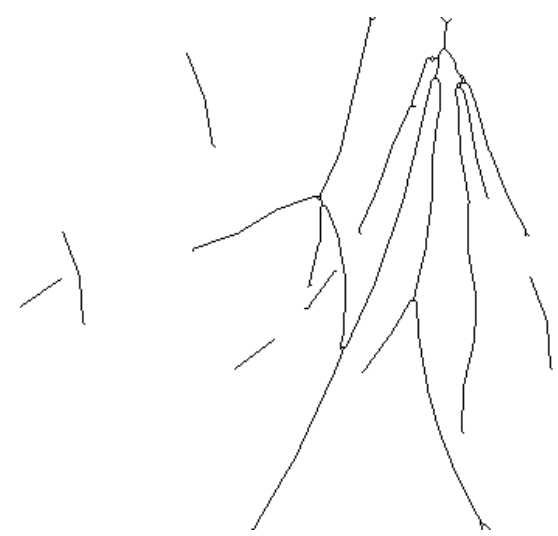

(b) Detecção de linha "ideal"

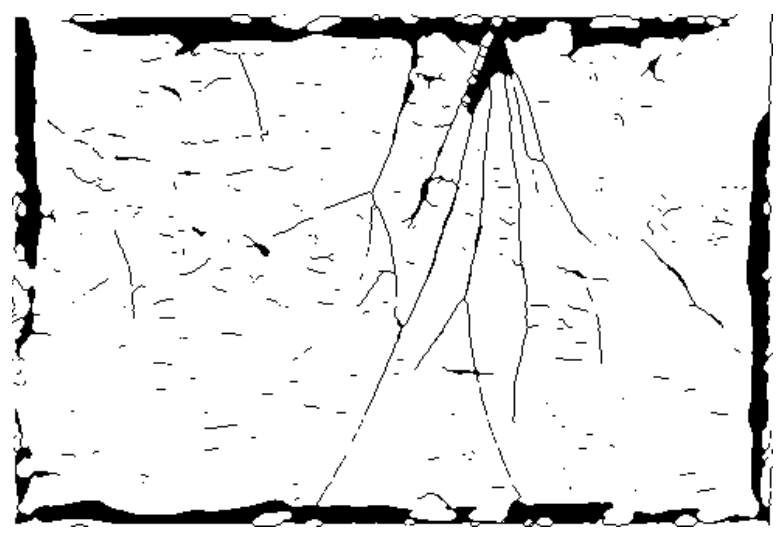

(d) Frangi

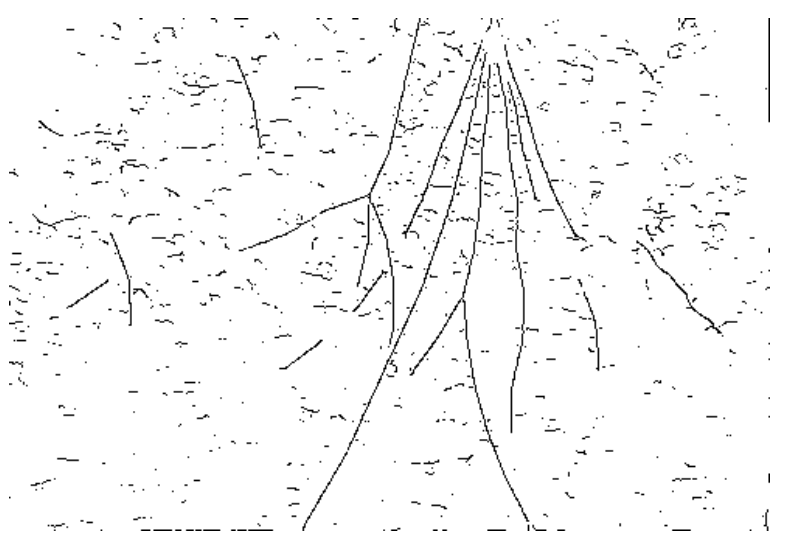

(f) Steerable

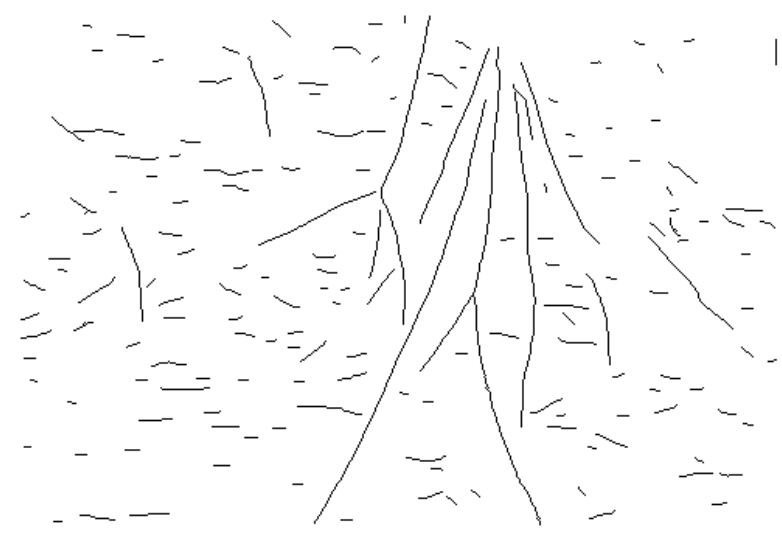

(g) Tupin

Figura 8.3: Resultados das detecções para uma imagem simulada de raiz usando os melhores parâmetros. 


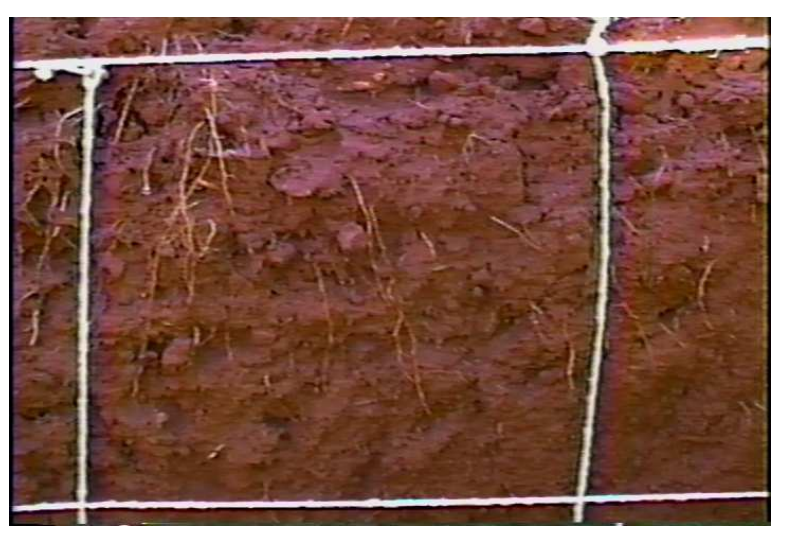

(a) Imagem original

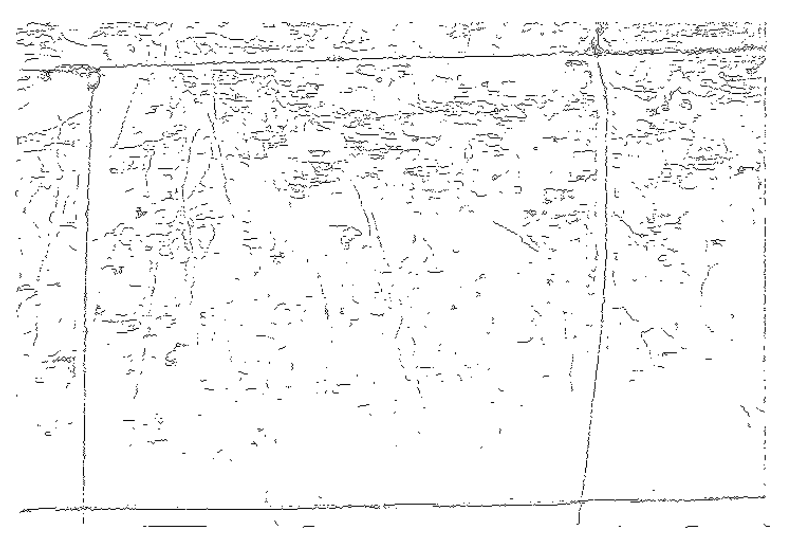

(c) Canny

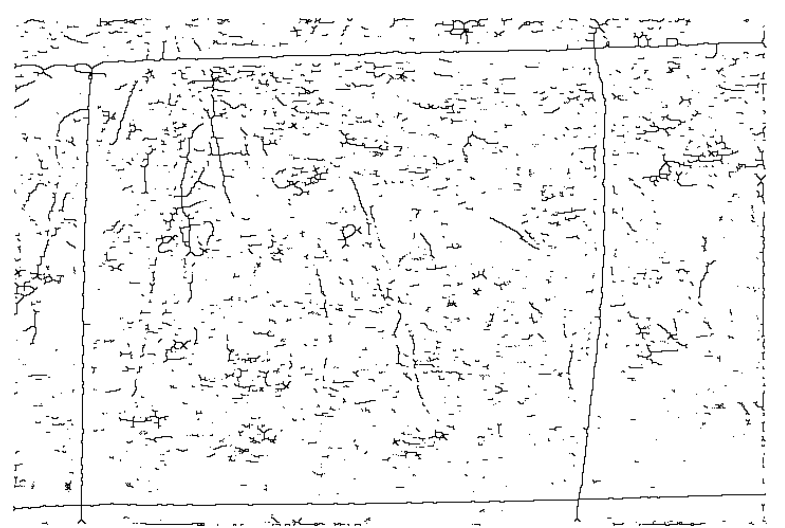

(e) Morfologia matemática

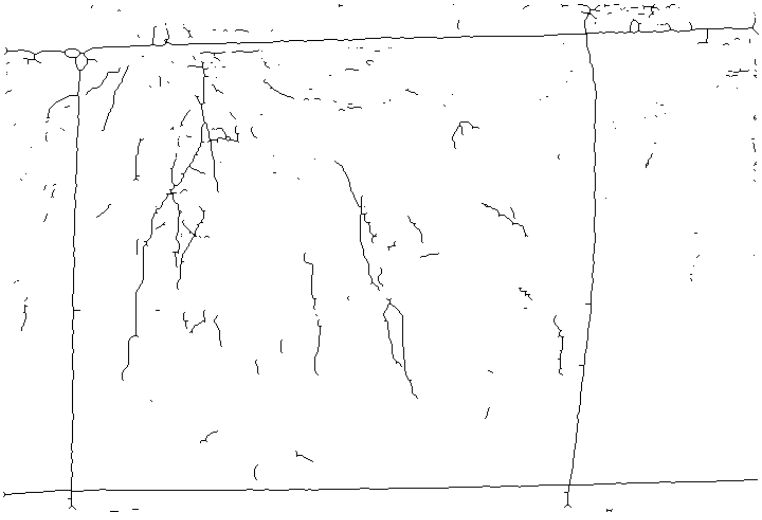

(b) Detecção de linha "ideal"

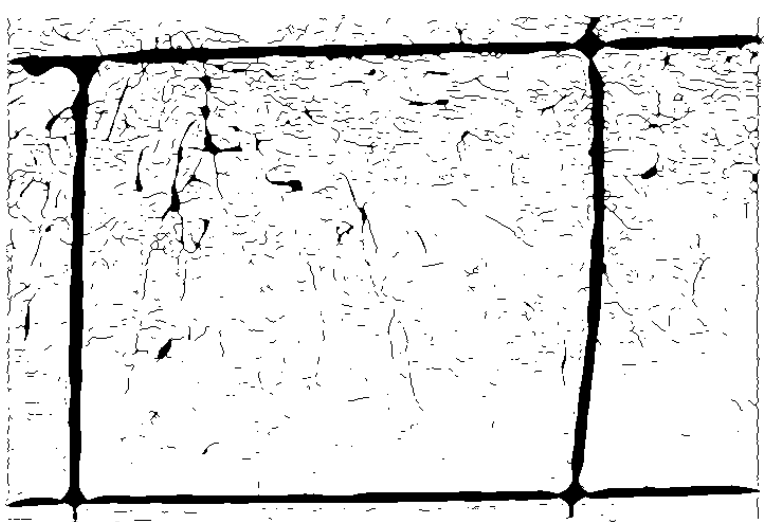

(d) Frangi

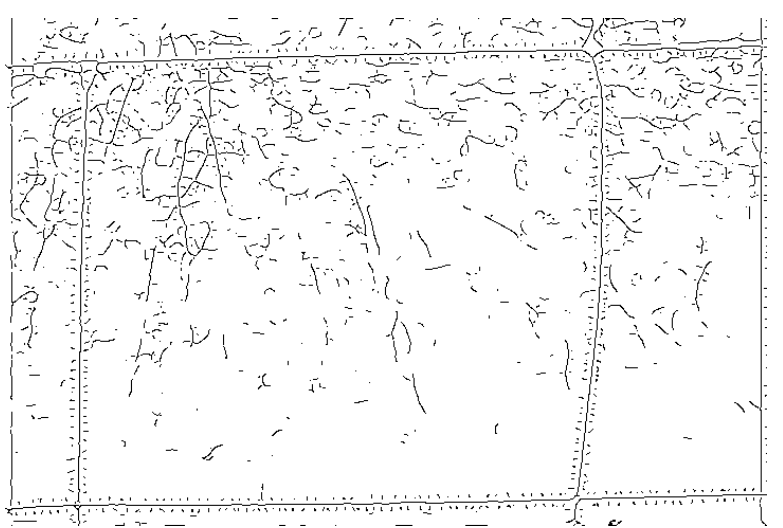

(f) Steerable

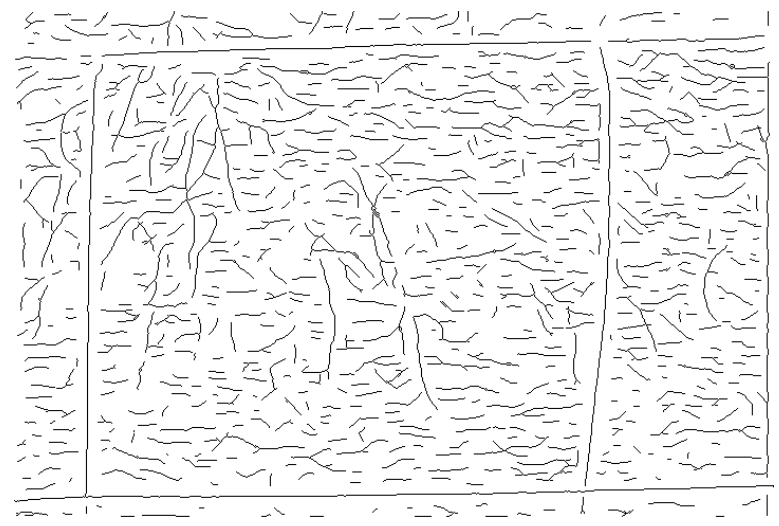

(g) Tupin

Figura 8.4: Resultados das detecções para uma imagem real de raiz usando os melhores parâmetros. 


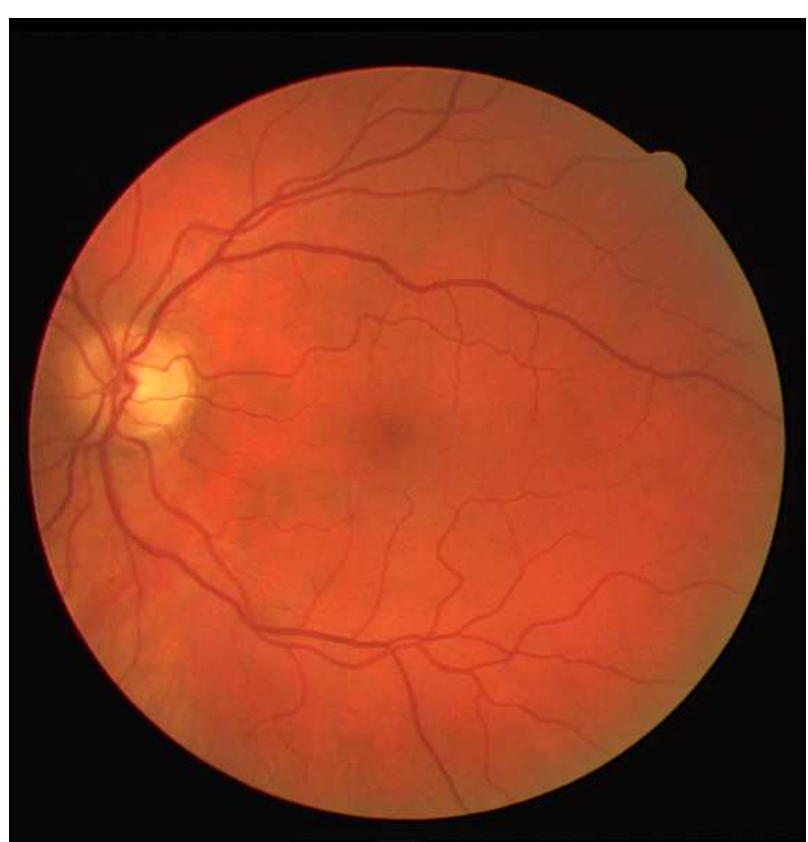

(a) Imagem original

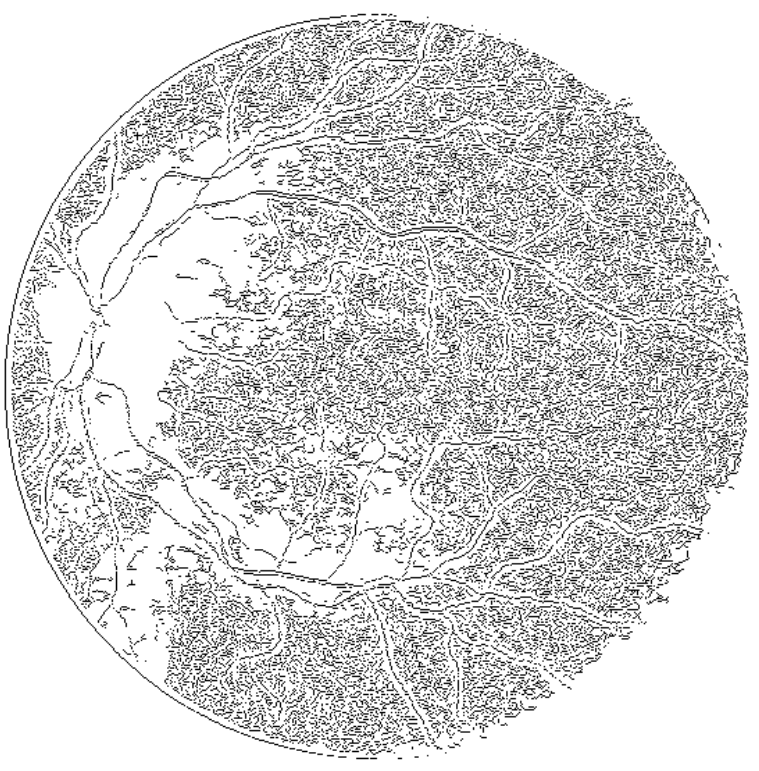

(c) Canny

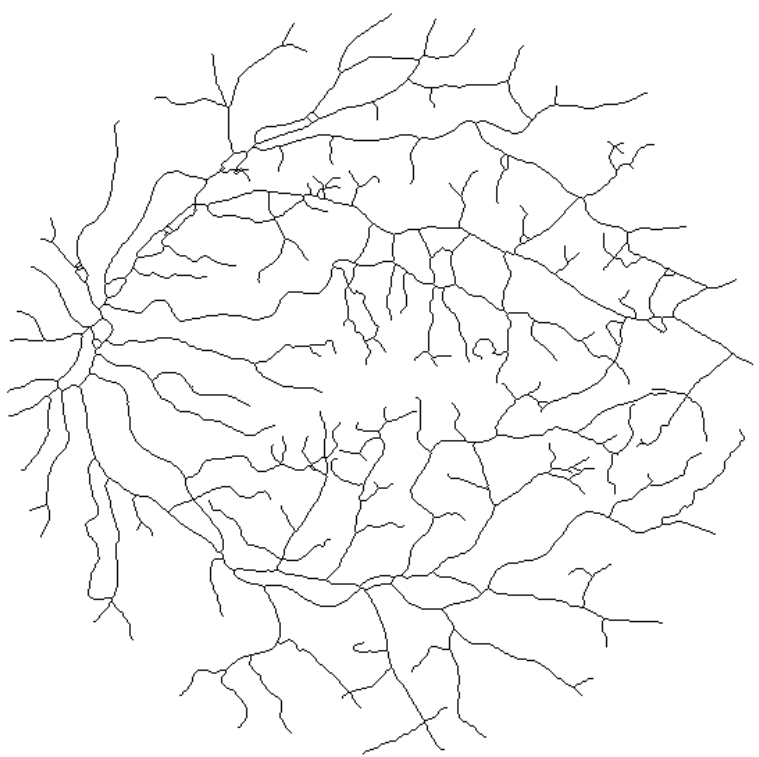

(b) Detecção de linha "ideal"

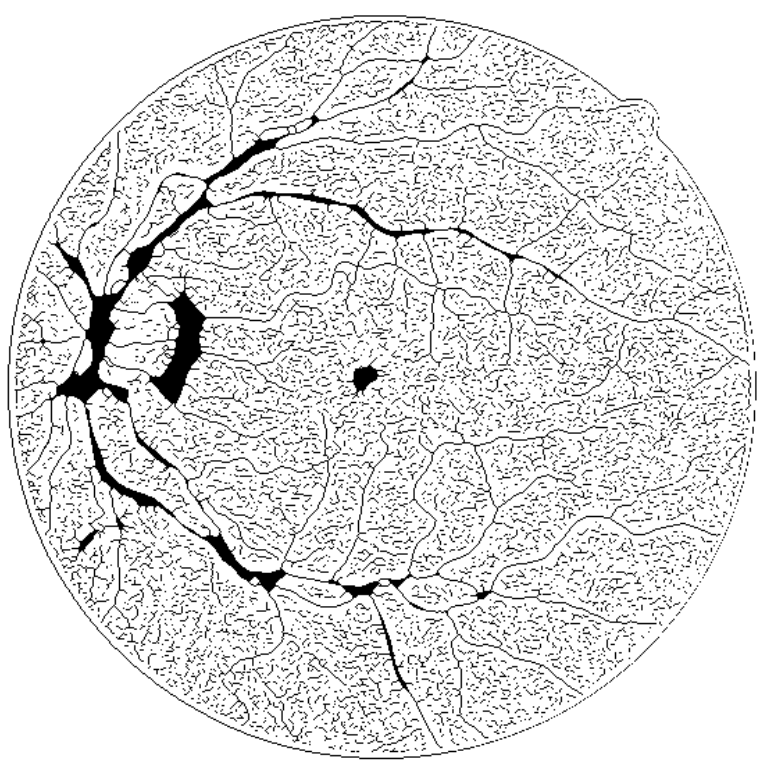

(d) Frangi

Figura 8.5: Resultados das deteç̧ões(Canny e Frangi) para uma imagem de retina usando os melhores parâmetros. 


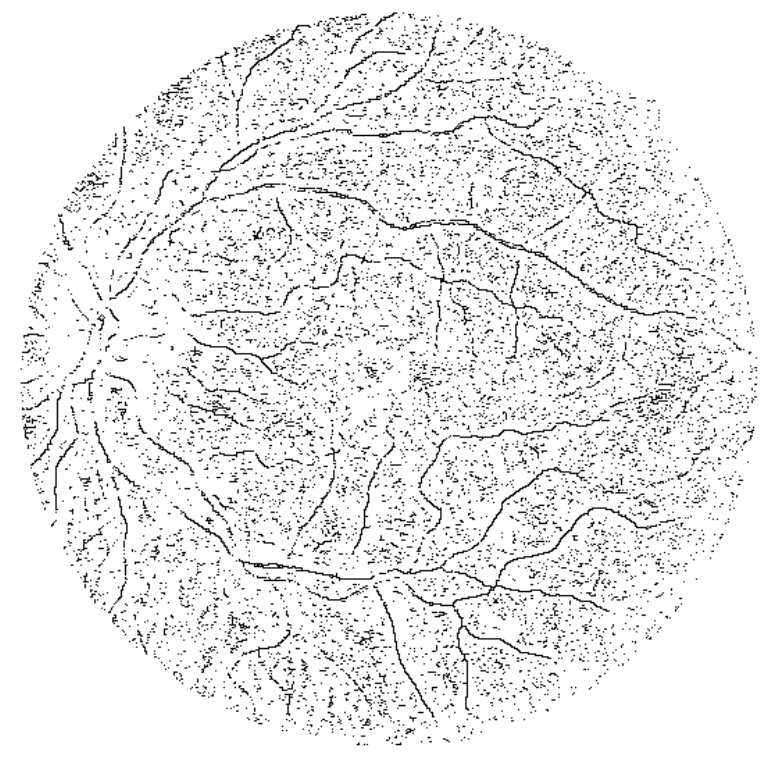

(a) Morfologia matemática

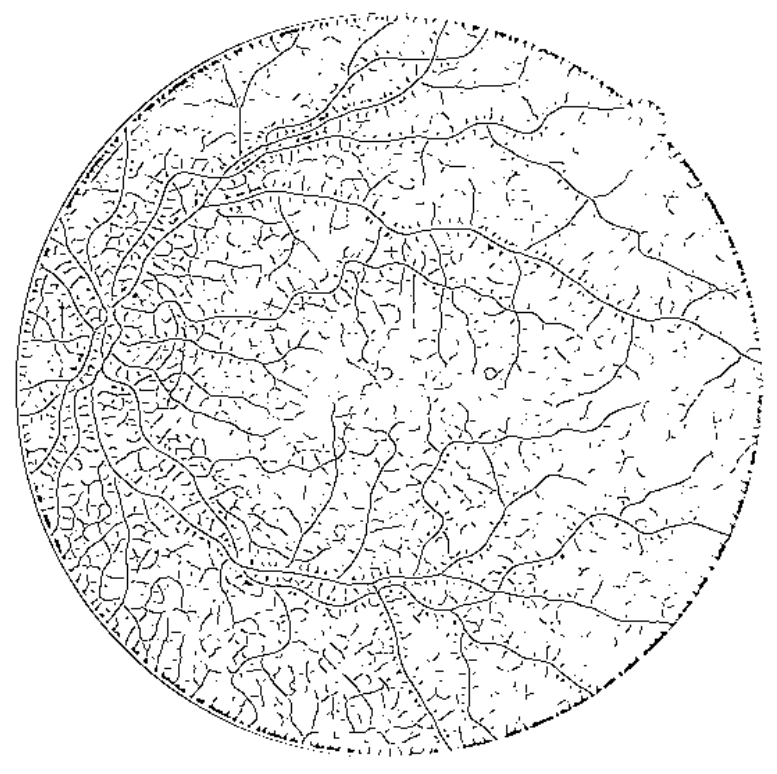

(b) Steerable

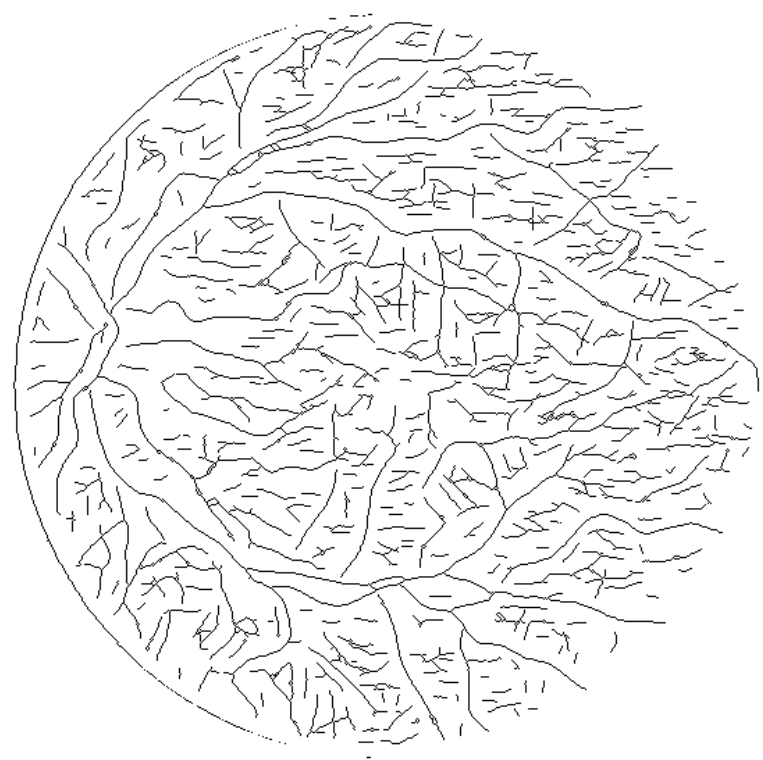

(c) Tupin

Figura 8.6: Resultados das detecções (Morfologia matemática, steerable e Tupin) para uma imagem de retina usando os melhores parâmetros. 


\subsection{Problema de ligação de cristas (Publicado em [Perciano et al., 2010b])}

A partir da revisão da bibliografia realizada sobre o problema de ligação de bordas e/ou cristas (ver Seção 2.3) e especificamente a partir do algoritmo descrito em [Wang \& Zhang, 2008], foram propostos melhoramentos para este algoritmo relacionados ao cálculo de direção de borda e à máscara usada durante o processo. Com estes aperfeiçoamentos, a qualidade das bordas ligadas pôde ser melhorada usando uma máscara adaptativa com relação à direção local principal ao redor de um ponto final de borda. Esta máscara adaptativa evita conexões desnecessárias entre pontos finais de bordas. Ademais, evita conexões que estão fora dos contextos direcionais locais e globais da imagem.

A partir de [Wang \& Zhang, 2008] foram propostos melhoramentos relacionados ao cálculo de direção de borda e à máscara usada durante o processo. Com estes aperfeiçoamentos, a qualidade das bordas ligadas pôde ser melhorada usando uma máscara adaptativa com relação à direção local principal ao redor de um ponto final de borda. Esta máscara adaptativa evita conexões desnecessárias entre pontos finais de bordas. Ademais, evita conexões que estão fora dos contextos direcionais locais e globais da imagem.

O processo de ligação do método proposto é baseado nos seguintes passos gerais:

1. Encontrar os pontos finais do mapa de bordas/cristas;

2. Selecionar pontos candidatos de ligação apropriados para cada ponto final de borda usando uma máscara direcional adaptativa, e

3. selecionar o ponto de ligação usando informação de direção da crista e distância geodésica.

A seguir são apresentados a abordagem usando uma máscara direcional utilizada pelo algoritmo proposto e uma revisão dos conceitos usados a partir dos algoritmos de ligação de bordas existentes.

\subsubsection{Máscara direcional adaptativa}

Dentre os métodos de ligação que usam informação de vizinhança, as máscaras usadas possuem forma e tamanho fixos dados pelo usuário. Em geral, a informação direcional local é usada apenas na decisão de qual ponto candidato de ligação deve ser conectado ao ponto final de borda. Propomos uma estratégia adicional para explorar esta informação de forma a suprimir alguns candidatos. Um histograma de orientação é usado para adaptar uma máscara retangular ou cônica com o contexto direcional local da imagem.

A Figura 8.7 ilustra este processo. Um ponto final de borda particular está sendo analisado (em vermelho) durante o processo. Na Figura 8.7(a) uma máscara retangular é representada em cinza e os pontos de ligação candidatos em preto. A Figura 8.7(b) apresenta o mapa de cristas para a janela analisada. Para encontrar a direção local principal, um histograma de orientação das cristas é calculado para esta janela. Como um pixel da imagem 
possui uma orientação relacionada, pode-se calcular o histograma de frequências de cada orientação. A orientação com a maior frequência é escolhida para ser a orientação da máscara. Neste caso particular, a orientação diagonal é escolhida. A Figura 8.7(c) apresenta a máscara rotacionada e a Figura 8.7(d) os pontos candidatos para ligação finais.

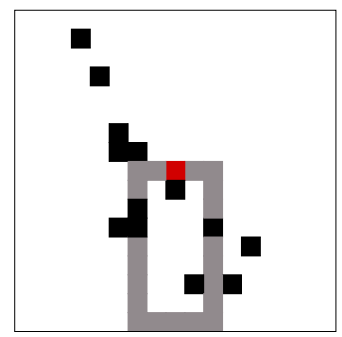

(a) Candidatos para ligação.

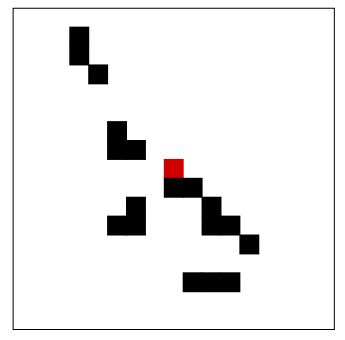

(b) Janela de cristas.

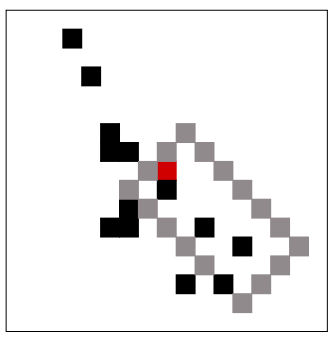

(c) Máscara rotacionada.

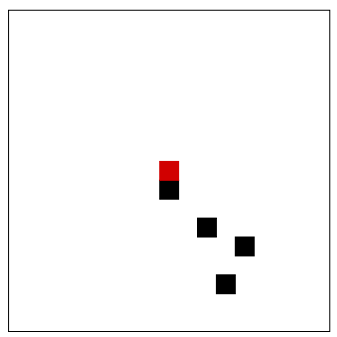

(d) Candidatos para ligação finais.

Figura 8.7: Exemplo da rotação da máscara dependendo do histograma direcional local.

Em um caso particular onde, por exemplo, duas orientações possuem (quase) a mesma frequência no histograma, a máscara é rotacionada nas duas direções e todos os pontos candidatos para ligação nos dois casos são escolhidos. As orientações levadas em consideração no histograma dependem do detector de bordas/cristas usado. As mesmas orientações dadas pelo detector serão usadas para o histograma.

A seguir, o processo de escolha do ponto dentre os candidatos para ser conectado com o ponto final é explicado.

\subsubsection{Direção da crista e distância geodésica}

Após o passo de supressão descrito anteriormente, os candidatos restantes são analisados usando a abordagem de direção de bordas/cristas e distância geodésica proposta em [Wang \& Zhang, 2008].

A Figura 8.8 ilustra o cálculo da direção de borda/crista. Existe uma parte de borda/crista (1's), o ponto final de borda/crista $P_{e}$ (quadrado cinza) e alguns candidatos para a continuação da borda/crista ( 2 pontos isolados na borda). Para o ponto final $P_{e}$ todos os pontos de borda/crista conectados a ele são usados para ajustar uma reta $\ell$. O vetor $\vec{d}_{c}$ representa a direção a partir do centroide destes pontos $P_{c}$ (círculo cinza) até $P_{e}$. Entre as duas possíveis direções de $\ell$, a mais próxima de $\vec{d}_{c}$ é escolhida como a direção de borda/crista de $P_{e}$, isto é, $\vec{d}_{1}$. Esta abordagem possui a vantagem de que todas as direções de $0^{\circ}$ até $360^{\circ}$ são possíveis, ao contrário de um número discreto de orientações.

A distância geodésica também proposta por Wang \& Zhang é usada por nosso algoritmo. A distância, $D_{g}\left(p_{i}, p_{j}\right)$, entre dois pixels $p_{i}$ e $p_{j}$ de uma imagem $I$ é definida como o caminho mínimo entre estes dois pixels. Seja o caminho $P=\left\{p_{1}, p_{2}, \ldots, p_{n}\right\}$, onde $p_{i}$ e $p_{i+1}$ são vizinhos conectados e $i \in\{1,2, \ldots, n-1\}$. O tamanho de $P$ é

$$
l(P)=\sum_{i=1}^{n-1} d_{N}\left(p_{i}, p_{i+1}\right),
$$




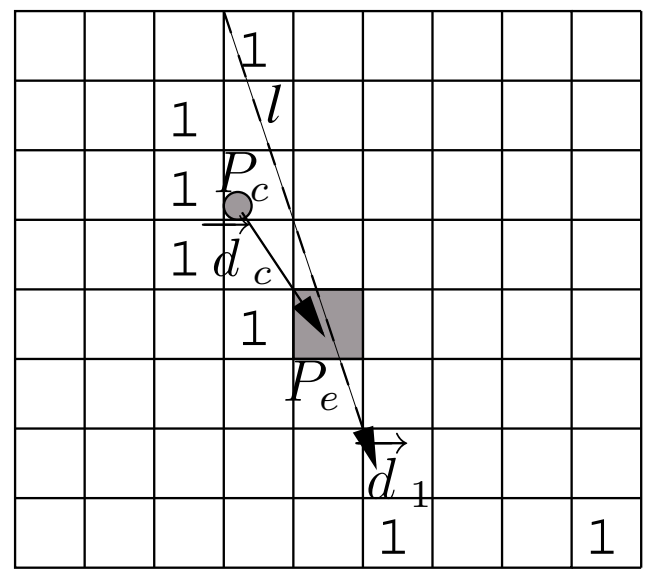

Figura 8.8: Cálculo da direção de borda por Wang 63 Zhang.

onde $d_{N}$ denota a distância entre vizinhos. Assim, distâncias geodésicas particulares podem ser derivadas dependendo da conectividade dos vizinhos e da distância entre vizinhos. No nosso caso, escolhemos uma vizinhança 8-conexa e $d_{N}\left(p_{i}, p_{i+1}\right)=\left|I\left(p_{i}\right)-I\left(p_{i+1}\right)\right|$. Usando a distância geodésica, pode-se considerar a informação de intensidade dos pixels, ao invés de apenas suas coordenadas como quando usa-se a distância Euclidiana.

Para a avaliação dos pontos candidatos para ligação, a seguinte função de custo é usada:

$$
H\left(P_{e}, P_{c}\right)=\frac{1}{D_{g}\left(P_{e}, P_{c}\right) \cdot \Theta\left(P_{e}, P_{c}\right)},
$$

onde $D_{g}\left(P_{e}, P_{c}\right)$ é a distância geodésica entre $P_{e}$ e $P_{c}$ e $\Theta\left(P_{e}, P_{c}\right)$ é o ângulo entre $\vec{d}_{1}$ e a direção da reta ligando diretamente $P_{e}$ e $P_{c}$. A Figura 8.9 ilustra o termo $\Theta\left(P_{e}, P_{c}\right)$.

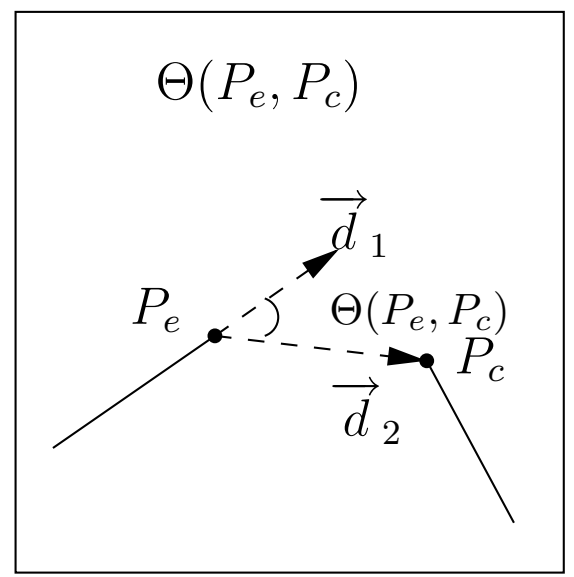

Figura 8.9: Termo $\Theta\left(P_{e}, P_{c}\right)$ da Equação 8.21.

O Algoritmo 8.3 resume o método proposto.

\subsubsection{Experimentos}

Alguns experimentos foram realizados usando o algoritmo proposto em imagens de raízes de plantas. O algoritmo original proposto por Wang \& Zhang também foi aplicado a estas imagens, porém ao invés das bordas das imagens, são usados as cristas das mesmas. 


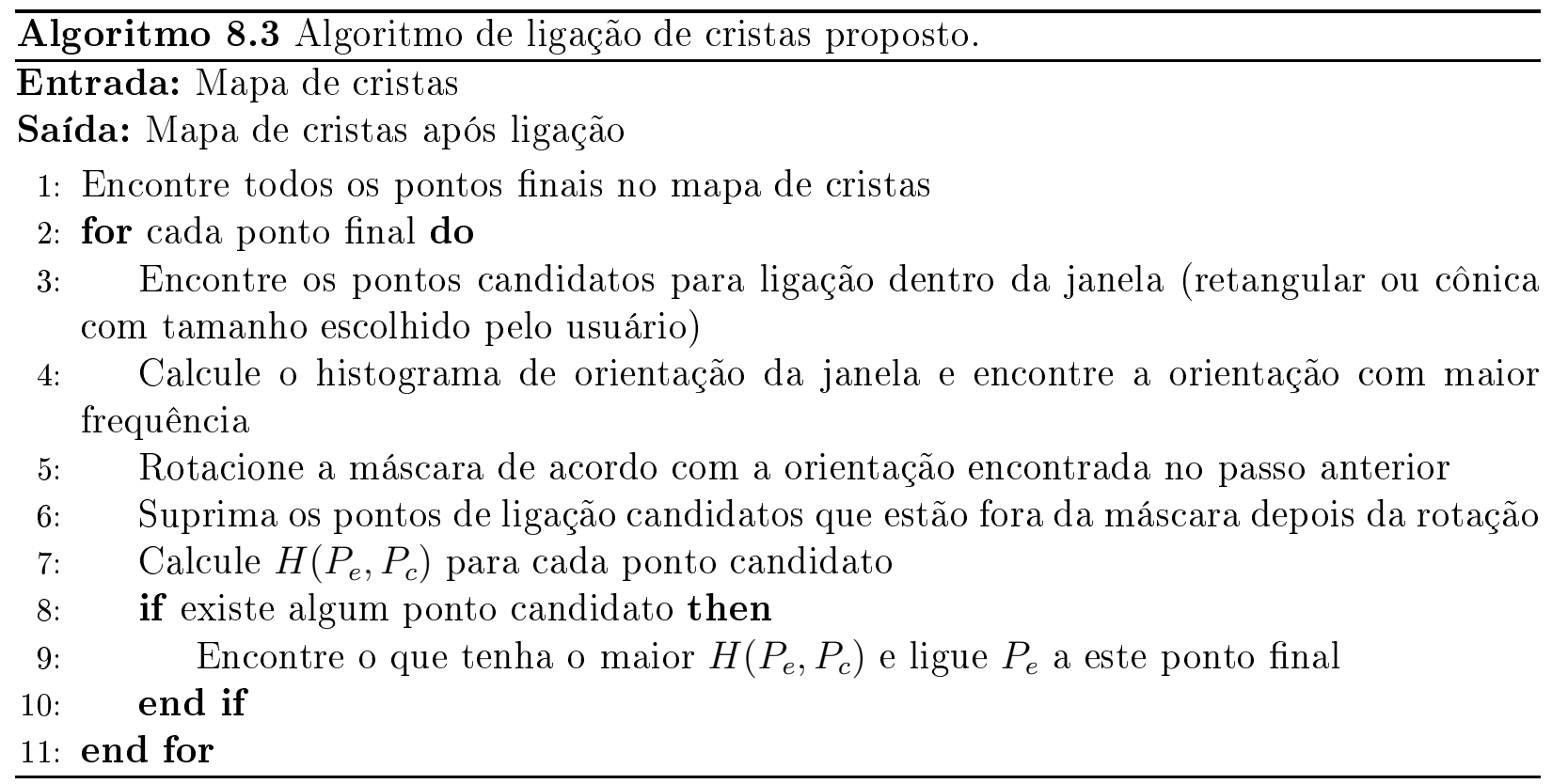

Primeiro, de forma a mostrar a melhora relativa à rotação da máscara e o contexto direcional da imagem, é apresentada nas Figuras 8.10 e 8.11, a aplicação do nosso método em imagens reais de raízes de plantas. A primeira linha mostra a imagem original e o mapa final das cristas ligados sobreposto a mesma, respectivamente. A segunda e terceiras linhas estão organizadas, da esquerda para a direita, como: área selecionada a partir do mapa de cristas, resultado da ligação por Wang \& Zhang e resultado da ligação pelo nosso método. Este tipo de estrutura é bem caracterizada por suas direções e pode-se notar que os resultados usando o método proposto são mais conectados, mais suaves e retêm mais o contexto direcional das estruturas na imagem. A Figura 8.12 apresenta mais uma aplicação do nosso algoritmo.

Observando os resultados pode-se perceber que o algoritmo proposto leva a boas conexões, o que faz com que a boa continuidade de estruturas como raízes de plantas seja mantida. Até onde sabemos, não existe outro método na literatura com esta característica. Aplicações específicas, principalmente aquelas que lidam com estruturas caracterizadas por suas direções, podem ter vantagens usando nossa técnica. Também aplicamos esta técnica em imagens comuns usando bordas e também obtemos bons resultados. Pretendemos estender esta abordagem usando informações de cor das imagens e características específicas sobre estruturas finas e ramificadas como padrões estruturais, ramificações e espessura das estruturas. 


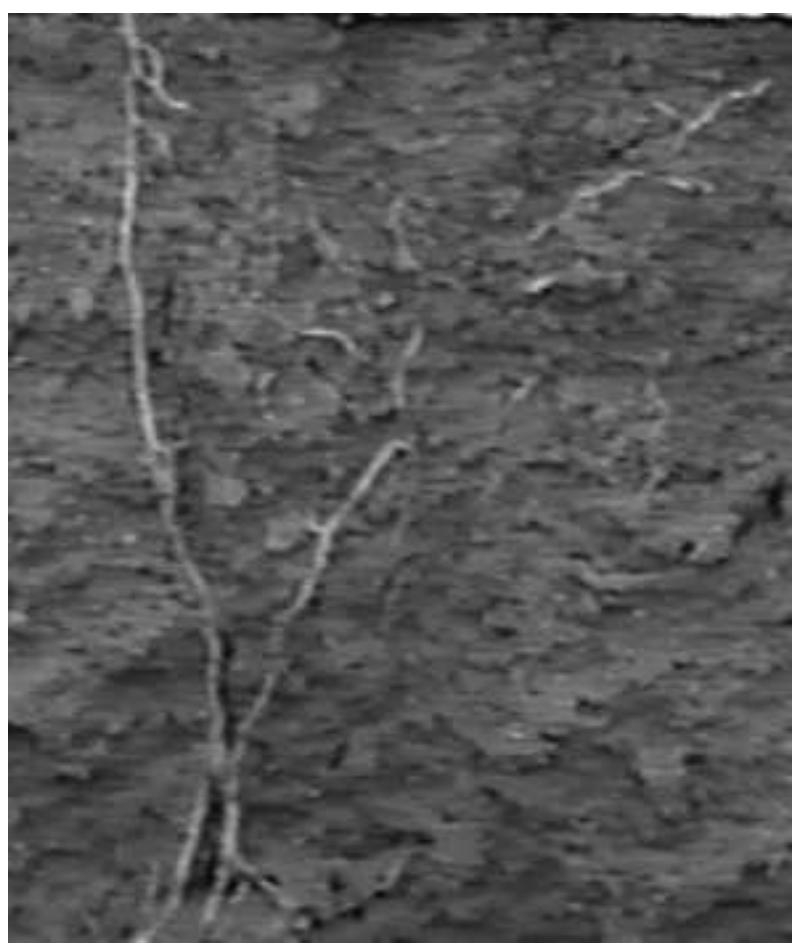

(a)

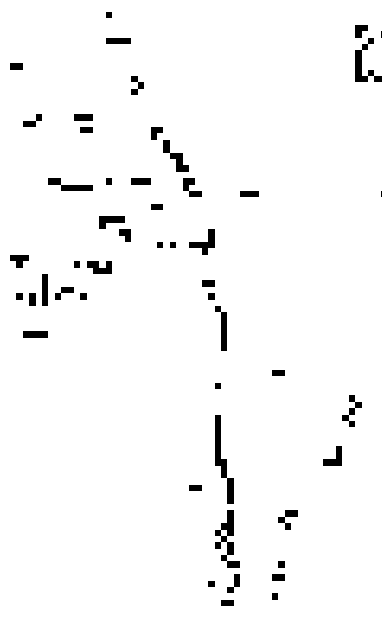

(c)

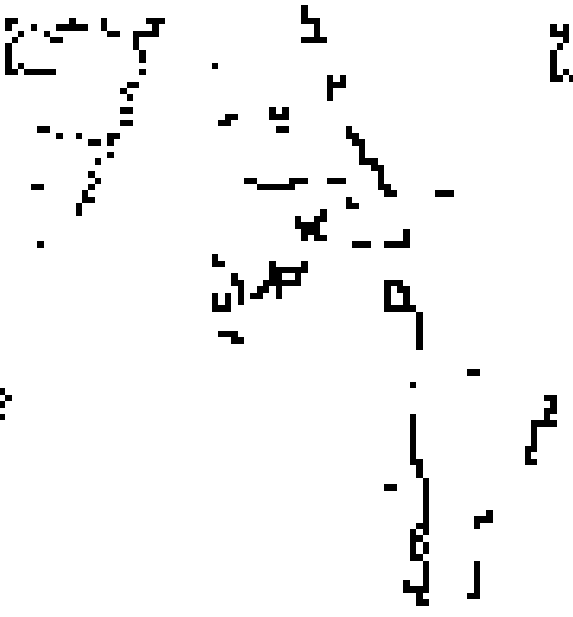

(d)

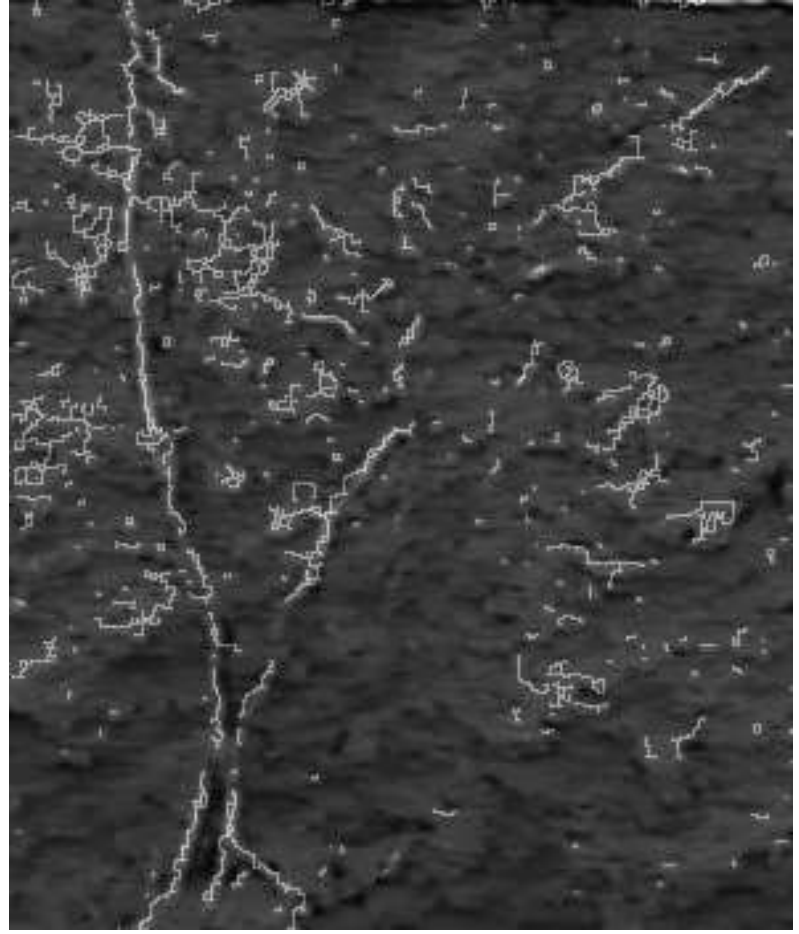

(b)

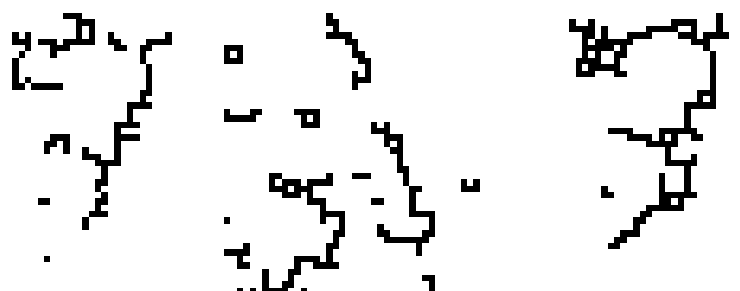

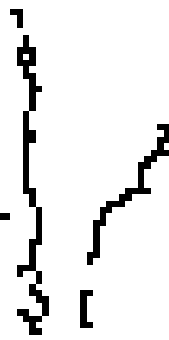

(e)

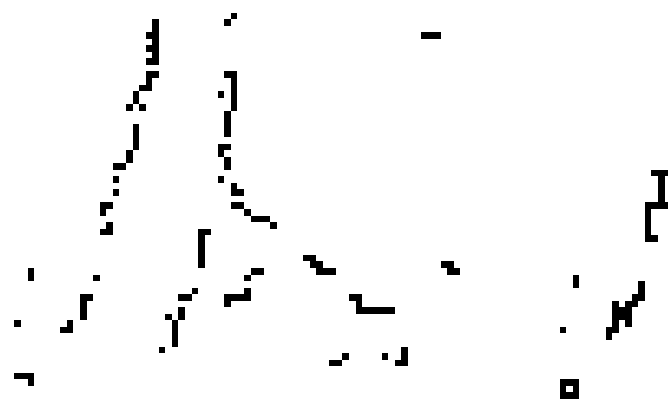

(f)

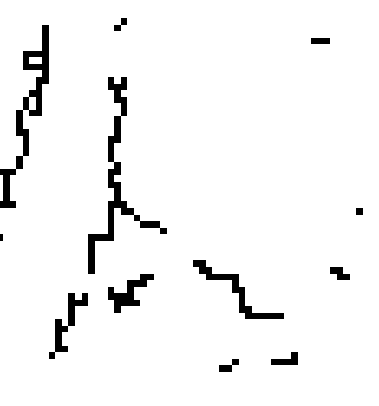

(g)

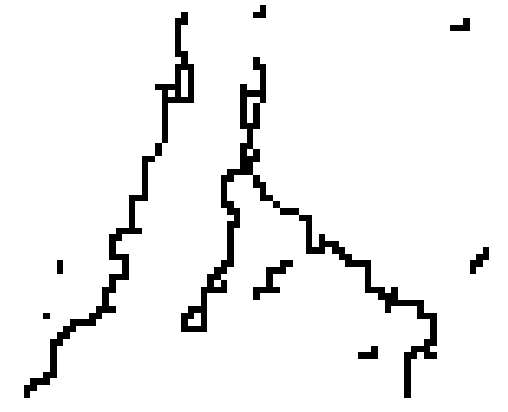

(h)

Figura 8.10: (a) Imagem original de raiz de planta. (b) Mapa de cristas final após ligação, sobreposto à imagem original. (c) e (f) Áreas selecionadas a partir do mapa de cristas. (d) e (g) Resultados da ligação por [Wang 83 Zhang, 2008]. (e) e (h) Resultados pelo método de ligação proposto. 


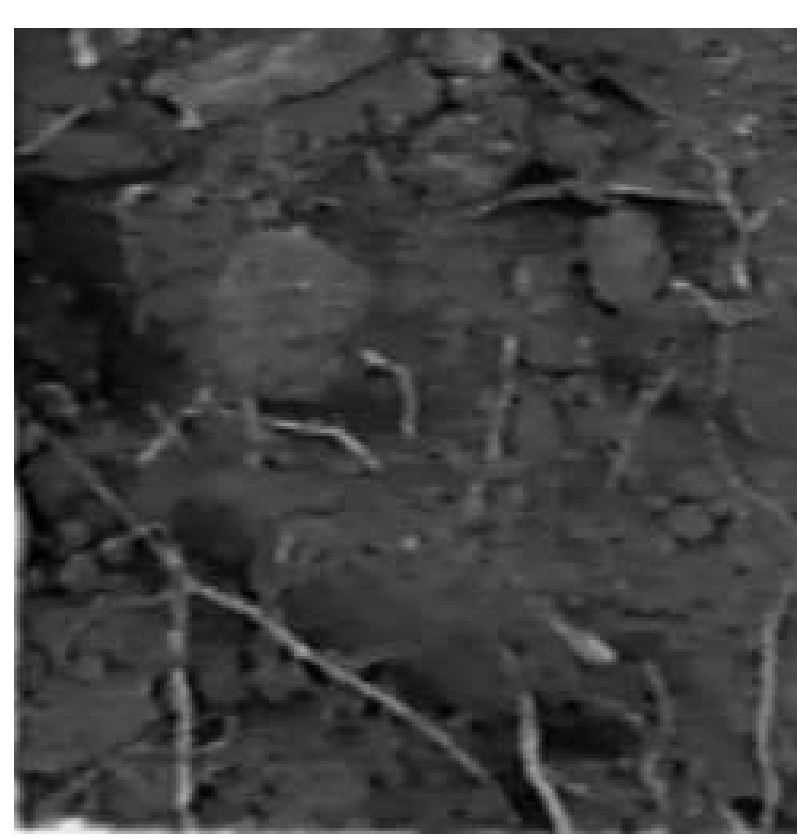

(a)

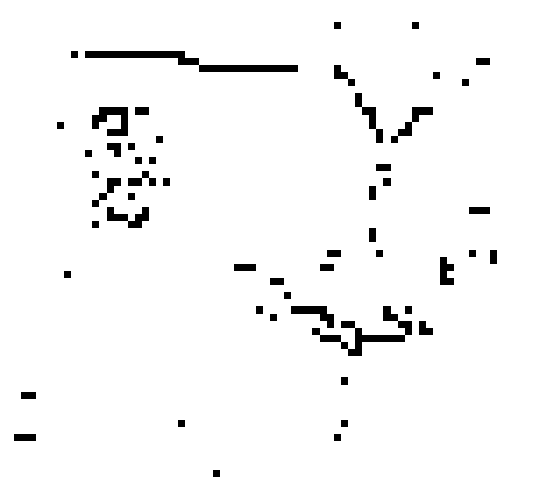

(c)

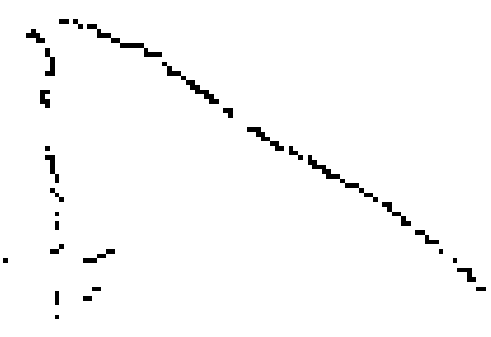

(f)

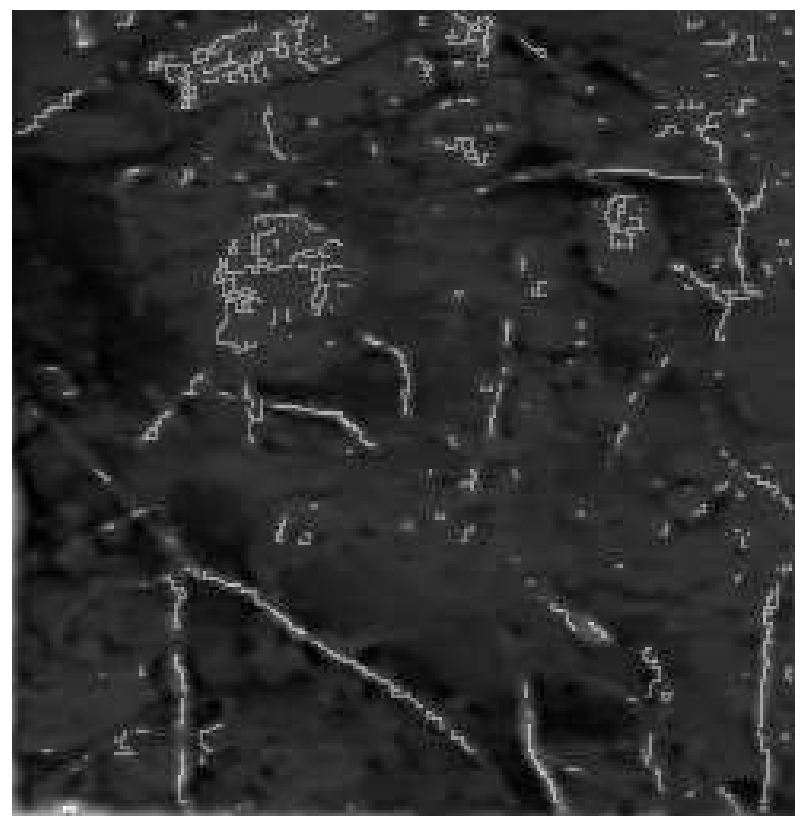

(b)

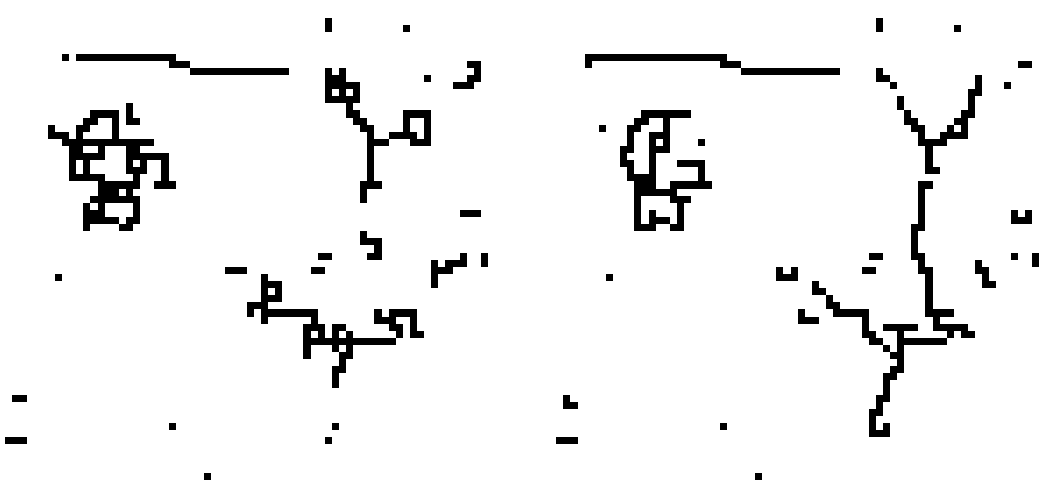

(d)

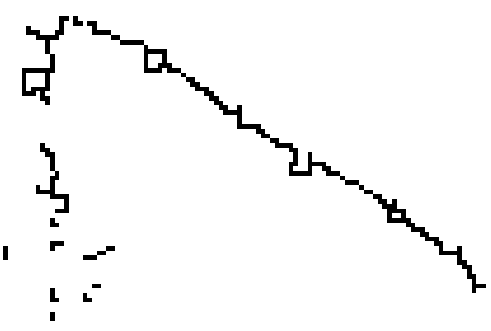

(g)

(e)

Figura 8.11: (a) Imagem original de raiz de planta. (b) Mapa de cristas final após ligação, sobreposto à imagem original. (c) e (f) Áreas selecionadas a partir do mapa de cristas. (d) e (g) Resultados da ligação por [Wang 83 Zhang, 2008]. (e) e (h) Resultados pelo método de ligação proposto. 


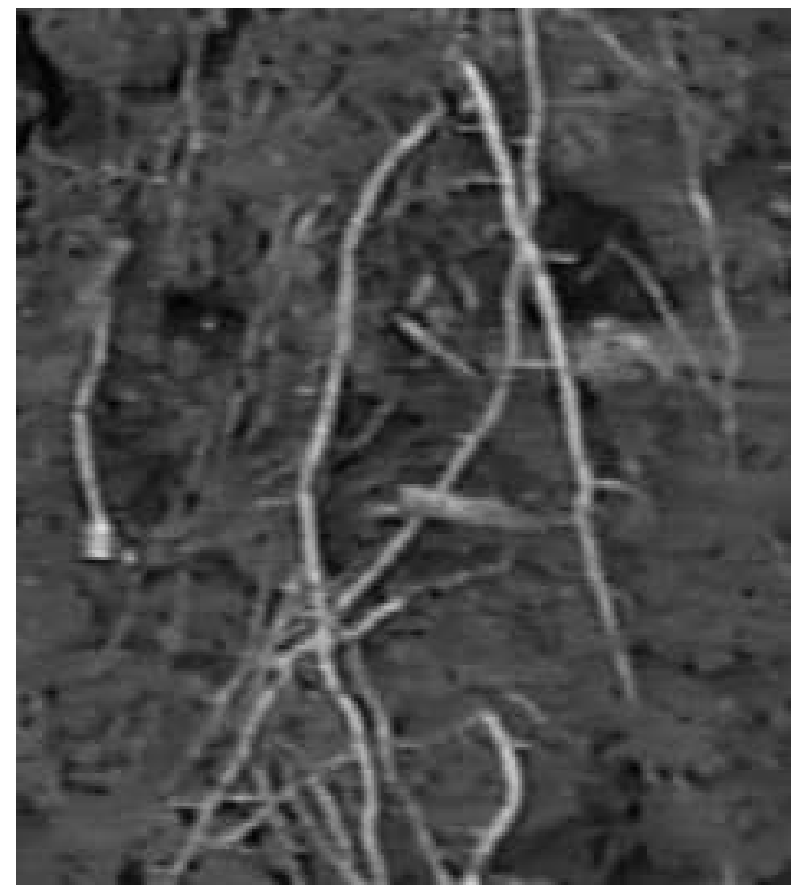

(a)

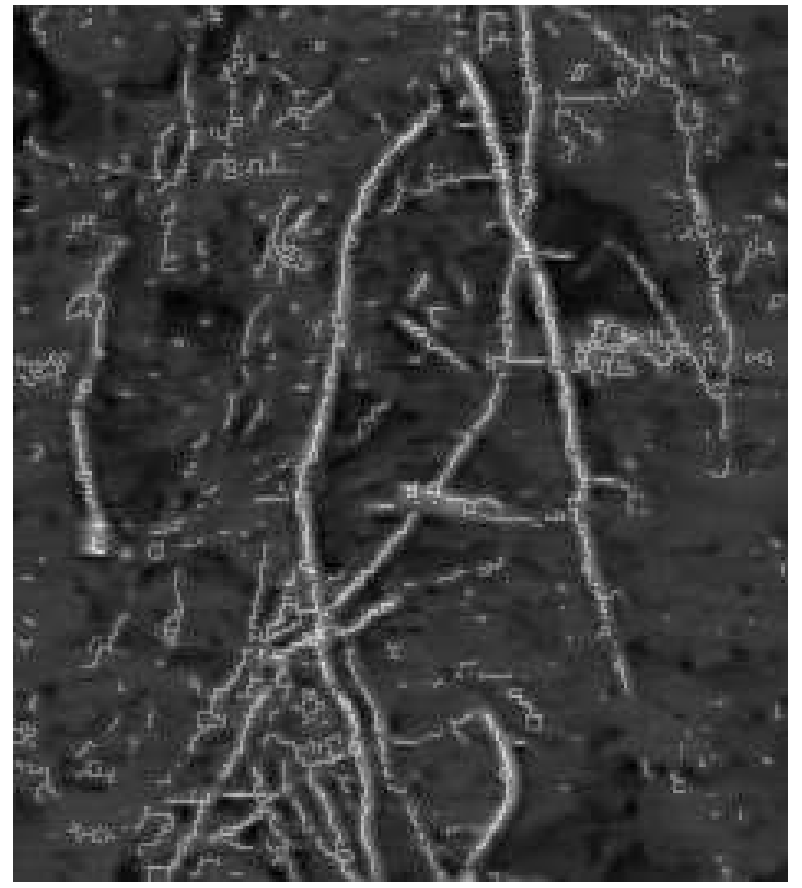

(b)

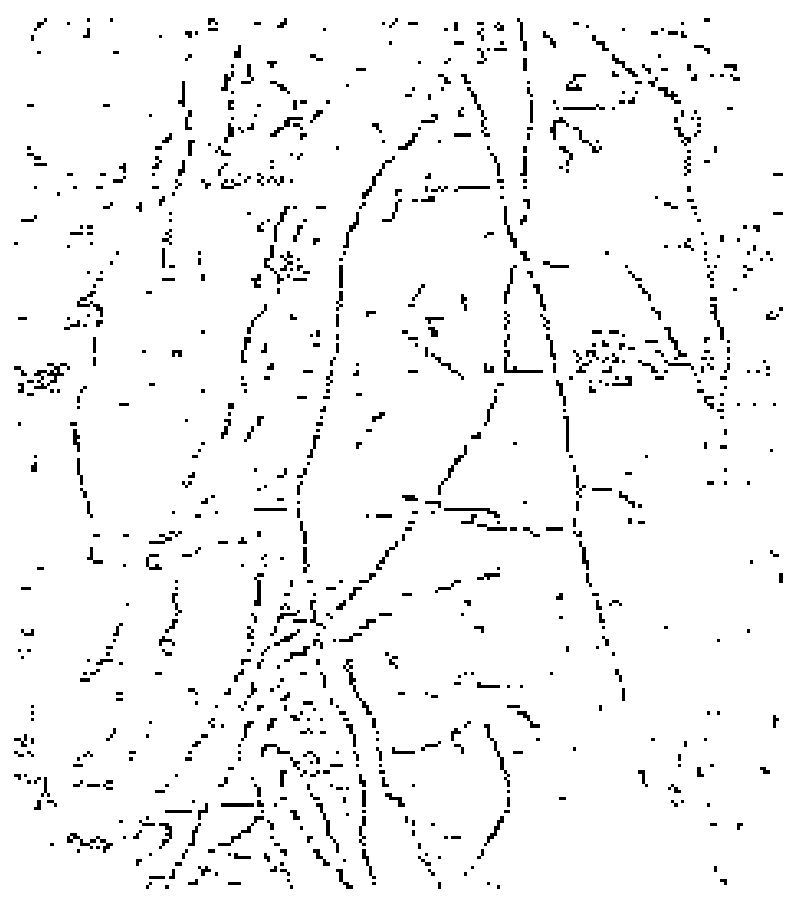

(c)

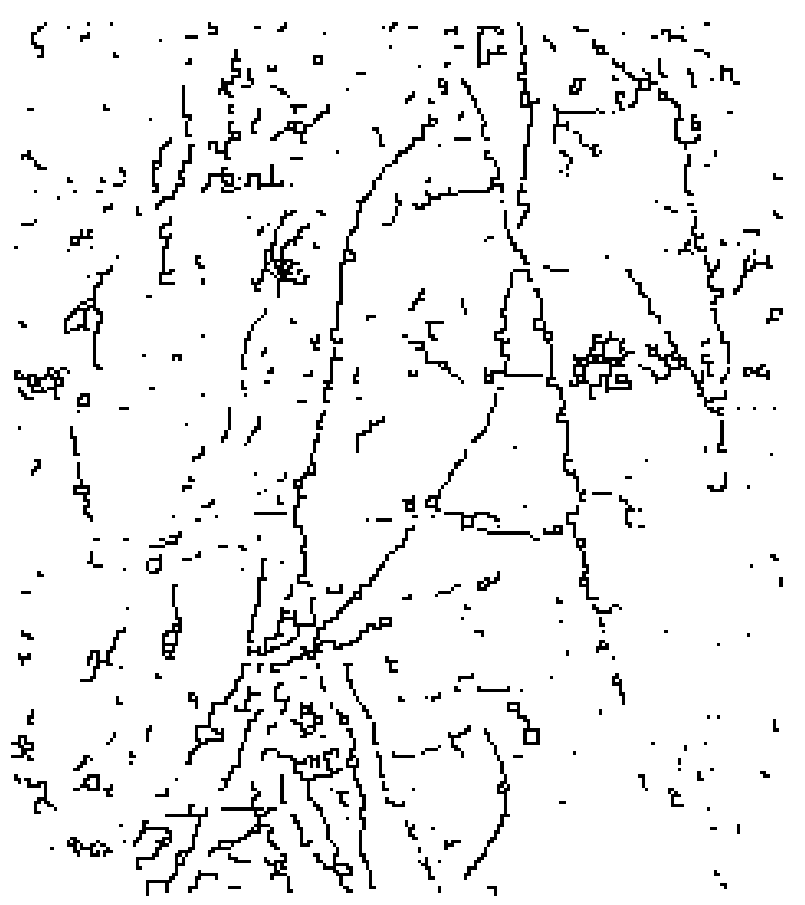

(d)

Figura 8.12: (a) Imagem original de raiz de planta. (b) Mapa de cristas final após ligação, sobreposto à imagem original. (c) Mapa de cristas sem ligação. (d) Mapa de cristas final após ligação pelo método proposto. 


\subsection{Introduzindo fusão de diferentes tipos de dados em baixo nível}

Na abordagem proposta neste trabalho introduzimos a ideia de fusão de dados em baixo nível. Para isso, dadas imagens de uma mesma região obtidas de diferentes sensores, os detectores de linhas apresentados anteriormente são aplicados para todas as imagens. No que segue, o detector por razão/correlação cruzada é considerado.

Suponha que $\mathcal{I}=\left\{I_{1}, I_{2}, \ldots, I_{m}\right\}$ é um conjunto de imagens de uma mesma região, obtidas a partir de diferentes sensores e apropriadamente registradas. Após o cálculo das respostas $d_{1}$ e $d_{2}$ para cada imagem em $\mathcal{I}$, um conjunto de respostas é obtido, $d_{\mathcal{I}}=$ $\left\{d_{1_{I_{1}}}, d_{2_{I_{1}}}, d_{1_{I_{2}}}, d_{2_{I_{2}}}, \ldots, d_{1_{I_{m}}}, d_{2_{I_{m}}}\right\}$. A soma simétrica apresentada na Equação 8.15 , em uma forma generalizada para o número de respostas, é usada para combinar todas as medidas em $d_{\mathcal{I}}$. Assim, a resposta final da detecção leva em conta as detecções de baixo nível de todas as imagens utilizadas como entrada.

A ideia por trás deste procedimento é que quanto maior a resposta do detector, maior é a chance de que uma estrutura esteja presente nas imagens. Uma vantagem clara da fusão das detecções de diferentes sensores é a de detectar estruturas mesmo que elas estejam presentes em apenas uma das imagens. Considere, por exemplo, imagens de satélite ópticas e de radar. Imagens ópticas dependem de boas condições climáticas para capturar de forma clara todas as estruturas, o que nem sempre é possível. Adicionando dados de uma imagem de radar da mesma área pode ajudar a resolver este problema, visto que este sensor não depende de condições climáticas. O resultado final da detecção, depois da fusão das respostas de todas as imagens, é uma imagem de magnitude com a resposta de detecção fusionada para cada pixel da imagem. Para obter o resultado binário, a imagem de magnitude passa pelas operações de limiarização e afinamento. A Figura 8.13 apresenta duas imagens de satélite, uma de radar e outra óptica, de uma mesma região. A Figura 8.14 apresenta os resultados

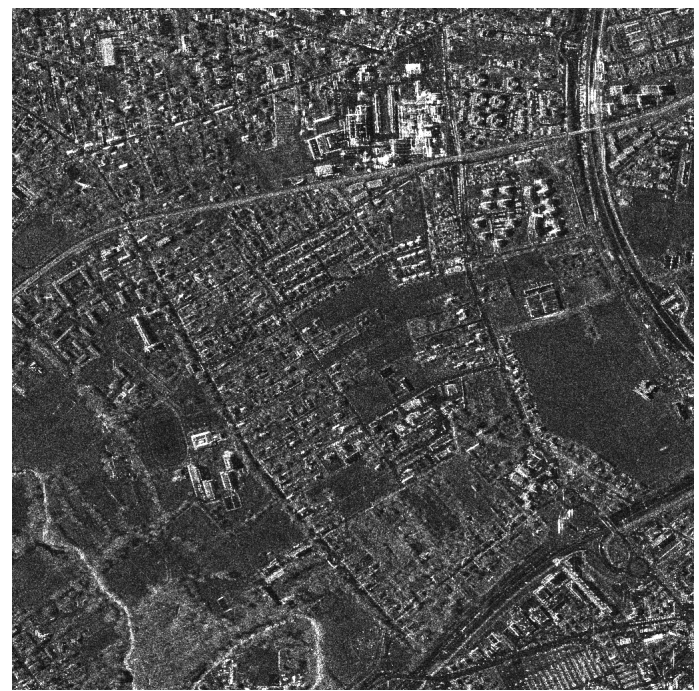

(a)

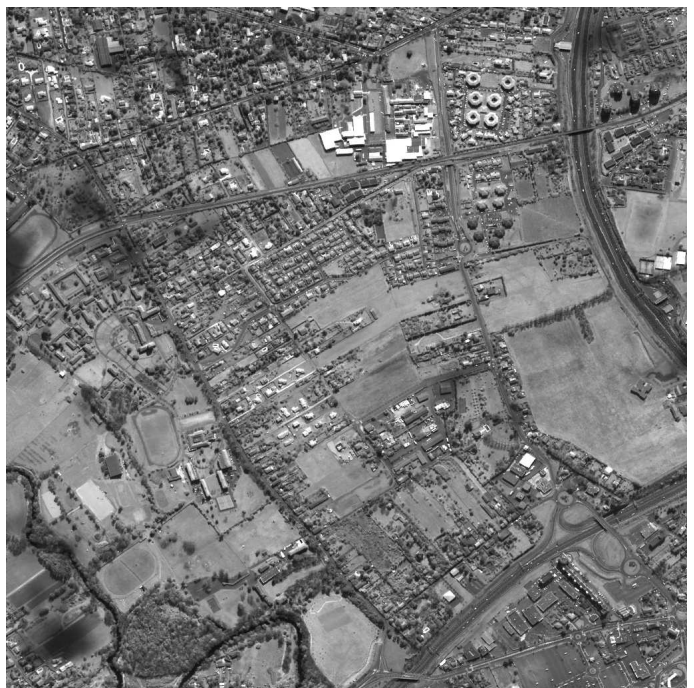

(b)

Figura 8.13: Duas imagens de satélite obtidas de uma mesma região sendo a da esquerda a imagem de radar (a) e a da direita a imagem óptica (b). 
de detecção sem fusão e com fusão de baixo nível das duas imagens da Figura 8.13.

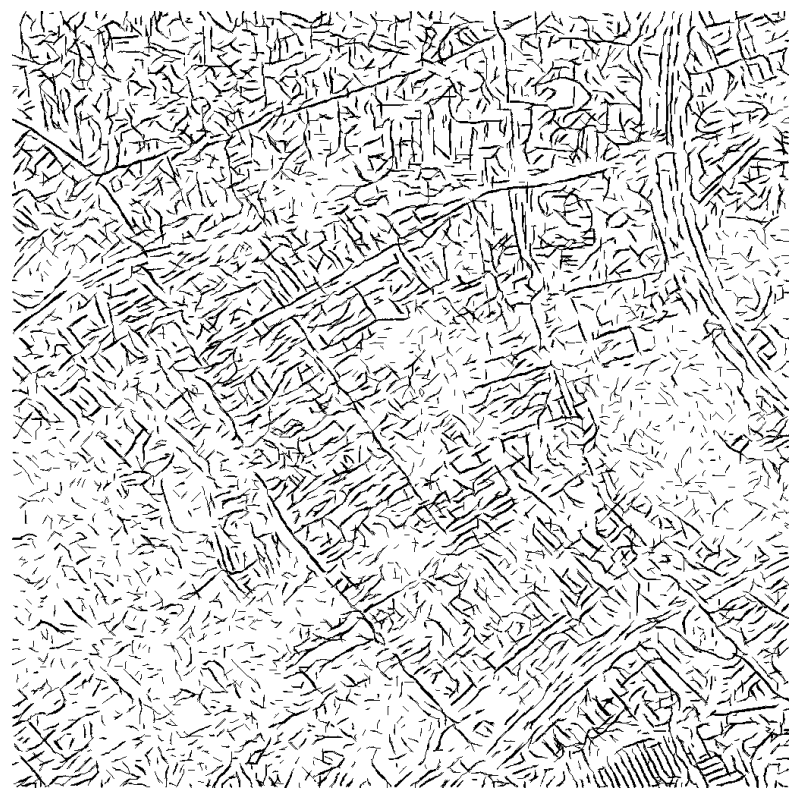

(a)

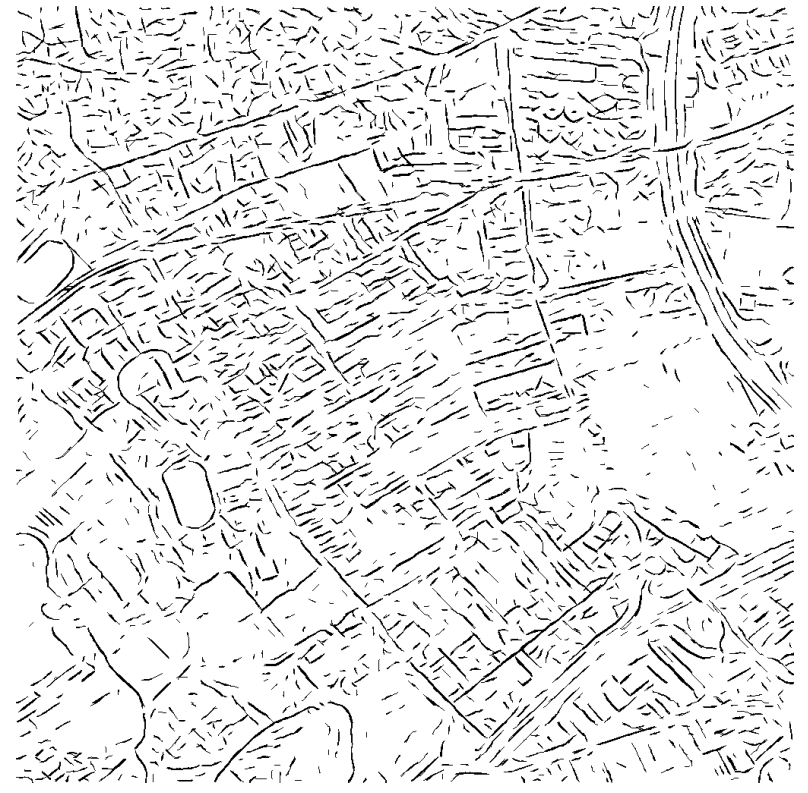

(b)

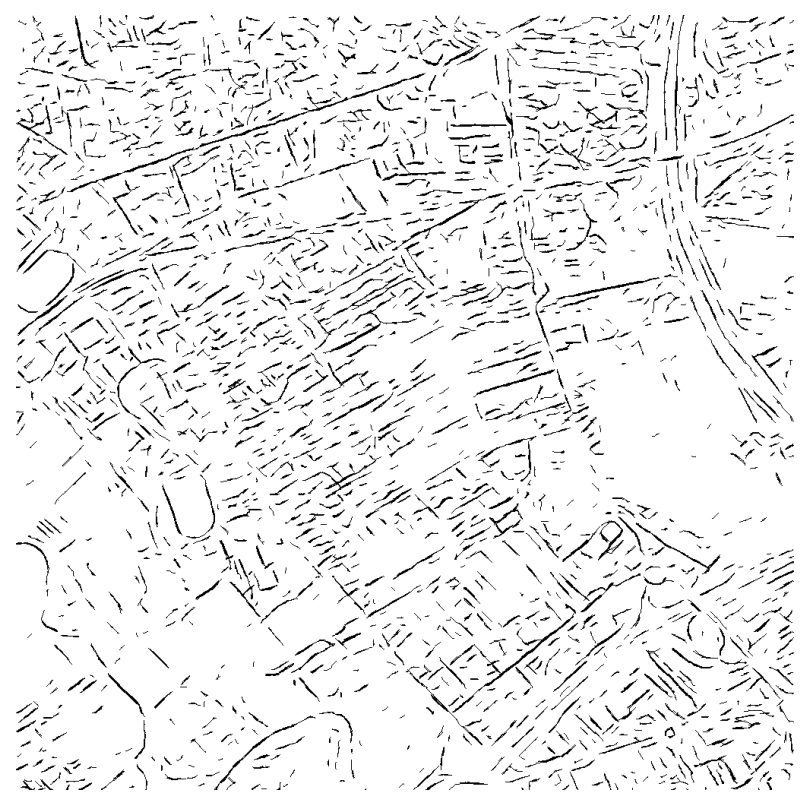

(c)

Figura 8.14: Exemplo de deteç̧ão de linhas usando o detector por razão/correlação cruzada e o método de fusão de baixo nivel proposto. (a) Resultado da detecção de linhas para a imagem radar. (b) Resultado da detecção de linhas para a imagem óptica. (c) Resultado da deteç̧ão de linhas através da fusão de baixo nível proposta. 


\section{Etapa de alto nível}

"Depois de termos conseguido subir a uma grande montanha, só descobrimos que existem ainda mais grandes montanhas para subir."

Nelson Mandela

O segundo nível de processamento da metodologia que apresentamos neste trabalho consiste em duas fases:

1. Modelagem/representação formal das estruturas detectadas no primeiro nível (abordado no capítulo anterior) e das relações espaciais entre as mesmas, e

2. Reconstrução da rede final das estruturas buscadas na imagem.

Esta etapa consiste, na verdade, dos passos apresentados na Seção 7.5.8, para utilizar a abordagem MAP/campos markovianos. Detalhamos, a seguir, as técnicas utilizadas neste trabalho para realizar todos estes passos.

\subsection{Modelagem com grafos - Introduzindo o uso de componentes conexas}

No Capítulo 7 algumas das formas mais conhecidas e utilizadas na literatura de representação de imagens com grafos foram apresentadas. Neste trabalho, um grafo de primitivas, que são as componentes conexas obtidas após a detecção de baixo nível, é utilizado. As primitivas aqui diferem das que são usadas de forma geral na literatura, como pixels, segmentos ou regiões. Por exemplo, em [Tupin et al., 1998] as primitivas utilizadas são segmentos de reta. Os seguintes passos são realizados para a construção do grafo:

- Aplicação de uma aproximação poligonal às estruturas detectadas na etapa de baixo nível de forma a obter apenas segmentos de reta como primitivas (Figura 9.1(b)); 
- Busca de todas as conexões possíveis entre os segmentos se reta usando propriedades geométricas como ângulo e distância entre os mesmos (linhas tracejadas na Figura 9.1(c));

- Construção de um grafo onde cada segmento de reta é um nó do grafo e dois nós são vizinhos se seus segmentos correspondentes compartilham uma extremidade (Figura 9.1(d)).

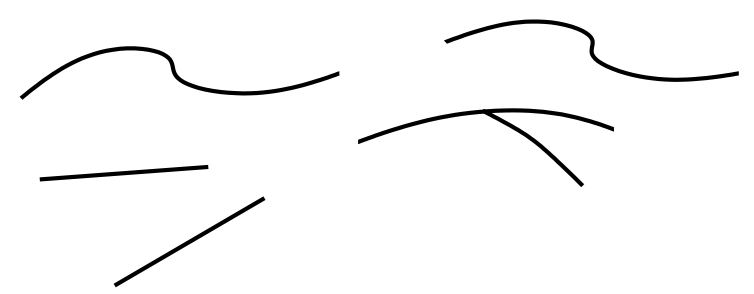

(a)

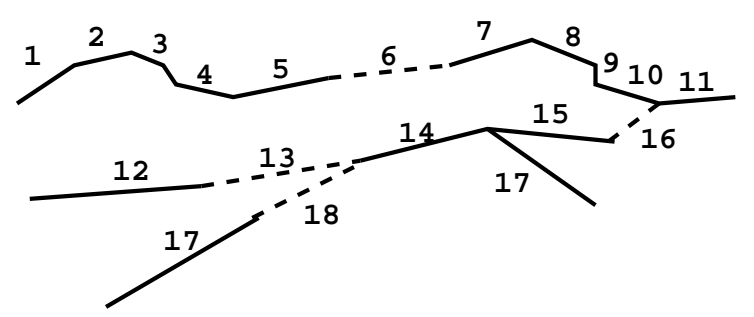

(c)

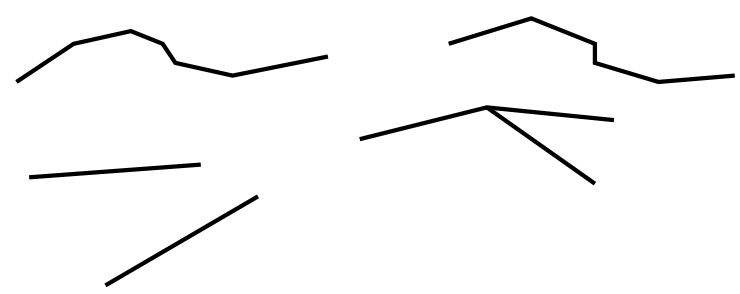

(b)

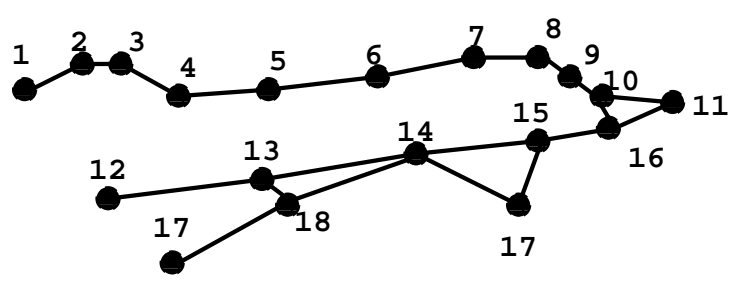

(d)

Figura 9.1: Modelagem do grafo proposto por Tupin et al.. (a) Exemplo de detecção de linhas. (b) Aproximação poligonal das estruturas. (c) Adição das conexões possiveis entre os segmentos de reta. (d) Grafo gerado a partir dos segmentos.

O presente trabalho propõe tratar as estruturas detectadas em baixo nível como componentes conexas. Partindo da detecção de cristas, imagem binária após afinamento (Figura 9.2(a)), todas as componentes conexas são detectadas e para cada uma:

1. todas as extremidades e cruzamentos das componentes são localizados, e

2. para cada cruzamento, a componente conexa é subdividida (Figura 9.2(b)).

Esta última etapa é realizada pois apenas são consideradas curvas simples com duas extremidades. Em seguida, todas as conexões possíveis entre as componentes conexas são encontradas (Figura 9.2(c)) e um grafo é construído onde cada componente conexa é um nó do grafo (incluindo todas as conexões possíveis) e dois nós do grafo são vizinhos se suas componentes conexas correspondentes compartilham um extremidade (Figura 9.2(d)). Note que, devido ao uso das componentes conexas, o passo de aproximação poligonal realizado em Tupin et al. [1998] não é mais necessário.

As conexões possíveis entre as componentes conexas são encontradas de acordo com algumas restrições de proximidade e alinhamento. Definimos que existe uma conexão entre duas componentes conexas se:

- esta conexão liga duas extremidades de duas componentes conexas diferentes; 


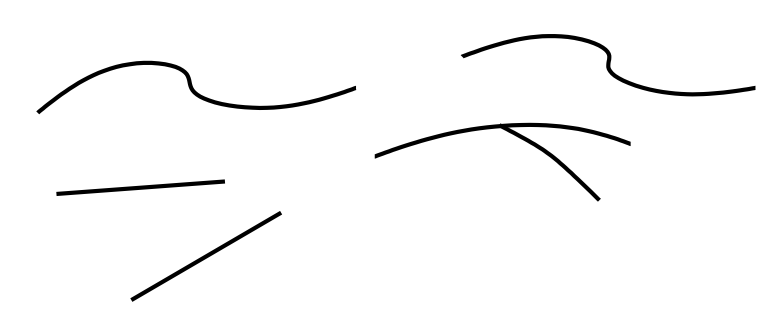

(a)

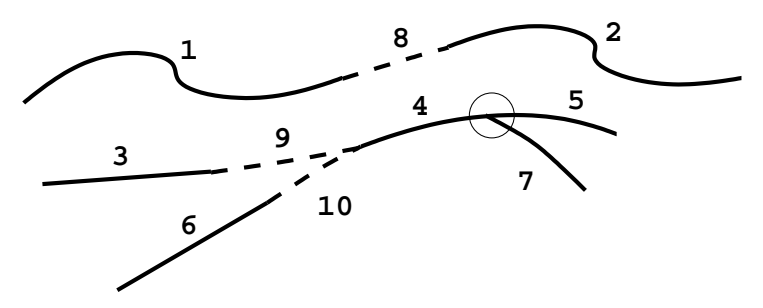

(c)

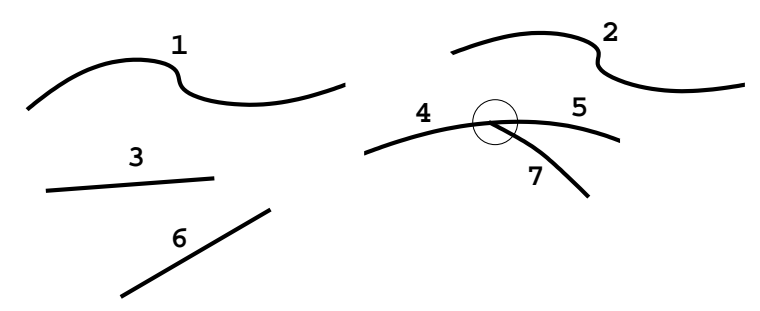

(b)

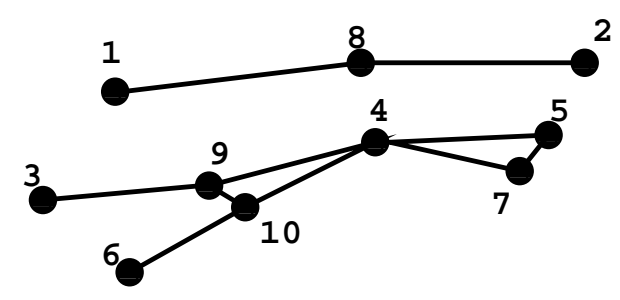

(d)

Figura 9.2: Modelagem de grafo proposta em que são usadas componentes conexas ao invés de segmentos de reta. (a) Exemplo de detecção de cristas. (b) Detecção das componentes conexas e dos cruzamentos. (c) Adição das possíveis conexões entre componentes conexas. (d) Grafo gerado a partir das componentes.

- se as duas extremidades estão próximas o suficiente;

- o alinhamento das duas componentes conexas é aceitável.

Nos dois últimos itens aplicam-se dois dos princípios apresentados na Seção 7.6: proximidade e boa continuidade. Estes dois princípios visam obter conexões que resultem em eventos $\epsilon$ significativos (Definição 8), ou seja, duas componentes só podem estar conectadas se elas estiverem próximas o suficiente e se essa conexão é "visualmente aceitável" em termos de percepção visual.

Propõe-se neste trabalho, visto que são consideradas componentes conexas ao invés de segmentos, que as conexões intermediárias sejam também representadas como componentes conexas. Assim, ao invés de traçar uma linha reta, uma conexão entre duas componentes corresponde ao melhor caminho entre as duas extremidades mais próximas destas componentes. O melhor caminho é calculado usando o algoritmo de programação dinâmica apresentado no Capítulo 8, Seção 8.7, que leva em consideração as intensidades dos pixels da imagem original [Perciano et al., 2010b]. Utilizando este procedimento, uma conexão mais precisa pode ser assegurada em casos complexos onde uma linha reta não corresponde à estrutura buscada como no exemplo ilustrado na Figura 9.3. Isto agora é possível através do uso de componentes conexas ao invés de segmentos. Na Figura 9.3(a), uma rotatória está presente em um região de interesse selecionada a partir de uma imagem radar. O resultado da detecção de cristas para esta região é mostrado na Figura 9.3(b). O método original usado por Tupin et al. traça linhas retas para todas as conexões possíveis entre as primitivas como apresentado na Figura 9.3(c). Desta forma, alguns detalhes da rotatória são perdidos. Por outro lado, usando o método proposto, todos os melhores caminhos entre as componentes conexas são calculados, mantendo a forma da rotatória, como apresentado na Figura 9.3(d). 


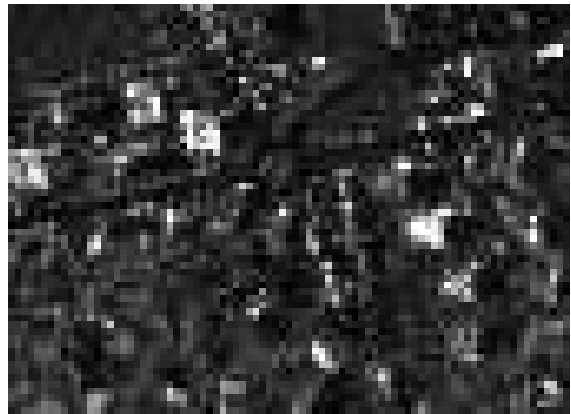

(a)

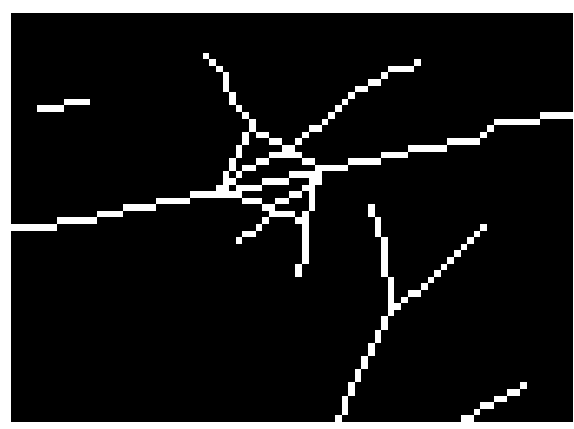

(c)

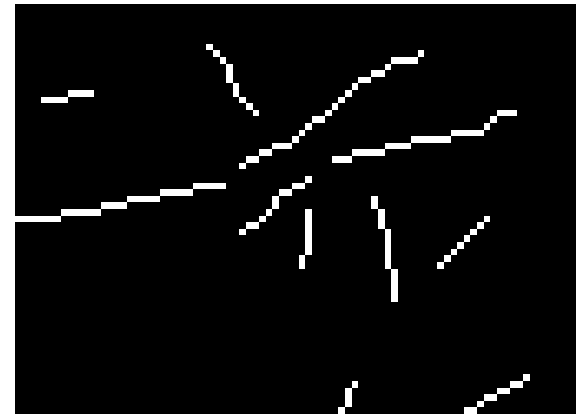

(b)

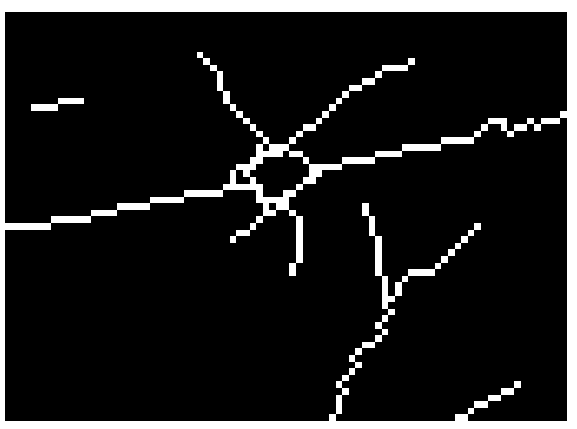

(d)

Figura 9.3: Exemplo do método de melhor caminho para obter as conexões possiveis entre primitivas. (a) Região de interesse de uma imagem radar. (b) Resultado da detecção de cristas da região escolhida. (c) Conexões obtidas por Tupin et al.. (d) Conexões obtidas usando o método proposto.

Formalmente, seja $C_{d}$ o conjunto de componentes conexas detectadas na etapa de baixo nível, já considerando apenas componentes como curvas simples com duas extremidades. No problema real de detecção de algum tipo de estrutura em uma imagem, estas componentes representam estruturas reais na imagem ou não. Assume-se que a rede de estruturas final é composta por estas componentes detectadas em baixo nível e pelas conexões entre as mesmas, além na remoção de forma apropriada das falsas detecções. Assim, também consideramos o conjunto de todas as conexões possíveis entre as componentes conexas, $C_{d}^{\prime}$, que são os melhores caminhos encontrados como apresentado anteriormente. Seja a componente conexa $i$ pertencente a $C_{d}$, e seja $E_{i}^{k} \operatorname{com} k \in\{1,2\}$ as extremidades de $i\left(i=E_{i}^{1} E_{i}^{2}\right)$. Sendo a relação de possível conexão entre duas componentes denotada por $i R j$, temos:

$$
C_{d}^{\prime}=\left\{E_{i}^{k} E_{j}^{l}, i \in C_{d}, j \in C_{d} \text { e } i R j\right\}
$$

O conjunto final de componentes conexas é dado por $C=C_{d} \cup C_{d}^{\prime}$. Este conjunto $C$ é dotado de uma estrutura em grafo onde cada vértice do grafo $G$ representa uma componente conexa e existe uma aresta entre dois vértices $i$ e $j$ se suas respectivas componentes possuem uma extremidade em comum como na Figura 9.2(d). De acordo com a construção apresentada 
anteriormente, são definimos a seguinte vizinhança para o grafo $G$ :

$$
\partial_{i}=\left\{j \in C \mid \exists(k, p) \in\{1,2\}, E_{j}^{k}=E_{i}^{p}, j \neq i\right\} .
$$

Observe que esta vizinhança engloba os dois casos de conexões envolvidos: através de um conexão possível entre duas componentes ou através da conexão por cruzamentos, como pode ser observado na Figura 9.2(b). Observe que de acordo com esta vizinhança, trabalhamos com uma grade irregular, diferentemente de grades regulares definidas por vizinhanças 4conexas ou 8-conexas por exemplo. $G$ é um grafo relacional com atributos: cada nó $i$ possui o atributo $\mathcal{L}_{i}=\min \left(1,\left(\right.\right.$ Length $\left.\left._{i} / \mathcal{D}_{\max }\right)\right) \in[0,1]$, onde Length ${ }_{i}$ é o tamanho da componente conexa e $\mathcal{D}_{\max }$ é a distância máxima aceitável entre duas componentes conexas e também um fator de normalização. Introduzimos também para cada nó $i$ um atributo de homogeneidade $\mathcal{H}_{i}=\sigma_{i} / \mu_{i}$, onde $\sigma_{i}$ e $\mu_{i}$ são o desvio padrão e a média das intensidades dos pixels pertencentes à componente. Cada aresta de $G$ ligando dois nós $i$ e $j$ guarda o atributo relacionado ao ângulo entre suas componentes conexas correspondentes: $\mathcal{R}_{i j} \bmod \pi$. Este ângulo é calculado considerando o vetor de direção nas extremidades de cada componente (ver Figura 9.4). Os cliques do grafo são os subgrafos completos de $G$ que correspondem a
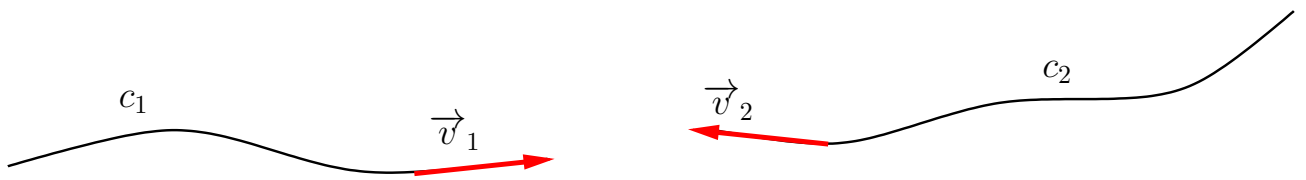

Figura 9.4: Cálculo do ângulo entre duas componentes conexas considerando o vetor direção nas extremidades de cada componente.

todos os subconjuntos de componentes que possuem uma extremidade em comum.

O objetivo de utilizar componentes conexas ao invés de segmentos de reta é o de manter, em geral, estruturas completas detectadas na etapa de baixo nível sem subdividí-las em muitos segmentos. Consequentemente, sem estas subdivisões, um menor número de estruturas primitivas tem que ser processadas na etapa seguinte e o número de caminhos falsos é reduzido. Além disso, o grafo construído é simplificado, já que o número de nós reduz substancialmente. Finalmente, o uso de componentes conexas torna o arcabouço proposto mais robusto no sentido de que ele pode ser aplicado para a detecção de estruturas diferentes e mais complexas, visto que é mais flexível com relação a curvatura das estruturas.

O grafo $G$ é utilizado na etapa de reconstrução da rede de estruturas, como um processo de rotulação, isto é, identificação dos nós do grafo que são realmente estruturas ou não. Este processo é explicado em detalhes na próxima seção.

\subsection{Processamento em alto nível - campos aleatórios de Markov}

Definiremos sobre o grafo $G$ construído anteriormente, um sistema de rotulação onde o conjunto de rótulos é dado por $\mathbb{L}=\{0,1\}$. Seja $L=\left\{L_{1}, L_{2} \ldots L_{N}\right\}$ o conjunto de todos 
os rótulos $L_{i}$ de cada nó $i$ do grafo $G$, ou seja, uma rotulação possível do grafo. $L$ é uma rotulação binária onde $l_{i}=1$ se a componente conexa representada pelo nó $i$ representa uma estrutura verdadeira na imagem e $l_{i}=0$ caso contrário. O campo aleatório de rótulos $L$ possui valores em $\Omega$, o conjunto de todas as configurações possíveis com cardinalidade $2^{N}$.

A rede de estruturas final é definida como a configuração mais provável para $L$ dado o processo de observação $D$ para as componentes conexas em $C$ através de um critério MAP. Isto significa que a solução corresponde ao máximo da distribuição de probabilidade condicional de $L$ dada a observação $D: P(L \mid D)$. Como visto no Capítulo 7 , de acordo com a regra de Bayes temos:

$$
P(L \mid D)=\frac{P(D \mid L) P(L)}{P(D)} .
$$

As probabilidades $P(L)$ e $P(D \mid L)$ precisam ser estimadas. A distribuição de probabilidade a priori consiste em um modelo Markoviano da rede de estruturas buscada.

O processo $L$ condicionalmente a $D$ é modelado como um campo Markoviano usando a equivalência entre os campos de Markov e de Gibbs. O processo de observação $D=$ $\left(D_{1}, D_{2}, \ldots, D_{N}\right)$ é definido através da detecção de baixo nível. A observação $d_{i}$ é calculada ao longo da componente conexa levando em consideração as mudanças de direção, diferentemente do caso em que utiliza-se segmentos de reta (ver Figura 9.5). Como exemplificado na Figura 9.5(a), utilizando segmentos de reta, a medida é calculada para cada segmento de reta separadamente. Por outro lado, no método aqui proposto, a medida é calculada uma única vez para cada componente considerando as variações de direção ao longo da estrutura. Assim, a observação $d_{i}$ relacionada a cada componente conexa é calculada como a média das

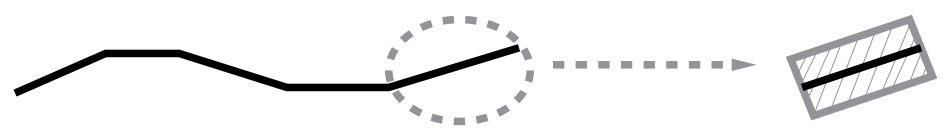

(a) Usando segmentos de reta.

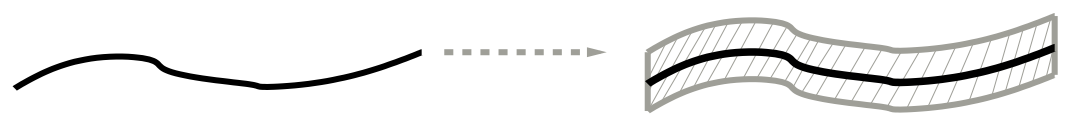

(b) Usando componentes conexas.

Figura 9.5: Comparação do cálculo da medida para o termo de verossimilhança usando segmentos de reta (a) e componentes conexas (b).

respostas do detector de linhas ao longo da mesma. Quanto maior a chance de uma componente conexa ser uma estrutura real, maior é a resposta. Sob a hipótese de independência entre $D_{i}$ e supondo que a distribuição de probabilidade condicional $D_{i}$ depende apenas de $L_{i}$, tem-se:

$$
P(D \mid L)=\prod_{i=1}^{N} P\left(D_{i} \mid L\right)=\prod_{i=1}^{N} P\left(D_{i} \mid L_{i}\right) \propto \exp \left[-\sum_{i=1}^{N} V\left(d_{i} \mid l_{i}\right)\right]
$$

onde $V\left(d_{i} \mid l_{i}\right)$ é o potencial da componente conexa $i$. As distribuições de probabilidade condi- 
cionais $P\left(D_{i} \mid L_{i}\right)$ dependem usualmente dos dados que estão sendo usados e refletem o comportamento geral do tipo de estrutura que está sendo buscada na imagem. Por isso que normalmente estes potenciais são obtidos através de um estudo de imagens juntamente com a segmentação manual das mesmas. Neste trabalho, são utilizados os potenciais $V\left(d_{i} \mid l_{i}\right)$ relacionados abaixo:

$$
\begin{array}{cc}
V\left(d_{i}, l_{i}=0\right)=0, & \text { se } d_{i}<t_{1} \\
V\left(d_{i}, l_{i}=0\right)=\frac{d_{i}-t_{1}}{t_{2}-t_{1}}, & \text { se } t_{1}<d_{i}<t_{2} \\
V\left(d_{i}, l_{i}=0\right)=1, & \text { se } d_{i}>t_{2} \\
V\left(d_{i}, l_{i}=1\right)=0, & \forall d_{i},
\end{array}
$$

onde $t_{1} \leq t_{2} \in[0,1]$. Se existe uma boa associação entre $d_{i}$ e $l_{i}$, o valor do potencial deve ser baixo. Para obter uma correspondência entre os potenciais e as distribuições de probabilidade, potenciais da forma $V\left(D_{i}=d_{i} \mid L_{i}=0\right)+Z$ são usados. $Z=t_{1}+(1-$ $\left.t_{2}\right)(1 / e)-\left(t_{2}-t_{1}\right)((1 / e)-1) \operatorname{com} e=\exp (1)$. Como $Z<1$ tem-se $\log Z<0$. Além disso, para levar em consideração o tamanho das componentes conexas, todos os potenciais são multiplicados por $\mathcal{L}_{i}$.

Assumindo que a detecção das estruturas pode ser deduzida de conhecimento contextual local, $L$ pode ser definido com um campo aleatório de Markov. Usando a equivalência dos campos de Markov-Gibbs, temos:

$$
P(L=l)=\frac{1}{Z^{\prime}} \exp [-U(l)]
$$

onde $Z^{\prime}$ é a constante de normalização e $U(l)$ é dada por:

$$
U(l)=\sum_{c \in \mathcal{C}} V_{c}(l)
$$

onde $\mathcal{C}$ é o conjunto de cliques. Os potenciais dos cliques são definidos para expressar o conhecimento a priori sobre as estruturas levando em consideração tamanho, curvatura e cruzamentos. Todos os potenciais $V_{c}(l)$ são nulos com exceção dos cliques de ordem maior que correspondem aos conjuntos de componentes conexas que possuem uma extremidade em comum para todas as componentes. Para um clique $c$ deste tipo, os potenciais são definidos 
como abaixo:

$$
\begin{aligned}
\forall i \in c \mid l_{i}=0 & \rightarrow V_{c}(l)=0 \\
\exists ! i \in c \mid l_{i}=1 & \rightarrow V_{c}(l)=K_{e}-K_{\mathcal{L}} \mathcal{L}_{i} \\
\exists(i, j) \in c^{2} \mid l_{i}=l_{j}=1, \mathcal{R}_{i j}>\frac{\pi}{2} & \rightarrow V_{c}(l)=-K_{\mathcal{L}}\left(\mathcal{L}_{i}+\mathcal{L}_{j}\right)+K_{c} \sin \mathcal{R}_{i j} \\
\exists !(i, j, k) \in c^{3} \mid l_{i}=l_{j}=l_{k}=1, i R j, i \mathcal{P} k, j \mathcal{P} k & \rightarrow V_{c}(l)=-K_{\mathcal{L}}\left(\mathcal{L}_{i}+\mathcal{L}_{j}+\mathcal{L}_{k}\right)+ \\
\exists !(i, j, k, l) \in c^{4} \mid l_{i}=\cdots=l_{l}=1, i R j, k R l, i \mathcal{P} k, j \mathcal{P} l & \rightarrow V_{c}(l)=-K_{\mathcal{L}}\left(\mathcal{L}_{i}+\mathcal{L}_{j}+\mathcal{L}_{k}+\mathcal{L}_{l}\right)+ \\
\text { para todos os outros casos } & \rightarrow V_{c}(l)=K_{i} \sum_{i \mid i \in c} l_{i} .
\end{aligned}
$$

Onde $i R j$ denota conexão entre duas componentes e $i \mathcal{P} j$ denota paralelismo entre duas componentes. A quarta e quinta regras são opcionais, dependendo do tipo de estrutura buscada. Estas regras são apropriadas para, por exemplo, redes de estradas em áreas urbanas as quais possuem muitos cruzamentos. Observe que existem quatro parâmetros envolvidos nas expressões acima, as quais "regulam" a informação contextual do campo Markoviano:

- $K_{e}$ : penaliza extremidades, ou seja, partes de estruturas pequenas e isoladas

- $K_{\mathcal{L}}$ : pondera o tamanho das componentes conexas

- $K_{c}$ : pondera a curvatura entre as componentes conexas

- $K_{i}$ : penaliza cliques com muitos cruzamentos

Escolhendo $K_{e}>0$ e $K_{\mathcal{L}}>0$, estruturas mais longas são favorecidas. Se $K_{c}>0$, estruturas com alta curvatura são penalizadas e se $K_{i}>0$, estruturas isoladas são penalizadas.

Como $P(L \mid D)$ e $P(L)$ correspondem a distribuições de Gibbs definidas no mesmo grafo, o mesmo ocorre com a distribuição de probabilidade global do campo. Assim, $L \mid D$ é um campo aleatório de Markov definido em $\Omega$ com energia global:

$$
U(l \mid d)=\sum_{i=1}^{N} V\left(d_{i} \mid l_{i}\right)+\sum_{c \in \mathcal{C}} V_{c}(l) .
$$

Os potenciais são os definidos anteriormente. $\sum_{i=1}^{N} V\left(d_{i} \mid l_{i}\right)$ é o termo de verossimilhança dos dados e $\sum_{c \in \mathcal{C}} V_{c}(l)$ é o termo que representa a informação contextual dos dados.

Como $P(D \mid L)=\frac{\exp [-U(d \mid l)]}{Z}$, a configuração MAP corresponde à energia mínima. Assim, para encontrar a rotulação ótima, e consequentemente a rede final de estruturas, é realizado um processo de minimização usando a Equação 9.12. Neste trabalho é utilizado o método de otimização Simulated Annealing juntamente com o amostrador de Gibbs. O processo de otimização é executado considerando conjuntos de configurações de três componentes conexas. Ou seja, para cada componente conexa escolhida aleatoriamente, são escolhidas 
duas componentes conexas vizinhas, o que resulta em oito configurações possíveis de rotulação. O amostrador de Gibbs é aplicado nos oito estados de energia correspondentes. O uso de configurações deste tipo, ao invés do processamento de componentes conexas em sequência, ajuda o algoritmo a deixar mínimos locais comparando configurações bem diferentes como três componentes com rótulo zero e três componentes com rótulo um.

Para mostrar como os parâmetros envolvidos na definição do campo Markoviano influenciam nos resultados, apresentamos a seguir um exemplo simples de detecção de estruturas variando-os. A Figura 9.6(a) apresenta uma imagem de teste com algumas estruturas lineares e curvilíneas. As Figuas 9.6(b), 9.6(c), 9.6(d) e 9.6(e) apresentam, respectivamente, a imagem de magnitude resultante do detector de cristas de razão e correlação cruzada, a imagem binária da deteç̧ão, imagem resultante do afinamento aplicado à imagem binária e o grafo das componentes conexas.

A Figura 9.7 apresenta alguns resultados diferentes variando os parâmetros do campo Markoviano. Na Figura 9.7(a), os parâmetros estão "equilibrados", permitindo a extração de quase todas as estruturas sem as conexões. Já na Figura 9.6(b), o valor mais baixo para o parâmetro de intersecções privilegia as conexões entre as estruturas. Na Figura 9.7(c), os valores mais baixos para os parâmetros de intersecções e curvatura privilegia as conexões inclusive com uma curvatura maior. Finalmente, a Figura 9.7(d) mostra o resultado para um valor bem baixo do parâmetro de extremidades, o que elimina as conexões (permitindo mais extremidades) e permite a extração de todas as estruturas.

\subsubsection{Abordagem multiescala}

Após o processo de otimização apresentado anteriormente, uma rede final de estruturas é obtida. Porém, considerando uma característica geral do tipo de estruturas que é estudado neste trabalho, a largura das estruturas na imagem varia ao longo da rede e suas ramificações. Ou seja, é possível que, considerando apenas a imagem em sua escala original, o detector de baixo nível seja capaz de detectar apenas uma parte das estruturas. Com o intuito de evitar a não deteç̧ão de certas estruturas na imagem, uma abordagem multiescala é usada:

- Uma pirâmide é criada degradando a resolução da imagem através da média das intensidades de blocos de $n \times n$ pixels;

- O processo de extração da rede de estruturas é realizado para cada imagem da pirâmide;

- Um único resultado é obtido fazendo a união dos resultados de cada escala.

Uma etapa de "limpeza" é aplicada ao resultado da união para remover possíveis dados sobrepostos devido a detecção de algumas estruturas em mais de uma escala da pirâmide. Para isso, aplica-se um método heurístico utilizando operadores morfológicos (dilatação seguida de afinamento). 


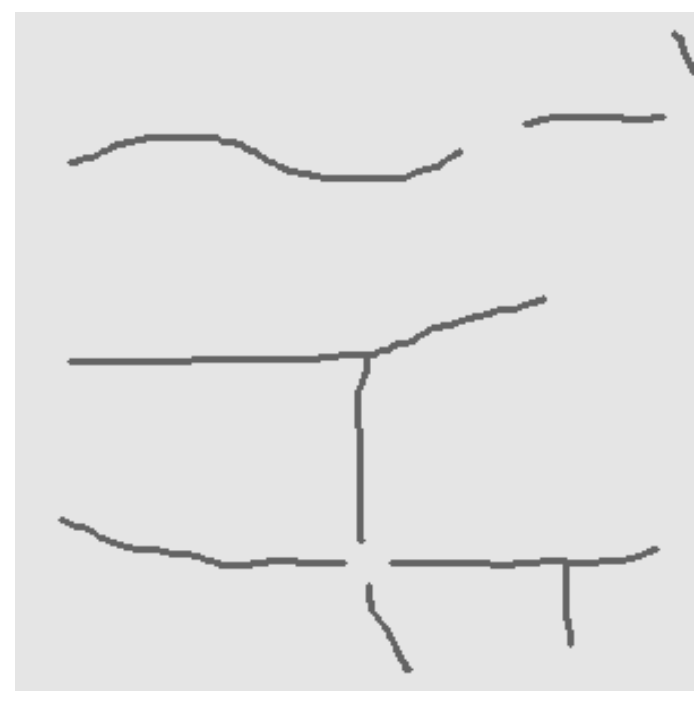

(a)

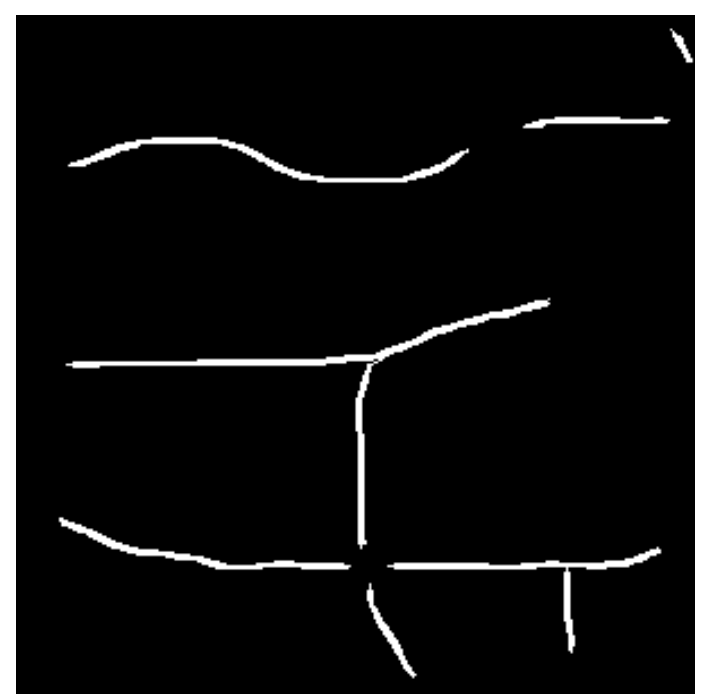

(c)

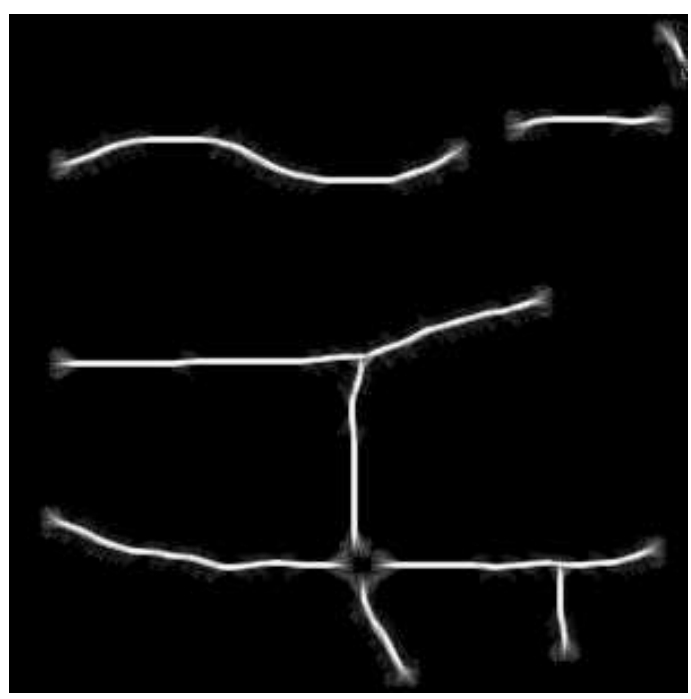

(b)

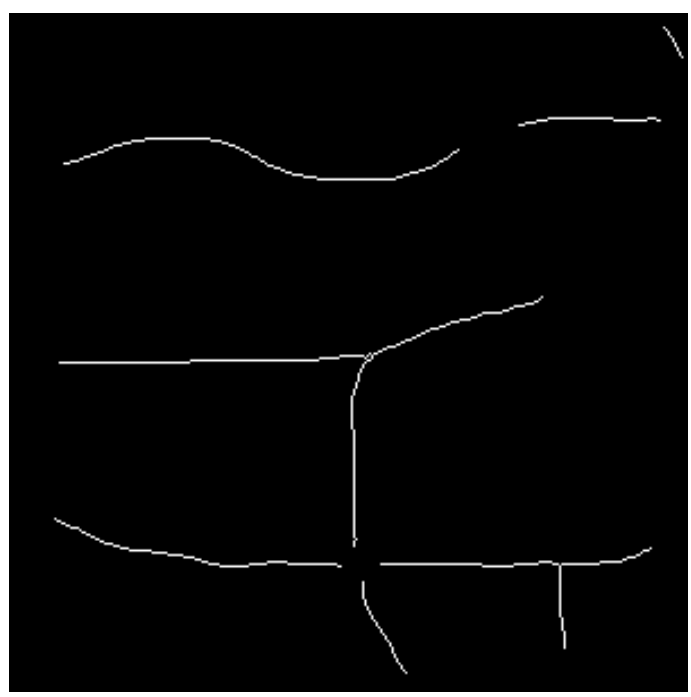

(d)

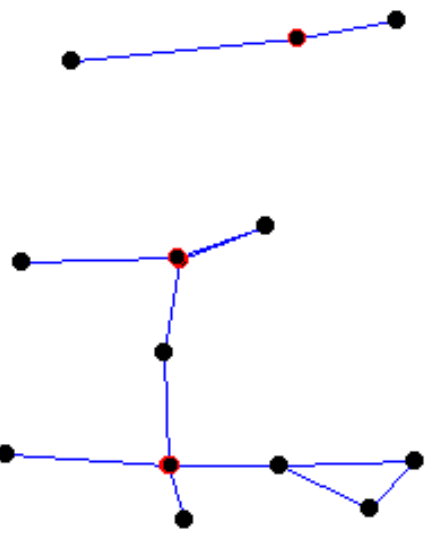

(e)

Figura 9.6: (a) Imagem de teste original (b) Imagem de magnitude resultante da detector de cristas por razão e correlação cruzada (c) Imagem binária da detecção de cristas (d) Imagem resultante do afinamento aplicado à imagem binária da detecção de cristas (e) Grafo de componentes conexas. 


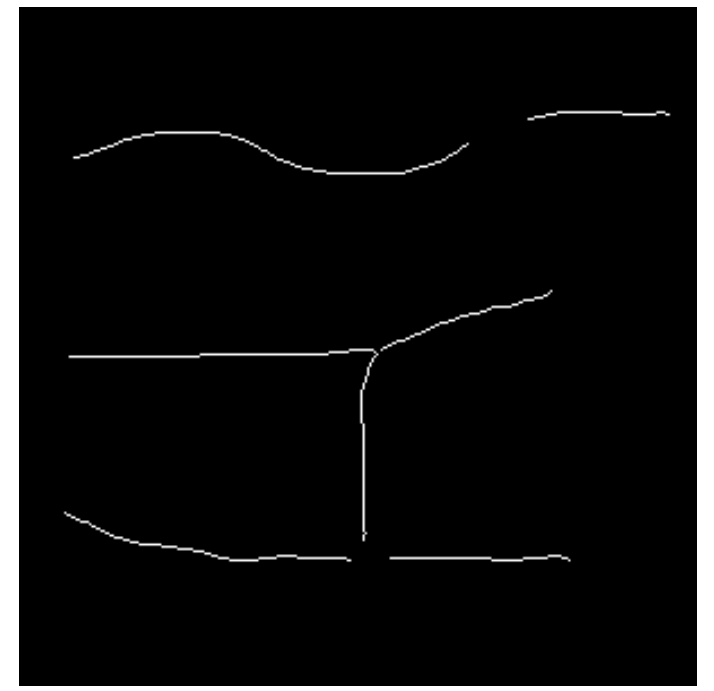

(a)

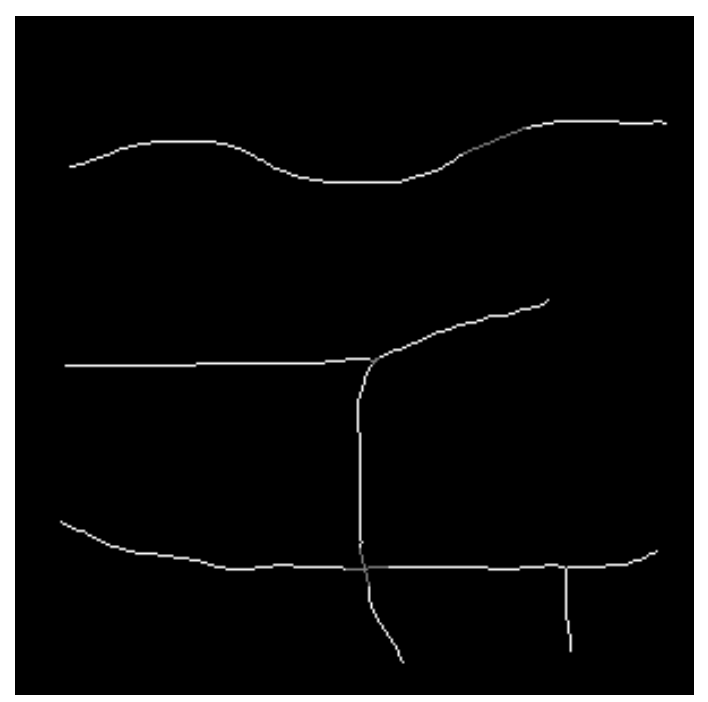

(c)

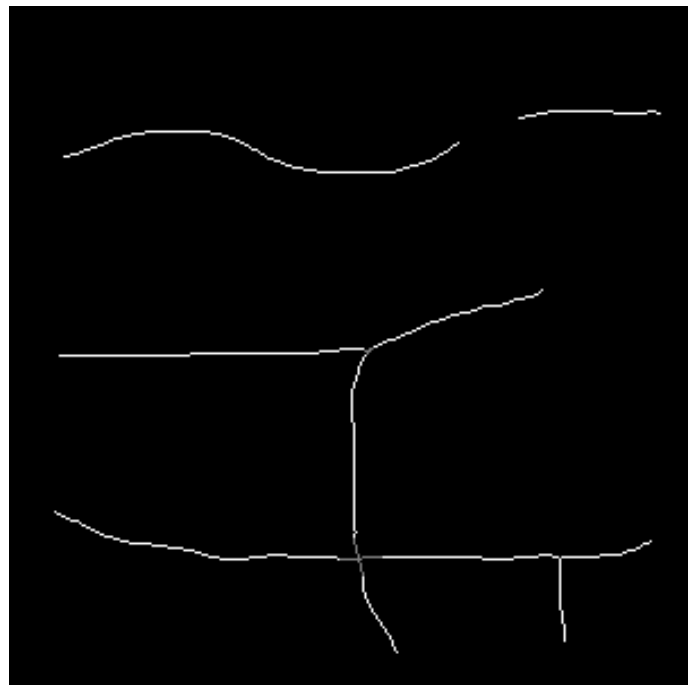

(b)

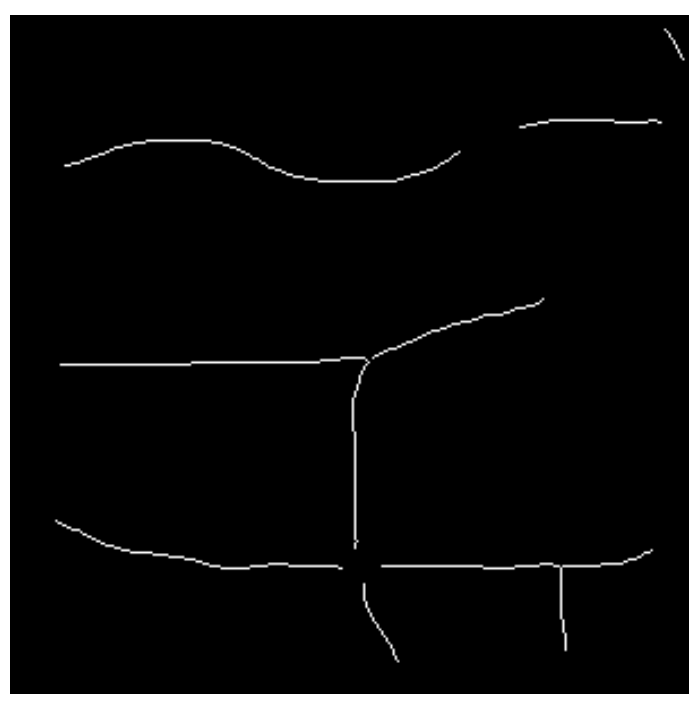

(d)

Figura 9.7: Alguns resultados de extração variando os parâmetros do campo Markoviano: (a) $K_{e}=0,3, K_{\mathcal{L}}=-0,12, K_{c}=0,3, K_{i}=0,3$ (b) $K_{e}=0,3, K_{\mathcal{L}}=-0,12, K_{c}=0,3, K_{i}=0,1$ (c) $K_{e}=0,3, K_{\mathcal{L}}=-0,12, K_{c}=0,1, K_{i}=0,1$ (a) $K_{e}=-0,05, K_{\mathcal{L}}=-0,12, K_{c}=0,1, K_{i}=0,1$ 


\subsubsection{Introduzindo uma segunda etapa de processamento em alto nível}

A rede final extraída após a execução de todos os passos descritos até aqui possui uma característica mais estruturada, por causa da informação contextual incluída no campo de Markov. Porém, este resultado pode ainda carregar uma quantidade razoável de falsas deteç̧ões e algumas partes das estruturas não são detectadas. Na tentativa de melhorar este resultado, propomos um passo adicional. A ideia é usar a saída do processo anterior e usá-la como entrada de uma nova otimização como explicado a seguir (ver Figura 9.8):

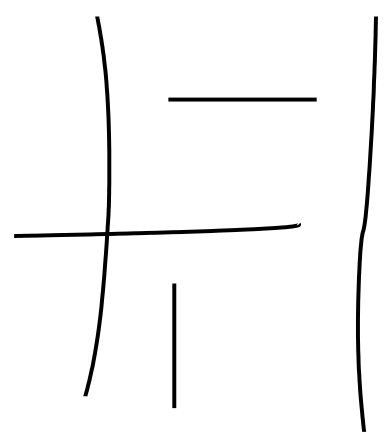

(a)

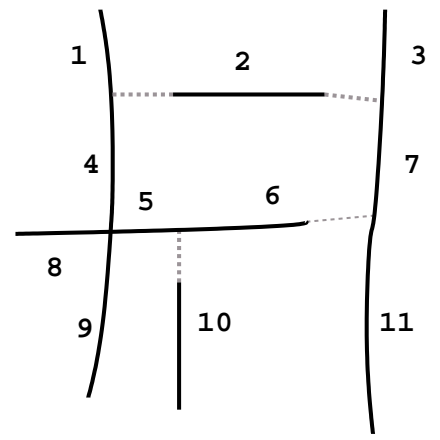

(b)

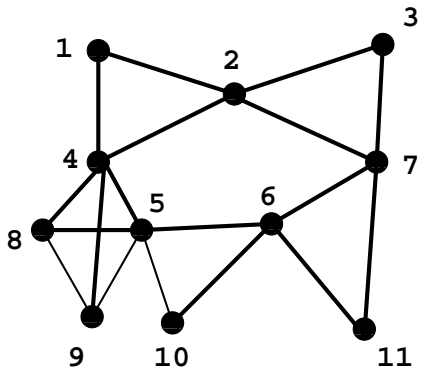

(c)

Figura 9.8: Modelagem do grafo para o passo adicional de alto nivel. (a) Exemplo de saída da primeira etapa de alto nível. (b) Extensão das componentes conexas. (c) Grafo final obtido após extensão.

- Manipular a imagem para obter apenas seções de estruturas e cruzamentos: para cada extremidade de uma componente conexa, estender a mesma até a componente conexa mais próxima ou até os limites da imagem;

- Construir um grafo similar ao apresentado na Seção 9.1 onde cada seção é um nó do grafo e dois nós possuem uma aresta entre si se suas seções correspondentes possuem um cruzamento em comum;

- Seguir com um novo passo de reconstrução como explicado na Seção 9.2. Para o cálculo do termo de verossimilhança da Equação 9.12, a melhor medida considerando todas as escalas da pirâmide multiescala é usada.

Uma consideração deve ser feita sobre o primeiro passo acima: uma componente conexa é estendida somente se a distância da extensão é menor do que um certo valor e se a medida de verossimilhança estivar acima de um determinado limiar. Isto é feito para garantir a boa qualidade da rede de estruturas.

Este passo adicional é muito mais simples e computacionalmente rápido do que o anterior, visto que o grafo construído é bem menor. Assim, o tempo total do processo não aumenta de forma considerável e a melhoria apresentada através das aplicações testadas justifica o uso desta etapa adicional.

No próximo capítulo uma visão geral do arcabouço do método proposto é apresentada juntamente com o software desenvolvido baseado no mesmo. 
Metodologia

\section{Visão global do método proposto}

"Eu caminho devagar, mas nunca caminho para trás."

Abraham Lincoln

\subsection{Arcabouço para detecção de estruturas finas e ramificadas}

Nos capítulos precedentes todas as etapas do arcabouço proposto foram apresentadas em detalhes. Nesta seção apresentamos um breve resumo de todo o processo descrito. A Figura 10.1 mostra o diagrama de blocos contendo todos os módulos que constituem o método proposto. Seguindo o diagrama, identifica-se dois blocos principais (retângulos com linhas tracejadas):

- O primeiro bloco trata-se de uma abordagem multiescala contendo três passos principais:

1. Passo de baixo nível: a partir da imagem de entrada (ou mais de uma imagem de diferentes fontes), um processo de detecção de linhas é executado com o objetivo de encontrar candidatos de estruturas, os quais são rotulados em componentes conexas;

2. Construção do grafo: usando as componentes conexas encontradas no passo anterior, um grafo relacional com atributos é gerado;

3. Rotulação do grafo: um campo aleatório de Markov é definido no grafo gerado no passo anterior e um processo de minimização é executado para encontrar uma rotulação binária ótima para o grafo. Nesta etapa, dados provenientes de diferentes sensores podem ser usados.

- Os resultados de cada escala são unidos para gerar a entrada do próximo bloco:

1. Nível de seções de estruturas: a imagem de entrada é processada obtendo-se apenas seções de estradas e cruzamentos; 
2. Segunda etapa de alto nível: um novo grafo é construído e uma segunda minimização é executada, resultando na extração final da rede de estruturas.

Vale observar que a abordagem de fusão proposta é feita da etapa de baixo nível, onde a detecção de linhas/cristas é aplicada a todas as imagens de entrada. Os dados provenientes de diferentes fontes também são usados nas duas etapas de alto nível.

\subsection{Software para deteç̧ão de estruturas finas}

Todas as etapas descritas anteriormente foram implementadas computacionalmente resultando em um framework completo e funcional. Apesar disso, o programa descrito nesta seção continua em desenvolvimento, sendo necessário a adição de algumas funcionalidades restantes. O objetivo final é disponibilizar o software de forma livre na Web. A seguir, são apresentadas as principais funcionalidades deste programa. As ferramentas usadas para sua implementação foram: a linguagem de programação C++, o OpenCV [Bornet, 2008] e o Qt [Corporation, 2008] para a construção da interface gráfica.

Leitura de imagens A leitura das imagens a serem processadas é realizada diretamente através de uma interface gráfica. A restrição para essa funcionalidade é que as imagens devem estar armazenadas em formato binário para serem lidas. No caso do uso de mais de uma imagem de entrada, necessita-se apenas da leitura da primeira imagem do conjunto, que deve estar organizada no padrão prefixo_numero, por exemplo, para um conjunto de $n$ imagens (que devem estar no mesmo diretório do computador) com o prefixo "radar":

radar_1, radar_2, ..., radar_n .

Após a leitura da imagem a mesma pode ser visualizada na tela principal do programa como ilustrado na Figura 10.2.

Detecção de linhas/cristas Na tela principal do programa o usuário pode escolher o algoritmo a ser utilizado para a detecção de cristas juntamente com os parâmetros relacionados. O resultado desta etapa também pode ser visualizado na tela principal do programa como ilustrado na Figura 10.3.

Construção do grafo De forma similar às funcionalidades anteriores, na tela principal o usuário escolhe os parâmetros para a construção do grafo de primitivas e o resultado é apresentado na mesma tela, como ilustrado na Figura 10.4.

Otimização Após a construção do grafo, o usuário pode manipular as opções para a fase de otimização. A execução do Simulated Annealing pode ser realizada através do amostrador de Gibbs ou dos algoritmos Metropolis e ICM. O resultado da rede de estruturas resultante da rotulação final do grafo é apresentado na tela do programa, juntamente com as energias calculadas da configuração global final, como ilustrado na Figura 10.5. 


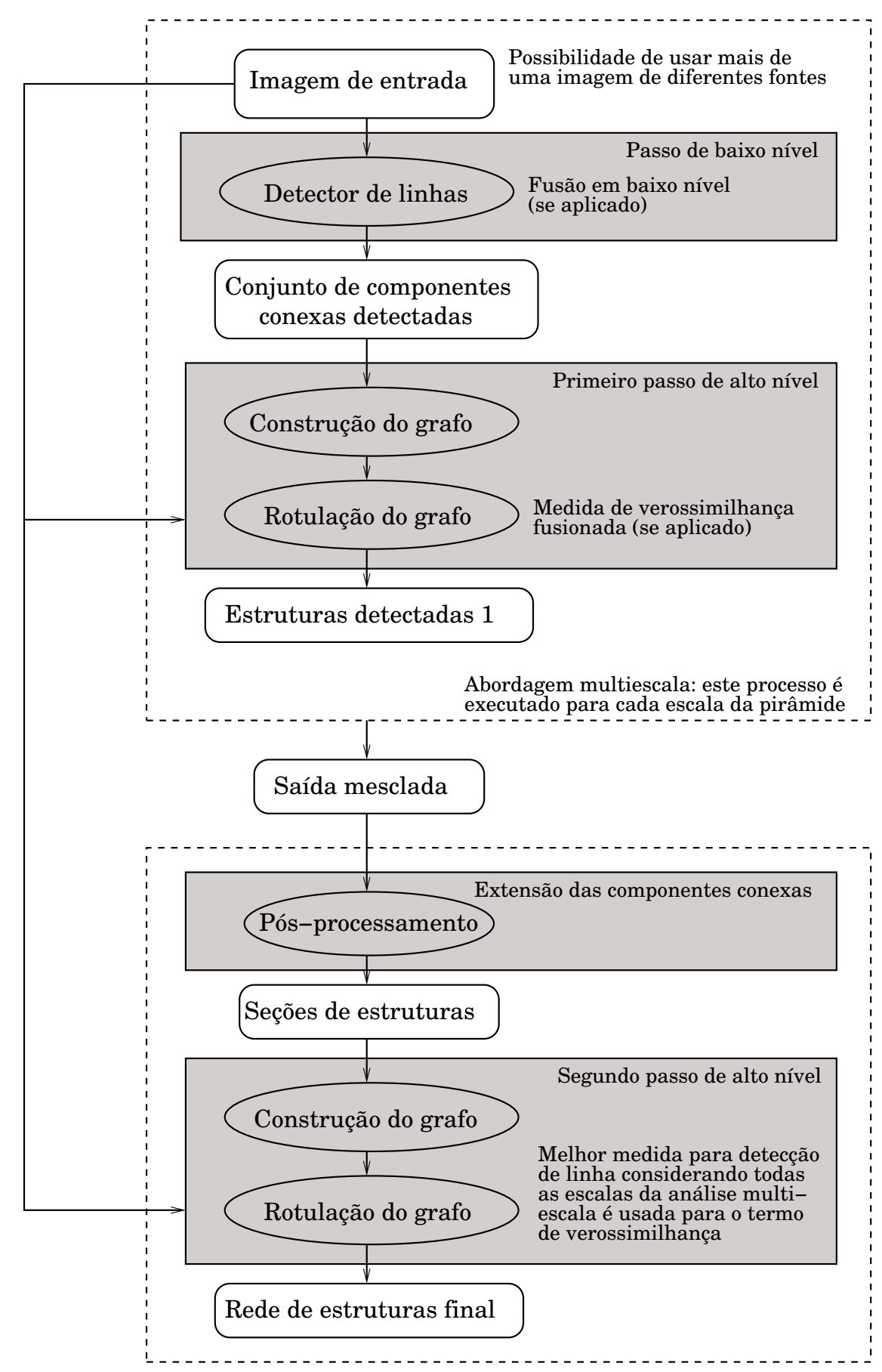

Figura 10.1: Diagrama de blocos representando todos os passos do arcabouço proposto. 


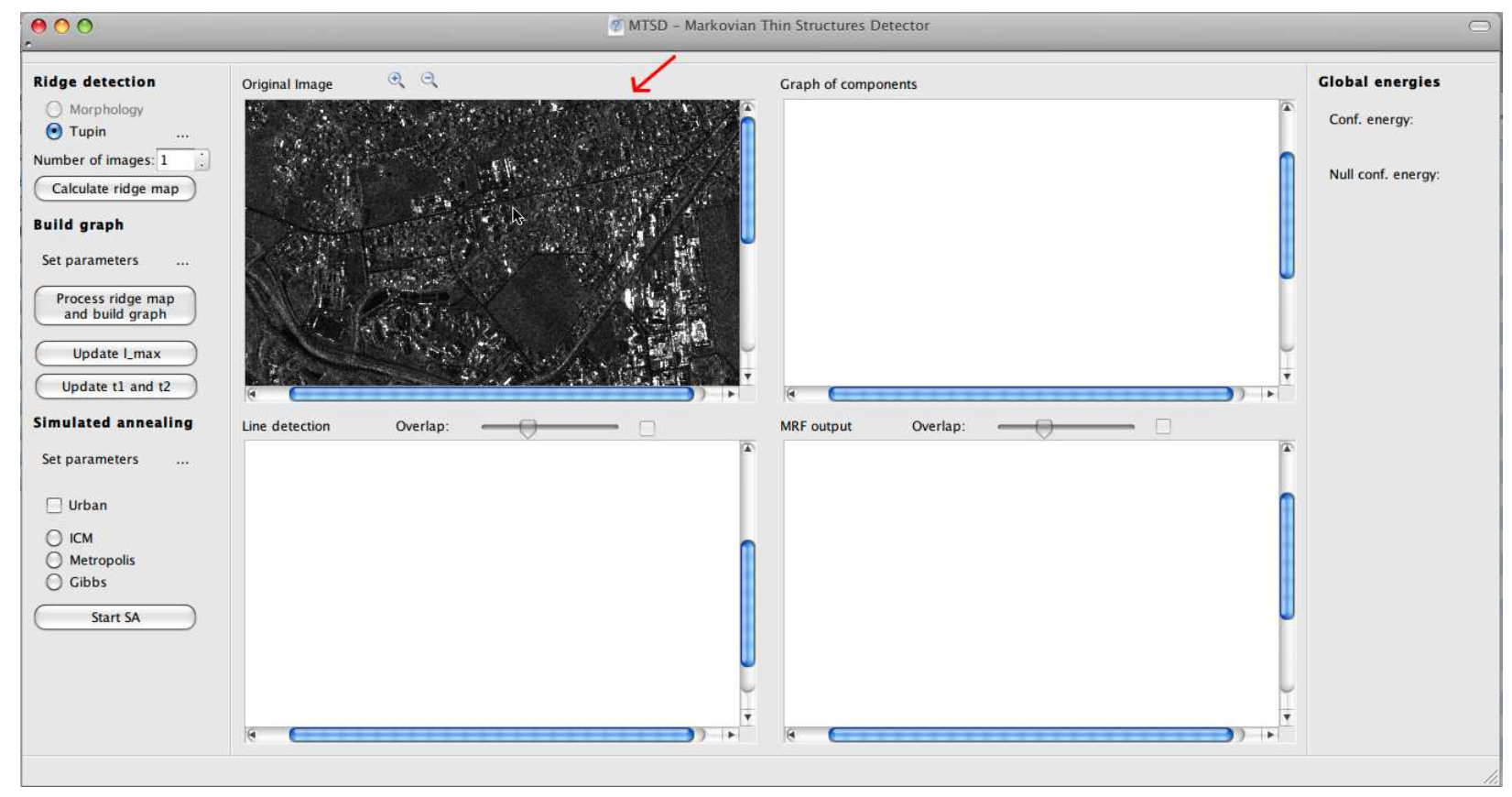

Figura 10.2: Tela principal do programa implementado - leitura de imagens. 


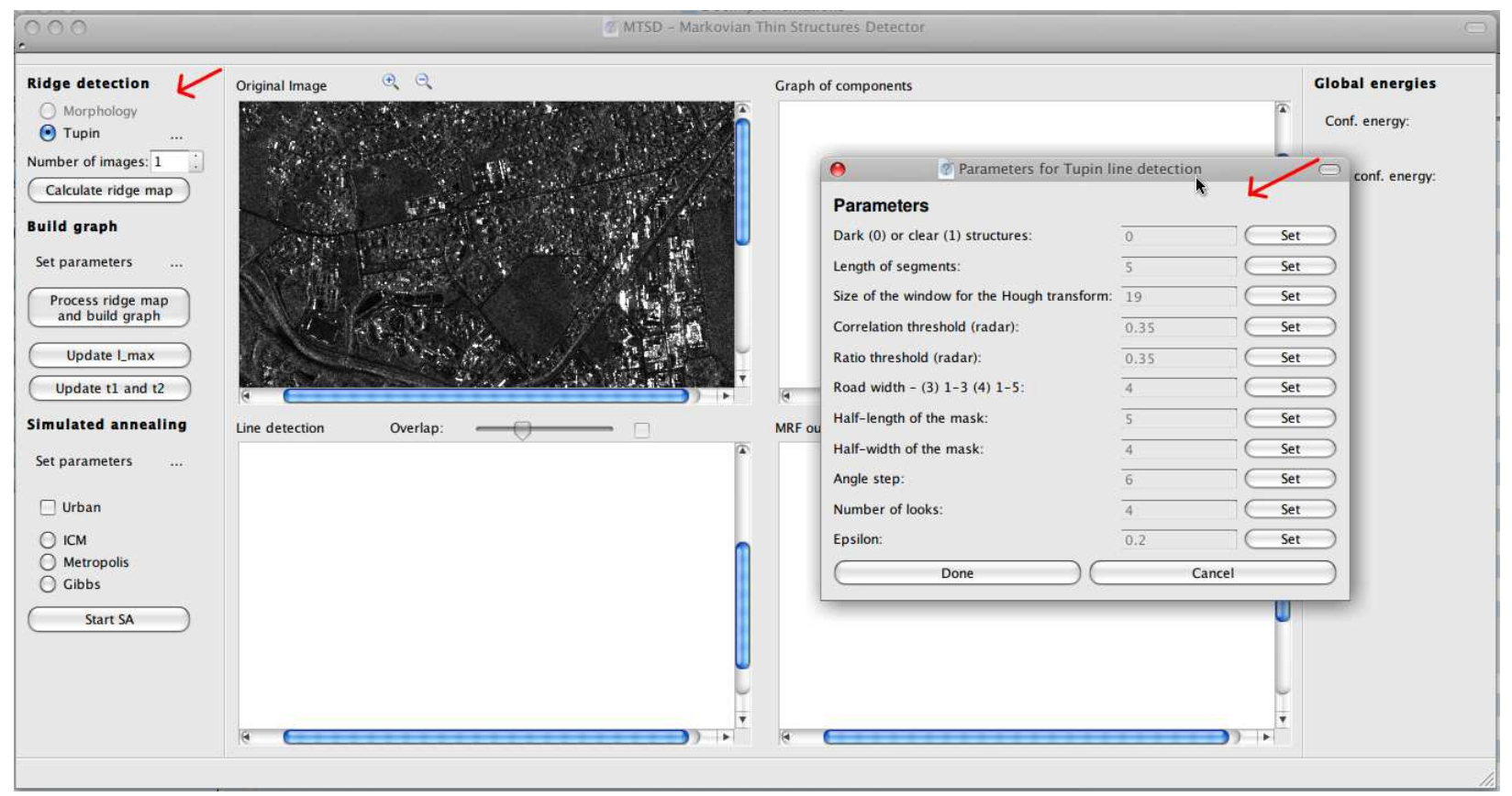

(a) Escolha do algoritmo de detecção e seus parâmetros.

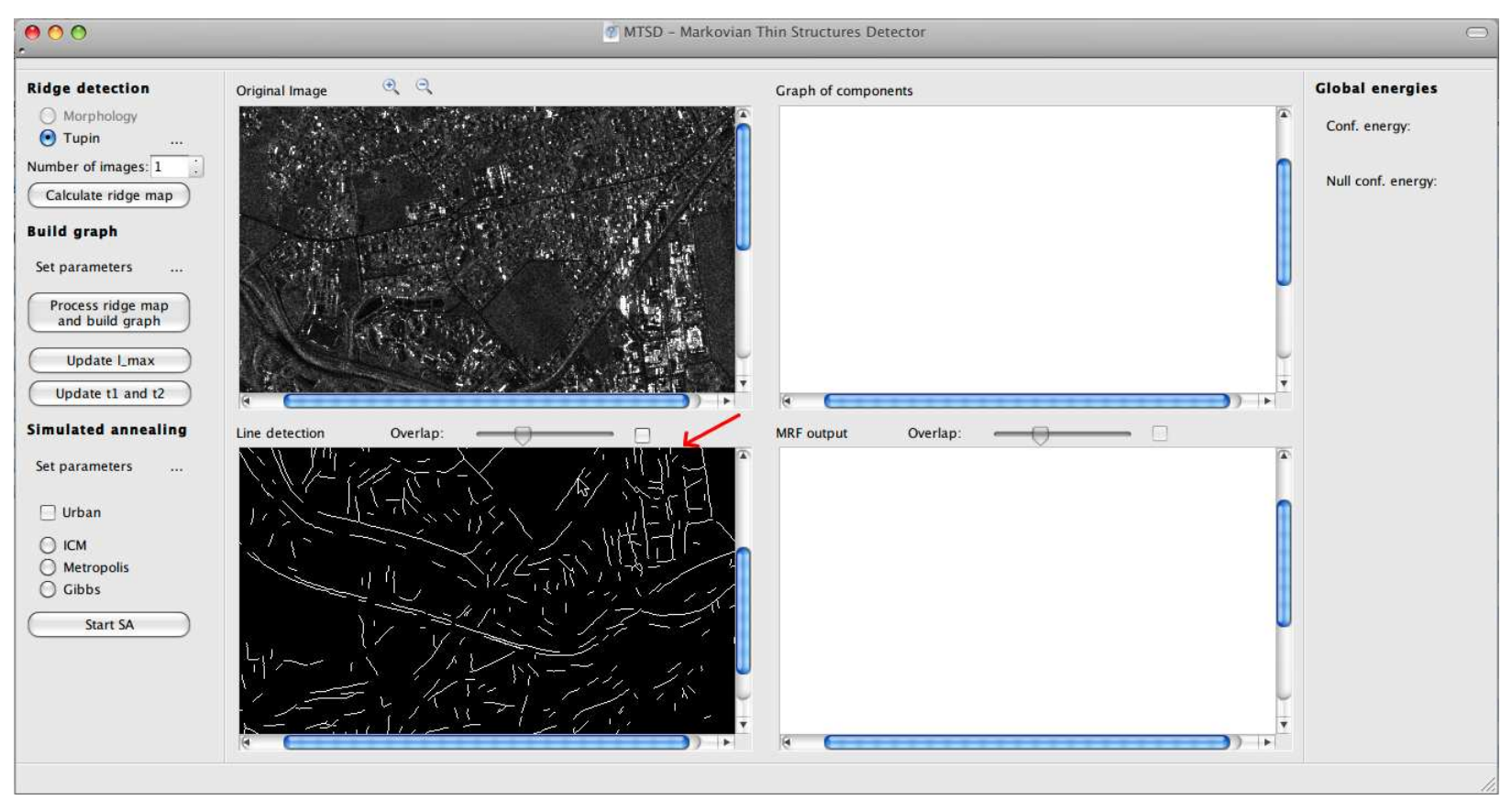

(b) Visualização do resultado da detecção.

Figura 10.3: Tela principal do programa implementado - detecção de cristas. 


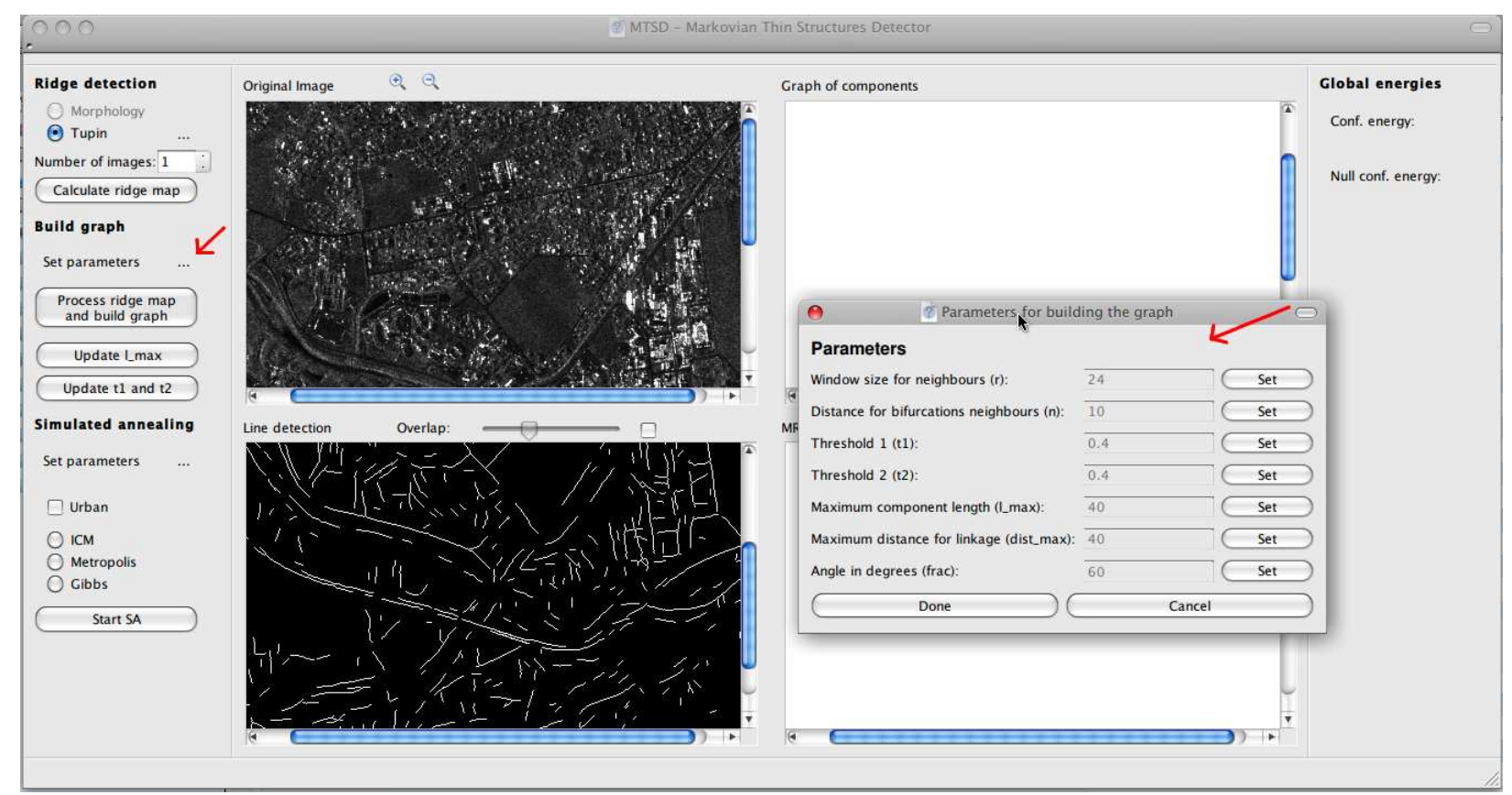

(a) Seleção de parâmetros para a construção do grafo.

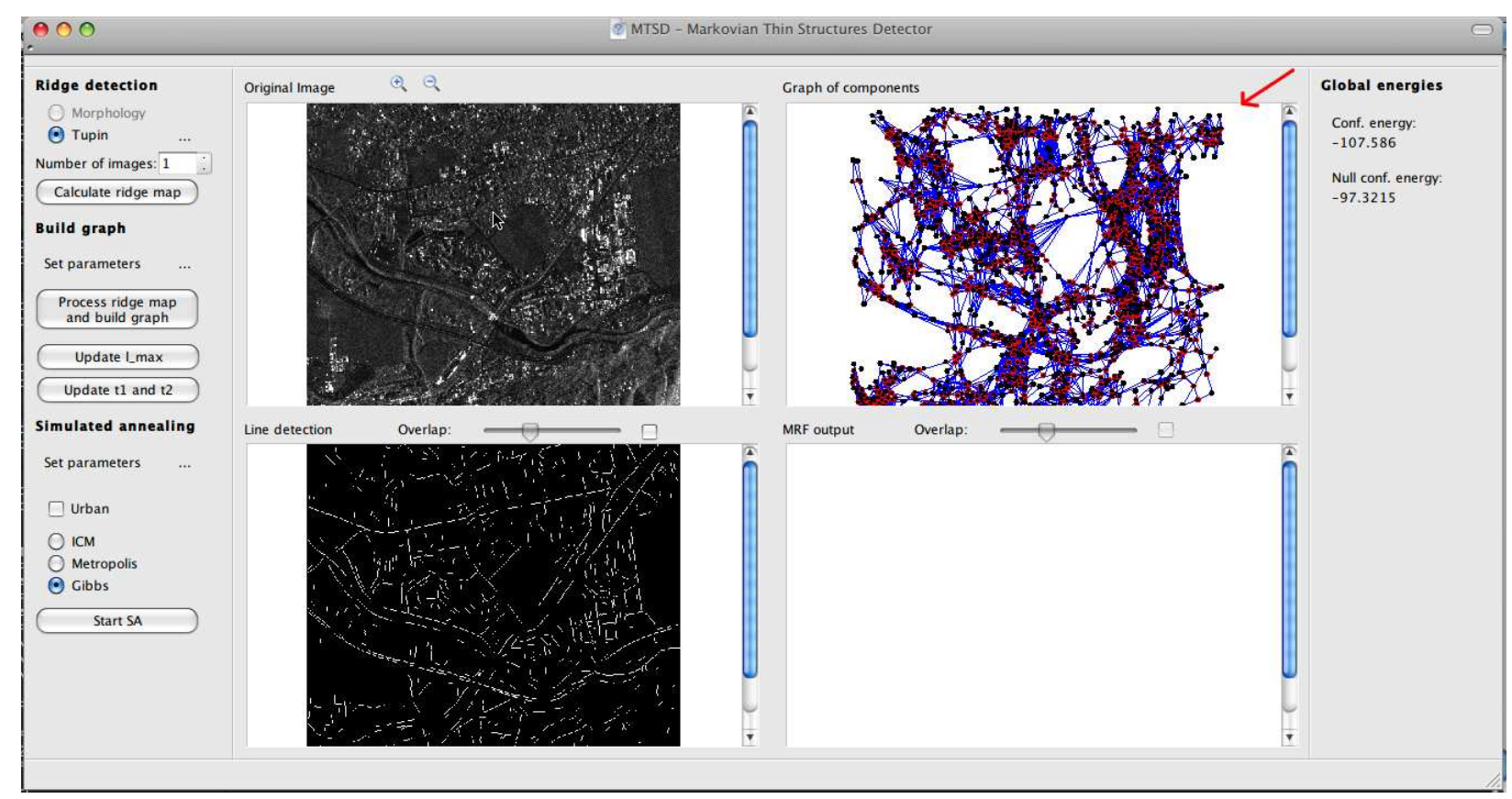

(b) Visualização do grafo gerado.

Figura 10.4: Tela principal do programa implementado - construção do grafo. 


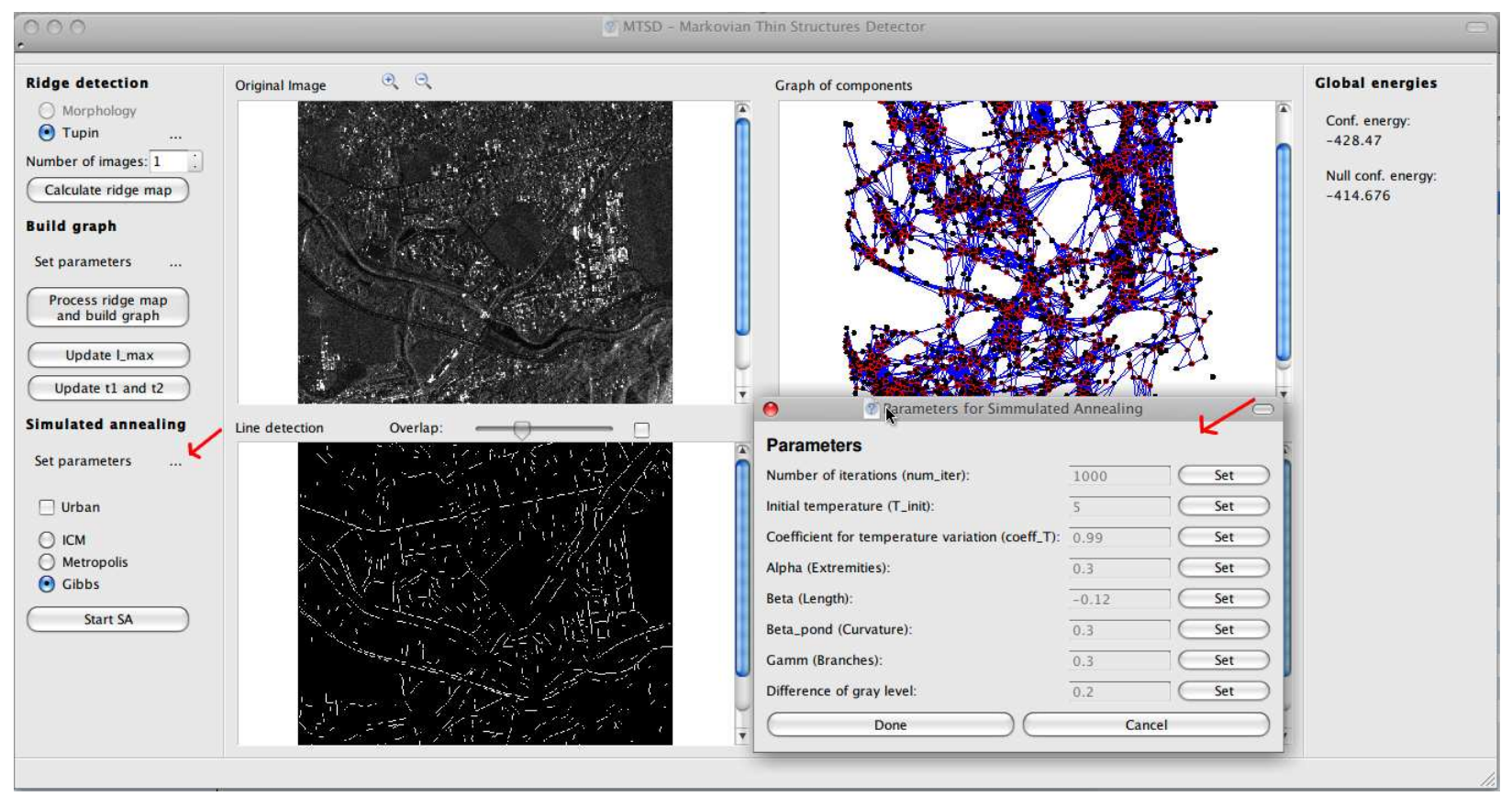

(a) Seleção de parâmetros para a otimização.

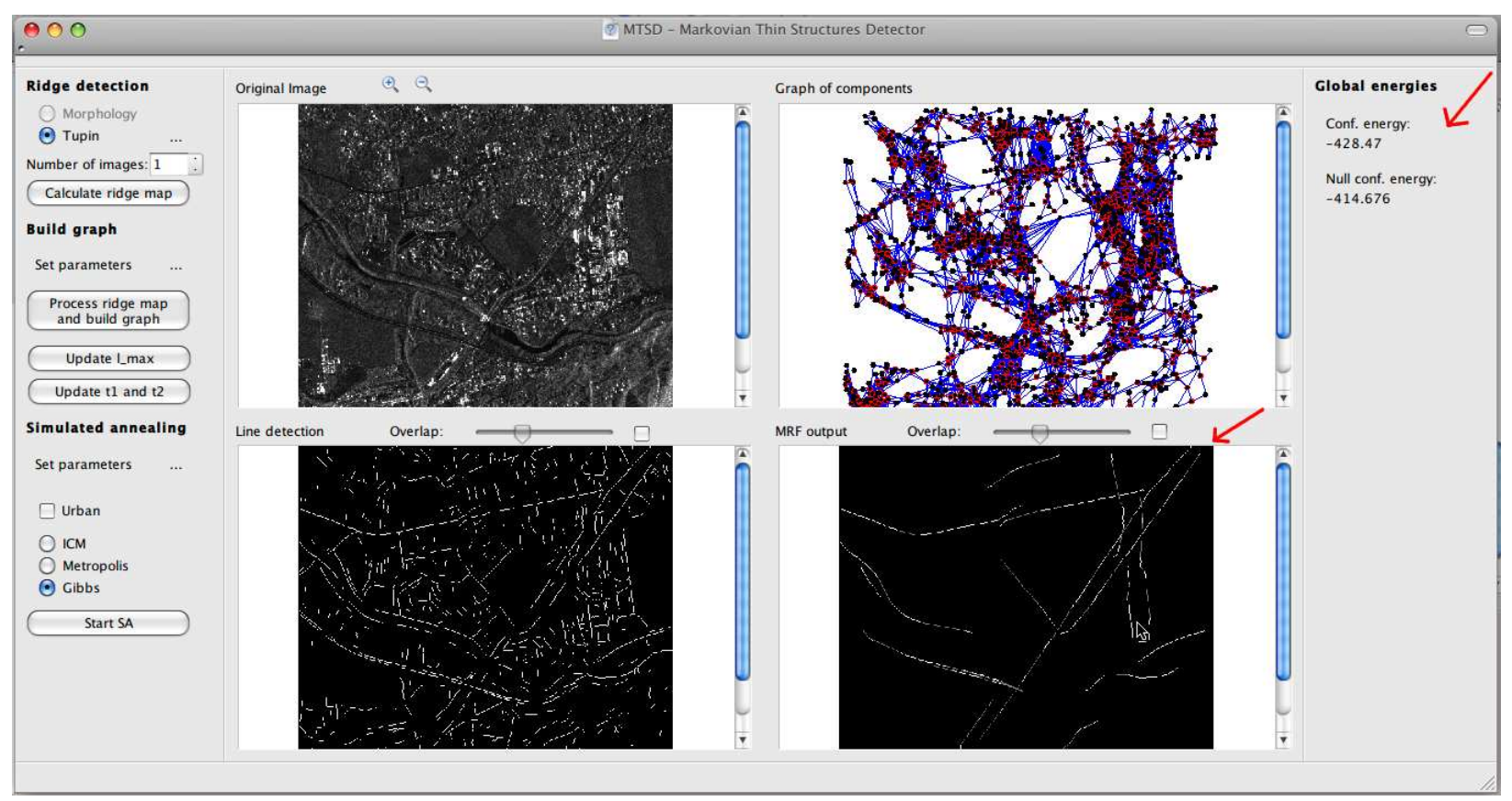

(b) Visualização da rede final de estruturas.

Figura 10.5: Tela principal do programa implementado - busca pela rotulação ótima do grafo por otimização. 


\section{Parte III}

\section{Aplicações}

Esta parte é dedicada aos experimentos realizados utilizando o método proposto. Duas aplicações são exploradas: extração de estradas em imagens de satélite e extração de raízes em imagens de perfis de solo. 



\section{Redes de estradas em imagens de satélite}

"O exemplo convence-nos mais do que as palavras."

Séneca

\subsection{Sensoriamento remoto}

Sensoriamento Remoto é o processo de medição das propriedades de um objeto na superfície da Terra utilizando dados adquiridos de aeronaves e satélites. A ideia é medir algo à distância, ao invés de medir através de contato físico direto e, assim, exibir essas medidas sobre uma grade espacial bidimensional, ou seja, imagens. Sistemas de sensoriamento remoto, especialmente aqueles implantados em satélites, fornecem uma visão repetitiva e consistente da Terra facilitando o monitoramento do sistema terrestre e das atividades humanas na Terra. A fotografia aérea dentro do intervalo visível do espectro eletromagnético foi a primeira forma de sensoriamento remoto. Porém, o desenvolvimento tecnológico permitiu a aquisição de informação em outros intervalos do espectro eletromagnético incluindo infravermelho, infravermelho termal e micro-ondas. O desenvolvimento de satélites tripulados e não-tripulados tem aprimorado a aquisição de dados de sensoriamento remoto e oferece uma maneira viável de obter informações sobre grandes áreas. A capacidade da técnica de sensoriamento remoto de identificar e monitorar superfícies terrestres e condições ambientais tem aumentado bastante nos último anos, e este tipo de dados é uma ferramenta essencial para o gerenciamento de recursos naturais.

\subsubsection{Espectro eletromagnético}

O espectro eletromagnético é um intervalo contínuo de radiação eletromagnética que se estende desde os raios gamma (mais alta frequência e mais baixo comprimento de onda) até as ondas de rádio (mais baixa frequência e mais alta comprimento de onda), além de incluir a luz visível. O espectro eletromagnético pode ser dividido em sete diferentes regiões: raios gamma, raios-X, ultravioleta, luz visível, infravermelho, micro-ondas e ondas de rádio. 
O sensoriamento remoto envolve a medição de energia em diversas partes do espectro eletromagnético. As regiões de maior interesse em satélite são a luz visível, ondas de infravermelho emitidas e refletidas e as regiões de micro-ondas. A medição desta radiação ocorre através das chamadas bandas de espectro. Uma banda espectral é definida como um intervalo discreto do espectro eletromagnético. Por exemplo, o intervalo de comprimento de onda de $0,4-0,5 \mu m$ é uma banda espectral. Sensores de satélite tem sido projetados para medir respostas dentro de bandas de espectro específicas para permitir a discriminação dos materiais presentes na superfície terrestre. Os cientistas escolhem bandas específicas do espectro para aquisição dependendo do que se deseja estudar. O desenvolvimento de sensores de satélite é baseado nas características de absorção dos materiais da superfície terrestre ao longo de todos os intervalos mensuráveis do espectro eletromagnético.

Quando a radiação proveniente do Sol atinge a superfície terrestre, parte da energia em comprimentos de onda específicos é absorvida e o restante da energia é refletida pelo material da superfície. As duas únicas exceções a esta situação são (de ocorrência muito rara): se a superfície de um objeto é um refletor perfeito ou um objeto perfeitamente/verdadeiramente preto. Na região visível do espectro eletromagnético, a característica de descrevemos como cor do objeto é a luz visível não absorvida por aquele objeto. No caso de uma folha verde por exemplo, os comprimentos de onda para o azul e o vermelho são absorvidos pela folha enquanto que o comprimento de onda para o verde é refletido e detectado por nossos olhos.

Em sensoriamento remoto, um detector mede a radiação eletromagnética que é refletida dos materiais da superfície. Estas medidas podem ajudar a diferenciar o tipo da cobertura de solo. Solo, água e vegetação possuem padrões de reflectância e absorção claramente diferentes sob diferentes comprimentos de onda.

A reflectância da radiação a partir de um tipo de material, como o solo, varia ao longo do intervalo de comprimentos de onda no espectro eletromagnético. Isto é conhecido como assinatura espectral do material. A vegetação, o solo, a água, a neve e outras coberturas e objetos presentes na superfície terrestre possuem assinaturas únicas.

\subsubsection{Sensores}

Um sensor é um dispositivo que mede e registra energia eletromagnética. Os sensores podem ser divididos em dois grupos. Os sensores passivos dependem de uma fonte externa de energia, geralmente o sol. O sensor passivo mais comum é a câmera fotográfica (sem flash). Já os sensores ativos possuem sua própria fonte de energia, como por exemplo um radar. Este tipo de sensor envia um sinal e mede a quantidade refletida. Sensores ativos são mais controlados pois eles não dependem das condições de iluminação.

A função básica da maioria dos sensores de satélite é coletar informações sobre a radiação refletida ao longo de um caminho (campo de visão) enquanto o satélite orbita a Terra. A menor área amostrada do solo é chamada de campo de visão instantâneo, também descrito como o tamanho do pixel do sensor. Esta amostragem ou medida ocorre em uma ou várias bandas do espectro eletromagnético. 
Os dados adquiridos por cada sensor de satélite são descritos em termos das resoluções espacial, espectral e temporal. A resolução espacial corresponde à área do solo imageada para o campo de visão instantâneo do sensor. A resolução espacial pode também ser descrita como a área da superfície que forma um pixel na imagem de satélite. A resolução temporal é uma medida do ciclo de repetição ou frequência com que o sensor repete a aquisição da mesma região. A frequência pode variar de diversas vezes por dia, para um típico satélite climático, até 8 - 20 vezes por ano para um satélite com resolução espacial moderada, como o Landsat TM. As características de frequência são determinadas pelo modelo do sensor do satélite e seu padrão orbital. A resolução espectral de um sensor é o número e o comprimento das bandas espectrais no dispositivo. A forma mais simples de resolução espectral é um sensor com apenas uma banda, que capta a luz visível. Uma imagem proveniente deste sensor seria similar a uma foto preta e branca. Um sensor com três bandas espectrais na região visível do espectro eletromagnético iria adquirir informação similar àquela do sistema visual humano.

Uma imagem pancromática consiste de apenas uma banda. Normalmente este tipo de imagem apresenta-se em níveis de cinza, onde o brilho de um pixel é proporcional ao número digital do pixel, o qual está relacionado à intensidade da radiação solar refletida e detectada pelo sensor.

Imagens multiespectrais e hiperespectrais consistem em várias bandas de dados. Para objetivo de visualização, cada banda por ser vista como uma imagem em níveis de cinza, ou uma combinação de três bandas por vez como uma imagem colorida. A interpretação deste tipo de imagem requer conhecimento das assinaturas espectrais dos alvos na cena.

\section{Sensor Quickbird [DigitalGlobe, 2001]}

O Quickbird é um satélite de observação terrestre comercial de alta resolução de propriedade da DigitalGlobe lançado em 2001. Foi o primeiro satélite com resolução submétrica do mundo. O sistema de imageamento utilizado pelo Quickbird é o BGIS 2000 (Ball Aerospace's Global Imaging System 2000), que faz a aquisição de imagens que estão entre as de maior resolução em termos comerciais. Este satélite também é destaque em termos de tamanho das imagens e capacidade de armazenamento interno. Este satélite adquire imagens pancromáticas com $60-70 \mathrm{~cm}$ de resolução e imagens multiespectrais com 2, $4 \mathrm{~m}$ e $2,8 \mathrm{~m}$ de resolução.

\section{Sensor TerraSAR-X [DLR, 2004]}

O TerraSAR-X é um satélite de observação terrestre alemão, lançado em 2007. Um segundo satélite (sister satellite) chamado TanDEM-X foi lançado em 2010. Estes dois satélites atuam em paralelo. Este satélite usa uma antena de radar de abertura sintética (SAR) em banda $\mathrm{X}$, ou seja, com comprimento de onda de $31 \mathrm{~mm}$ e frequência de 9,6 GHz. O TerraSAR$\mathrm{X}$ foi projetado para trabalhar independentemente das condições climáticas e de iluminação e fornece, de forma confiável, imagens de radar com resolução de até $1 \mathrm{~m}$.

Algumas das principais característica deste satélite são as excelentes precisões radiométrica e geométrica, e a agilidade de alternar entre os modos de imageamento e polarizações. Os 
três modos de imageamento do TerraSAR-X são o SpotLight, o StripMap e o ScanSAR. No primeiro tipo as imagens possuem resolução de até $1 \mathrm{~m}$ de resolução e o tamanho da cena é de $10 \mathrm{~km} \times 5 \mathrm{~km}$. Já as imagens StripMap possuem resolução de até $3 \mathrm{~m}$ com cena de tamanho $30 \mathrm{~km} \times 50 \mathrm{~km}$. Finalmente, as imagens do último tipo possuem resolução de até $18 \mathrm{~m}$ com cena de tamanho $100 \mathrm{~km} \times 150 \mathrm{~km}$.

\section{Sensor COSMO-SkyMed [Rum, 2003]}

O COSMO-SkyMed (COnstellation of small Satellites for the Mediterranean basin Observation) é um sistema de satélites de observação terrestre. Financiado pelo Ministério Italiano de Pesquisa e pelo Ministério da Defesa, e gerenciado pela Agência Espacial Italiana, o COSMO-SkyMed possui objetivos de uso militar e civil. O sistema é composto por quatro satélites equipados com sensores SAR com cobertura completa da Terra. Os sensores foram lançados em 2007 (COSMO-1 e COSMO-2), 2008 (COSMO-3) e 2010 (COSMO-4). A aquisição de imagens de uma única região é repetida várias vezes em um único dia, independentemente de condições climáticas. Desta forma, torna-se um satélite ideal para aplicações como monitoramento de gelo, inundações e poluição. De forma similar ao TerraSAR-X, este satélite trabalha nos modos SpotLight (1 m de resolução), StripMap (3m de resolução), PingPong (15 m de resolução) e ScanSAR (30 - $100 \mathrm{~m}$ de resolução)

\subsection{Resultados}

Esta seção apresenta alguns dos resultados usando o arcabouço proposto. Primeiramente, os resultados obtidos nas imagens de radar e imagens ópticas separadamente são apresentados na Seção 11.2.1. A Seção 11.2.2 apresenta os resultados usando a abordagem de fusão de baixo nível proposta (veja Seção 8.8) considerando dados ópticos e de radar, e ainda dados de imagens multitemporais.

\subsubsection{Imagens provenientes de um mesmo sensor}

\section{Imagens ópticas}

Para os experimentos usando dados ópticos, imagens pancromáticas com resolução espacial de $0.7 \mathrm{~m}$ obtidas do sensor Quickbird são usadas. As duas regiões escolhidas correspondem a uma área da cidade de Toulouse - França e são mostradas nas Figuras 11.1(a) e 11.2(a) juntamente com seus ground-truths nas Figuras 11.1(b) e 11.2(b). Os ground-truths foram obtidos manualmente usando o mapa de estradas de cada região como referência. Os resultados aplicando o arcabouço proposto para detecção de estradas sem fusão para cada região são apresentados nas Figuras 11.1(c) e 11.2(c). As estradas detectadas corretamente estão marcadas em verde, as marcadas incorretamente estão marcadas em vermelho e as estradas ausentes estão marcadas em preto. Os parâmetros utilizados nestes experimentos são apresentados na Tabela 11.1. 


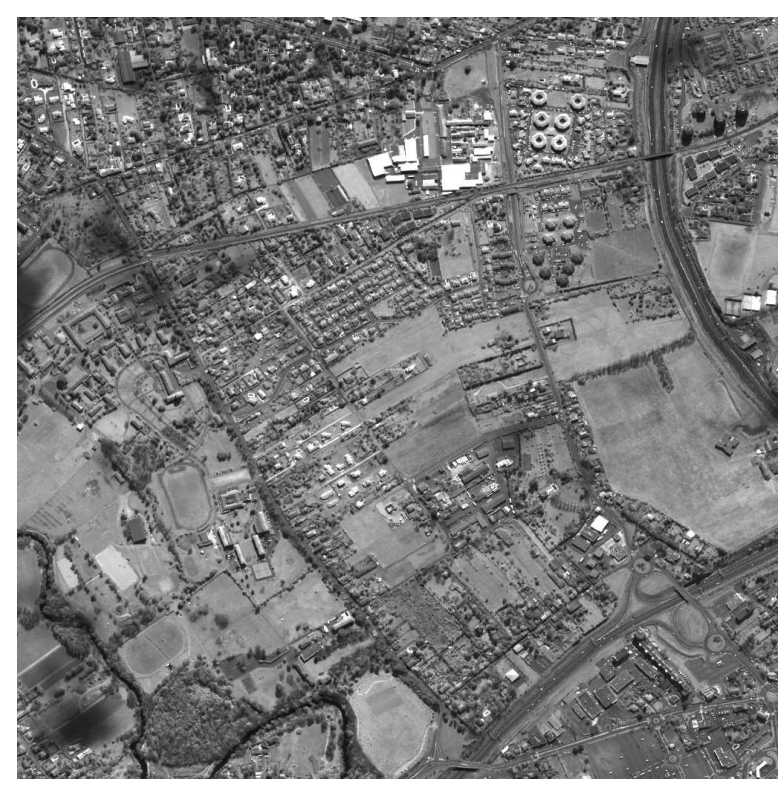

(a)

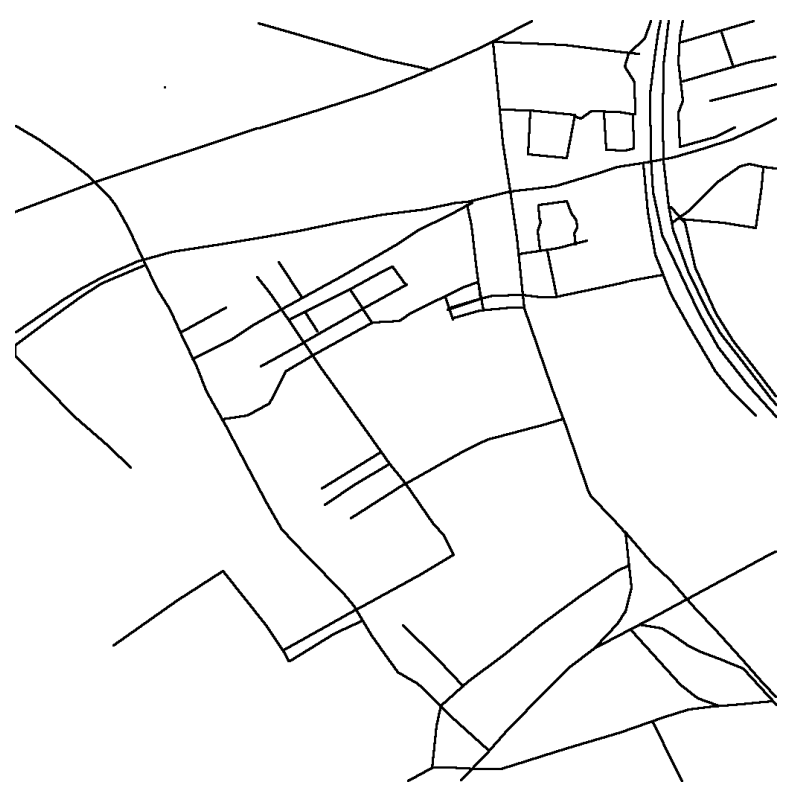

(b)

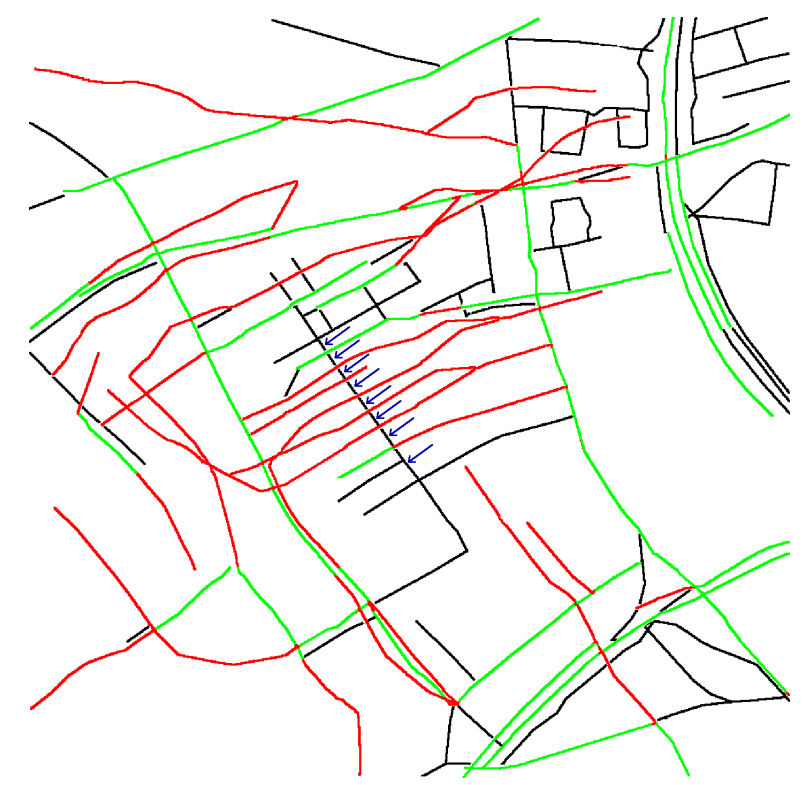

(c)

Figura 11.1: Resultados para imagens ópticas: (a) Imagem original (b) Ground-truth (c) Resultado da detecção onde as estradas detectadas corretamente estão marcadas em verde, as detectadas incorretamente estão marcadas em vermelho e as estradas ausentes estão marcadas em preto. As setas em azul destacam uma estrada importante que não foi detectada.

\section{Imagens de radar}

Para os experimentos usando dados de radar, imagens com $1 \mathrm{~m}$ de resolução obtidas através do sensor TerraSAR-X são usadas. As mesmas regiões usadas para os dados ópticos são usadas neste caso. Estas regiões e seus respectivos ground-truths são apresentados nas Figuras 11.3(a), 11.4(a), 11.3(b) e 11.4(b). Os resultados aplicando o arcabouço proposto sem a abordagem de fusão para cada região são mostrados nas Figuras 11.3(c) e 11.4(c). Da mesma maneira que anteriormente, as estradas corretamente detectadas estão marcadas em verde, as detectadas incorretamente estão marcadas em vermelho e as não detectadas em 


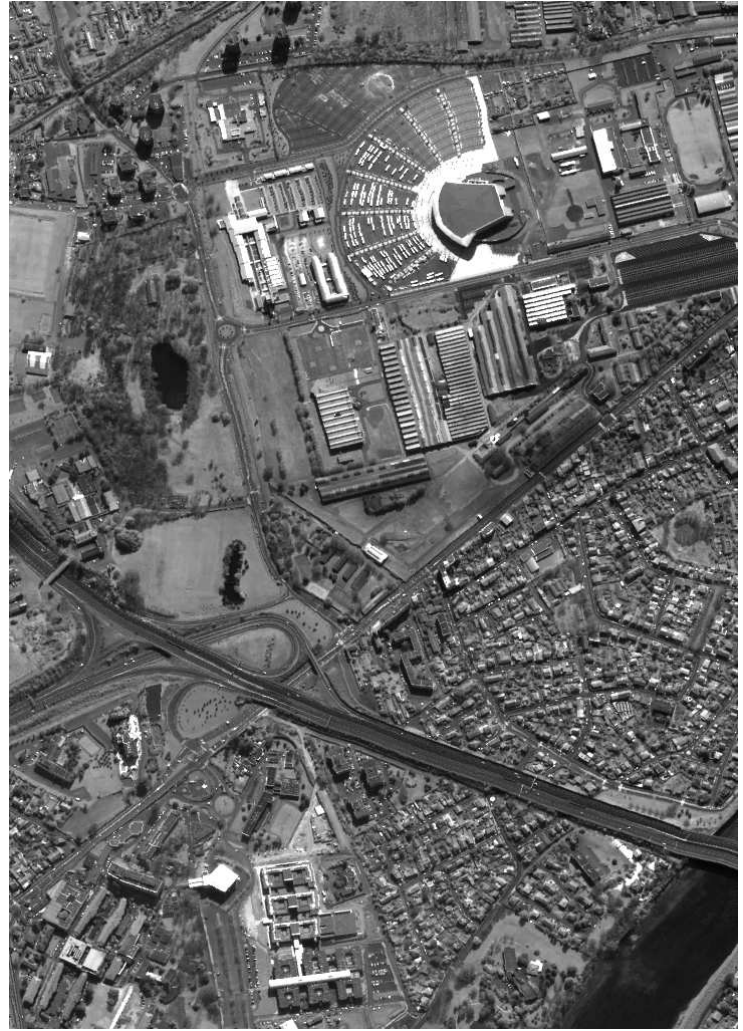

(a)

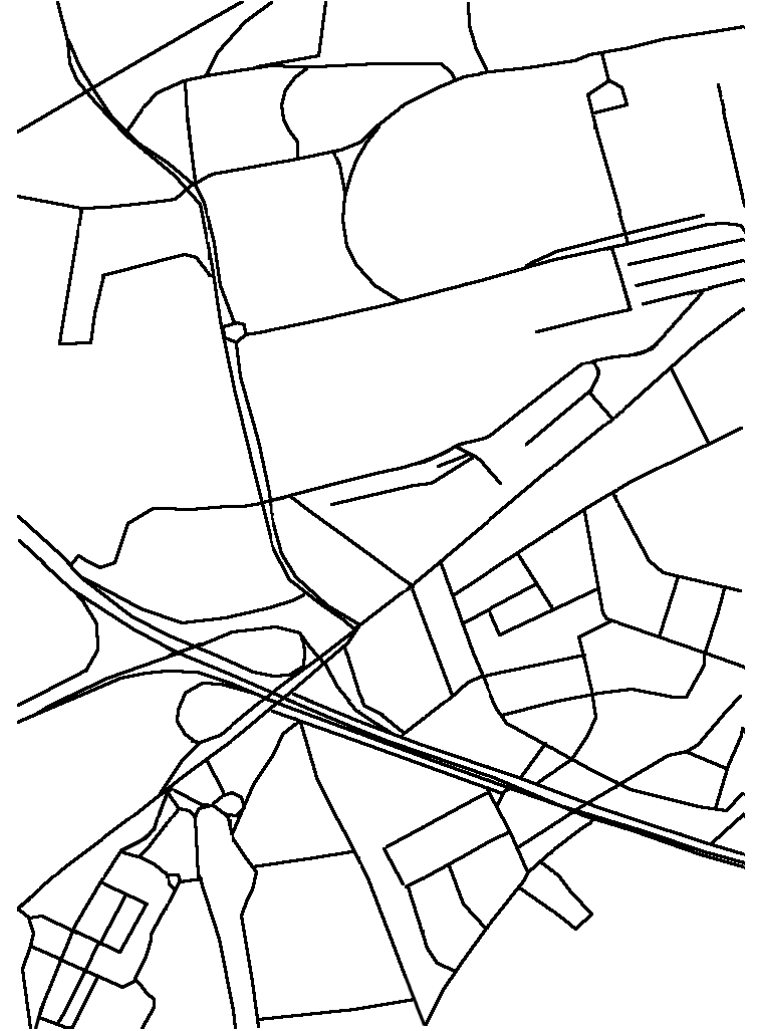

(b)

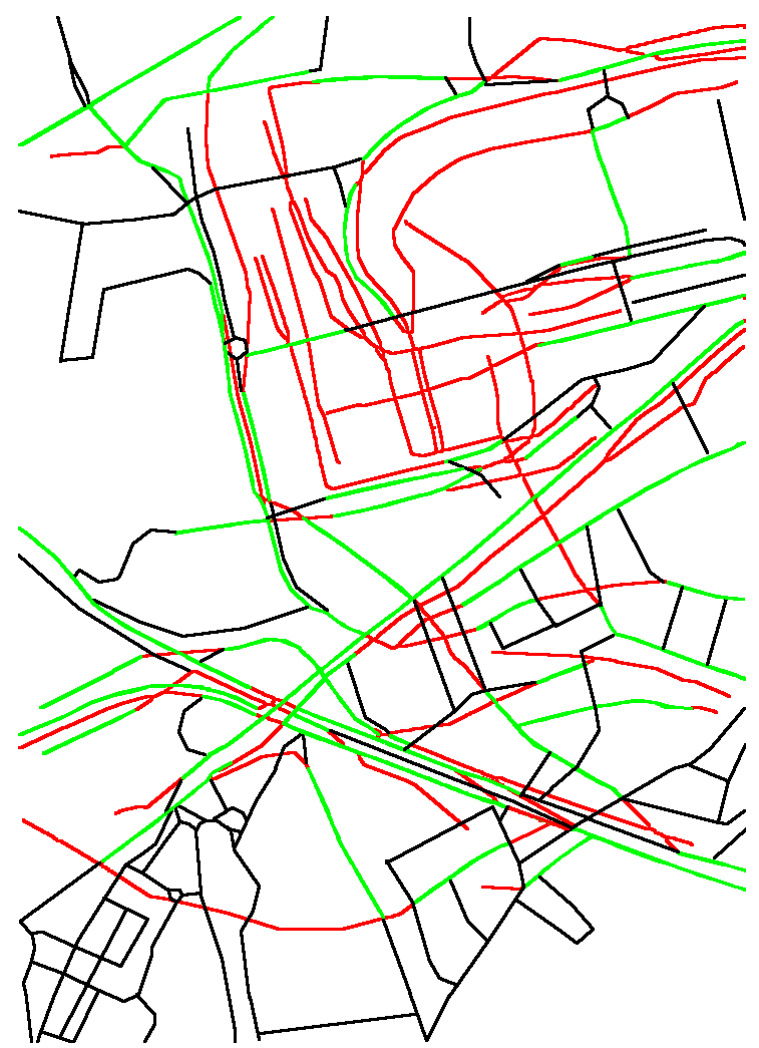

(c)

Figura 11.2: Resultados para imagens ópticas: (a) Imagem original (b) Ground-truth (c) Resultado da detecção onde as estradas detectadas corretamente estão marcadas em verde, as detectadas incorretamente estão marcadas em vermelho e as estradas ausentes estão marcadas em preto. 
Tabela 11.1: Parâmetros utilizados para as imagens ópticas.

\begin{tabular}{l|l|l|l|c|c|c|c|c}
\hline & \multicolumn{3}{|c|}{ Baixo nível } & Grafo & \multicolumn{3}{|c}{ Alto nível } \\
\hline & $\rho$ & & $r$ & (altura, largura) & $\mathcal{L}_{\text {max }}\left|\mathcal{D}_{\max }\right|$ & $K_{e}$ & $K_{\mathcal{L}}$ & $K_{c} \mid K_{i}$ \\
\hline
\end{tabular}

Região 1

\begin{tabular}{l|c|c|c|c|c|c|c|c|c}
\hline Escala 3 & 0,35 & 0,35 & $(3,3)$ & 40 & 40 & $0,25 \mid$ & $-0,12$ & 0,3 & 0,3 \\
\hline Escala 2 & 0,3 & 0,3 & $(5,4)$ & 70 & 70 & 0,4 & $-0,12$ & 0,3 & 0,3 \\
\hline Escala 1 & 0,3 & 0,3 & $(5,5)$ & 110 & 110 & 0,4 & $-0,12$ & 0,3 & 0,3 \\
\hline
\end{tabular}

Região 2

\begin{tabular}{l|l|l|l|c|c|c|c|c|c}
\hline Escala 3 & 0,38 & 0,35 & $(4,3)$ & 40 & 40 & 0,21 & $-0,2$ & 0,3 & 0,3 \\
\hline Escala 2 & 0,35 & 0,35 & $(5,4)$ & 70 & 70 & 0,3 & $-0,12$ & 0,3 & 0,3 \\
\hline Escala 1 & 0,3 & 0,3 & $(5,5)$ & 100 & 100 & 0,3 & $-0,12$ & 0,3 & 0,3 \\
\hline
\end{tabular}

preto. Os parâmetros utilizados nos experimentos são apresentados na Tabela 11.3.

Pode-se notar diferentes aspectos dos resultados em cada caso relacionado às características de cada imagem, óptica ou radar. O processo de extração usando as imagens de radar parece ser eficiente para detectar as estradas principais das regiões, porém alguns detalhes (estradas pequenas e/ou finas) são perdidos durante o processo. Por outro lado, o resultado da extração usando as imagens ópticas contém mais falsas detecções, apesar de ser também capaz de detectar as estradas principais. Isto ocorre pelo fato das imagens ópticas serem de alta resolução e, assim, a detecção de baixo nível é muito sensível aos detalhes presentes na imagem. Desta forma, mais estruturas candidatas são detectadas no passo de baixo nível. Além disso, é possível notar que algumas outras estruturas são confundidas com as estradas, como os rios, por exemplo. Outro aspecto interessante é que, dependendo da região, pode ser difícil detectar algumas estradas na imagem óptica, pois algumas vezes o contraste entre a região pertencente à estrada e as regiões nos seus arredores é muito baixo. Por exemplo, no resultado apresentado para a primeira região, observa-se uma estrada localizada no meio da região que não foi detectada usando a imagem óptica (setas em azul na Figura 11.1). Isto também pode ocorrer de forma contrária, em que estradas que não foram detectadas nas imagens de radar e que foram detectadas nas imagens ópticas (seta em azul na Figura 11.4).

A seguir, na Tabela 11.2, apresentamos alguns resultados comparativos entre o método proposto e o método apresentado por Tupin et al., usando as mesmas duas regiões analisadas anteriormente. A tabela compara o número de vértices do grafo construído usando segmentos de reta [Tupin et al., 1998] e usando componentes conexas (método proposto). Observa-se uma diminuição média de vértices de quase $30 \%$. Além disso, também comparamos os valores 
Tabela 11.2: Comparação de resultados entre o método proposto e o método de Tupin et al..

\begin{tabular}{|c|c|c|c|c|}
\hline & \multicolumn{4}{|c|}{ Região 1} \\
\hline & \multicolumn{2}{|l|}{ Óptica } & \multicolumn{2}{|l|}{ Radar } \\
\hline & Método proposto & Tupin & Método proposto & Tupin \\
\hline \multirow[t]{4}{*}{$\begin{array}{c}\text { \# Vértices do grafo } \\
\text { MCC }\end{array}$} & $\begin{array}{c}14754 \\
0,2872\end{array}$ & $\begin{array}{l}20205 \\
0,256\end{array}$ & $\begin{array}{l}18265 \\
0,378\end{array}$ & $\begin{array}{c}23991 \\
0,3274\end{array}$ \\
\hline & \multicolumn{4}{|c|}{ Região 2} \\
\hline & \multicolumn{2}{|l|}{ Óptica } & \multicolumn{2}{|l|}{ Radar } \\
\hline & Método proposto & Tupin & Método proposto & Tupin \\
\hline $\begin{array}{c}\text { \# Vértices do grafo } \\
\text { MCC }\end{array}$ & $\begin{array}{c}9242 \\
0,2368\end{array}$ & $\begin{array}{c}14442 \\
0,2098\end{array}$ & $\begin{array}{c}14384 \\
0,2779\end{array}$ & $\begin{array}{l}20071 \\
0,2249\end{array}$ \\
\hline
\end{tabular}

do MCC (Coeficiente de Correlação de Matthews):

$$
M C C=\frac{v p . v n-f p . f n}{\sqrt{(v p+f p)(v p+f n)(v n+f p)(v n+f n)}},
$$

para cada uma das regiões e o método proposto supera o outro método em todos os resultados. 
Tabela 11.3: Parâmetros utilizados para as imagens de radar.

\begin{tabular}{l|l|l|l|l|l|l|l|l}
\hline & \multicolumn{3}{|c|}{ Baixo nível } & Grafo & \multicolumn{4}{|c}{ Alto nível } \\
\cline { 2 - 7 } & $\rho$ & $r$ & (altura, largura) & $\mathcal{L}_{\max }\left|\mathcal{D}_{\max }\right| K_{e}$ & $K_{\mathcal{L}}$ & $K_{c}$ & $K_{i}$ \\
\hline
\end{tabular}

Região 1

\begin{tabular}{l|c|c|c|c|c|c|c|c|c}
\hline Escala 3 & 0,4 & 0,4 & $(3,3)$ & 40 & 40 & 0,4 & $-0,12$ & 0,3 & 0,3 \\
\hline Escala 2 & 0,35 & 0,4 & $(5,4)$ & 70 & 70 & 0,3 & $-0,12$ & 0,3 & 0,3 \\
\hline Escala 1 & 0,3 & 0,3 & $(5,5)$ & 100 & 100 & 0,3 & $-0,12$ & 0,3 & 0,3 \\
\hline
\end{tabular}

Região 2

\begin{tabular}{l|c|c|c|c|c|c|c|c|c}
\hline Escala 3 & 0,4 & 0,4 & $(3,3)$ & 40 & 40 & 0,3 & $-0,12|0,3| 0,3$ \\
\hline Escala 2 & 0,35 & 0,35 & $(5,4)$ & 70 & 70 & 0,3 & $-0,12|0,3| 0,3$ \\
\hline Escala 1 & 0,35 & 0,35 & $(5,4)$ & 100 & 100 & 0,3 & $-0,12$ & 0,3 & 0,3 \\
\hline
\end{tabular}




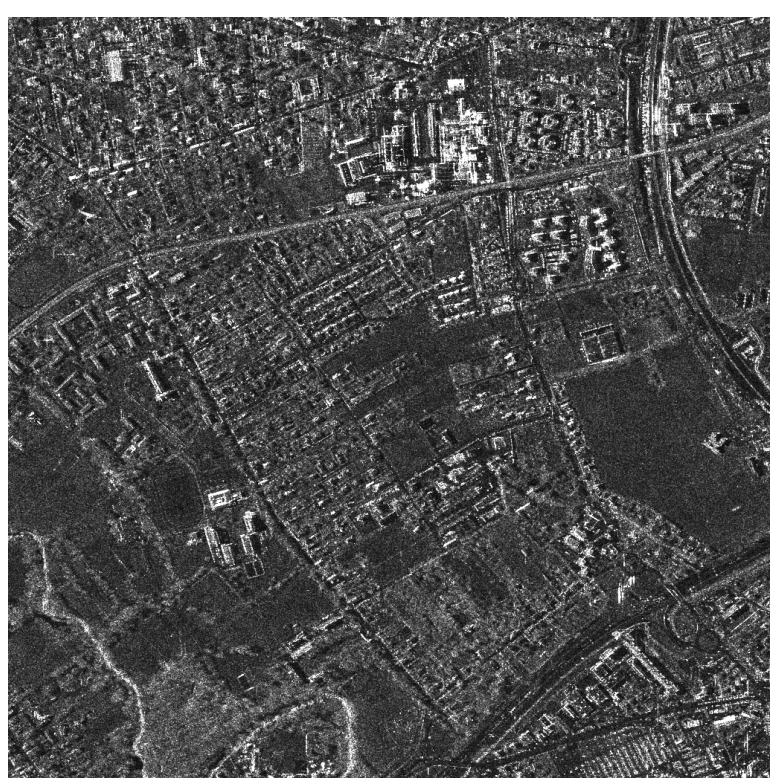

(a)

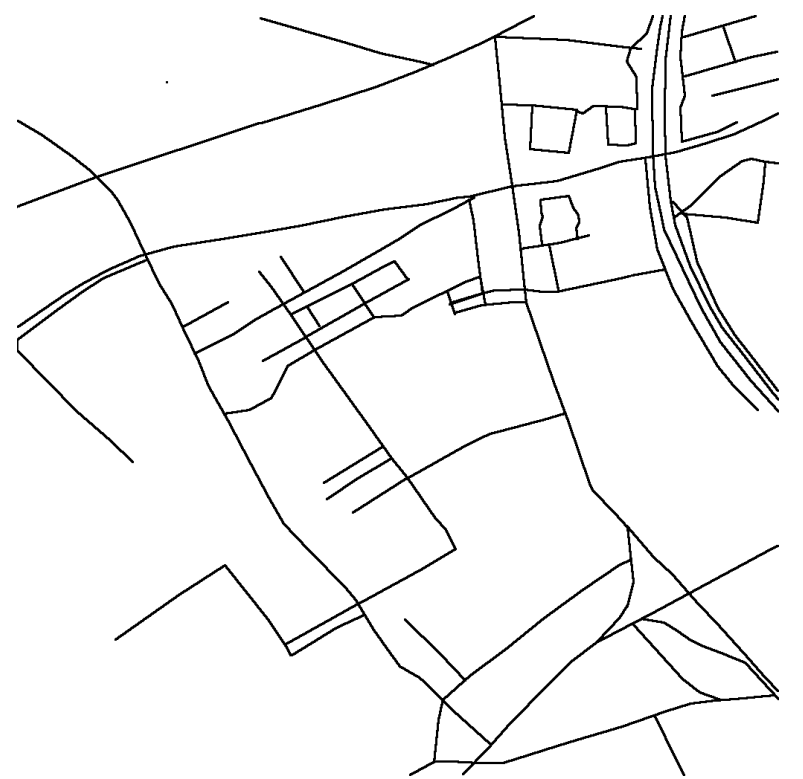

(b)

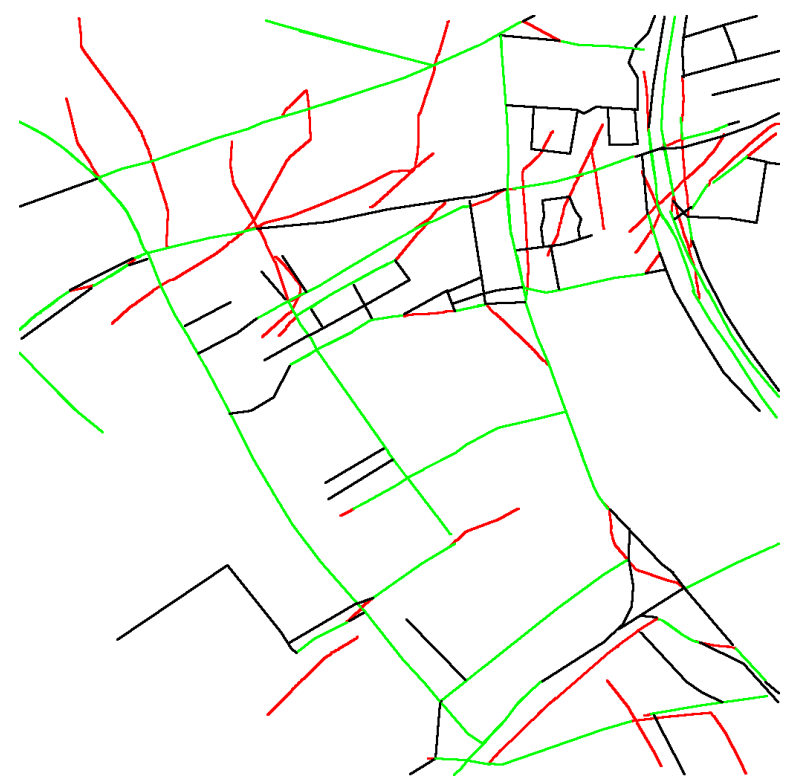

(c)

Figura 11.3: Resultados para imagens de radar: (a) Imagem original (b) Ground-truth (c) Verde: detecção correta. Vermelho: deteç̧ão incorreta. Preto: estradas não detectadas. Observe que a estrada que não foi detectada usando a imagem óptica (Figura 11.1(c)), foi detectada neste caso. 


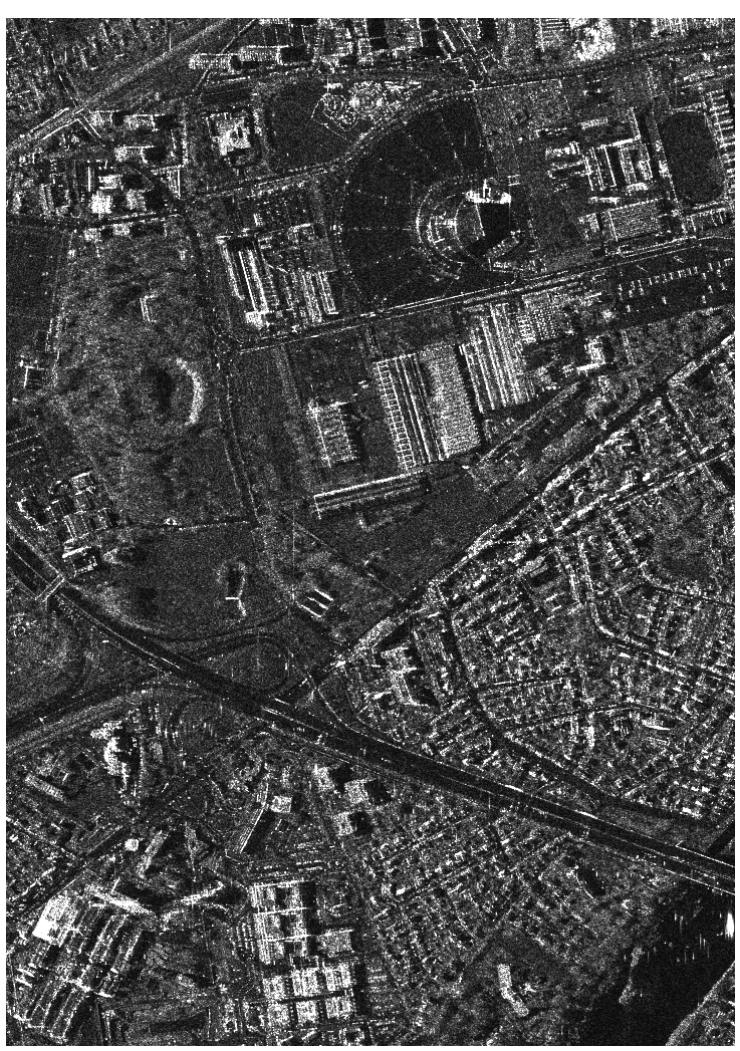

(a)

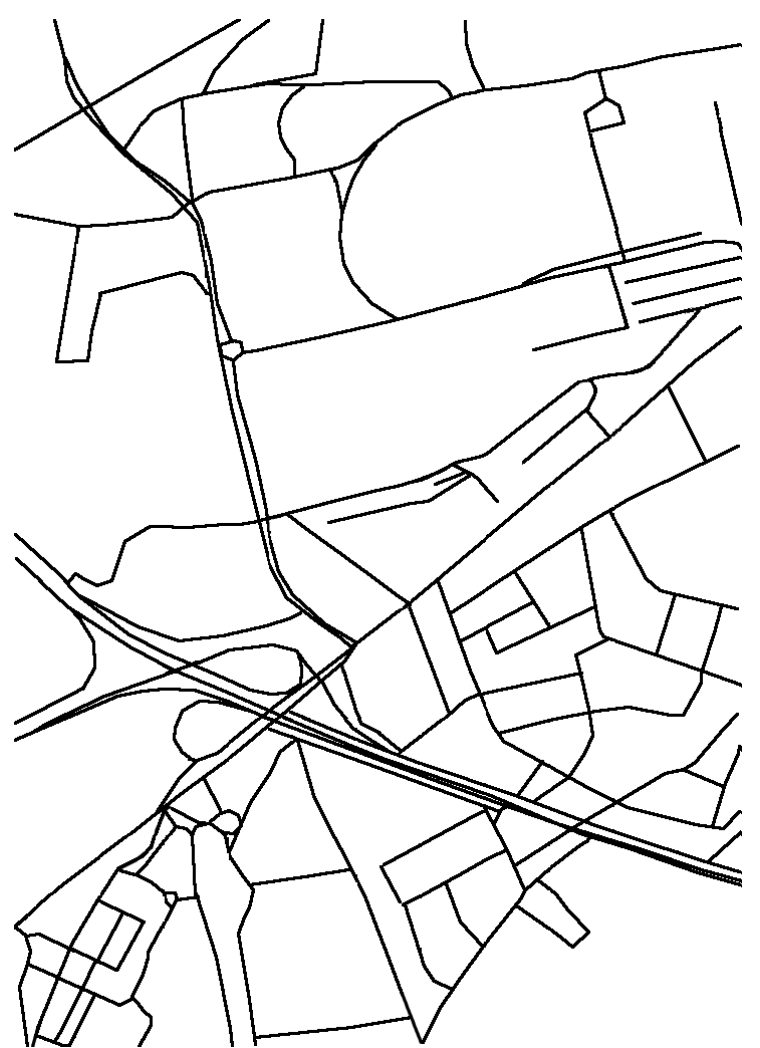

(b)

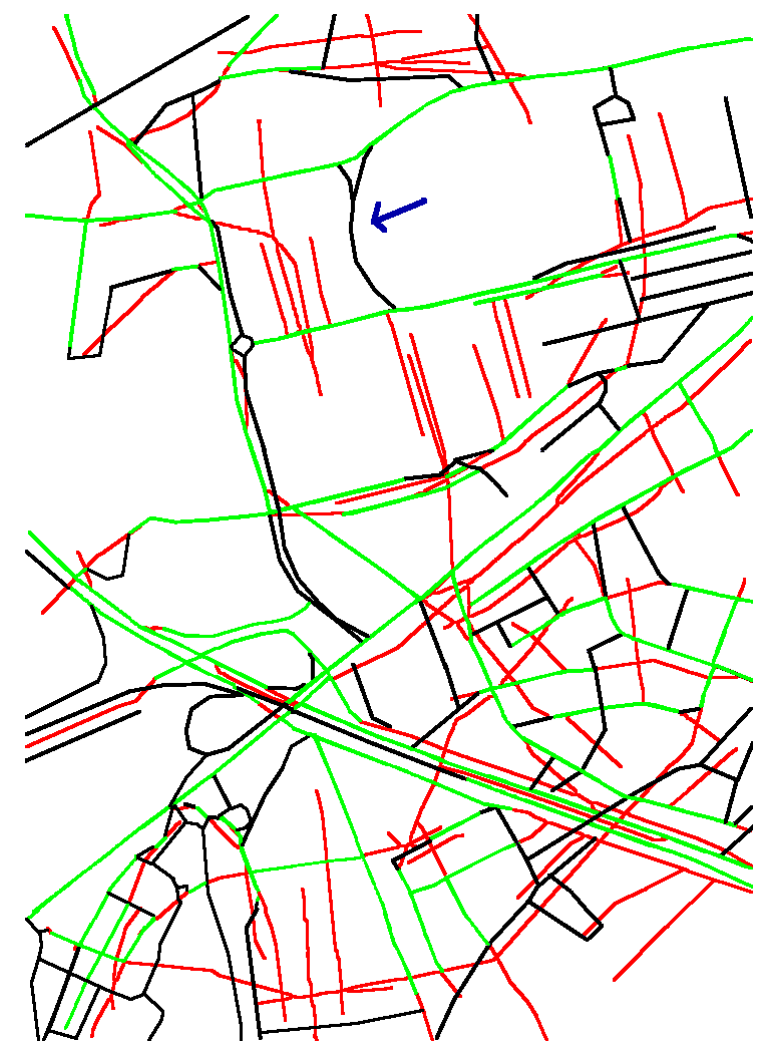

(c)

Figura 11.4: Resultados para imagens de radar: (a) Imagem original (b) Ground-truth (c) Verde: detecção correta. Vermelho: detecção incorreta. Preto: estradas não detectadas. A seta em azul destaca uma estrada que não foi detectada usando a imagem de radar, mas que foi detectada usando a imagem óptica (Figura 11.2(c)) 


\subsubsection{Imagens provenientes de sensores diferentes}

\section{Fusão de imagens SAR e ópticas}

Para testar a abordagem de fusão proposta, as mesmas regiões apresentadas anteriormente são usadas. As regiões foram previamente registradas usando informações geométricas e de aquisição. A Figura 11.5 apresenta os resultados para as duas regiões aplicando a abordagem de fusão proposta. A Tabela 11.5 apresenta os parâmetros utilizados nestes experimentos.

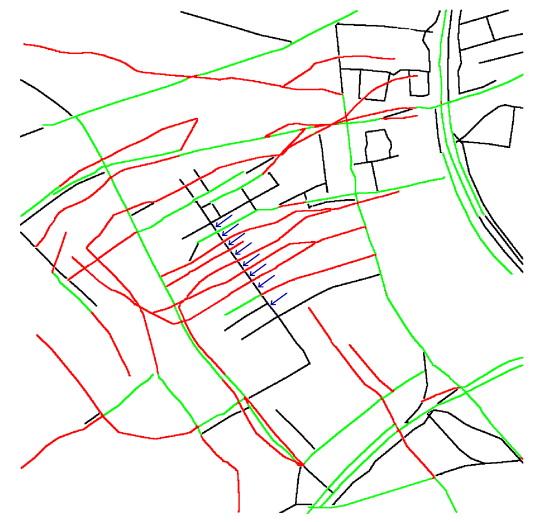

(a)

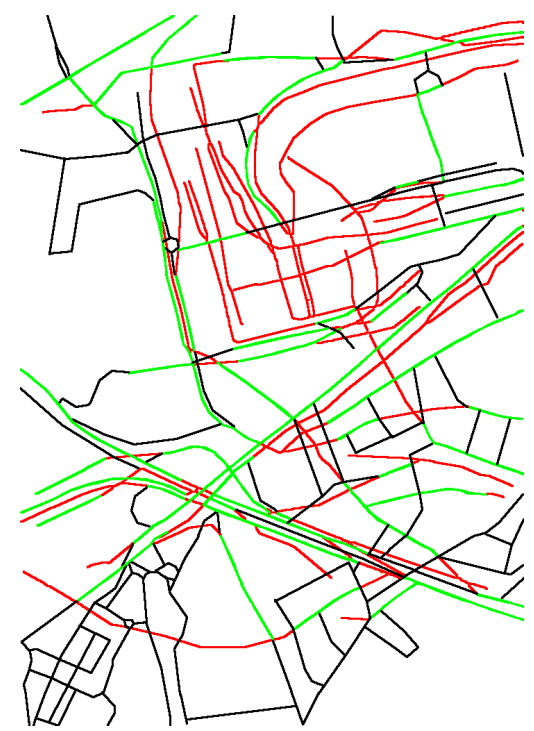

(d)

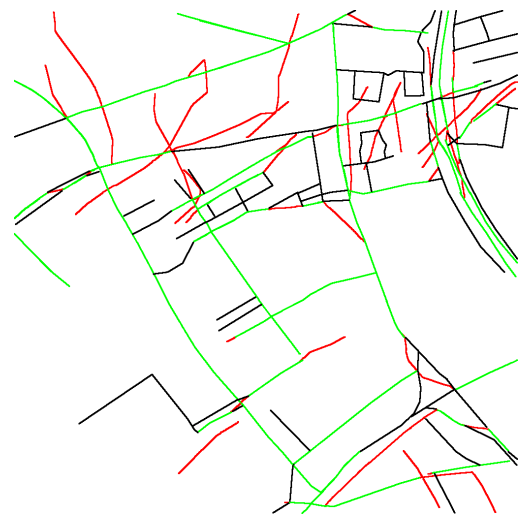

(b)

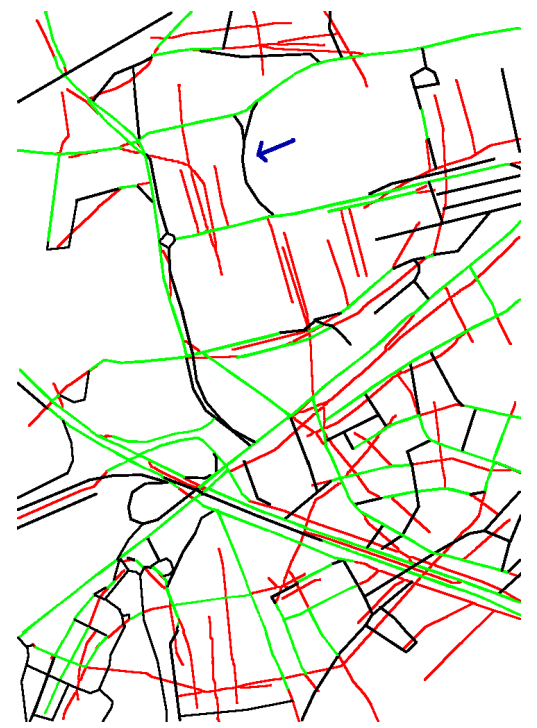

(e)

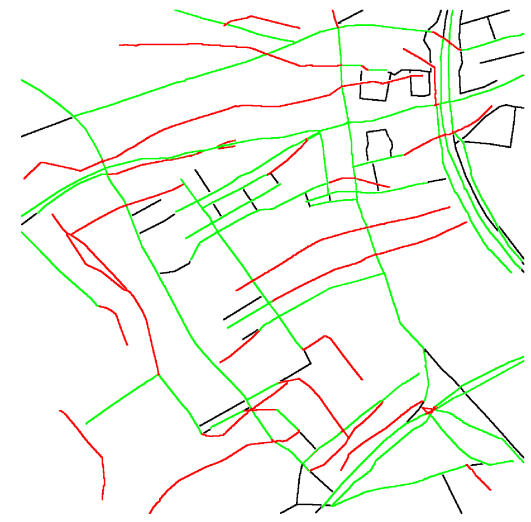

(c)

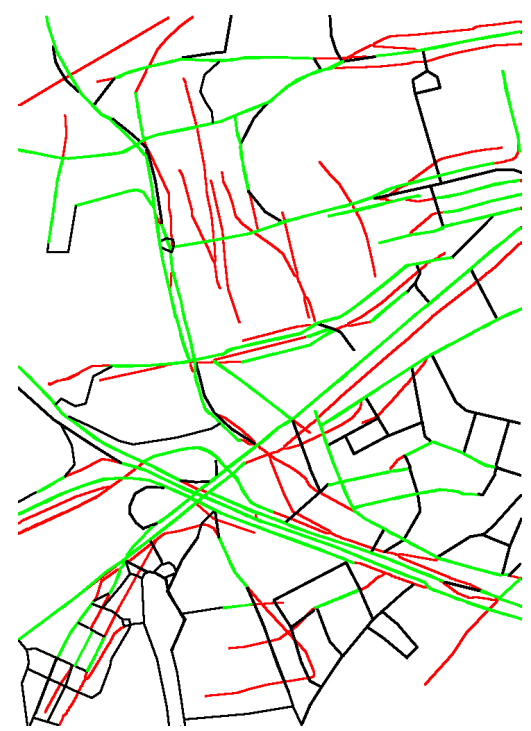

(f)

Figura 11.5: Resultados para a fusão das imagens de radar e ópticas: (a) (d) Resultados usando apenas as imagens ópticas (b) (e) Resultados usando apenas as imagens de radar (c) (f) Resultados usando a abordagem de fusão proposta. Verde: detecção correta. Vermelho: detecção incorreta. Preto: estradas ausentes.

Como esperado, o resultado usando a fusão dos dois sensores possui informações complementares, que produzem um resultado mais satisfatório. A Tabela 11.4 apresenta uma análise quantitativa dos resultados obtidos para as duas regiões através dos índices de corretude (precisão), completude (sensibilidade) e MCC. A corretude mede a precisão da detecção relativa ao ground-truth. A medida de completude pode ser interpretada como o inverso do 
Tabela 11.4: Avaliação quantitativa dos resultados comparando o uso de um único sensor e a abordagem de fusão.

\begin{tabular}{c|c|c|c|c}
\hline Dados & Completude & Corretude & MCC \\
\hline Região 1 & Imagem óptica & $36.64 \%$ & $33.70 \%$ & 0.2872 \\
& Imagem radar & $48.60 \%$ & $39.38 \%$ & 0.3780 \\
& Fusão & $\mathbf{6 5 . 6 4 \%}$ & $\mathbf{5 5 . 1 0} \%$ & $\mathbf{0 . 5 6 0 1}$ \\
\hline \multirow{2}{*}{ Região 2 } & Imagem óptica & $34.79 \%$ & $33.76 \%$ & 0.2368 \\
& Imagem radar & $41.51 \%$ & $35.60 \%$ & 0.2779 \\
& Fusão & $\mathbf{4 7 . 0 3} \%$ & $\mathbf{4 5 . 3 0} \%$ & $\mathbf{0 . 3 7 4 4}$ \\
\hline
\end{tabular}

Tabela 11.5: Parâmetros utilizados para fusão de imagens ópticas e de radar.

\begin{tabular}{l|l|l|l|l|l|l|l|l}
\hline & \multicolumn{3}{|c|}{ Baixo nível } & Grafo & \multicolumn{3}{|c}{ Alto nível } \\
\cline { 2 - 7 } & $\rho$ & $r$ & (altura, largura) & $\mathcal{L}_{\max } \mid \mathcal{D}_{\max }$ & $K_{e}$ & $K_{\mathcal{L}}$ & $K_{c}$ & $K_{i}$ \\
\hline
\end{tabular}

Região 1

\begin{tabular}{l|c|c|c|c|c|c|c|c|c}
\hline Escala 3 & 0,5 & 0,5 & $(3,3)$ & 30 & 30 & 0,4 & $-0,12|0,3| 0,3$ \\
\hline Escala 2 & 0,45 & 0,5 & $(5,4)$ & 60 & 60 & 0,4 & $-0,12$ & 0,3 & 0,3 \\
\hline Escala 1 & 0,3 & 0,6 & $(5,5)$ & 100 & 100 & 0,3 & $-0,12$ & 0,3 & 0,3 \\
\hline
\end{tabular}

Região 2

\begin{tabular}{l|c|c|c|c|c|c|c|c|c}
\hline Escala 3 & 0,45 & 0,5 & $(3,3)$ & 30 & 30 & 0,4 & $-0,12|0,3| 0,3$ \\
\hline Escala 2 & 0,35 & 0,5 & $(4,4)$ & 70 & 70 & 0,3 & $-0,12|0,3| 0,3$ \\
\hline Escala 1 & 0,3 & 0,55 & $(5,4)$ & 100 & 100 & 0,3 & $-0,12$ & 0,3 & 0,3 \\
\hline
\end{tabular}

erro de falha. Todas as medidas da matriz de confusão da classificação binária são usados para calcular o MCC, o qual pode ter valores compreendidos entre -1 e 1 , onde -1 indica total discordância com o ground-truth e 1 indica uma classificação perfeita.

Como a rede de estradas verdadeira foi obtida manualmente, os valores apresentados na Tabela 11.4 possuem maior valor relativo do que absoluto. O mais importante é a melhora apresentada pelos resultados obtidos usando a fusão dos sensores em relação aos resultados sem o uso da fusão.

\section{Fusão multitemporal}

Outro conjunto de experimentos realizados compreende a fusão de imagens multitemporais. Duas pilhas de imagens multitemporais da região de Saint Gervais - França, com datas de aquisição diferentes, foram utilizadas:

- 13 imagens obtidas através do sensor TerraSAR-X com 1 m de resolução; 
- 4 imagens obtidas através do sensor COSMO-SkyMed com 3 m de resolução.

E uma pilha de imagens multitemporais da região de Chamonix - França:

- 13 imagens obtidas através do sensor TerraSAR-X com 1 m de resolução.

O objetivo dos experimentos é comparar os resultados da aplicação da abordagem de fusão de baixo nível usando todas as imagens das pilhas com o resultado aplicando o arcabouço apenas sobre a imagem da média quadrática de todas as imagens. Considera-se aqui que a extração realizada sobre a imagem da média representa um resultado ideal, visto que a mesma possui uma alta qualidade, similar a uma imagem filtrada. Isto ocorre devido ao fato de que as estradas são estruturas estáveis e os ângulos de incidência no ato da aquisição das imagens eram similares.

A primeira linha da Figura 11.6 apresenta uma das imagens pertencentes à pilha TerraSAR$\mathrm{X}$, juntamente com a imagem da média quadrática e seu ground-truth. A segunda linha da mesma figura apresenta uma das imagens da pilha COSMO-SkyMed, assim como a imagem da média quadrática e o ground-truth. Os resultados obtidos usando estas imagens são mostrados na Figura 11.7. Para as três pilhas, as redes de estrada detectadas usando a imagem da média quadrática (Figuras 11.7(a), 11.7(d) e 11.7(g)) e a abordagem de fusão de baixo nível (Figuras 11.7(b), 11.7(e) e 11.7(h)) resultam em índices de qualidade muito similares, como pode-se observar na Tabela 11.7, nas primeiras linhas de cada pilha de imagens. Por outro lado, também para as três pilhas, os melhores índices de qualidade são alcançados pelos resultados obtidos através da combinação entre os resultados da imagem da média quadrática e da fusão de baixo nível (Figuras 11.7(c), 11.7(f) e 11.7(i)). Essa combinação consiste apenas na união direta dos dois resultados. Apesar de observarmos o aumento de falsas detecções nestes últimos resultados, o número de detecções verdadeiras aumenta de forma considerável. A Tabela 11.6 apresenta os parâmetros usados para os experimentos com as imagens multitemporais. 


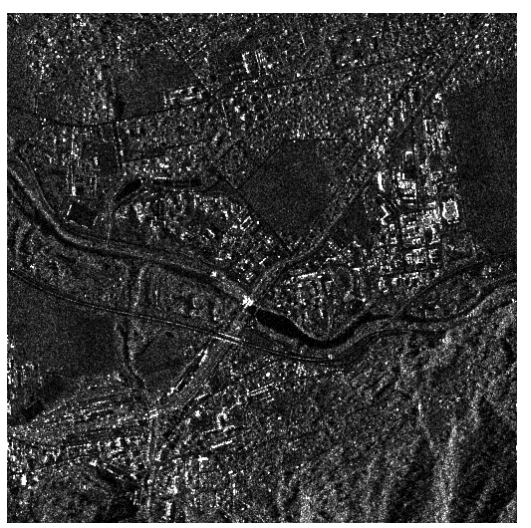

(a)

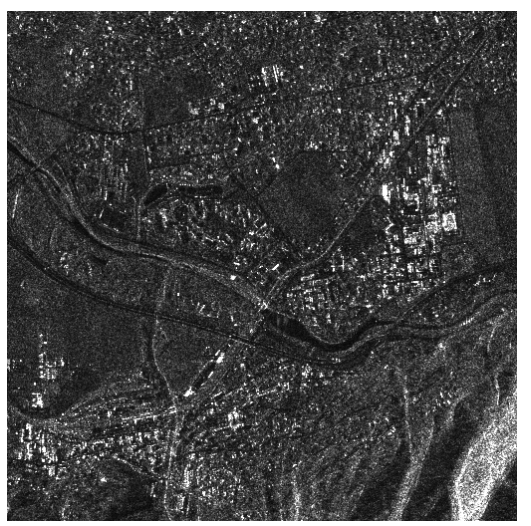

(d)

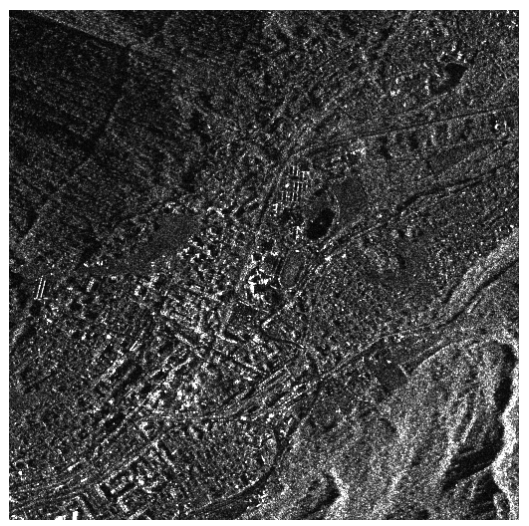

(g)

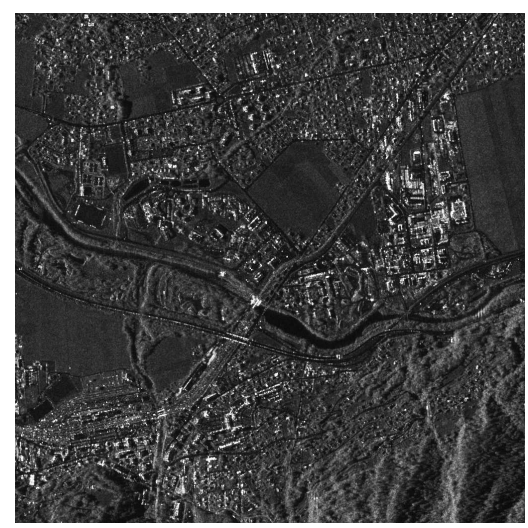

(b)

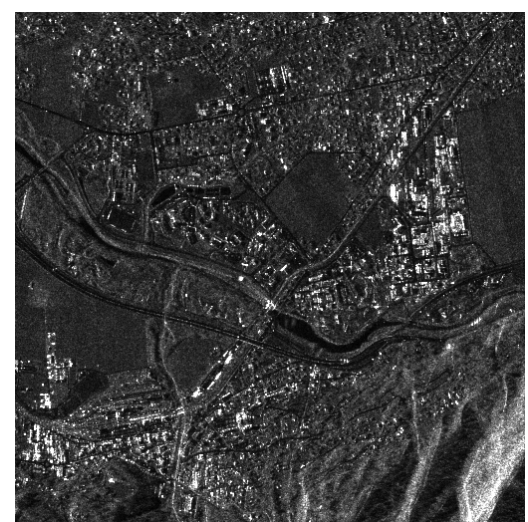

(e)

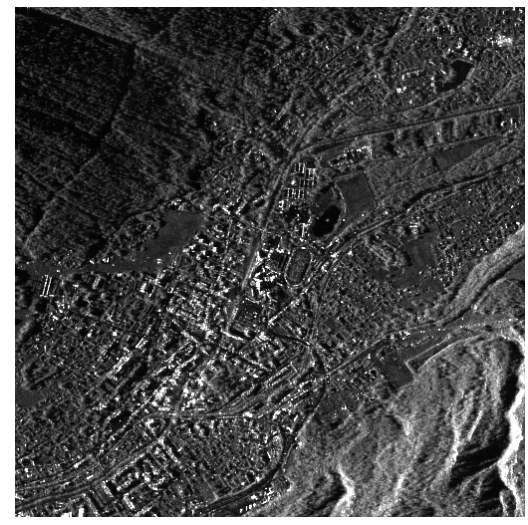

(h)

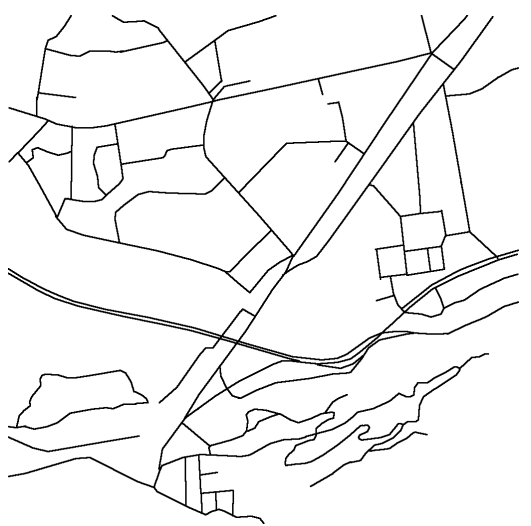

(c)

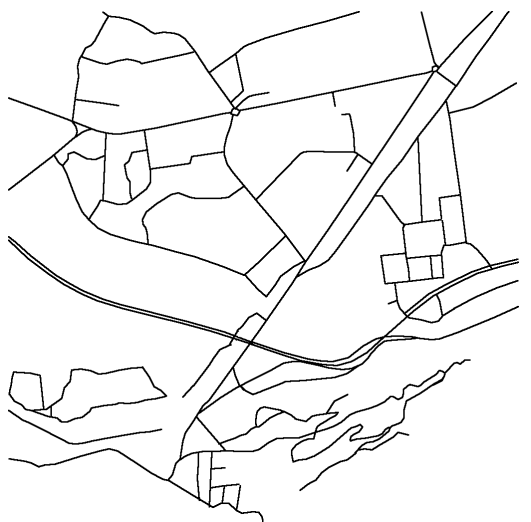

(f)

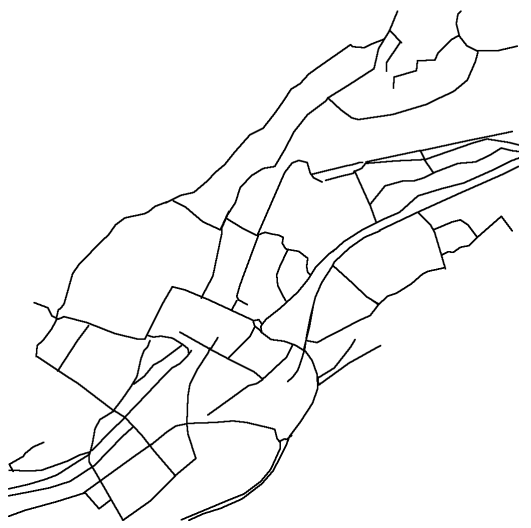

(i)

Figura 11.6: Imagens multitemporais originais. Primeira linha: (a) Uma das imagens da pilha de imagens TerraSAR-X (b) Média quadrática das 13 imagens da pilha TerraSAR-X (c) Ground-truth correspondente à região. Segunda linha: (d) Uma das imagens da pilha COSMO-SkyMed (e) Média quadrática das 4 imagens da pilha (f) Ground-truth correspondente à região. Terceira linha: (g) Uma das imagens da pilha TerraSAR-X, região de Chamonix (h) Média quadrática das 13 imagens da pilha (i) Ground-truth correspondente à região. 


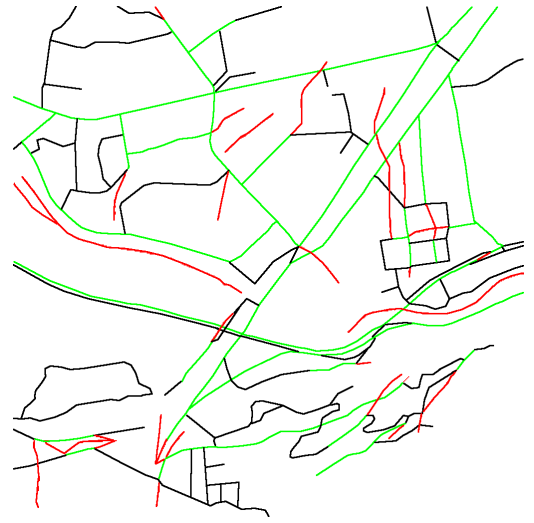

(a)

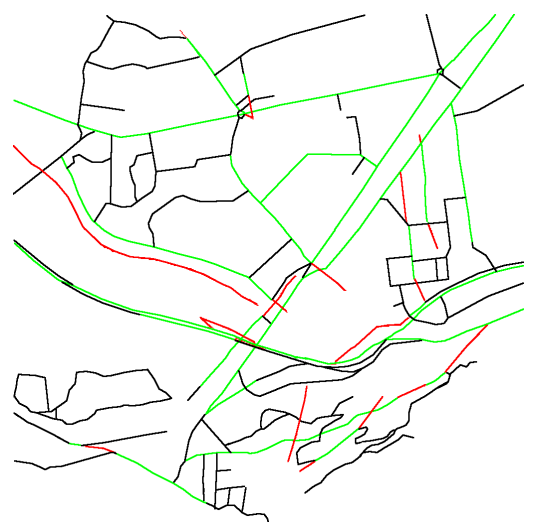

(d)

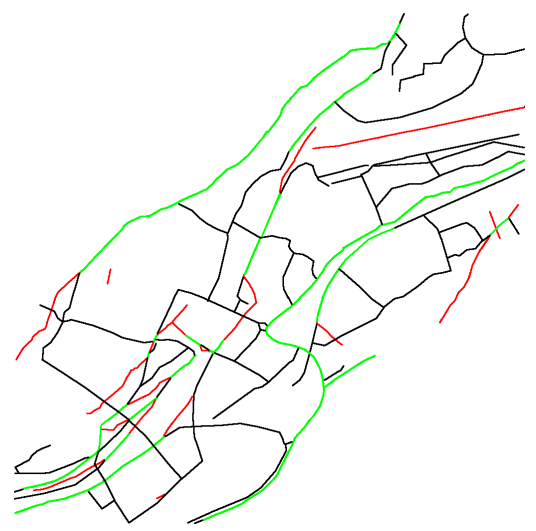

(g)

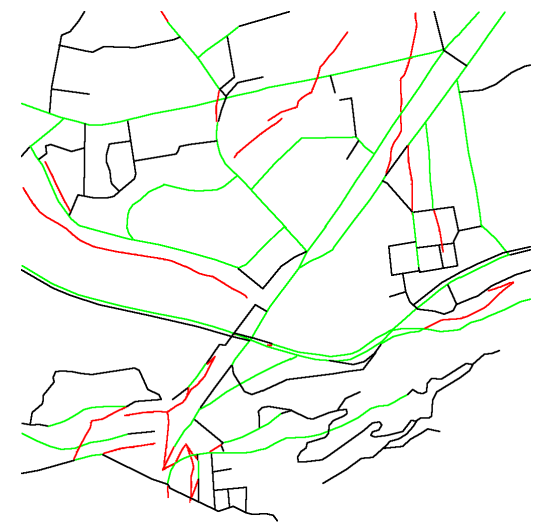

(b)

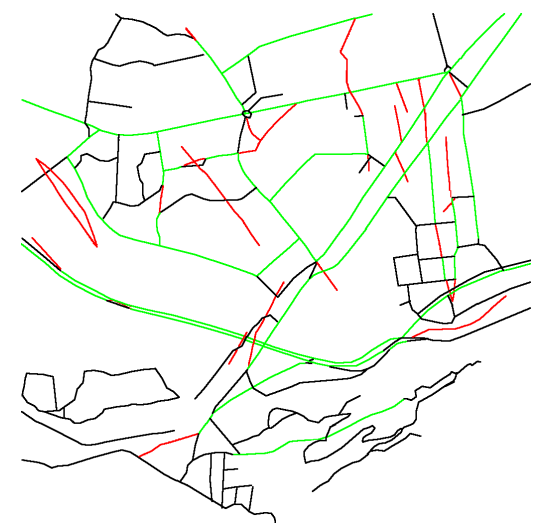

(e)

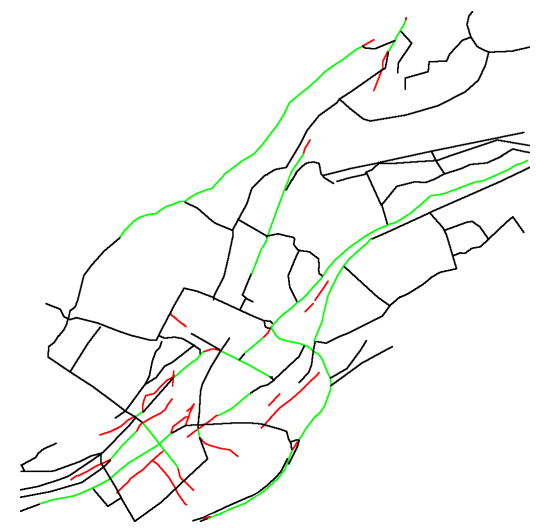

(h)

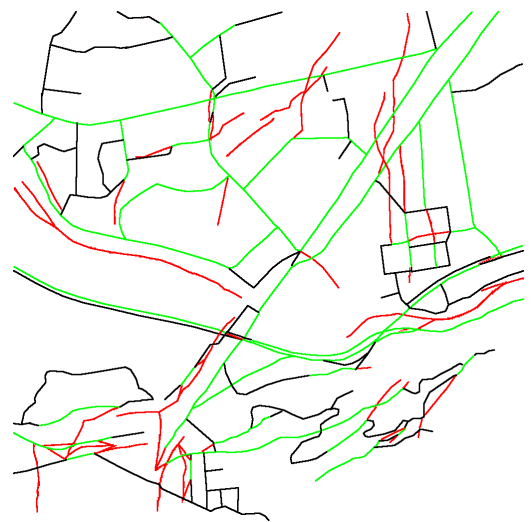

(c)

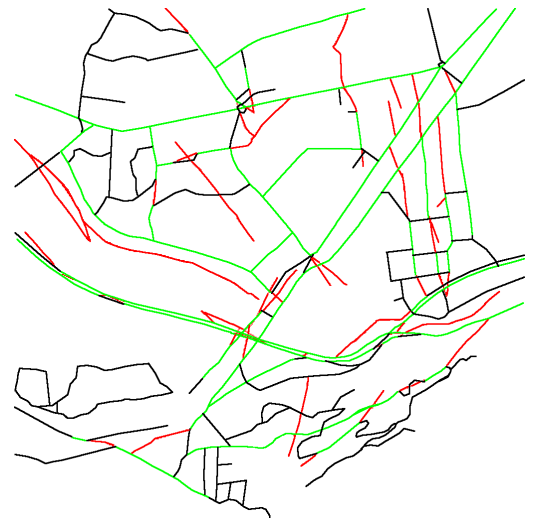

(f)

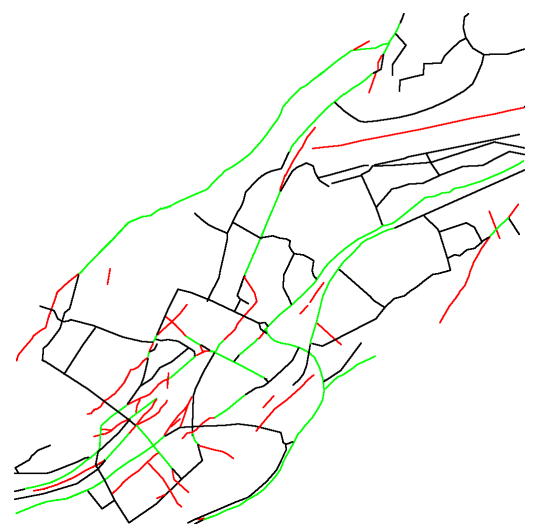

(i)

Figura 11.7: Resultados para as imagens multitemporais. Primeira linha: (a) Resultado obtido usando apenas a imagem da média quadrática da pilha de imagens TerraSAR-X (b) Resultado obtido usando a abordagem de fusão proposta nas 13 imagens TerraSAR-X (c) Resultado obtido fundindo os últimos dois resultados apresentados anteriormente. Segunda linha: (d) Resultado obtido usando apenas a imagem da média quadrática das imagens da pilha COSMO-SkyMed (e) Resultado obtido aplicando a fusão de baixo nivel proposta nas 4 imagens da pilha COSMO-SkyMed (f) Resultado obtido fundindo os últimos dois resultados apresentados anteriormente. Terceira linha: (g) Resultado obtido usando apenas a imagem da média quadrática das imagens da pilha TerraSAR-X (região de Chamonix) (h) Resultado obtido aplicando a fusão de baixo nivel proposta nas 13 imagens da pilha TerraSAR-X (região de Chamonix) (i) Resultado obtido fundindo os últimos dois resultados apresentados anteriormente. Verde: detecção correta. Vermelho: detecção incorreta. Preto: estradas ausentes. 
Tabela 11.6: Parâmetros utilizados para fusão de imagens multitemporais.

\begin{tabular}{|c|c|c|c|c|c|c|c|c|c|}
\hline & \multicolumn{3}{|c|}{ Baixo nível } & \multicolumn{2}{|c|}{ Grafo } & \multicolumn{4}{|c|}{ Alto nível } \\
\hline & $\rho$ & $r$ & (altura, largura) & $\mathcal{L}_{\max }$ & $\mathcal{D}_{\max }$ & $K_{e}$ & $K_{\mathcal{L}}$ & $K_{c}$ & $K_{i}$ \\
\hline \multicolumn{10}{|c|}{ St-Gervais (TSX) } \\
\hline Média & 0,45 & 0,45 & $(4,4)$ & 120 & 30 & 0,2 & $-0,22$ & 0,35 & 0,08 \\
\hline Fusão & 0,44 & 0,44 & $(5,4)$ & 120 & 30 & 0,3 & $-0,4$ & 0,35 & 0,1 \\
\hline \multicolumn{10}{|c|}{ St-Gervais (CSK) } \\
\hline Média & 0,35 & 0,35 & $(3,3)$ & 120 & 30 & 0,21 & $-0,2$ & 0,3 & 0,1 \\
\hline Fusão & 0,45 & 0,45 & $(3,3)$ & 120 & 30 & 0,25 & $-0,3$ & 0,3 & 0,15 \\
\hline \multicolumn{10}{|c|}{ Chamonix (TSX) } \\
\hline Média & 0,3 & 0,35 & $(3,3)$ & 110 & 30 & 0,21 & $-0,21$ & 0,3 & 0,1 \\
\hline Fusão & 0,45 & 0,5 & $(3,3)$ & 110 & 30 & 0,3 & $-0,35$ & 0,3 & 0,1 \\
\hline
\end{tabular}

A partir dos resultados quantitativos apresentados na Tabela 11.7, pode-se notar que os resultados para as duas pilhas da região de St-Gervais são muito parecidos, apesar do maior número de imagens TerraSAR-X e da melhor resolução desta pilha. Da mesma forma que em outros problemas explorados em sensoriamento remoto, imagens com melhor resolução nem sempre garantem melhores resultados. Para entender melhor estes resultados, uma análise da fusão das 13 imagens TerraSAR-X foi realizada. A fusão de baixo nível foi usada para números variados de imagens, de 1 à 13, na ordem cronológica de aquisição das imagens. Para cada experimento o MCC foi calculado, como apresentado na Figura 11.8. Observa-se a partir da análise feita, que o resultado usando 6 imagens fornece uma medida

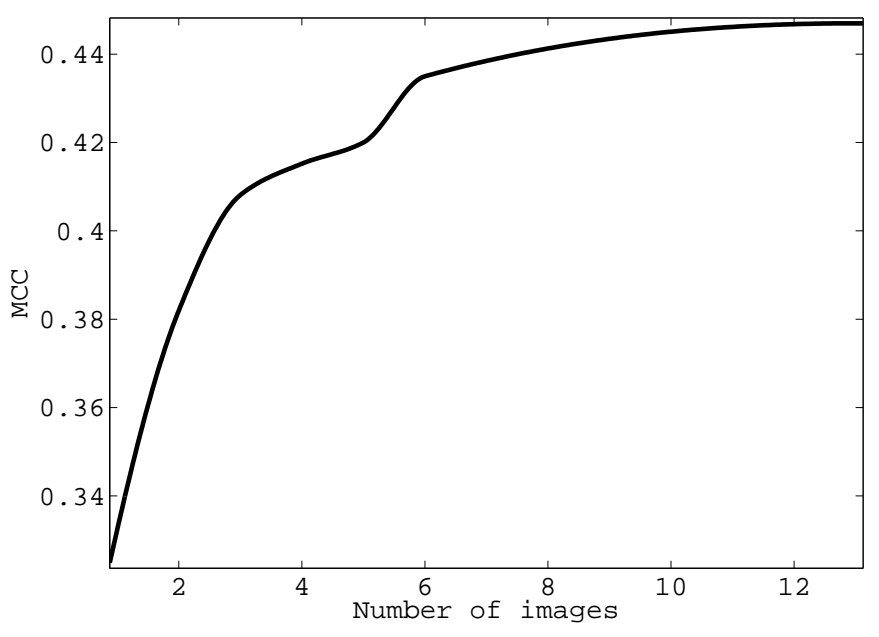

Figura 11.8: Análise da influência do número de imagens usadas para a fusão das imagens da pilha TerraSAR-X. Pode-se observar que realizando a fusão das primeiras 6 imagens da pilha, obtém-se uma medida próxima da melhor. 
Tabela 11.7: Avaliação quantitativa dos resultados.

\begin{tabular}{c|c|c|c|c}
\hline \multicolumn{2}{c|}{ Dados } & Completude & Corretude & MCC \\
\hline \multirow{3}{*}{ St-Gervais (TSX) } & Média & $42.09 \%$ & $57.65 \%$ & 0.4437 \\
& Fusão & $41.09 \%$ & $59.47 \%$ & 0.4473 \\
& Fusão + Média & $\mathbf{5 0 . 8 7 \%}$ & $\mathbf{5 1 . 7 7 \%}$ & $\mathbf{0 . 4 6 0 7}$ \\
\hline \multirow{3}{*}{ St-Gervais (CSK) } & Média & $40.66 \%$ & $61.54 \%$ & 0.462 \\
& Fusão & $44.09 \%$ & $58.77 \%$ & 0.4684 \\
& Fusão + Média & $\mathbf{5 3 . 1 3} \%$ & $\mathbf{5 2 . 1 4} \%$ & $\mathbf{0 . 4 7 9 5}$ \\
\hline \multirow{3}{*}{ Chamonix (TSX) } & Média & $22.92 \%$ & $42.85 \%$ & 0.2735 \\
& Fusão & $20.62 \%$ & $45.85 \%$ & 0.2700 \\
& Fusão + Média & $\mathbf{2 8 . 0 9 \%}$ & $\mathbf{4 0 . 0 5 \%}$ & $\mathbf{0 . 2 9 1 1}$ \\
\hline
\end{tabular}

de qualidade próxima a do melhor resultado. Isto pode ser um indício de que, dependendo da combinação das imagens escolhidas da pilha, um bom resultado pode ser obtido com um menor número de imagens. Além disso, as imagens CSK e TerraSAR-X, apesar de muito parecidas, não são exatamente as mesmas. Análises adicionais com pilhas multitemporais devem ser realizadas em trabalhos futuros, além da fusão de imagens CSK e TerraSAR-X que também poderão se exploradas. Resultados preliminares nesta última linha podem ser vistos em [Sportouche et al., 2012]. 


\section{Aplicações}

\section{Raízes de plantas}

"Com paciência e perseverança muito se alcança."

Théophile Gautier

\subsection{Introdução}

Técnicas de processamento e análise de imagens digitais são usadas na Ciência do Solo com o intuito principal de obter informações complementares às técnicas experimentais convencionais, que possuem tempo e custo maiores, possibilitando o desenvolvimento de ferramentas mais precisas, rápidas e de custo reduzido. Dentre os estudos relacionados à Ciência do Solo podem ser citados: o estudo do sistema radicular, morfologia e cobertura do solo. A caracterização da morfologia do solo (agregados e poros) usando técnicas de imagens facilita e permite maior rapidez nas análises.

Com relação ao estudo da cobertura do solo, observa-se uma forte contribuição na avaliação das características físicas, como teores de matéria orgânica e textura dos diversos tipos de solos, pois estas estão relacionadas com a resposta espectral registrada em imagens provenientes dos campos. Apesar de serem influenciadas por outras variáveis como tratos culturais, umidade, seleção adequada de bandas espectrais e resolução espacial, imagens podem proporcionar uma boa caracterização dos solos dentro de um campo de cultivo, gerando a identificação de zonas homogêneas de propriedades físicas do solo. O uso de técnicas de processamento de imagens pode ser uma ótima ferramenta para o aprimoramento de amostras de solo coletadas em campo através da interpolação dos parâmetros dessas amostras. Desta forma, modelos de interpretação podem ser ajustados produzindo um excelente mapa de sítios homogêneos, os quais servem de base para a definição de tratos culturais e aplicações diferenciadas dentro do campo. Ainda sim, muitos cultivos principais e secundários são avaliados em relação à taxa de cobertura do solo visando, principalmente, a sua proteção contra o impacto das gotas de chuva. Essas gotas causam, dentre outros efeitos, um selamento superficial do solo e processos de erosão. Imagens de alta resolução permitem calcular a cobertura 
do solo com precisão e alimentam modelos de previsibilidade de erosão permitindo, assim, uma ação preventiva e corretiva. Estas técnicas são úteis também para manejos como o plantio direto onde se torna importante a determinação de matéria seca sobre o solo.

O presente trabalho tem por objetivo o estudo e análise do sistema radicular. Neste caso, o processamento de imagens facilita a determinação do comprimento, da área superficial, do volume e da análise da distribuição radicular ao longo do perfil de solo. Estes parâmetros, quando calculados manualmente, são extremamente trabalhosos, sendo este o motivo dos estudos do sistema radicular terem tido avanço mais significativo após a introdução de técnicas de imagens. A segmentação das imagens do sistema radicular é uma forma muito mais adequada e eficiente de calcular tais parâmetros.

Existem dois principais métodos utilizados para coleta de informações de raízes: diretamente no perfil do solo ou através de raízes lavadas. A escolha de um deles depende, entre outros, do objetivo do estudo, da facilidade na coleta dos dados e da disponibilidade de recursos.

O método do monólito, ou seja, a retirada de um monólito de solo e a separação de raízes por lavagem, é um dos mais utilizados para o estudo de raízes. Mesmo sendo um método padrão, existem algumas variações do método, tais como: placa de pregos e anéis volumétricos [Bohm, 1979; Schuurmann \& Goedewaagen, 1971]. Entre estas, o método com placa de pregos se destaca como referência no estudo de raízes. Apesar de ser trabalhoso e consumir muito tempo, este método é sempre usado como um método padrão, pois, a partir dele, é possível fazer um estudo tanto qualitativo como quantitativo das raízes e além disso, entre os métodos do monólito, este é o que possui maior exatidão dos resultados. A Figura 12.1 apresenta uma placa com pregos depois de lavada.

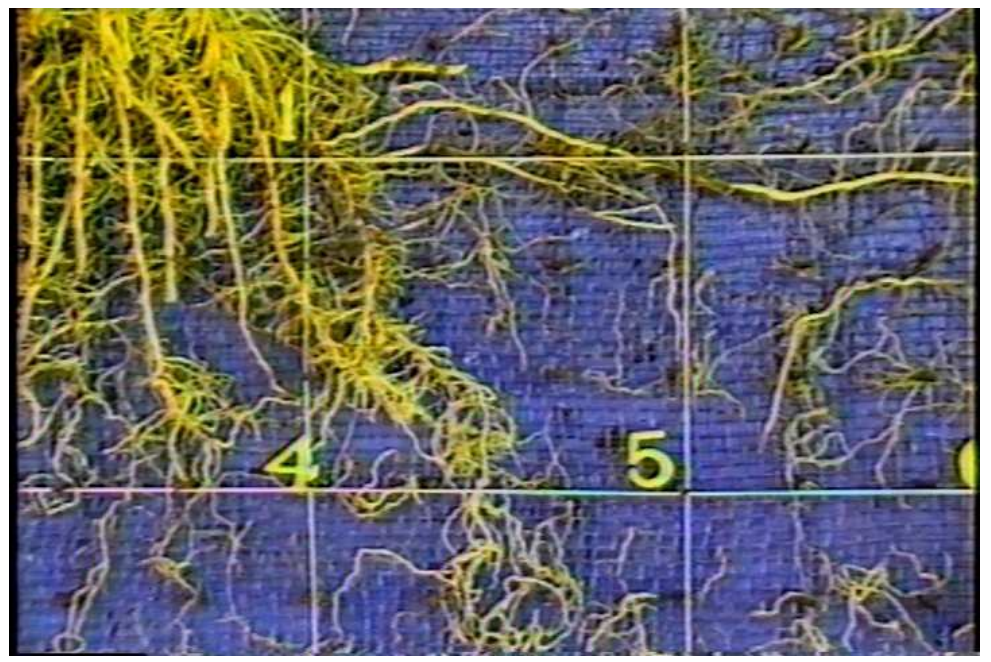

Figura 12.1: Perfil da placa com pregos depois de lavada.

O método do perfil de solo, também chamado de Método de Trincheira, fundamenta-se na abertura de trincheiras para melhor visualização e avaliação da distribuição das raízes da planta em estudo. A avaliação da distribuição de raízes in situ, consiste em cavar uma trincheira ao lado da planta e remover uma fina camada de parede do perfil, de modo a 
expor as raízes, que depois são contadas e registradas em desenhos ou tabelas. Uma variação deste método tem sido usada para análise a partir de imagens digitalizadas dos perfis, a partir das quais pode-se determinar o comprimento, a distribuição e a área ocupada pelas raízes. A Figura 12.2 apresenta um perfil de solo para a análise de raízes por processamento de imagens.

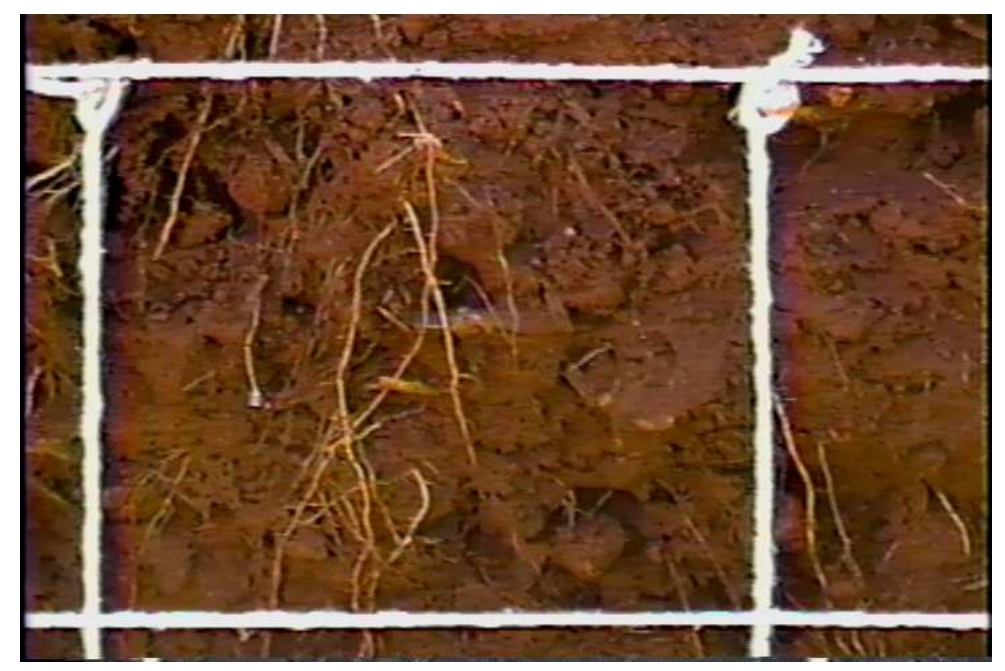

Figura 12.2: Imagem típica de um perfil de solo com raízes.

Neste trabalho serão usadas tanto imagens de perfis de raízes, como também imagens de raízes lavadas. Estas imagens foram cedidas pelo Prof. Lúcio André de Castro Jorge, pesquisador da Embrapa Instrumentação Agropecuária, São Carlos, SP. Mais informações sobre imagens de raízes e técnicas de aquisição podem ser vistas em [Neto et al., 2007].

\subsubsection{Imagens simuladas}

Além dos conjuntos de imagens citados anteriormente, foi decidido utilizar também imagens simuladas de raízes para o projeto. Imagens simuladas são, de certa forma, mais adequadas para testar um método de segmentação, pois as mesmas podem ser bem definidas com relação a todos os parâmetros envolvidos (quantidade de raízes, largura, tamanho, resolução da imagem, tipo e nível de ruído). Imagens simuladas podem ser geradas de tal forma que "imitem" as características das imagens reais de raízes com a vantagem de ter controle sobre os parâmetros. Sendo assim, além das imagens, podem ser gerados os ground-truths, ou seja, o que seria as segmentações manuais das mesmas. Pelo acima mencionado, a análise dos resultados gerados pelo método pode ser realizada com mais precisão.

Para gerar as imagens foi desenvolvido um simulador com o intuito de fornecer uma ferramenta de fácil utilização para gerar imagens de raízes com características similares às reais. As tecnologias usadas no desenvolvimento foram:

- A linguagem de programação C++;

- O Qt [Corporation, 2008], sistema usado especificamente para o desenvolvimento de programas com interface gráfica; 
- A OpenCV - Open Source Computer Vision [Bornet, 2008], biblioteca contento funções voltadas principalmente para visão computacional em tempo real.

Além disso, para a construção da rede de raízes propriamente dita, foi usado o Sistema de Lindenmayer ou sistema-L (L-system). Os sistemas-L foram introduzidos e desenvolvidos em 1968 pelo biólogo e botânico húngaro Aristid Lindenmayer da Universidade de Utrecht. Um sistema-L é um tipo particular de gramática formal (um conjunto de regras e símbolos) usados principalmente para modelar o processo de desenvolvimento ou crescimento biológico. Pode, por exemplo, modelar o crescimento de plantas e também a morfologia de uma variedade de organismos. Estes sistemas também podem ser usados para gerar fractais auto-similares como os sistemas de função iterada.

A natureza recursiva das regras dos sistemas-L conduz a auto-similaridade e, assim, facilita a descrição de formas tipo fractais. Os modelos de plantas, raízes e formas orgânicas de aspecto natural são fáceis de definir: ao incrementar um nível de recursão a forma cresce e torna-se mais completa. Estes sistemas também são populares na geração de vida artificial.

Um sistema-L é definido como um conjunto

$$
G=\{\Sigma, S, \omega, P\}
$$

onde

- $\Sigma$ (alfabeto) é um conjunto de símbolos que contêm elementos que podem ser substituídos (variáveis)

- $S$ é um conjunto de símbolos que contêm elementos que se mantem fixos (constantes)

- $\omega$ é uma cadeia de símbolos de $\Sigma$ que definem o estado inicial do sistema

- P é um conjunto de regras ou produções que definem a forma em que as variáveis podem ser substituídas por combinações de constantes e outras variáveis. Uma produção é formada por duas cadeias: o predecessor e o sucessor.

As regras gramaticais dos sistemas-L se aplicam iterativamente a partir de um estado inicial.

O simulador de raízes possui uma base com algumas regras, como acima definidas, que geram tipos diferentes de raízes. As imagens geradas pelo simulador são constituídas por raízes de diferentes tipos escolhidos aleatoriamente da base. As raízes são "desenhadas" em cima de uma textura de terra. Após criadas as imagens o usuário pode adicionar ruído gaussiano ou sal-e-pimenta e escolher o nível de borramento do filtro gaussiano que será aplicado às imagens. Além das imagens, são criadas as imagens de referência (ground-truth), sem o fundo (background) e sem o ruído. A Figura 12.3 mostra as telas do programa e a Figura 12.4 mostra dois exemplos de imagens simuladas geradas pelo programa. 


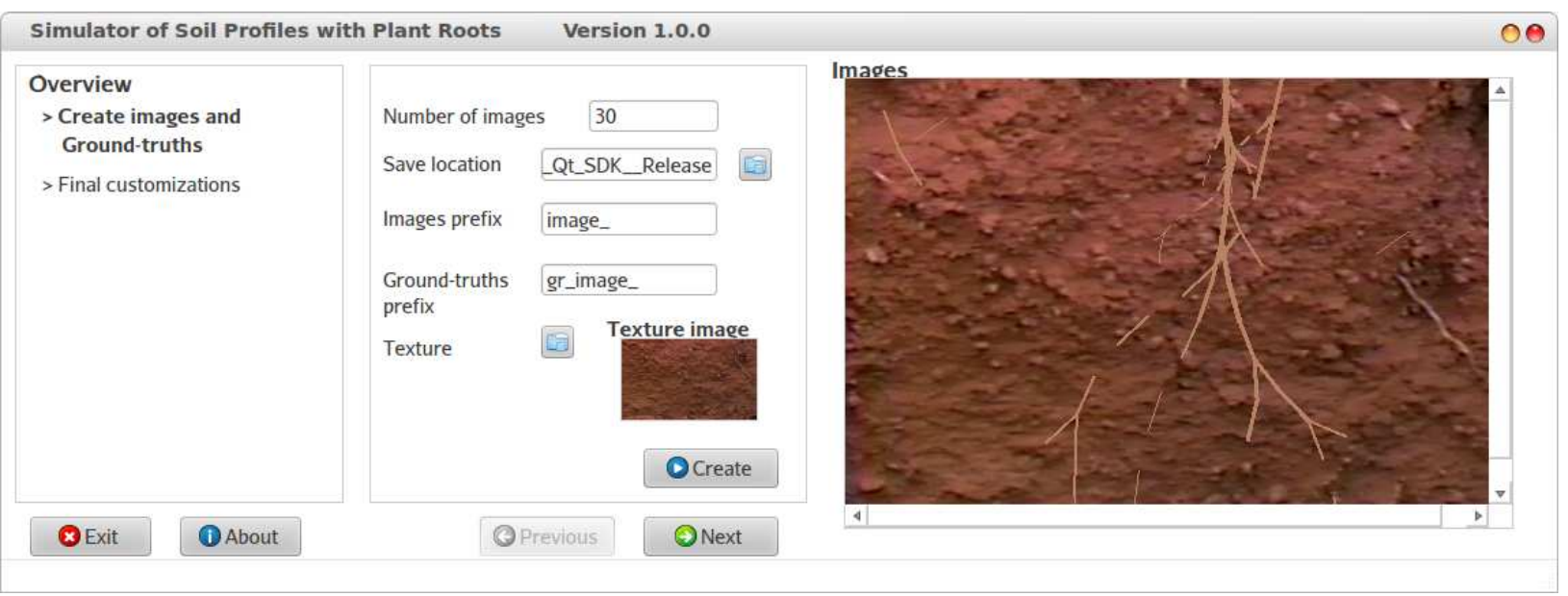

(a) Primeira tela

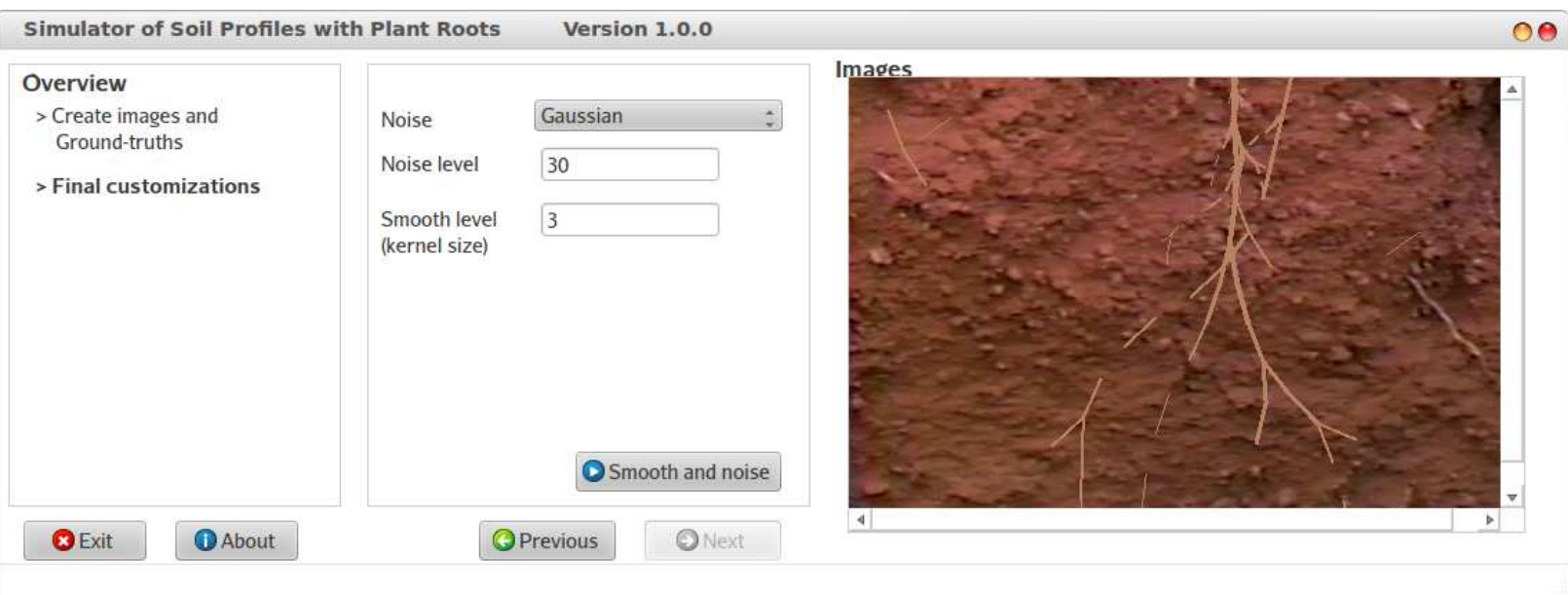

(b) Segunda tela

Figura 12.3: Telas do simulador de raízes implementado. 


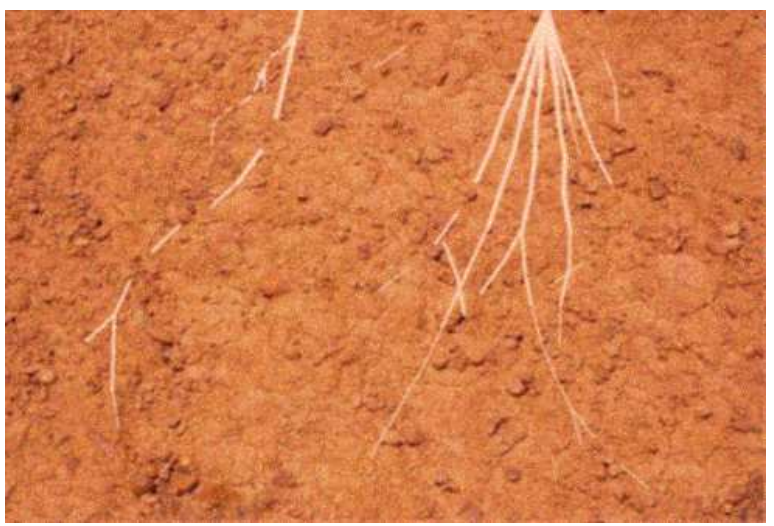

(a) Imagem 1

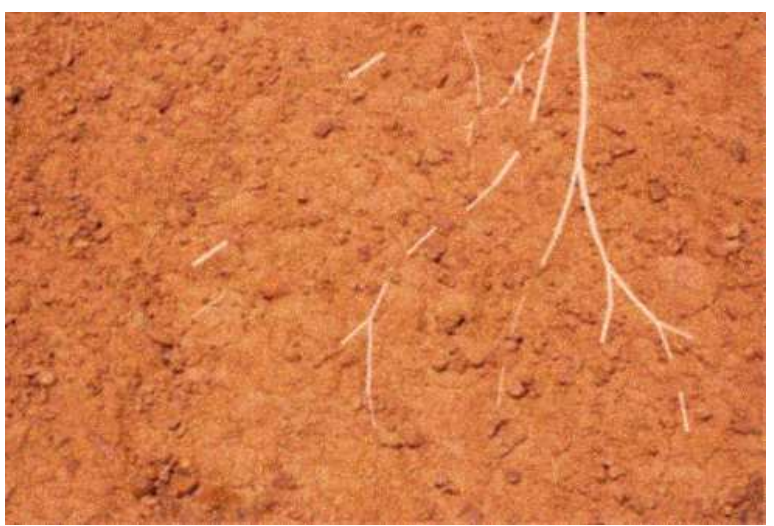

(c) Imagem 2

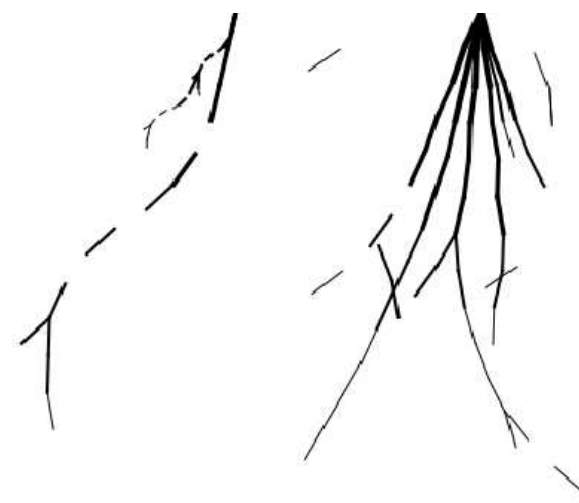

(b) Imagem 1 - referência

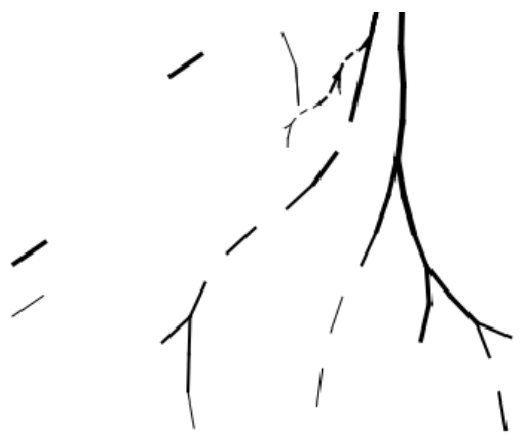

(d) Imagem 2 - referência

Figura 12.4: Imagens simuladas geradas pelo programa com suas respectivas imagens de referência. 


\subsection{Experimentos preliminares}

Utilizando as imagens apresentadas anteriormente, alguns experimentos preliminares para a extração de raízes de plantas foram realizados. O objetivo inicial é observar o comportamento do arcabouço desenvolvido para esta aplicação. A seguir são apresentados os resultados obtidos em três imagens simuladas e três imagens reais de perfil de solo.

\subsubsection{Imagens simuladas}

As Figuras 12.5, 12.6 e 12.7 apresentam os resultados obtidos para duas imagens simuladas de perfil de solo geradas com ruído gaussiano de desvio padrão 30 e com uma máscara de suavização tamanho $3 \times 3$. O detector utilizado para a fase de baixo nível foi o de razão e correlação cruzada (veja Seção 8.5). Apesar deste detector ter sido desenvolvido especificamente para imagens com ruído speckle, os resultados para as imagens ópticas com ruído gaussiano utilizadas neste trabalho foram consideravelmente bons. As partes das raízes em azul nos resultados representam partes que foram adicionadas por conexão perceptual (como explicado na Seção 9.1). Os parâmetros utilizados para o detector de baixo nível, para a construção do grafo e para a fase de alto nível são apresentados na Tabela 12.1 e a avaliação quantitativa desses resultados é apresentada na Tabela 12.2.

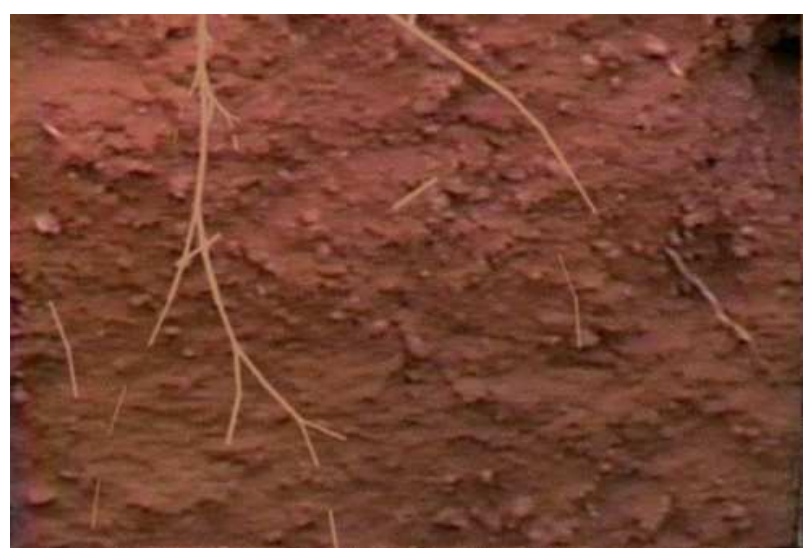

(a) Imagem original

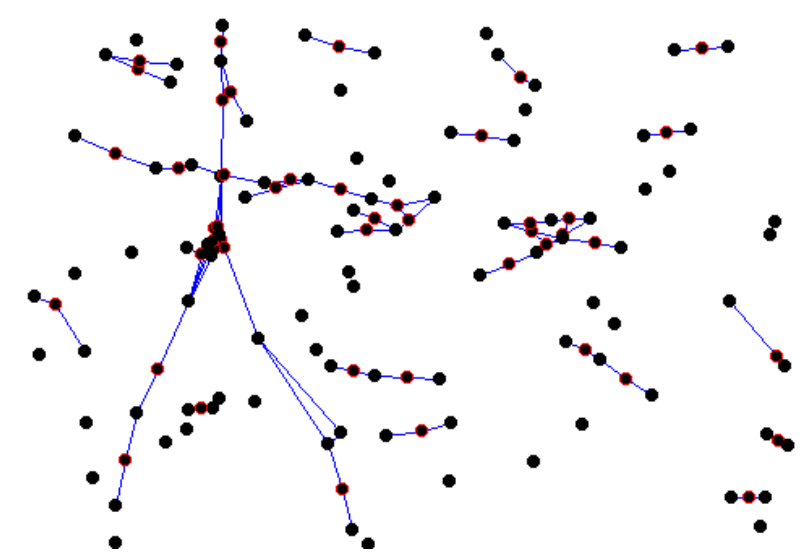

(c) Grafo construído a partir da deteç̧ão de baixo nível

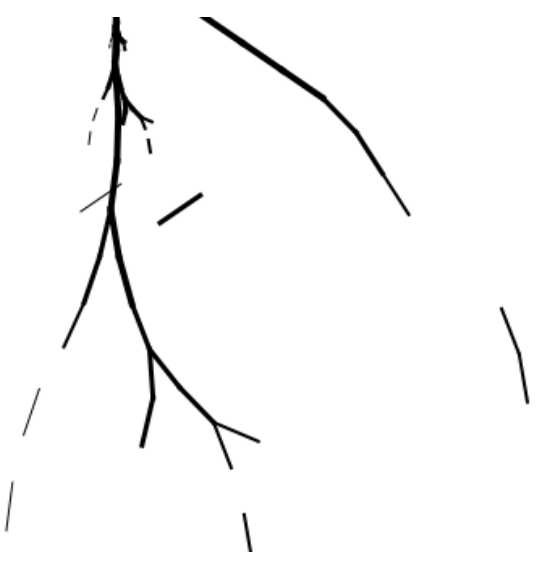

(b) Ground-truth

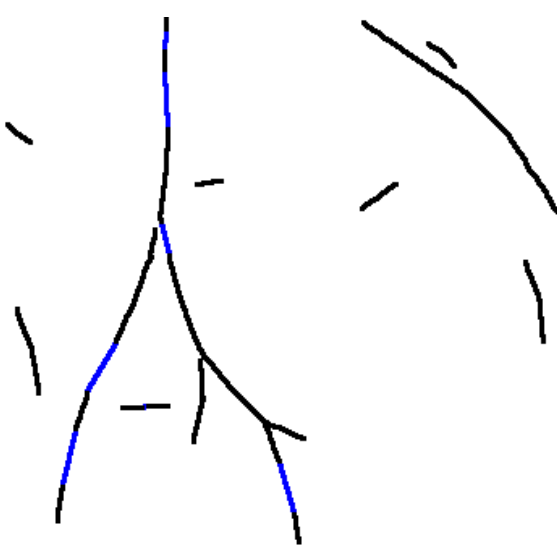

(d) Rede de raízes obtida

Figura 12.5: Experimento para extração de raízes realizado com imagem simulada. 
Tabela 12.1: Parâmetros utilizados para as imagens simuladas/reais de perfil de solo.

\begin{tabular}{|c|c|c|c|c|c|c|c|c|}
\hline \multicolumn{3}{|r|}{ Baixo nível } & \multicolumn{2}{|c|}{ Grafo } & \multicolumn{4}{|c|}{ Alto nível } \\
\hline$\rho$ & $r$ & | (altura, largura) janela & $\mathcal{L}_{\max }$ & $\mathcal{D}_{\max }$ & $K_{e}$ & $K_{\mathcal{L}}$ & $K_{c}$ & $K_{i}$ \\
\hline \multicolumn{9}{|c|}{ Imagens Simuladas } \\
\hline 0,35 & 0,4 & $(3,3)$ & 40 & 40 & $0,15 / 0,18$ & $-0,2 /-0,1$ & 0,2 & $-0,01$ \\
\hline \multicolumn{9}{|c|}{ Imagens Reais } \\
\hline 0,35 & 0,37 & $(3,3)$ & 40 & 40 & 0,25 & $-0,2$ & 0,18 & $-0,03$ \\
\hline
\end{tabular}

Tabela 12.2: Avaliação quantitativa dos resultados nas imagens de perfil de solo.

\begin{tabular}{c|l|c|r|c}
\hline \multicolumn{2}{c|}{ Dados } & Completude & Corretude & MCC \\
\hline \multirow{2}{*}{ Simulados } & Imagem 1 & $66,31 \%$ & $71,19 \%$ & 0,6726 \\
\cline { 2 - 5 } & Imagem 2 & $75,74 \%$ & $76,31 \%$ & 0,7443 \\
\cline { 2 - 5 } & Imagem 3 & $76,71 \%$ & $76,76 \%$ & 0,7471 \\
\hline \multirow{3}{*}{ Reais } & Imagem 1 & $41,48 \%$ & $32,13 \%$ & 0,3374 \\
\cline { 2 - 5 } & Imagem 2 & $48,32 \%$ & $56,13 \%$ & 0,4964 \\
\cline { 2 - 5 } & Imagem 3 & $58,70 \%$ & $44,66 \%$ & 0,4868 \\
\hline
\end{tabular}




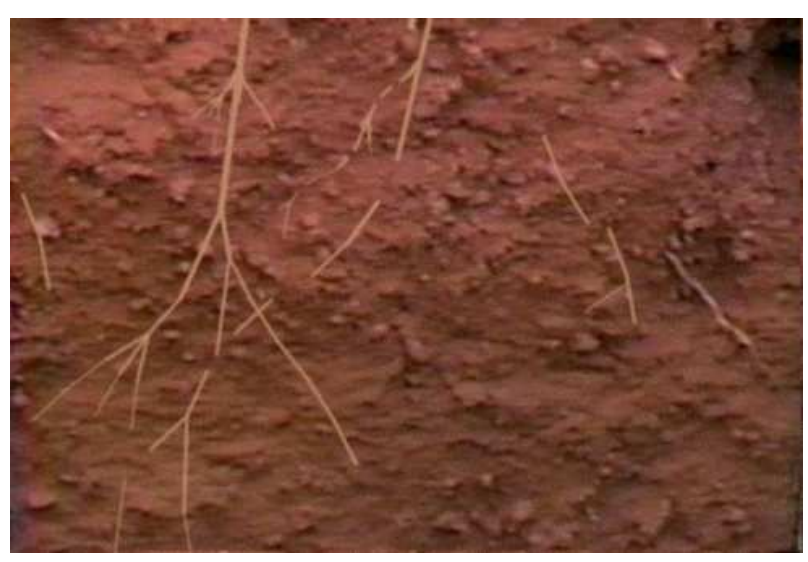

(a) Imagem original

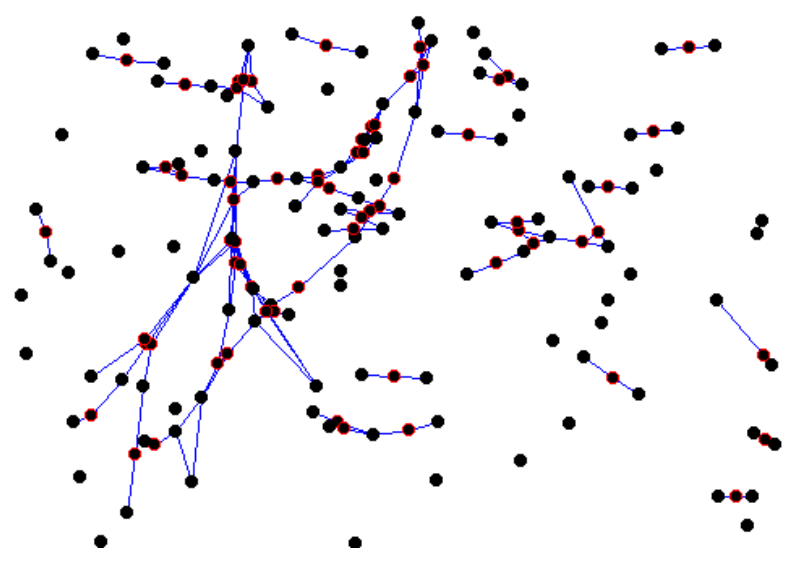

(c) Grafo construído a partir da detecção de baixo nível
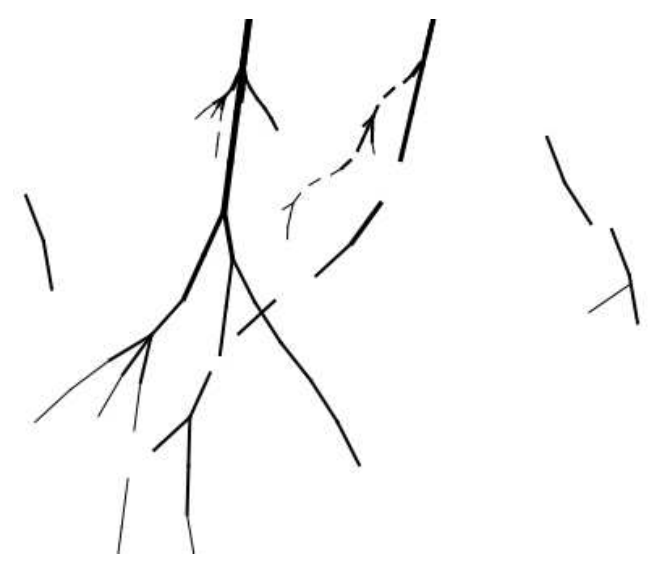

(b) Ground-truth

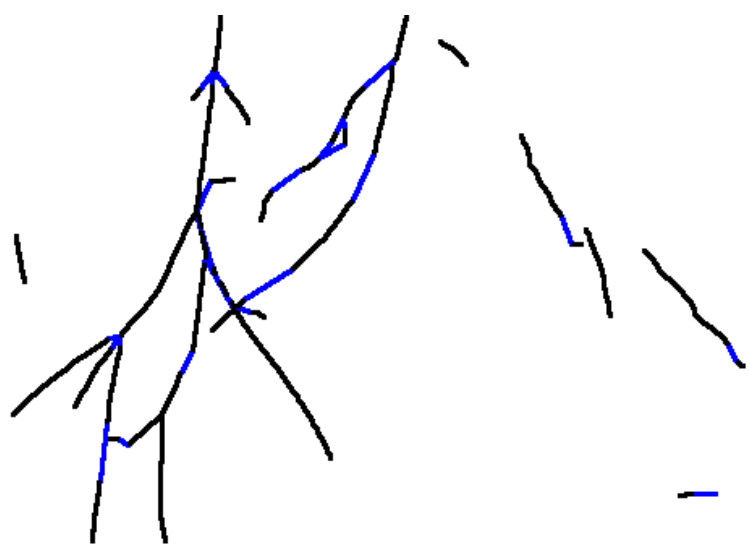

(d) Rede de raízes obtida

Figura 12.6: Experimento para extração de raízes realizado com imagem simulada.

A partir dos resultados das imagens simuladas é interessante observar que praticamente todas as raízes presentes nas imagens são detectadas. Além disso, observa-se claramente que as raízes "quebradas" são completadas de forma "perceptualmente agradável", comprovando que o método proposto é capaz de adicionar informação perceptual como desejado.

\subsubsection{Imagens reais}

As Figuras 12.8 e 12.9 apresentam os resultados obtidos para duas imagens simuladas de perfil de solo. O detector utilizado para a fase de baixo nível também foi o de razão e correlação cruzada. Os parâmetros utilizados para o detector de baixo nível, para a construção do grafo e para a fase de alto nível são apresentados na Tabela 12.1 e a avaliação quantitativa desses resultados é apresentada na Tabela 12.2.

Os resultados apresentados para as imagens reais são também bastante promissores. A grande dificuldade destas imagens é a clara "confusão" entre as raízes e a textura da imagem, além da própria complexidade estrutural das raízes e problemas de oclusão. Apesar destas dificuldades, observamos que o método foi capaz de detectar a maioria das raízes presentes na imagem, com um número aceitável de falsas detecções, principalmente na imagem da Figura 12.8. 


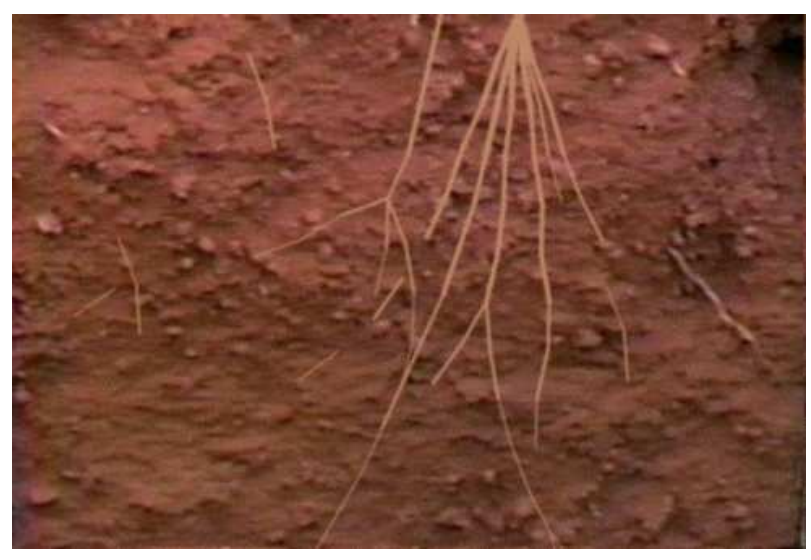

(a) Imagem original

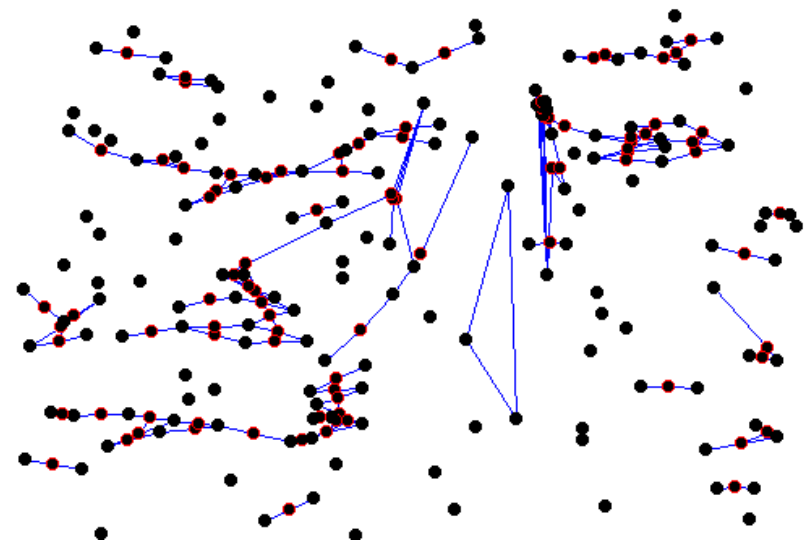

(c) Grafo construído a partir da deteç̧ão de baixo nível

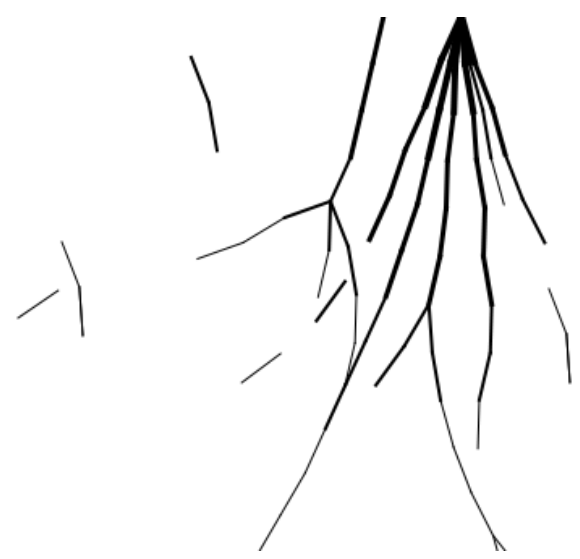

(b) Ground-truth

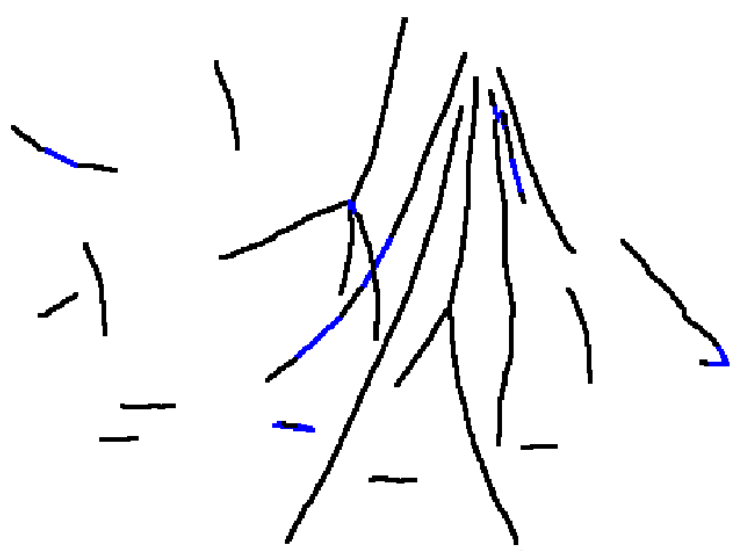

(d) Rede de raízes obtida

Figura 12.7: Experimento para extração de raízes realizado com imagem simulada. 


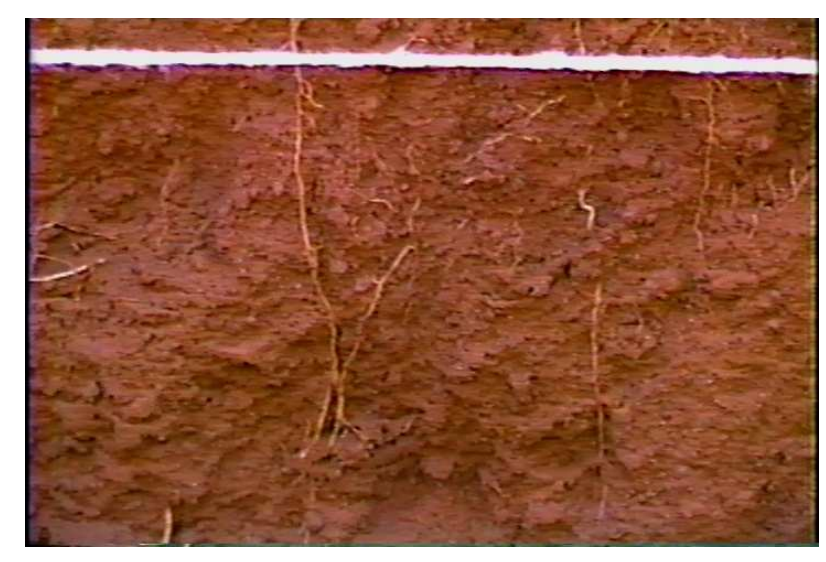

(a) Imagem original

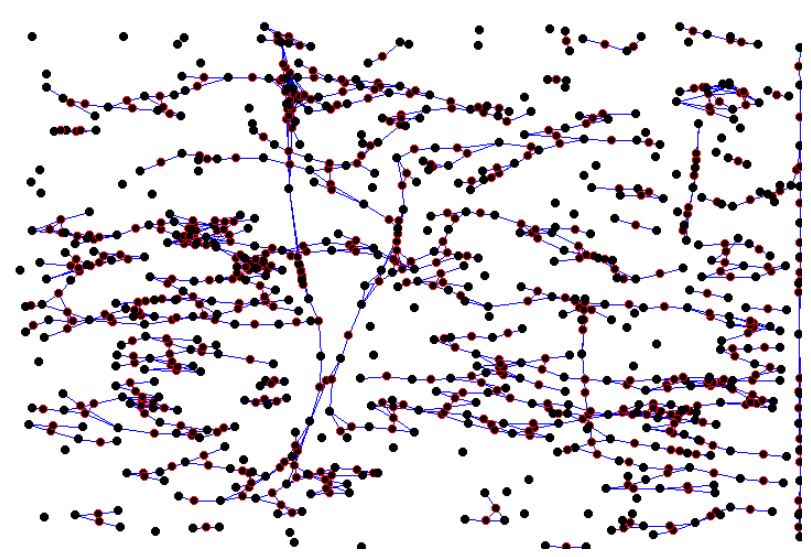

(c) Grafo construído a partir da detecção de baixo nível

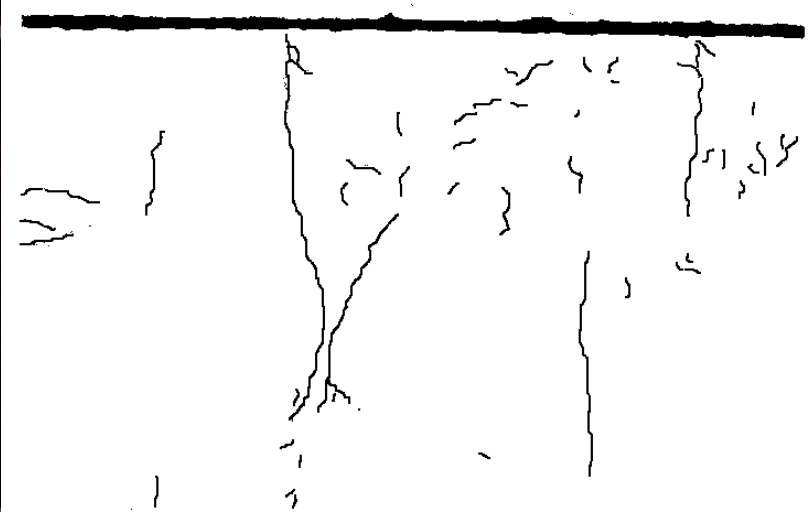

(b) Ground-truth

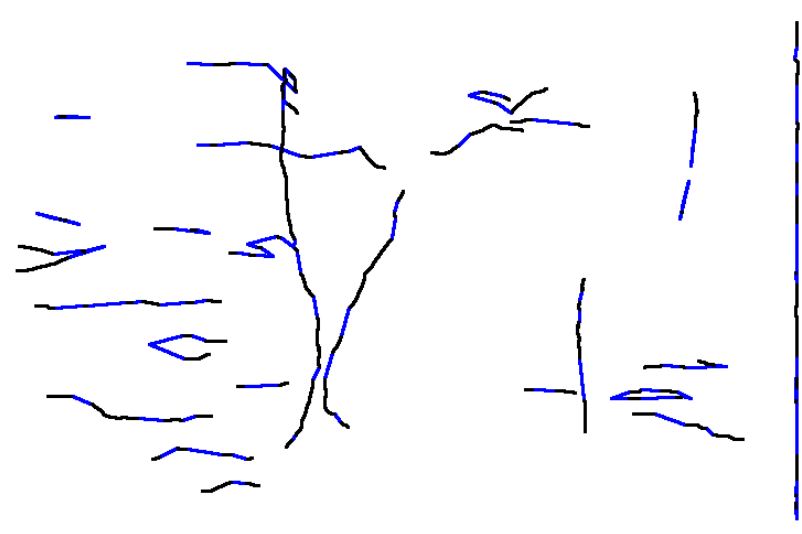

(d) Rede de raízes obtida

Figura 12.8: Experimento para extração de raízes realizado com imagem real de perfil de solo. 


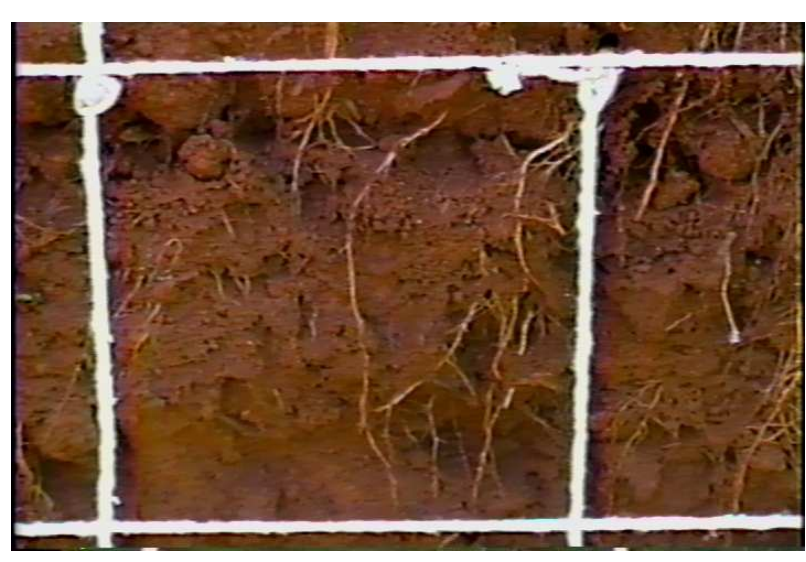

(a) Imagem original

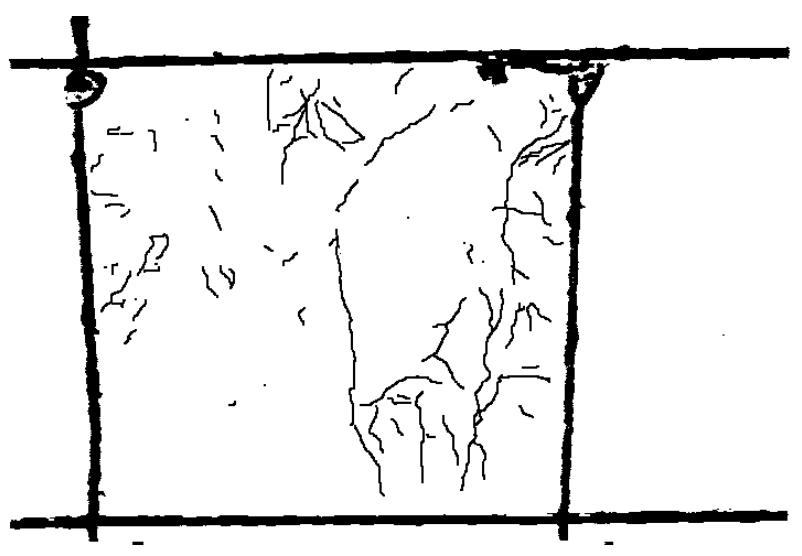

(b) Ground-truth
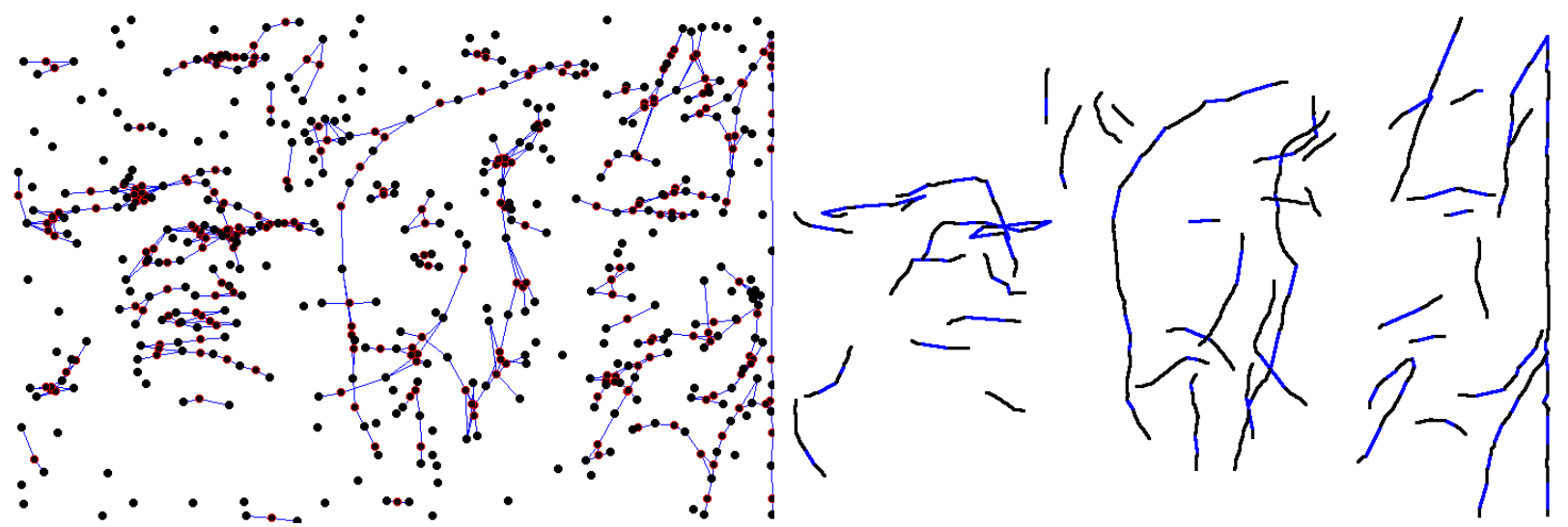

(c) Grafo construído a partir da detecção de baixo nível

(d) Rede de raízes obtida

Figura 12.9: Experimento para extração de raízes realizado com imagem real de perfil de solo. 


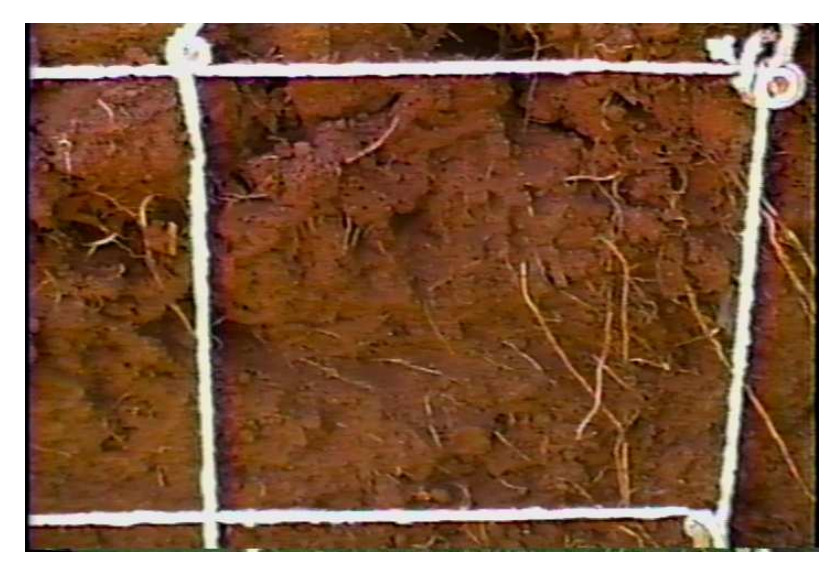

(a) Imagem original

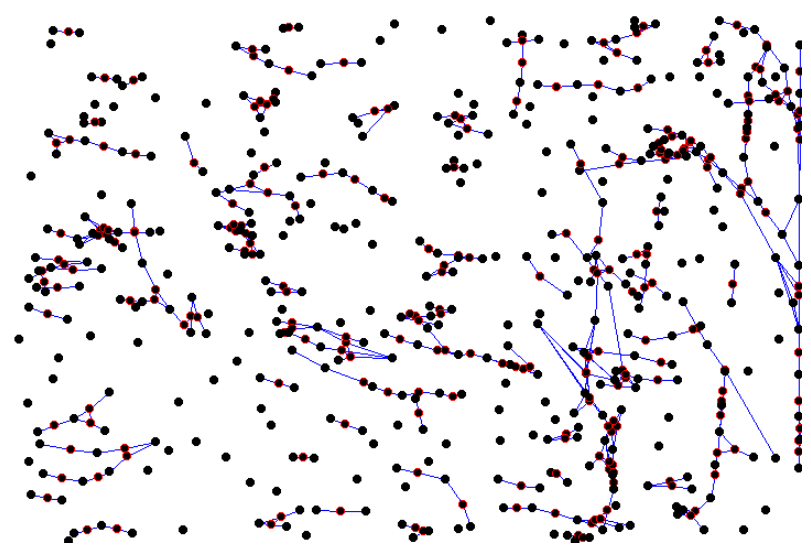

(c) Grafo construído a partir da detecção de baixo nível

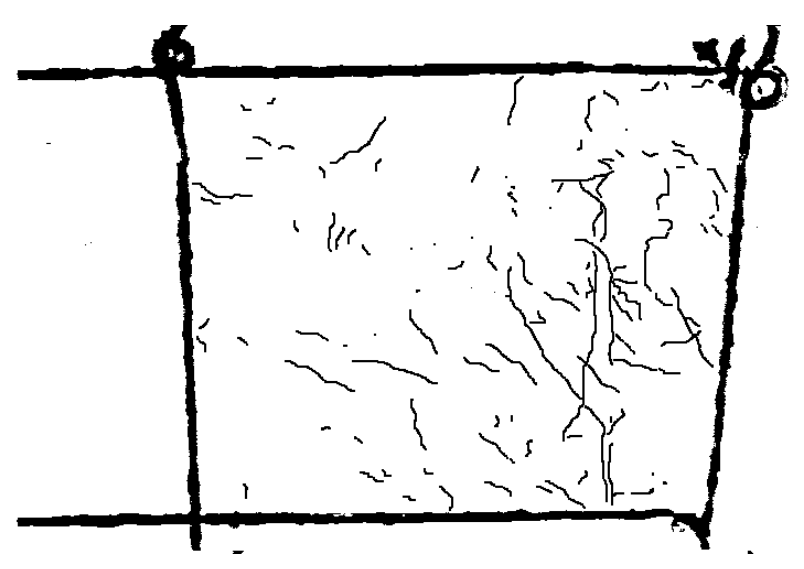

(b) Ground-truth

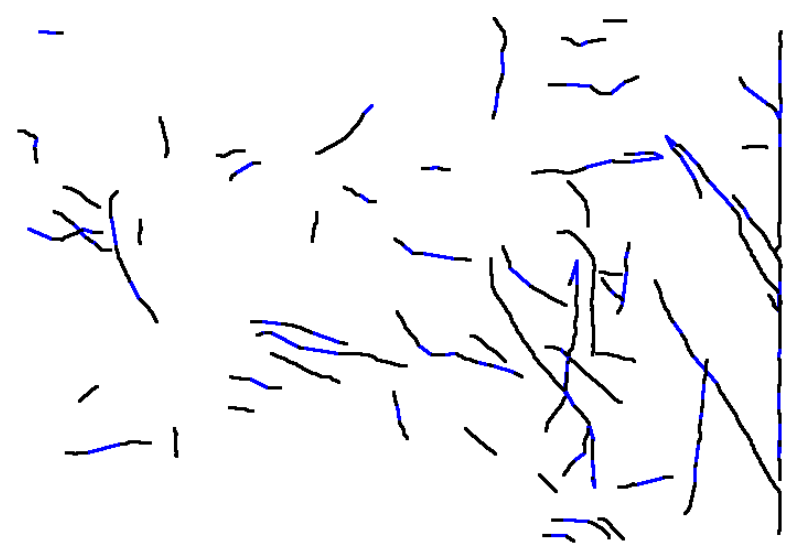

(d) Rede de raízes obtida

Figura 12.10: Experimento para extração de raízes realizado com imagem real de perfil de solo. 


\section{Parte IV}

\section{Considerações finais}

Esta parte conclui a tese. Considerações finais sobre o trabalho descrito são apresentadas e sugerimos alguns trabalhos futuros em seguida. Após esta parte, todas as publicações resultantes deste projeto são citadas. 

Considerações finais

\section{Conclusões e comentários adicionais}

"A persistência é o caminho do êxito."

Charles Chaplin

\subsection{Contribuições}

Nesta tese, exploramos o problema da detecção e análise de estruturas finas, alongadas e ramificadas. Duas aplicações são investigadas mais profundamente: a extração de redes de estradas em imagens de satélite e a extração de raízes de plantas em imagens de perfil de solo. Cada uma destas aplicações possui um nível de importância elevado nas suas respectivas áreas. De fato, esta pesquisa envolveu o trabalho conjunto entre pesquisadores de diferentes áreas como sensoriamento remoto, ciência do solo e medicina, fazendo com que ricas colaborações pudessem ser consolidadas.

Uma primeira contribuição desta tese é a revisão dos principais métodos relacionados a este trabalho, desde o problema da detecção de estruturas finas até as técnicas que utilizam modelagem com grafos e campos markovianos. Este estudo nos ajudou a guiar o desenvolvimento do trabalho no que se diz respeito às escolhas de estratégias e aos métodos envolvidos.

Na Parte II, onde discutimos detalhadamente cada fase envolvida do arcabouço proposto, algumas contribuições foram apresentadas. Primeiramente, propusemos um simulador de imagens de perfis de solo com raízes de plantas. Este simulador foi disponibilizado com licença GPL no sourceforge (http://sourceforge.net/projects/plantrootssimul/) e foi utilizado para gerar um dos grupos de imagens usado nas avaliações feitas no decorrer da pesquisa. Também realizamos uma análise detalhada de cinco detectores de cristas nas imagens de perfil de solo (reais e simuladas) e em imagens de retina com o intuito de verificar a viabilidade e desempenho destes detectores. Além disso, propusemos um novo algoritmo para ligação de cristas e bordas. Finalmente, introduzimos um novo método de fusão de baixo nível para o uso combinado de imagens de diferente modalidades, possibilitando o uso de informações complementares de forma a alcançar melhores resultados de detecção. Já no que 
diz respeito a fase de alto nível do arcabouço proposto, introduzimos o uso de componentes conexas para a representação das primitivas obtidas na fase de baixo nível, diferentemente dos métodos existentes na literatura, que normalmente usam segmentos de linha para essa representação. Esta mudança trouxe benefícios para o processamento: retenção de estruturas completas detectadas na etapa de baixo nível sem subdividí-las em muito segmentos fazendo com que haja uma diminuição considerável do tamanho do grafo construído a partir das primitivas; maior robustez no sentido da possibilidade de detecção de estruturas diferentes e com formas mais complexas. Além disso, propomos o uso de conceitos de percepção visual na modelagem markoviana, o que resulta numa melhor conexão da rede de estruturas e da possível adição de informação visual em casos de ausência de partes das estruturas.

O arcabouço proposto resultou em um software que foi usado para a avaliação do método nas duas aplicações exploradas na tese. Obtivemos resultados significativos na extração de redes de estradas em imagens de satélite ópticas e de radar, e em pilhas de imagens multitemporais. Resultados mostraram melhora em comparação a método existente na literatura e comprovaram a viabilidade do uso da abordagem de fusão proposta. Por fim, apresentamos resultados inéditos da extração de raízes de plantas em imagens de perfil de solo.

\subsection{Perspectivas}

Diversas linhas podem ser exploradas a partir do trabalho descrito nesta tese. O arcabouço proposto deve ser avaliado de forma mais ampla com o uso de um número maior de imagens, assim como regiões maiores, para as aplicações apresentadas. Uma comparação mais ampla com outros métodos existentes também deve realizada. A análise de imagens de satélite multitemporais apresentada também pode ser amplamente estendida:

1. Analisar qual a interferência da ordem de processamento das imagens de uma pilha no caso da fusão de baixo nível. Neste trabalho realizamos uma análise da fusão usando um número crescente de imagens em ordem cronológica. É possível que a mudança desta ordem possa influenciar no resultado final da extração da rede de estradas.

2. Explorar outros métodos de cálculo da média das imagens de uma pilha e outras técnicas de fusão de imagens multitemporais [Chanussot et al., 1999]. Estas técnicas podem ser estendidas ou adaptadas para o arcabouço proposto.

3. Uso de mais informações sobre aquisição das imagens.

Além disso, existem diversas outras aplicações que podem ser exploradas com o uso deste arcabouço (apresentamos um exemplo na seção seguinte).

Especificamente com relação à aplicação em imagens de satélite, observamos que o método proposto possui a característica interessante de detectar pontos de interesse na imagem, como cruzamentos de estradas. Este tipo de informação pode ser usado em outras linhas de estudo como, por exemplo, em registro de imagens, que é um problema bastante explorado e importante na área de sensoriamento remoto, por ser uma fase inicial necessária 
em vários tipos de processamento. Esses pontos de interesse podem ser usados para guiar um processo de registro das imagens. Além disso, outras modalidades de aquisição podem ser exploradas.

A fase de detecção de baixo nível pode ser melhorada através do uso de outros detectores ou da proposta de novas técnicas de detecção que levem em conta as características especícifas de estruturas finas. Na fase de alto nível, outras construções para a modelagem das primitivas de baixo nível podem ser exploradas, visto que diferentes vizinhanças podem ser usadas como intuito de melhorar a representação das estruturas. O modelo markoviano também pode ser explorado de diferentes maneiras como, por exemplo:

- Modificação de sua definição com o intuito do uso de outros algoritmos de otimização como o Graph Cuts [Greig et al., 1989];

- Extensão do modelo para o uso de mais de dois rótulos (multilabeling);

- Estimação dos parâmetros envolvidos no modelo.

Apesar do uso de conceitos de visão computacional proposto por este trabalho ser bastante preliminar, esta técnica parece ser muito promissora para o processamento e análise de estruturas complexas. Alguns trabalhos podem ser encontrados na literatura explorando o tema em campos markovianos [Ackermann et al., 1997; Posch \& Schlüter, 1998; Zhu, 1999] além de trabalhos bem recentes que envolvem agrupamento perceptual [Ming et al., 2012; Song et al., 2011b].

\subsubsection{Uma aplicação em desenvolvimento}

Uma das aplicações que está se beneficiando dos resultados desta tese é o estudo da quantificação de angiogênese em imagens de membranas corioalantóicas (CAM) de embrião de galinha. Este projeto é liderado pela professora Nina S. T. Hirata, do Instituto de Matemática e Estatística da USP e é realizado em colaboração com o Laboratório de Imunologia do Departamento de Análises Clínicas e Toxicológicas da Faculdade de Ciências Farmacêuticas da USP. A angiogênese é um processo natural de formação de vasos sanguíneos a partir de vasos pré-existentes. O crescimento descontrolado ou insuficiente dos vasos é causado pela perturbação no equilíbrio entre fatores de estímulo ou inibição da angiogênese e é considerado uma das causas de várias doenças. O efeito dos diferentes fatores é portanto estudado em laboratório, na busca do controle da angiogênese. Um dos modelos in vivo bastante utilizado nesses estudos são as membranas corioalantóicas (CAM) de embrião de galinha. A quantificação da angiogênese é importante para que resultados de diferentes ensaios possam ser comparados. No entanto, ainda não existe uma metodologia bem difundida para a quantificação, tarefa que é em geral realizada manualmente. Assim, uma abordagem computacional para a quantificação de angiogênese em imagens CAM faz-se necessária. A Figura 13.1(a) apresenta um exemplo de uma imagem em níveis de cinza de membranas corioalantóicas e a Figura 13.1(b) mostra um resultado preliminar de detecção utilizando o método proposto por este projeto. 


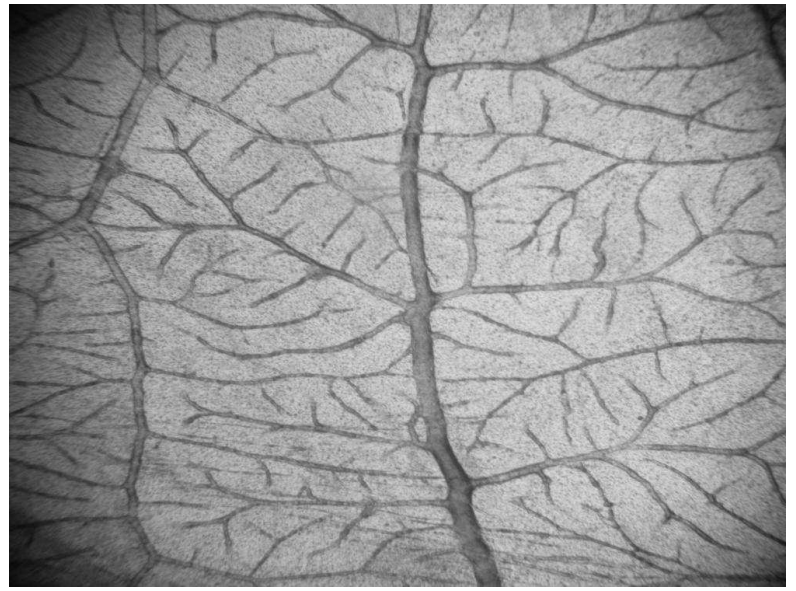

(a) Exemplo de imagem CAM original.

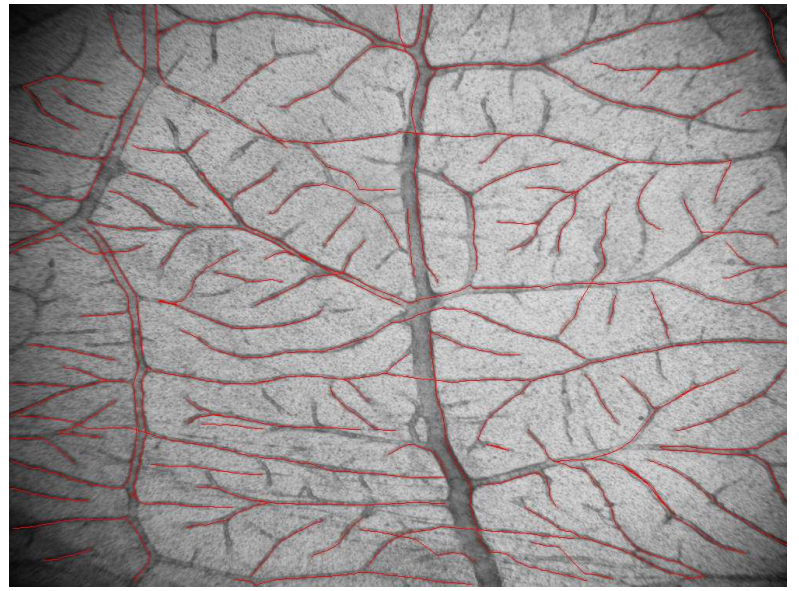

(b) Resultado da extração das veias.

Figura 13.1: Exemplo de aplicação do arcabouço proposto a uma imagem de membranas corioalantóicas: (a) Imagem original (b) Resultado da detecção.

O trabalho descrito nesta tese constitui apenas o início de um amplo estudo necessário sobre técnicas de análise e processamento de imagens com estrutudas finas. De fato, o arcabouço proposto ajudará no desenvolvimento dessas pesquisas futuras. As referências seguintes são resultantes do trabalho descrito nesta tese: [Perciano et al., 2009, 2010a,b, 2011; Sportouche et al., 2012]. 


\section{Bibliografia}

Abramoff, M. D., Magelhaes, P. J. \& Ram, S. J. (2004). Image processing with ImageJ. Biophotonics Int 11(7), 36-42. 63

Ackermann, F., Massmann, A., Posch, S., Sagerer, G. \& Schlüter, D. (1997). Perceptual Grouping of Contour Segments Using Markov Random Fields. Int. Journal of Pattern Recognition and Image Analysis 7, 11-17. 141

Adams, R. \& Bischof, L. (1994). Seeded region growing. IEEE Trans. Pattern Anal. Mach. Intell. 16(6), 641-647. URL http://dx.doi.org/10.1109/34.295913. 13

AgAm, G., III, S. G. A. \& Wu, C. (2005). Vessel tree reconstruction in thoracic CT scans with application to nodule detection. IEEE Trans. Med. Imaging 24(4), 486-499. 14

Andersson, M. T. \& Knutsson, H. (1991). Orientation estimation in ambiguous neighbourhoods. In: Proceedings of SCIA91 : Aalborg, Denmark. 10

Andrey, P. \& TARroux, P. (1998). Unsupervised segmentation of Markov random field modeled textured images using selectionist relaxation. IEEE Trans. Pattern Anal. Mach. Intell. 20(3), 252 -262 . 24

Asian, C. \& TARI, S. (2005). An axis-based representation for recognition. In: Tenth IEEE International Conference on Computer Vision, 2005. ICCV 2005., vol. 2. 20

Baeza-Yates, R. \& Ribeiro-Neto, B. (1999). Modern Information Retrieval. Addison Wesley, 1 ed. 65

Barzohar, M. \& Cooper, D. B. (1996). Automatic finding of main roads in aerial images by using geometric-stochastic models and estimation. IEEE Trans. Pattern Anal. Mach. Intell. 18, 707-721. 13

Basak, J., Chanda, B. \& Dutta Majumder, D. (1994). On edge and line linking with connectionist models. IEEE Trans. Syst., Man, Cybern. 24(3), 413-428. 15

Bauer, C. \& Bischof, H. (2008). Extracting curve skeletons from gray value images for virtual endoscopy. In: Medical Imaging and Augmented Reality (Dohi, T., SAKuma, I. \& Liao, H., eds.), vol. 5128 of Lecture Notes in Computer Science. Springer Berlin / Heidelberg, pp. 393-402. 13

Berger, J. O. (1985). Statistical Decision Theory and Bayesian Analysis. New York: SpringerVerlag. 49 
Berthod, M. \& Serendero, M. (1988). Extraction of thin networks on satellite imagery. In: ICPR88. 12

Besag, J. (1974). Spatial Interaction and the Statistical Analysis of Lattice Systems. Journal of the Royal Statistical Society. Series B (Methodological) 36(2), 192-236. URL http://dx.doi.org/10.2307/2984812. 44, 45, 46

Besag, J. (1986). On the Statistical Analysis of Dirty Pictures. Journal of the Royal Statistical Society. Series B (Methodological) 48(3), 259-302. URL http://dx.doi.org/10.2307/2345426. 51

Bigun, J., Bigun, T. \& Nilsson, K. (2004). Recognition by Symmetry Derivatives and the Generalized Structure Tensor. IEEE Trans. Pattern Anal. Mach. Intell. 26(12), 1590-1605. URL http://dx.doi.org/10.1109/TPAMI.2004.126. 10

Bigun, J. \& Granlund, G. H. (1987). Optimal orientation detection of linear symmetry. In: First International Conference on Computer Vision, ICCV (Dc, ed.). 10, 11

Bigün, J. \& Hans du Buf, J. M. (1994). N-folded Symmetries by Complex Moments in Gabor Space and their Application to Unsupervised Texture Segmentation. IEEE Trans. Pattern Anal. Mach. Intell. 16(1), 80-87. URL http://dx.doi.org/10.1109/34.273714. 10

Bitter, I., Kaufman, A. \& Sato, M. (2001). Penalized-distance volumetric skeleton algorithm. Visualization and Computer Graphics, IEEE Transactions on 7(3), 195 -206. 19

Blanchfield, P. \& Chen, X. (2010). Improving the automatic measurement of plant root growth. In: MELECON 2010 - 2010 15th IEEE Mediterranean Electrotechnical Conference. 14

BLOCH, I. (1996). Information combination operators for data fusion: a comparative review with classification. IEEE Trans. Syst., Man, Cybern. A, Syst. ,Humans 26(1), 52 -67. 64

Blum, H. (1967). A Transformation for Extracting New Descriptors of Shape. Models for the Perception of Speech and Visual Form , 362-380. 19

Bонм, W. (1979). Methods of studying root systems. New York: Springer-Verlag. 124

Bondy, A. \& MurTy, U. S. R. (2008). Graph Theory (Graduate Texts in Mathematics). London, UK, UK: Springer, 3 ed. 37, 42

Bornet, O. (2008). Opencv Library Wiki. URL http://opencvlibrary.sourceforge.net/. 96,126

Bouix, S., Siddiqi, K. \& Tannenbaum, A. (2005). Flux driven automatic centerline extraction. Medical Image Analysis 9(3), 209-221. 20

Bowyer, K., Kranenburg, C. \& Dougherty, S. (2001). Edge detector evaluation using empirical ROC curves. Comput. Vis. Image Underst. 84(1), 77-103. 66

Brunner, D., Lemoine, G. \& Bruzzone, L. (2008). Extraction of building heights from VHR SAR imagery using an iterative simulation and match procedure. In: IEEE Int. Geosci. and Remote Sensing Symp., 2008. IGARSS '08. 28

Bustos, O. H. \& Frery, A. C. (1992). Simulação estocástica: teoria e algoritmos (versão completa). Monografias de Matemática, 49. Rio de Janeiro, RJ: CNPq/IMPA. 41

Camps-Valls, G., Bandos Marsheva, T. \& Zhou, D. (2007). Semi-supervised graph-based hyperspectral image classification. Geoscience and Remote Sensing, IEEE Transactions on 45(10), $3044-3054.18$ 
CAnny, J. (1986). A computational approach to edge detection. IEEE Trans. Pattern Anal. Mach. Intell. 8(6), 679-698. 10, 12, 13, 57, 58

Carincotte, C., Derrode, S. \& Bourennane, S. (2006). Unsupervised change detection on SAR images using fuzzy hidden Markov chains. Geoscience and Remote Sensing, IEEE Transactions on $\mathbf{4 4}(2), 432-441.26$

Cesar, R., Bengoetxea, E. \& Bloch, I. (2002). Inexact graph matching using stochastic optimization techniques for facial feature recognition. In: Proceedings. 16th International Conference on Pattern Recognition, vol. 2. 21

Chanussot, J., Mauris, G. \& Lambert, P. (1999). Fuzzy Fusion Techniques for Linear Features Detection in Multitemporal SAR Images. IEEE Trans. Geosci. Remote Sens. 37(3), 1292-1305. 12, 140

Chen, F. \& Li, Y.-F. (2007). A multiresolution segmentation method for tree crown image using wavelets. In: International Conference on Wavelet Analysis and Pattern Recognition, $200 \%$. ICWAPR '0\%., vol. 4.3

Chen, H. \& Hale, J. (1995). An algorithm for mr angiography image enhancement. Magnetic Resonance in Medicine 33(4), 534-540. URL http://dx.doi.org/10.1002/mrm.1910330412. 11

Chen, J., Sato, Y. \& Tamura, S. (2000). Orientation Space Filtering for Multiple Orientation Line Segmentation. IEEE Trans. Pattern Anal. Mach. Intell. 22(5), 417-429. URL http://dx.doi.org/10.1109/34.857000. 10

Chen, X., Fang, T., Huo, H. \& Li, D. (2011). Graph-Based Feature Selection for ObjectOriented Classification in VHR Airborne Imagery. Geoscience and Remote Sensing, IEEE Transactions on 49(1), $353-365.18$

Chen, Y. \& Zhou, X. (2010). Plant root image processing and analysis based on 2D scanner. In: IEEE Fifth International Conference on Bio-Inspired Computing: Theories and Applications (BIC-TA). 3, 14

Clemens, D. T. (1991). Region-based Feature Interpretation for Recognizing 3D Models in 2D Images. No. 1307 in AI-TR. MIT Artificial Intelligence Laboratory. URL http://books.google.com.br/books?id=rI1VPgAACAAJ. 13

CNPDIA, E. . (1996). Sistema integrado para análise de raízes e cobertura do solo - SIARCS. BR NPI 004276. Patente requerida em dez. 1996. 14

Consularo, L. \& Cesar, R. (2005). Quadtree-based inexact graph matching for image analysis. In: Computer Graphics and Image Processing, 2005. SIBGRAPI 2005. 18th Brazilian Symposium on. 18

Consularo, L., Cesar, R. \& Bloch, I. (2007). Structural image segmentation with interactive model generation. In: IEEE International Conference on Image Processing, 200\%. ICIP 200\%., vol. 6.18

Cordero-Grande, L., Vegas-Sanchez-Ferrero, G., Casaseca-de-la Higuera, P. \& Alberola-Lopez, C. (2012). A Markov Random Field Approach for Topology-Preserving Registration: Application to Object-Based Tomographic Image Interpolation. IEEE Trans. Image Process. 21(4), $2047-2061.25$

Cornforth, D. J., Jelinek, H. F., Leandro, J. J., Soares, J. V. B., Cesar-Jr., R. M., Cree, M. J., Mitchell, P. \& Bossomaier, T. R. J. (2005). Development of retinal blood vessel segmentation methodology using wavelet transforms for assessment of diabetic retinopathy. Complexity International 11. 3, 14 
Corporation, N. (2008). Qt - A cross-plataform application and UI framework. URL http://qt.nokia.com/products/. Última consulta em junho de 2009. 96, 125

Cree, M. J., Leandro, J. J. G., Soares, J. V. B., Cesar-Jr., R. M., Tang, G., Jelinek, H. F. \& Cornforth, D. J. (2005). Comparison of various methods to delineate blood vessels in retinal images. In: Proc. of the 16th National Congress of the Australian Institute of Physics. 3,14

Czerwinski, R. N., Jones, D. L. \& JR., W. D. O. (1999). Detection of lines and boundaries in speckle images - application to medical ultrasound. IEEE Trans. Med. Imaging 18(2), 126-136. 11

Danielsson, P.-E. E. \& Lin, Q. (2001). A New Shape Space for Second Order 3D-Variations. In: Proceedings of the 4th International Workshop on Visual Form, IWVF-4. London, UK, UK: Springer-Verlag. URL http://dl.acm.org/citation. cfm?id=645651.665323. 11

Davies, E. R. (2005). Machine Vision: Theory, Algorithms, Practicalities. Morgan Kaufmann. 1

Deguchi, K., Izumitani, T. \& Hontani, H. (2001). Detection and enhancement of line structures in an image by anisotropic diffusion. In: Proceedings of the 4th International Workshop on Visual Form, IWVF-4. London, UK, UK: Springer-Verlag. URL http://dl.acm.org/citation.cfm?id=645651.665347. 11

Deguchi, K., Izumitani, T. \& Hontani, H. (2002). Detection and enhancement of line structures in an image by anisotropic diffusion. Pattern Recognition Letters 23(12), 1399 - 1405. URL http://www.sciencedirect.com/science/article/pii/S0167865502001009. 13

Dehkordi, M. T., Sadri, S. \& Doosthoseini, A. (2011). A review of coronary vessel segmentation algorithms. Journal of Medical Signals and Sensors 1(1). URL http://www.jmss.mui.ac.ir/article/view/6686. 13

Dekking, F. M., Kraaikamp, C., Lopuhä̈, H. P. \& Meester, L. E. (2005). A Modern Introduction to Probability and Statistics: Understanding Why and How. Springer. 39

Dell'Acqua, F., Gamba, P. \& Lisini, G. (2005). Road extraction aided by adaptive directional filtering and template matching. In: Proc. URBAN, vol. 34. Tempe, AZ. 12

Deng, H. \& Clausi, D. (2005). Unsupervised segmentation of synthetic aperture Radar sea ice imagery using a novel Markov random field model. IEEE Trans. Geosci. Remote Sens. 43(3), 528 $-538.24$

Desolneux, A., Moisan, L. \& Morel, J. M. (2000a). Maximal Meaningful Events and Applications to Image Analysis. Tech. rep., preprint CMLA No 2000-22. URL http://www. cmla.ens-cachan.fr/Cmla/Publications/2000/Abstract2000-22.html. 55

Desolneux, A., Moisan, L. \& Morel, J.-M. (2000b). Meaningful Alignments. International Journal of Computer Vision 40, 7-23. URL http://dx.doi.org/10.1023/A:1026593302236. 10.1023/A:1026593302236. 56

Desolneux, A., Moisan, L. \& Morel, J.-M. (2001). Edge Detection by Helmholtz Principle. J. Math. Imaging Vis. 14(3), 271-284. URL http://dx.doi.org/10.1023/A:1011290230196. 55

Desolneux, A., Moisan, L. \& Morel, J.-M. (2007). From Gestalt Theory to Image Analysis: A Probabilistic Approach. Springer Publishing Company, Incorporated, 1st ed. 53

Deza, M. M. \& Deza, E. (2006). Dictionary of Distances. London, UK, UK: Elsevier Science, 1 ed. 36 
DigitalGlobe (2001). Satellite imagery and geospatial information products. URL http://www.digitalglobe.com/. Última consulta em julho de 2012. 107

Dima, A., Scholz, M. \& Obermayer, K. (2002). Automatic segmentation and skeletonization of neurons from confocal microscopy images based on the 3-D wavelet transform. IEEE Transactions on Image Processing 11(4), 790-801. 3, 14

Dixon, R. N. \& TAYlor, C. J. (1979). Automated asbestos fibre counting. In: Machine Aided Image Analysis. Institute of Physics, pp. 178-185. 10

DLR (2004). TerraSAR-X science service system. URL http://sss.terrasar-x.dlr.de/. Última consulta em julho de 2012. 107

Dodds, P. S. \& Rothman, D. H. (1999). Unified view of scaling laws for river networks. Physical Review E 59(5), 4865-4877. 9

Dougherty, E. R. \& Lotufo, R. A. (2003). Hands-on Morphological Image Processing. SPIE Publications. 61

Eichel, P. H. \& Delp, E. J. (1985). Sequential edge detection in correlated random fields. In: Proceedings of the IEEE Computer Vision and Pattern Recognition Conference. 15

Eichel, P. H., Delp, E. J., Koral, K. \& Buda, A. J. (1988). A method for a fully automatic definition of coronary arterial edges from cineangiograms. IEEE Trans. Med. Imag. 7(4), 313-320. 15

El-Baz, A., Farag, A., Gimelfarb, G. \& Abdel-Hakim, A. (2006). Robust Image Registration Based on Markov-Gibbs Appearance Model. In: 18th International Conference on Pattern Recognition, 2006. ICPR 2006., vol. 2. 24

Espona, L., Carreira, M. J., Penedo, M. F. G. \& Ortega, M. (2008a). Retinal vessel tree segmentation using a deformable contour model. In: ICPR. IEEE. 14

Espona, L., Carreira, M. J., Penedo, M. G. \& Ortega, M. (2008b). Comparison of pixel and subpixel retinal vessel tree segmentation using a deformable contour model. In: CIARP 08: Proceedings of the 13th Iberoamerican congress on Pattern Recognition. Berlin, Heidelberg: Springer-Verlag. 14

Falcão, A. X., Udupa, J. K., Samarasekera, S., Sharma, S., Hirsch, B. E. \& Lotufo, R. D. A. (1998). User-steered image segmentation paradigms: live wire and live lane. Graph. Models Image Process. 60(4), 233-260. URL http://dx.doi.org/10.1006/gmip.1998.0475. 18

Falcao, A., Udupa, J. \& Miyazawa, F. (2000). An ultra-fast user-steered image segmentation paradigm: live wire on the fly. Medical Imaging, IEEE Transactions on 19(1), 55-62. 18

Falcão, A. X. \& Bergo, F. P. G. (2004). Interactive volume segmentation with differential image foresting transforms. IEEE Trans. on Med. Imaging 23(9), 1100-1108. 18

FAlcÃo, A. X. \& Udupa, J. K. (2000). A 3D generalization of usersteered live-wire segmentation. Medical Image Analysis 4(4), 389 - 402. URL http://www.sciencedirect.com/science/article/pii/S1361841500000232. 18

Figueiredo, M. \& Leitao, J. (1997). Unsupervised image restoration and edge location using compound Gauss-Markov random fields and the MDL principle. IEEE Trans. Image Process. 6(8), $1089-1102.25$

Fuortoft, R., Delignon, Y., Pieczynski, W., Sigelle, M. \& Tupin, F. (2003). Unsupervised classification of radar images using hidden Markov chains and hidden Markov random fields. IEEE Trans. Geosci. Remote Sens. 41(3), 675 - 686. 24 
Frangi, R. F., Niessen, W. J., Vincken, K. L. \& Viergever, M. A. (1998). Multiscale vessel enhancement filtering. In: Medical Image Computing and Computer-Assisted Interventation MICCAI'98. Springer-Verlag. 10, 62

Frery, A. C., Correia, A. H. \& Freitas, C. C. (2007). Classifying multifrequency fully polarimetric imagery with multiple sources of statistical evidence and contextual information. IEEE Trans. Geosci. Remote Sens. 45(10), 3098-3109. 24

Fridman, Y., Pizer, S., Aylward, S. \& Bullitt, E. (2003). Segmenting 3D Branching Tubular Structures Using Cores. In: Medical Image Computing and Computer-Assisted Intervention MICCAI 2003 (Ellis, R. \& PETERs, T., eds.), vol. 2879 of Lecture Notes in Computer Science. Springer Berlin / Heidelberg, pp. 570-577. 13

Gamba, P., Dell'Acqua, F. \& Lisini, G. (2006). Improving urban road extraction in highresolution images exploiting directional filtering, perceptual grouping, and simple topological concepts. IEEE Geosci. Remote Sens. Lett. 3(3), 387-391. 12

Ge, Y., Stelts, D. R., Wang, J. \& Vining, D. J. (1999). Computing the centerline of a colon: a robust and efficient method based on 3d skeletons. J Comput Assist Tomogr 23(5), 786-94. 20

Geman, S. \& Geman, D. (1984). Stochastic Relaxation, Gibbs Distributions, and the Bayesian Restoration of Images. IEEE Trans. Pattern Anal. Mach. Intell. PAMI-6(6), 721 -741. 47, 51

Glocker, B., Zikic, D., Komodakis, N., Paragios, N. \& Navab, N. (2009). Linear image registration through mrf optimization. In: Biomedical Imaging: From Nano to Macro, 2009. ISBI '09. IEEE International Symposium on. 24

Golzarian, M. (2011). Adaptive segmentation of plant images, an integration of color space features and self-organizing maps. In: 2011 International Conference on Multimedia Technology (ICMT). 3

Gonzalez, R. C. \& Woods, R. E. (2008). Digital Image Processing. Prentice Hall, 3 ed. 1, 10, 58,61

Granlund, G. H. \& Knutsson, H. (1995). Signal Processing for Computer Vision. Norwell, MA, USA: Kluwer Academic Publishers. 10

Greig, D. M., Porteous, B. T. \& Seheult, A. H. (1989). Exact maximum a posteriori estimation for binary images. Journal of the Royal Statistical Society. Series B (Methodological), 271-279. 141

Griffeath, D. (1976). Introduction to random fields, chap. 12. New York: Springer-Verlag, 2 ed., p. $425-458.47$

Hahn, H. K., Preim, B., Selle, D. \& Peitgen, H.-O. (2001). Visualization and interaction techniques for the exploration of vascular structures. In: Visualization, 2001. VIS '01. Proceedings. 13

HajJar, A. \& Chen, T. (1999). A VLSI architecture for real-time edge linking. IEEE Trans. Pattern Anal. Mach. Intell. 21(1), 89-94. 15

Hammersley, J. M. \& Clifford, P. (1971). Markov field on finite graphs and lattices. 45, 46 Han, X., Xu, C., Braga-Neto, U. \& Prince, J. (2002). Topology correction in brain cortex segmentation using a multiscale, graph-based algorithm. Medical Imaging, IEEE Transactions on $\mathbf{2 1}(2), 109-121.18$

Hanson, A. R. \& Riseman, E. M. (1978). Segmentation of natural scenes. Computer Vision Systems , 129-163. 13 
Haralick, R. \& Shapiro, L. (1985). Image segmentation techniques. Computer vision, graphics, and image processing $\mathbf{2 9}(1), 100-132.13$

Haralick, R. M. (1983). Ridges and valleys on digital images. Computer Vision, Graphics, and Image Processing 22(1), 28 - $38 . \quad$ URL http://www.sciencedirect.com/science/article/pii/0734189X83900944. 10

Hassouna, M. \& FArag, A. (2009). Variational curve skeletons using gradient vector flow. IEEE Trans. Pattern Anal. Mach. Intell. 31(12), 2257-2274. 20

Hedman, K., Stilla, U., Lisini, G. \& Gamba, P. (2010). Road network extraction in VHR SAR images of urban and suburban areas by means of class-aided feature-level fusion. IEEE Geosci. Remote Sens. Lett. 48(3), 1294 - 1296. 12, 28

Held, K., Kops, E., Krause, B., Wells, I., W.M., Kikinis, R. \& Muller-Gartner, H.W. (1997). Markov random field segmentation of brain MR images. IEEE Trans. Med. Imag. 16(6), $878-886.24$

Hladi̊Vka, J. \& GRÖller, E. (2002). Exploiting the Hessian matrix for contentbased retrieval of volume-data features. The Visual Computer 18, 207-217. URL http://dx.doi.org/10.1007/s003710100141. 10.1007/s003710100141. 14

Horowitz, S. L. \& Pavlidis, T. (1974). Picture Segmentation by a directed split-and-merge procedure. Proceedings of the 2nd International Joint Conference on Pattern Recognition, Copenhagen, Denmark , 424-433. 13

Horsfield, K. \& Cumming, G. (1967). Angles of branching and diameters of branches in the human bronchial tree. Bull. Math. Biophys. 29, 245-259. 9

Horsfield, K., Dart, G., Olson, D. E., F., F. G. \& Cumming, G. (1971). Models of the human bronchial tree. J. Appl. Physiol. 31(2), 207-217. 9

Huang, A., Abugharbieh, R. \& Tam, R. (2010). A Novel Rotationally Invariant Region-Based Hidden Markov Model for Efficient 3-D Image Segmentation. IEEE Trans. Image Process. 19(10), $2737-2748.24$

Huang, Q., Jain, A., Stockman, G. \& Smucker, A. (1992). Automatic image analysis of plant root structures. In: Pattern Recognition, 1992. Vol.II. Conference B: Pattern Recognition Methodology and Systems, Proceedings., 11th IAPR International Conference on. 3, 14

Jacob, M. \& Unser, M. (2004). Design of Steerable Filters for Feature Detection Using CannyLike Criteria. IEEE Trans. Pattern Anal. Mach. Intell. 26, 1007-1019. 10, 63

Jenneson, P., Gilboy, W., Morton, E., Luggar, R., Gragory, P. \& Hutchinson, D. (1999). Optimisation of X-ray micro-tomography for the in situ study of the development of plant roots. In: Nuclear Science Symposium, 1999. Conference Record. 1999 IEEE, vol. 1.14

JeOn, B.-K., JAng, J.-H. \& Hong, K.-S. (2002). Road detection in spaceborne SAR images using a genetic algorithm. IEEE Trans. Geosci. Remote Sens. 40(1), 22-29. URL http://dx.doi.org/10.1109/36.981346. 13

Jing, G., Wenlong, S. \& Heming, J. (2011). Edge detection of plant roots image based on genetic BP neural network. In: 2011 IEEE International Conference on Automation and Logistics (ICAL). 3,14

Kang, H. W. \& Shin, S. Y. (2002). Enhanced lane: interactive image segmentation by incremental path map construction. Graph. Models 64(5), 282-303. URL http://dx.doi.org/10.1016/S1077-3169(02)00007-2. 18 
Kanizsa, G. (1979). Organization in Vision: Essays on Gestalt Perception. Praeger. 5

Kanizsa, G. (1996). Grammatica del Vedere. Diderot Editeur. Traduction française: La grammaire du voir. 53

Katartzis, A., Sahli, H., Pizurica, V. \& Cornelis, J. (2001). A model-based approach to the automatic extraction of linear features from airborne images. IEEE Trans. Geosci. Remote Sens. 39(9), 2073-2079. 12, 13

Kervrann, C. \& Heitz, F. (1995). A Markov random field model-based approach to unsupervised texture segmentation using local and global spatial statistics. IEEE Trans. Image Process. $4(6), 856-862.24$

Kindermann, R. (1980). Markov Random Fields and Their Applications. Amer Mathematical Society, 1 ed. 43

Kirbas, C. \& Quek, F. (2004). A review of vessel extraction techniques and algorithms. ACM Comput. Surv. 36(2), 81-121. URL http://doi.acm.org/10.1145/1031120.1031121. 13

Kirkpatrick, S., Gelatt, C. D. \& Vecchi, M. P. (1983). Optimization by Simulated Annealing. Science 220, 4598(4598), 671-680. URL http://citeseerx.ist.psu.edu/viewdoc/summary?doi=10.1.1.18.4175. 50

Knutsson, H. (1989). Representing local structure using tensors. Tech. rep., Computer Vision Laboratory, Linkoping University. 10

Krissian, K. (2002). Flux-based Anisotropic Diffusion Applied to Enhancement of 3-D Angiogram. IEEE Trans Med Imaging 21(11), 1440-1442. 11

Krissian, K., Malandain, G. \& Ayache, N. (1997). Directional anisotropic diffusion applied to segmentation of vessels in 3d images. In: Proceedings of the First International Conference on Scale-Space Theory in Computer Vision, SCALE-SPACE '97. London, UK, UK: Springer-Verlag. URL http://dl.acm.org/citation.cfm?id=647081.714947. 11

Kutka, R. \& Stier, S. (1996). Extraction of line properties based on direction fields. IEEE Trans Med Img 15(1), 51-58. 11

Lacoste, C., Descombes, X. \& Zerubia, J. (2005). Point processes for unsupervised line network extraction in remote sensing. IEEE Transactions on Pattern Analysis and Machine Intelligence 27(10), 1568-1579. 12

Lesage, D., Angelini, E. D., Bloch, I. \& Funka-Lea, G. (2009). A review of 3D vessel lumen segmentation techniques: Models, features and extraction schemes. Medical Image Analysis 13(6), 819 - 845. URL http://www.sciencedirect.com/science/article/pii/S136184150900067X. Includes Special Section on Computational Biomechanics for Medicine. 13

Li, J., Randall, J. \& Guan, L. (2003). Perceptual image processing for digital edge linking. In: Canadian Conference on Electrical and Computer Engineering, 2003. IEEE CCECE 2003., vol. 2. 15

Li, Q., You, J., Zhang, L. \& Bhattacharya, P. (2006). A multiscale approach to retinal vessel segmentation using gabor filters and scale multiplication. In: IEEE International Conference on Systems, Man and Cybernetics, 2006. SMC '06., vol. 4. 14

LI, S. Z. (1994). Markov random field models in computer vision. In: Proceedings of the Third European Conference-Volume II on Computer Vision - Volume II, ECCV '94. London, UK, UK: Springer-Verlag. URL http://dl.acm.org/citation.cfm?id=645308.649134. 23 
LI, S. Z. (1995). Markov random field modeling in computer vision. London, UK, UK: SpringerVerlag. 23, 44

LI, S. Z. (2009). Markov Random Field Modeling in Image Analysis. Springer Publishing Company, Incorporated, 3rd ed. 43, 46

LindeBerg, T. (1996). Edge detection and ridge detection with automatic scale selection. International Journal of Computer Vision 30, 465-470. 10

LindeberG, T. (1998). Feature detection with automatic scale selection. International Journal of Computer Vision 30, 79-116. 11

Lisini, G., Gamba, P., Dell'Acqua, F. \& Holecz, F. (2011). First results on road network extraction and fusion on optical and SAR images using a multi-scale adaptive approach. International Journal of Image and Data Fusion 2(4), 363-375. URL http://www.tandfonline.com/doi/abs/10.1080/19479832.2011.613412. 28

Lisini, G., Tison, C., Tupin, F. \& Gamba, P. (2006). Feature fusion to improve road network extraction in high-resolution SAR images. IEEE Geosci. Remote Sens. Lett. 3(2), 217 - 221. 28

Liu, J. \& LeE, Y. T. (2001). Graph-based method for face identification from a single 2D line drawing. IEEE Trans. Pattern Anal. Mach. Intell. 23(10), 1106 -1119. 21

LiU, T.-L., Geiger, D. \& Kohn, R. (1998). Representation and self-similarity of shapes. In: Sixth International Conference on Computer Vision, 1998. 20

LiU, Z., AN, J. \& Jing, Y. (2012). A simple and robust feature point matching algorithm based on restricted spatial order constraints for aerial image registration. Geoscience and Remote Sensing, IEEE Transactions on 50(2), 514 -527. 19

Lotufo, R. A. \& Machado, R. C. (2003). Pymorph morphology toolbox. URL http://www.mmorph.com/pymorph. Última consulta em maio de 2012. 62

Lowe, D. G. (1985). Perceptual Organization and Visual Recognition. Kluwer Academics. 5

Ma, B., Hero, A., Gorman, J. \& Michel, O. (2000). Image registration with minimum spanning tree algorithm. In: 2000 International Conference on Image Processing., vol. 1. 19

Mabrouk, S., Mhiri, S. \& Ghorbel, F. (2012). Segmentation of MRI brain with a bootstrapped version of the HMRF-EM algorithm. In: 16th IEEE Mediterranean Electrotechnical Conference (MELECON). 24

Mahapatra, D. \& Sun, Y. (2011). MRF-Based Intensity Invariant Elastic Registration of Cardiac Perfusion Images Using Saliency Information. IEEE Trans. Biomed. Eng. 58(4), 991 $-1000.25$

Mahapatra, D. \& Sun, Y. (2012). Integrating Segmentation Information for Improved MRFBased Elastic Image Registration. Image Processing, IEEE Transactions on 21(1), $170-183$. 19, 25

Majumdar, A., Alencar, A. M., Buldyrev, S. V., Hantos, Z., Stanley, H. E. \& Suki, B. (2001). Characterization of the branching structure of the lung from "macroscopic" pressure-volume measurements. Physical Review Letters 87(5), 058102-+. URL http://adsabs.harvard.edu/abs/2001PhRvL..87e8102M. Provided by the SAO/NASA Astrophysics Data System. 9

Manjunath, B. \& Chellappa, R. (1991). Unsupervised texture segmentation using Markov random field models. IEEE Trans. Pattern Anal. Mach. Intell. 13(5), 478 -482. 24 
Manniesing, R., Viergever, M. A. \& Niessen, W. J. (2006). Vessel enhancing diffusion: A scale space representation of vessel structures. Medical Image Analysis 10(6), 815 - 825. URL http://www.sciencedirect.com/science/article/pii/S1361841506000442. 14

Masters, B. R. (2004). Fractal analysis of the vascular tree in the human retina. Annual Review of Biomedical Engineering 6(1), 427-452. URL http://dx.doi.org/10.1146/annurev.bioeng.6.040803.140100. 9

Merlet, N. \& Zerubia, J. (1996). New prospects in line detection by dynamic programming. IEEE Trans. Pattern Anal. Mach. Intell. 18(4), 426-431. URL http://dx.doi.org/10.1109/34.491623. 12

Metropolis, N., Rosenbluth, A. W., Rosenbluth, M. N., Teller, A. H. \& Teller, E. (1953). Equation of State Calculations by Fast Computing Machines. The Journal of Chemical Physics 21(6), 1087-1092. URL http://dx.doi.org/10.1063/1.1699114. 48

Miller, F. R., Maeda, J. \& Kubo, H. (1993). Template based method of edge linking using a weighted decision. In: Proceedings of the 1993 IEEE/RSJ International Conference on Intelligent Robots and Systems '93, IROS '93, vol. 3. 15

Ming, Y., Li, H. \& He, X. (2012). Connected contours: A new contour completion model that respects the closure effect. In: 2012 IEEE Conference on Computer Vision and Pattern Recognition (CVPR). 141

Molina, R., Mateos, J., Katsaggelos, A. \& Vega, M. (2003). Bayesian multichannel image restoration using compound Gauss-Markov random fields. IEEE Trans. Image Process. 12(12), 1642 - 1654. 25

Mortensen, E. N. \& Barrett, W. A. (1995). Intelligent scissors for image composition. In: Proceedings of the 22nd annual conference on Computer graphics and interactive techniques, SIGGRAPH '95. New York, NY, USA: ACM. URL http://doi.acm.org/10.1145/218380.218442. 18

Moser, G., Angiati, E. \& Serpico, S. (2011). Multiscale Unsupervised Change Detection on Optical Images by Markov Random Fields and Wavelets. IEEE Geosci. Remote Sens. Lett. 8(4), $725-729.26$

Moussouris, J. (1974). Gibbs and Markov random systems with constraints. Journal of Statistical Physics 10, 11-33. URL http://dx.doi.org/10.1007/BF01011714. 10.1007/BF01011714. 46

Murino, V. (1994). A stochastic graph-based technique for grouping of inhomogeneous image primitives. In: Multisensor Fusion and Integration for Intelligent Systems, 1994. IEEE International Conference on MFI'94. 20

Naegel, B., Passat, N. \& Ronse, C. (2007). Grey-level hit-or-miss transforms-part II: Application to angiographic image processing. Pattern Recognition 40(2), 648 - 658. URL http://www.sciencedirect.com/science/article/pii/S0031320306002913. 13

Naegell, B., Ronse, C. \& Soler, L. (2005). Using Grey Scale Hit-Or-Miss Transform for Segmenting the Portal Network of the Liver. In: Mathematical Morphology: 40 Years On (Ronse, C., Najman, L. \& Decencière, E., eds.), vol. 30 of Computational Imaging and Vision. Springer Netherlands, pp. 429-440. 13

Neemuchwala, H., Hero, A. \& Carson, P. (2002). Image registration using entropic graphmatching criteria. In: Conference Record of the Thirty-Sixth Asilomar Conference on Signals, Systems and Computers, 2002., vol. 1.19 
Negri, M., Gamba, P., Lisini, G. \& Tupin, F. (2006). Junction-aware extraction and regularization of urban road networks in high-resolution SAR images. IEEE Geosci. Remote Sens. Lett. 44(10), 2962 - 2971. 3, 12, 13

Nemitz, O., Rumpf, M., Tasdizen, T. \& Whitaker, R. (2007). Anisotropic Curvature Motion for Structure Enhancing Smoothing of 3D MR Angiography Data. J. Math. Imaging Vis. 27(3), 217-229. URL http://dx.doi.org/10.1007/s10851-006-0645-2. 14

Neto, L. M., Vaz, C. M. P. \& CRestana, S. (2007). Instrumentação avançada em ciência do solo. EMBRAPA, 1 ed. 125

Nixon, M. \& Aguado, A. S. (2008). Feature Extraction 83 Image Processing. Academic Press, 2 ed. 59

Noma, A., Graciano, A. B. V., Cesar Jr, R. M., Consularo, L. A. \& Bloch, I. (2012). Interactive image segmentation by matching attributed relational graphs. Pattern Recogn. 45(3), 1159-1179. URL http://dx.doi.org/10.1016/j.patcog.2011.08.017. 18

Olson, D. L. \& Delen, D. (2008). Advanced Data Mining Techniques. Springer, 1 ed. 65

Orkisz, M., Bresson, C., Magnin, I., Champin, O. \& Douek, P. (1997). Improved vessel visualization in MR angiography by non-linear anisotropic filtering. Magn Reson Med 37, 914-919. 11

Orlowski, P. \& Orkisz, M. (2009). Efficient computation of Hessian-based enhancement filters for tubular structures in 3D images. IRBM 30(3), 128 - 132. URL http://www.sciencedirect.com/science/article/pii/S1959031809000487. 14

Palmer, S. E. (1999). Vision Science. MIT Press, 1 ed. 4

Panjwani, D. \& Healey, G. (1995). Markov random field models for unsupervised segmentation of textured color images. IEEE Trans. Pattern Anal. Mach. Intell. 17(10), 939 -954. 24

Paproki, A., Fripp, J., Salvado, O., Sirault, X., Berry, S. \& Furbank, R. (2011). Automated 3D Segmentation and Analysis of Cotton Plants. In: 2011 International Conference on Digital Image Computing Techniques and Applications (DICTA). 3

Park, B.-G., LeE, K.-M. \& LeE, S.-U. (2005). Face recognition using face-arg matching. IEEE Trans. Pattern Anal. Mach. Intell. 27(12), 1982 -1988. 21

Passat, N., Ronse, C., Baruthio, J., Armspach, J.-P., Maillot, C. \& Jahn, C. (2005). Region-growing segmentation of brain vessels: An atlas-based automatic approach. Journal of Magnetic Resonance Imaging 21(6), 715-725. 13

Peng, S., Urbanc, B., Cruz, L., Hyman, B. T. \& Stanley, H. E. (2003). Neuron recognition by parallel Potts segmentation. Proceedings of the National Academy of Sciences of the United States of America 100(7), 3847-3852. 3, 14

Perciano, T., Hirata, R. \& Cesar, R. M. (2009). An image simulator of soil profiles with plant roots for image segmentation. In: Workshops of Sibgrapi 2009 - Posters (PEDRINI, H., ao Marques de Carvalho, J. \& Lewiner, T., eds.). Rio de Janeiro, RJ: SBC. URL http://www .matmidia.mat.puc-rio.br/Sibgrapi2009. 142

Perciano, T., Hirata, R. \& de Castro Jorge, L. (2010a). Parameter estimation for ridge detection in images with thin structures. In: Progress in Pattern Recognition, Image Analysis, Computer Vision, and Applications (Bloch, I. \& CesAR, R., eds.), vol. 6419 of Lecture Notes in Computer Science. Springer Berlin / Heidelberg, pp. 386-393. 64, 142 
Perciano, T., Hirata, R. \& De Castro Jorge, L. (2010b). Ridge linking using an adaptive oriented mask applied to plant root images with thin structures. In: Progress in Pattern Recognition, Image Analysis, Computer Vision, and Applications (BLOCH, I. \& CESAR, R., eds.), vol. 6419 of Lecture Notes in Computer Science. Springer Berlin / Heidelberg, pp. 378-385. 74, 85, 142

Perciano, T., Tupin, F., Jr., R. H. \& Cesar, R. M. (2011). A hierarchical Markov random field for road network extraction and its application with optical and SAR data. In: IGARSS'11. 142

Perona, P. (1991). Deformable kernels for early vision. IEEE Trans. Pattern Anal. Mach. Intell. 17, 488-499. 10

Perona, P. (1998). Orientation diffusions. IEEE Trans. Image Processing , 457-467. 11

Picco, M. \& Palacio, G. (2011). Unsupervised Classification of SAR Images Using Markov Random Fields and Model. IEEE Geosci. Remote Sens. Lett. 8(2), 350 -353. 24

Poli, R. \& VAlli, G. (1997). An algorithm for real-time vessel enhancement and detection. Computer Methods and Programs in Biomedicine 52(1), 1 - 22 . URL http://www.sciencedirect.com/science/article/pii/S0169260796017737. 11

Posch, S. \& Schlüter, D. (1998). Perceptual Grouping using Markov Random Fields and Cue Integration of Contour and Region Information. Technical report, SFB 360, Universität Bielefeld. 141

Poulain, V., Inglada, J. \& Spigai, M. (2008). High resolution remote sensing image analysis with exogenous data: A generic framework. In: IEEE Int. Geosci. and Remote Sensing Symp., 2008. IGARSS '08., vol. 2. 12

Poulain, V., Inglada, J., Spigai, M., Tourneret, J.-Y. \& Marthon, P. (2009). Fusion of high resolution optical and SAR images with vector data bases for change detection. In: IEEE Int. Geosci. and Remote Sensing Symp., 2009. IGARSS '09., vol. 4. 28

Qian, X., Brennan, M. P., Dione, D. P., Dobrucki, W. L., Jackowski, M. P., Breuer, C. K., Sinusas, A. J. \& Papademetris, X. (2009). A non-parametric vessel detection method for complex vascular structures. Medical Image Analysis 13(1), 49 - 61. URL http://www.sciencedirect.com/science/article/pii/S136184150800056X. 13

QUAN, L. (2009). Invited talk: Image-based modeling of plants and trees. In: Plant Growth Modeling, Simulation, Visualization and Applications (PMA), 2009 Third International Symposium on. 3

Revaud, J., Lavoue, G., Ariki, Y. \& Baskurt, A. (2010). Learning an Efficient and Robust Graph Matching Procedure for Specific Object Recognition. In: 20th International Conference on Pattern Recognition (ICPR). 21

Roberts, G. \& Smith, A. (1994). Simple conditions for the convergence of the Gibbs sampler and Metropolis-Hastings algorithms. Stochastic Processes and their Applications 49(2), 207 - 216. URL http://www.sciencedirect.com/science/article/pii/0304414994901341. 48

Ruberto, C. D. (2004). Recognition of shapes by attributed skeletal graphs. Pattern Recognition $\mathbf{3 7}(1), 21-31 . \quad$ URL http://www.sciencedirect.com/science/article/pii/S0031320303002486. 20

Rum, G. (2003). COSMO-SkyMed: Mission definition and main applications and products. In: Proceedings of the Workshop on POLinSAR. 108 
Sabuncu, M. \& Ramadge, P. (2008). Using spanning graphs for efficient image registration. Image Processing, IEEE Transactions on 17(5), 788 -797. 19

Sánchez, J. A., Lasker, H. R., Zeng, W., Coluci, V. R. \& Simpson, C. (2003). How similar are branching networks in nature? A view from the ocean: Caribbean gorgonian corals. Journal of Theoretical Biology 222(1), 135-138. 3, 9

Sappa, A. D. \& Vintimilla, B. X. (2006). Edge point linking by means of global and local schemes. In: IEEE Int. Conf. on Signal-Image Technology and Internet-Based Systems. 15

Sappa, A. D. \& Vintimilla, B. X. (2007). Cost-based closed-contour representations. Journal of Electronic Imaging 16(2), 023009/1-023009/9. 15

Sarkar, S. \& Soundararajan, P. (2000). Supervised learning of large perceptual organization: graph spectral partitioning and learning automata. IEEE Trans. Pattern Anal. Mach. Intell. 22(5), $504-525.20$

Sato, Y., Nakajima, S., Atsumi, H., Koller, T., Gerig, G., Yoshida, S. \& Kikinis, R. (1997). 3D multi-scale line filter for segmentation and visualization of curvilinear structures in medical images. In: CVRMed-MRCAS'g7 (Troccaz, J., Grimson, E. \& Mösges, R., eds.), vol. 1205 of Lecture Notes in Computer Science. Springer Berlin / Heidelberg, pp. 213-222. URL http://dx.doi.org/10.1007/BFb0029240. 10.1007/BFb0029240. 10

Scherrer, B., Forbes, F., Garbay, C. \& Dojat, M. (2009). Distributed Local MrF Models for Tissue and Structure Brain Segmentation. IEEE Trans. Med. Imag. 28(8), 1278 -1295. 24

Schmitt, S., Evers, J. F., Duch, C., Scholz, M. \& Obermayer, K. (2004). New methods for the computer-assisted 3-D reconstruction of neurons from confocal image stacks. NeuroImage $\mathbf{2 3}(4), 1283-1298$. URL http://www.sciencedirect.com/science/article/pii/S1053811904004550. 14

Schuurmann, J. J. \& Goedewangen, M. A. J. (1971). Methods for the Examination of Root Systems and Roots. Wageningen, 2 ed. 124

Sebastian, T., Klein, P. \& Kimia, B. (2004). Recognition of shapes by editing their shock graphs. IEEE Trans. Pattern Anal. Mach. Intell. 26(5), $550-571.20$

Segl, K. \& Kaufmann, H. (2001). Detection of small objects from high-resolution panchromaticsatellite imagery based on supervised image segmentation. IEEE Transactions on Geoscience and Remote Sensing 39(9), 2080-1083. 12

Shapiro, L. G. \& Stockman, G. C. (2001). Computer Vision. Prentice Hall. 1

Shi, J. \& MALIK, J. (2000). Normalized cuts and image segmentation. IEEE Trans. Pattern Anal. Mach. Intell. 22(8), 888-905. 18

Shin, F. Y. \& Cheng, S. (2004). Adaptive mathematical morphology for edge linking. Inf. Sci. Inf. Comput. Sci. 167(1-4), 9-21. 15

ShneIER, M. (1982). Extracting linear features from images using pyramids. IEEE Transactions on Systems, Man and Cybernetics 12(4), 569-572. 12

Siddiqi, K., Shokoufandeh, A., Dickenson, S. \& Zucker, S. (1998). Shock graphs and shape matching. In: Sixth International Conference on Computer Vision. 20

Skriver, H., Schou, J., Nielsen, A. A. \& Conradsen, K. (2005). Polarimetric edge detector based on the complex Wishart distribution. In: Proc. IGARSS, vol. 7. Sydney, Australia. 12 
Smits, P., Dellepiane, S. \& Serpico, S. (1996). Markov random field based image segmentation with adaptive neighborhoods to the detection of fine structures in SAR data. In: Geoscience and Remote Sensing Symposium, vol. 1. 3, 12, 13

Soares, J. V. B., Leandro, J. J. G., Cesar-Jr., R. M., Jelinek, H. F. \& Cree, M. J. (2006). Retinal vessel segmentation using the 2-D Gabor wavelet and supervised classification. IEEE Trans. Med. Imag. 25, 1214-1222. 3, 14

Soccorsi, M., Gleich, D. \& Datcu, M. (2010). Huber-Markov Model for Complex SAR Image Restoration. IEEE Geosci. Remote Sens. Lett. 7(1), 63 -67. 25

Song, W.-L., WAng, L.-H., ZHu, L.-K. \& QU, F.-Y. (2011a). Edge detection of plant roots image via gabor wavelet theory. In: Control and Decision Conference (CCDC), 2011 Chinese. 3, 14

Song, Y.-Z., XiaO, B., Hall, P. \& Wang, L. (2011b). In search of perceptually salient groupings. IEEE Trans. Image Process. 20(4), 935 -947. 141

Soundararajan, P. \& Sarkar, S. (2001). Investigation of measures for grouping by graph partitioning. In: Proceedings of the 2001 IEEE Computer Society Conference on Computer Vision and Pattern Recognition, 2001. CVPR 2001., vol. 1. 20

Sportouche, H., Deledalle, C.-A., Nicolas, J.-M., Tupin, F. \& Perciano, T. (2012). How to combine TerraSAR-X and COSMO-Skymed high-resolution images for a better scene understanding? In: Geoscience and Remote Sensing Symposium (IGARSS), 2012 IEEE International. 122,142

Sportouche, H., Tupin, F. \& Denise, L. (2009). Building detection by fusion of optical and SAR features in metric resolution data. In: IEEE Int. Geosci. and Remote Sensing Symp., 2009. IGARSS '09., vol. 4. 28

Stahl, J. S. \& Wang, S. (2007). Edge Grouping Combining Boundary and Region Information. IEEE Trans. Image Process. 16(10), 2590-2606. 15

Steger, C. (1998). An unbiased detector of curvilinear structures. IEEE Trans. Pattern Anal. Mach. Intell. 20(3), 113-125. 12

Suri, J. S., Liu, K., Reden, L. \& Laxminarayan, S. (2002a). A review on MR vascular image processing algorithms: acquisition and prefiltering: part I. IEEE Transactions on Information Technology in Biomedicine 6(4), 324-337. 13

Suri, J. S., Liu, K., Reden, L. \& Laxminarayan, S. (2002b). A review on MR vascular image processing: skeleton versus nonskeleton approaches: part II. IEEE Transactions on Information Technology in Biomedicine 6(4), 338-350. 13

Ta, V. T., Lezoray, O. \& Elmoataz, A. (2007). Graph based semi and unsupervised classification and segmentation of microscopic images. In: Signal Processing and Information Technology, 2007 IEEE International Symposium on. 18

TARboton, D. (1996). Fractal river networks, Horton's laws and Tokunaga cyclicity. Journal of Hydrology 187, 105-117. 9

Tefas, A., Kotropoulos, C. \& Pitas, I. (2001). Using support vector machines to enhance the performance of elastic graph matching for frontal face authentication. IEEE Trans. Pattern Anal. Mach. Intell. 23(7), $735-746.21$

Tian, X., Han, G., Chen, M. \& Situ, Z. (2006). Skeleton-based surface reconstruction for visualizing plant roots. In: 16th International Conference on Artificial Reality and TelexistenceWorkshops, 2006. ICAT'06. 14 
Tison, C., Nicolas, J.-M., Tupin, F. \& Maitre, H. (2004). A new statistical model for Markovian classification of urban areas in high-resolution SAR images. IEEE Geosci. Remote Sens. Lett. 42(10), 2046 - 2057. 12

Torsello, A. \& Hancock, E. (2001). A Skeletal Measure of 2D Shape Similarity. In: Visual Form 2001 (Arcelli, C., Cordella, L. \& Di BAJA, G., eds.), vol. 2059 of Lecture Notes in Computer Science. Springer Berlin / Heidelberg, pp. 260-271. 20

Truc, P. T. H., Khan, M. A. U., Lee, Y.-K., Lee, S. \& Kim, T.-S. (2009). Vessel enhancement filter using directional filter bank. Comput. Vis. Image Underst. 113(1), 101-112. URL http://dx.doi.org/10.1016/j.cviu.2008.07.009. 11

Tsaig, Y. \& Averbuch, A. (2002). Automatic segmentation of moving objects in video sequences: a region labeling approach. Circuits and Systems for Video Technology, IEEE Transactions on $\mathbf{1 2}(7), 597-612.18$

Tupin, F., Bloch, I. \& Maître, H. (1999). A first step toward automatic interpretation of SAR images using evidential fusion of several structure detectors. IEEE Transactions on Geoscience and Remote Sensing 37(3), 1327-1343. 12

Tupin, F., Houshmand, B. \& Dactu, M. (2002). Road Detection in Dense Urban Areas Using SAR Imagery anf the Usefulness of Multiple Views. IEEE Trans. Geosci. Remote Sensing 40(11), 2405-2414. 3, 13, 32

Tupin, F., Maître, H., Nicolas, J.-M. \& Pechersky, E. (1998). Detection of linear features in SAR images: Application to road network extraction. IEEE Trans. Geosci. Remote Sensing 36, 434-453. xx, xxi, xxv, 3, 13, 31, 63, 83, 84, 85, 86, 111, 112

Tupin, F. \& Roux, M. (2003). Detection of building outlines based on the fusion of SAR and optical features. ISPRS Journal of Photogrammetry and Remote Sensing 58(1-2), 71 - 82. Algorithms and Techniques for Multi-Source Data Fusion in Urban Areas. 28

Tupin, F. \& Roux, M. (2005). Markov random field on region adjacency graph for the fusion of SAR and optical data in radargrammetric applications. Geoscience and Remote Sensing, IEEE Transactions on $\mathbf{4 3}(8), 1920$ - 1928. 26

Turcottea, D. L., Pelletiera, J. D. \& Newman, W. I. (1998). Networks with Side Branching in Biology. Journal of Theoretical Biology 193(4), 577-592. 9

Umbaugh, S. E. (2005). Computer Imaging: Digital Image Analysis and Processing. CRC Press. 1

Unser, M. \& Van De Ville, D. (2009). Higher-order Riesz transforms and steerable wavelet frames. In: Proceedings of the 16th IEEE international conference on Image processing, ICIP'09. Piscataway, NJ, USA: IEEE Press. URL http://dl.acm.org/citation.cfm?id=1819298.1819777. 10

VAn DER Brug, G. (1976). Line detection in satellite imagery. IEEE Transactions on Geoscience Electronics 14(1), 37-44. 12

ČERnÝ, V. (1985). Thermodynamical approach to the traveling salesman problem: An efficient simulation algorithm. Journal of Optimization Theory and Applications 45(1), 41-51. URL http://dx.doi.org/10.1007/BF00940812. 50

Verdú-Monedero, R. \& Angulo, J. (2008). Spatially-variant directional mathematical morphology operators based on a diffused average squared gradient field. In: Advanced Concepts for Intelligent Vision Systems (Blanc-Talon, J., Bourennane, S., Philips, W., Popescu, D. \& Scheunders, P., eds.), vol. 5259 of Lecture Notes in Computer Science. Springer Berlin / Heidelberg, pp. 542-553. 13 
Vosselman, G. \& Knecht, J. D. (1995). Road tracing by profile matching and Kalman filtering. Proc Workshop on Automatic Extraction of ManMade Objects from Aerial and Space Images 2(1976). 13

Waite, K. W. (1988). Modelling Natural Branching Structures. Comput. Graph. Forum 7(2), 105-115. 9

Walter, T., Massin, P., Erginay, A., Ordonez, R., Jeulin, C. \& Klein, J.-C. (2007). Automatic detection of microaneurysms in color fundus images. Medical Image Analysis 11(6), 555 - 566. URL http://www.sciencedirect.com/science/article/pii/S1361841507000461. 3,14

Wan, M., Liang, Z., Ke, Q., Hong, L., Bitter, I. \& Kaufman, A. (2002). Automatic centerline extraction for virtual colonoscopy. IEEE Trans. Med. Imag. 21(12), $1450-1460.20$

Wang, S., Petrick, N., Van Uitert, R. L., Periaswamy, S., Wei, Z. \& Summers, R. M. (2012). Matching 3-D Prone and Supine CT Colonography Scans Using Graphs. Information Technology in Biomedicine, IEEE Transactions on 16(4), 676 -682. 19

WANG, Z. \& Zhang, H. (2008). Edge linking using geodesic distance and neighborhood information. In: IEEE/ASME International Conference on Advanced Intelligent Mechatronics, 2008. AIM 2008. xx, $15,74,75,76,77,78,79$

Weibel, E. R. (1987). Scaling of structural and functional variables in the respiratory system. Annu. Rev. Physiol. 49, 147-159. 9

Wertheimer, M. (1923). Untersuchungen zur Lehre von der Gestalt. II. Psychological Research 4, 301-350. URL http://dx.doi.org/10.1007/BF00410640. 10.1007/BF00410640. 53

Wiskott, L., Fellous, J.-M., Kuiger, N. \& von der Malsburg, C. (1997). Face recognition by elastic bunch graph matching. IEEE Trans. Pattern Anal. Mach. Intell. 19(7), $775-779.21$

Wyatt, C., Bayram, E. \& Ge, Y. (2006). Minimum Reliable Scale Selection in 3D. IEEE Trans. Pattern Anal. Mach. Intell. 28(3), 481-487. URL http://dx.doi.org/10.1109/TPAMI .2006.58. 14

Xie, H., Pierce, L. \& Ulaby, F. (2002). SAR speckle reduction using wavelet denoising and Markov random field modeling. Geoscience and Remote Sensing, IEEE Transactions on 40(10), $2196-2212.25$

Xingshi, H., Lianying, G., Fei-yue, H. \& Min, W. (2011). Mrf image denoising based on fuzzy classification. In: Cross Strait Quad-Regional Radio Science and Wireless Technology Conference (CSQRWC), 2011, vol. 2. 25

Xu, M., Chen, H. \& Varshney, P. K. (2011a). An Image Fusion Approach Based on Markov Random Fields. Geoscience and Remote Sensing, IEEE Transactions on 49(12), 5116 -5127. 26

Xu, X., Niemeijer, M., Song, Q., Sonka, M., Garvin, M. K., Reinhardt, J. M. \& Abramoff, M. D. (2011b). Vessel Boundary Delineation on Fundus Images Using Graph-Based Approach. Medical Imaging, IEEE Transactions on 30(6), 1184-1191. 18

Xu, Z. \& LuO, J. (2006). Face Recognition by Expression-Driven Sketch Graph Matching. In: 18th International Conference on Pattern Recognition, 2006. ICPR 2006., vol. 3. 21

Yu, J., TAO, D. \& WANG, M. (2012). Adaptive hypergraph learning and its application in image classification. IEEE Trans. Image Process. 21(7), $3262-3272.18$ 
Zaboli, H. \& Rahmati, M. (2007). An improved shock graph approach for shape recognition and retrieval. In: Proceedings of the First Asia International Conference on Modelling $\&$ Simulation, AMS '07. Washington, DC, USA: IEEE Computer Society. URL http://dx.doi.org/10.1109/AMS.2007.13. 20

Zhang, B., Li, S., Jia, X., Gao, L. \& Peng, M. (2011). Adaptive Markov Random Field Approach for Classification of Hyperspectral Imagery. IEEE Geosci. Remote Sens. Lett. 8(5), 973 $-977.24$

ZhANG, J. (1993). The mean field theory in EM procedures for blind Markov random field image restoration. IEEE Trans. Image Process. 2(1), $27-40.25$

Zhang, Y., Brady, M. \& Smith, S. (2001). Segmentation of brain MR images through a hidden Markov random field model and the expectation-maximization algorithm. IEEE Trans. Med. Imag. 20(1), $45-57.24$

Zheng, C., Qin, Q., Liu, G. \& Hu, Y. (2012). Image segmentation based on multiresolution Markov random field with fuzzy constraint in wavelet domain. Image Processing, IET 6(3), 213 $-221.24$

Zheng, Y., Gu, S., Edelsbrunner, H., Tomasi, C. \& Benfey, P. (2011). Detailed reconstruction of 3D plant root shape. In: 2011 IEEE International Conference on Computer Vision $(I C C V) .14$

Zhi, W., Ming, Z. \& Q.-XIng, Y. (2001). Modeling of Branching Structures of Plants. Journal of Theoretical Biology 209(4), 383-394. 9

Zhou, J., Bischof, W. F. \& Caelli, T. (2005). Robust and efficient road tracking in aerial images. In: In International Archives of the Photogrammetry, Remote Sensing and Spatial Information Sciences (CMRT05), volume XXXVI. 13

Zhou, Y., Venkateswar, V. \& Chellappa, R. (1989). Edge Detection and Linear Feature Extraction Using a 2-D Random Field Model. IEEE Trans. Pattern Anal. Mach. Intell. 11, 84-95. 12

Zhu, S. \& Yuille, A. (1995). FORMS: a flexible object recognition and modelling system. In: Fifth International Conference on Computer Vision, 1995. 20

Zhu, S.-C. (1999). Embedding Gestalt Laws in Markov Random Fields. IEEE Trans. Pattern Anal. Mach. Intell. 21(11), 1170-1187. URL http://dx.doi.org/10.1109/34.809110. 141 


\section{Artigos em conferências}

1. PERCIANO, Talita ; HIRATA JR., R. ; CESAR JR., R. M. . An Image Simulator of Soil Profiles with Plant Roots for Image Segmentation. In: XXII Brazilian Symposium on Computer Graphics and Image Processing, 2009, Rio de Janeiro. Anais do XXII Brazilian Symposium on Computer Graphics and Image Processing, 2009.

2. PERCIANO, Talita ; HIRATA JR., R. ; JORGE, Lúcio André de Castro . Ridge Linking Using an Adaptive Oriented Mask Applied to Plant Root Images with Thin Structures. In: 15th Iberoamerican Congress On Pattern Recognition, 2010, São Paulo. CIARP 2010, Lecture Notes in Computer Science. Heidelberg : Springer, 2010. v. 6419. p. 378-385.

3. PERCIANO, Talita ; HIRATA JR., R. ; JORGE, Lúcio André de Castro . Parameter Estimation for Ridge Detection in Images with Thin Structures. In: 15th Iberoamerican Congress On Pattern Recognition, 2010, São Paulo. CIARP 2010, Lecture Notes in Computer Science. Heidelberg : Springer, 2010. v. 6419. p. 386-393.

4. PERCIANO, Talita ; Florence Tupin ; HIRATA JR., R. ; CESAR JUNIOR, R. M. . A hierarchical Markov random field For road network extraction and its application with optical and SAR data. In: IEEE International Geoscience and Remote Sensing Symposium, 2011, Vancouver. Proc. IEEE International Geoscience and Remote Sensing Symposium, 2011. p. $1-4$.

5. SPORTOUCHE, Helene ; DELEDALLE, Charles-Alban ; TUPIN, Florence ; NICOLAS, Jean-Marie ; PERCIANO, Talita . How to combine TerraSAR-X and COSMO-SkyMed highresolution images for a better scene understanding?. In: IEEE International Geoscience and Remote Sensing Symposium, 2012, Munich. Proc. IEEE International Geoscience and Remote Sensing Symposium, 2012. p. 1-4. 


\section{Artigos em periódicos - em produção}

1. PERCIANO, Talita ; TUPIN, Florence ; HIRATA JR., R. ; CESAR JUNIOR, R. M. . A hierarchical Markov random field For road network extraction and its application with optical, SAR, and multitemporal data. (Submetido para IEEE TGRS)

2. PERCIANO, Talita ; HIRATA JR., R. ; CESAR JUNIOR, R. M. ; JORGE, Lúcio André de Castro. Segmentation of plant roots in soil profile images. 